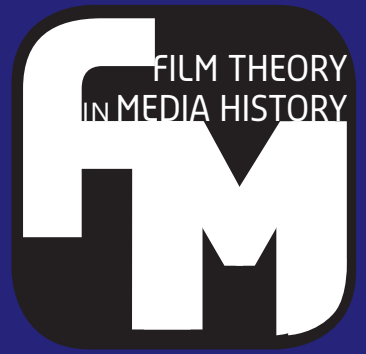

\title{
THE STRUCTURES OF THE FILM EXPERIENCE BY JEAN-PIERRE MEUNIER
}

HISTORICAL ASSESSMENTS AND PHENOMENOLOGICAL EXPANSIONS

EDITED BY JULIAN HANICH AND DANIEL FAIRFAX 
The Structures of the Film Experience by Jean-Pierre Meunier 


\section{Film Theory in Media History}

Film Theory in Media History explores the epistemological and theoretical foundations of the study of film through texts by classical authors as well as anthologies and monographs on key issues and developments in film theory. Adopting a historical perspective, but with a firm eye to the further development of the field, the series provides a platform for ground-breaking new research into film theory and media history and features high-profile editorial projects that offer resources for teaching and scholarship. Combining the book form with open access online publishing the series reaches the broadest possible audience of scholars, students, and other readers with a passion for film and theory.

Series editors: Vinzenz Hediger (Goethe University Frankfurt, Germany), Weihong Bao (University of California, Berkeley, United States),

Trond Lundemo (Stockholm University, Sweden).

Editorial Board Members:

Dudley Andrew, Yale University, United States

Raymond Bellour, CNRS Paris, France

Chris Berry, Goldsmiths, University of London, United Kingdom

Francesco Casetti, Yale University, United States

Thomas Elsaesser, University of Amsterdam, the Netherlands

Jane Gaines, Columbia University, United States

André Gaudreault, University of Montreal, Canada

Gertrud Koch, Free University of Berlin, Germany

John MacKay, Yale University, United States

Markus Nornes, University of Michigan, United States

Patricia Pisters, University of Amsterdam, the Netherlands

Leonardo Quaresima, University of Udine, Italy

David Rodowick, University of Chicago, United States

Philip Rosen, Brown University, United States

Petr Szczepanik, Masaryk University Brno, Czech Republic

Brian Winston, Lincoln University, United Kingdom

Film Theory in Media History is published in cooperation with the Permanent Seminar for the History of Film Theories. 


\title{
The Structures of the Film Experience by Jean-Pierre Meunier
}

Historical Assessments and Phenomenological Expansions

\author{
Edited by \\ Julian Hanich and Daniel Fairfax
}

Translated by Daniel Fairfax 


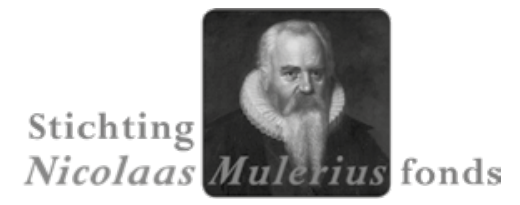

Cover illustration: Screenshot of Jean-Pierre Meunier taken from a video by Peter Matthies. Lay-out: Crius Group, Hulshout

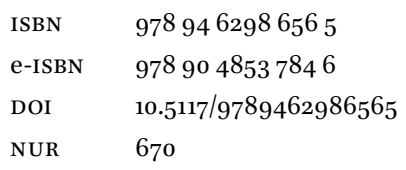

Some rights reserved. Without limiting the rights under copyright reserved above, any part of this book may be reproduced, stored in or introduced into a retrieval system, or transmitted, in any form or by any means (electronic, mechanical, photocopying, recording or otherwise). 


\section{Table of Contents}

Introduction

Julian Hanich/Daniel Fairfax

"Every Theory Needs a Reference to Lived Experience":

An Interview with Jean-Pierre Meunier

Julian Hanich/Daniel Fairfax

\section{Part I - Jean-Pierre Meunier \\ The Structures of the Film Experience: Filmic Identification}

Introduction

Part One: Introduction to the General Structures of Experience $\quad 38$

$\begin{array}{ll}\text { Chapter I: Perception } & 38\end{array}$

I. The Point of View of Traditional Psychology 38

II. The Findings of Phenomenology 39

$\begin{array}{ll}\text { Chapter II: Identification } & 46\end{array}$

I. The Origins of the Concept $\quad 46$

II. Identification as the Behavior of Private Intersubjectivity 48

III. The Principal Aspects of Identification 52

a) The Motor Aspect $\quad 52$

b) The Affective Aspect 53

c) The Dramatic Aspect 54

d) Identification as the Basis for the Valorization (or Devalorization) of Other People $\quad 54$

IV. Fleeting and Structuring Identifications $\quad 5^{8}$

V. Identification, Projection, Introjection $\quad 5^{8}$

VI. Identification, Mimicry, and Imitation 61

VII. Identification and Personality 63

VIII. Identification, Communication, and Information 66

Part Two: The Film Experience $\quad 69$

Chapter I: Filmic Consciousness Faced with Its Object 69

I. The Film as an Object of Perception 69

II. Film, Real, and Unreal $\quad 72$ 
III. The Imaginary Consciousness

IV. The Attitudes of Filmic Consciousness Faced with Its $\begin{array}{ll}\text { Object } & 87\end{array}$

a) The Home Movie $\quad 87$

b) The Documentary Film $\quad 88$

c) The Fiction Film $\quad 91$

V. From the Home Movie to the Fiction Film 99

$\begin{array}{ll}\text { VI. Movement } & 100\end{array}$

1. The Experience of Movement 101

2. Movement in the Cinema 106

a) Movement in the Home Movie 107

b) Movement in the Documentary Film 109

c) Movement in the Fiction Film 111

VII. Conclusion $\quad 115$

Chapter II: Filmic Behavior, Identification $\quad 118$

I. The Types of Filmic Identification $\quad 119$

a) Identification in the 'Home-Movie Attitude' 119

b) Identification in the 'Documentary Attitude' 124

c) Identification in the 'Fiction Attitude' 127

II. The Differentiation of Identification According to Different Characters 134

Chapter III: Towards Post-Filmic Behavior 144

$\begin{array}{lr}\text { General Conclusion } & 15^{2}\end{array}$

\section{Part II - Critical Essays, Historical Assessments, Phenomenological Expansions}

\section{I: Placing Meunier in the History of Film Theory}

Stages of an Encounter with Filmic Identification

Dudley Andrew

Between Phenomenology and Psychoanalysis: Jean-Pierre

Meunier's Theory of Identification in the Cinema 
The Missing Link: Meunier on Imagination and Emotional Engagement

Robert Sinnerbrink

\section{II: ON the Home-MOVIE ATtITUde}

'Me, Myself, and I': On the Uncanny in Home Movies

Vivian Sobchack

Remembering Cinema: On the film-souvenir

Marie-Aude Baronian

\section{III: ON IDENTIFICATION}

You Talkin' to Me? On Filmic Identification in Video-Selfies

Illuminating Reality: Cinematic Identification Revisited in the Eyes of Buddhist Philosophies

Victor Fan

Whose Identification? A Brief Meditation on the Relevance of Jean-Pierre Meunier's The Structures of the Film Experience to Contemporary Feminist Film Phenomenology

Kate Ince

\section{IV: Referentiality and Mediation}

Jean-Pierre Meunier's Modalities of the "Filmic Attitude":

Towards a Theory of Referentiality in Cinematic Discourse

Guido Kirsten

Phenomenology, Immediacy, and Mediation: On Derrida,

Meunier, and Landgrebe

Florian Sprenger 


\section{V: Phenomenological Expansions}

Cinema and Child's Play

Jennifer M. Barker

Engines of the Historical Imagination: Towards a

Phenomenology of Cinema as Non-Art

Vinzenz Hediger

When Viewers Drift Off: A Brief Phenomenology of Cinematic Daydreaming

Julian Hanich

List of Illustrations 


\title{
Introduction
}

\author{
Julian Hanich/Daniel Fairfax
}

Fifty years ago, a young Belgian psychologist wrote a short book for a small publisher in the Belgian town of Leuven, a book that had little resonance in the French-speaking world and was almost completely overlooked elsewhere. The psychologist, 27 years old at the time, was Jean-Pierre Meunier, and his study bore the title Les Structures de l'expérience filmique: L'identification filmique. ${ }^{1}$ Meunier, born in 1941 in Namur (Wallonia), had studied psychology at the Catholic University in Leuven from 1960 to 1964, and subsequently became a chercheur at the Centre des techniques de diffusion under the auspices of Victor Bachy, one of the first professors to teach film courses at a Belgian university. Later promoted to research assistant, Meunier joined an interdisciplinary team consisting of philosophers, psychologists, specialists in law, and sociologists to study the effects of media. It was at that time that he developed a phenomenological approach to the study of film and set out to write The Structures of the Film Experience.

With the benefit of hindsight, it is difficult to overlook that the year 1969, when the book appeared in a simple green and white cover, was hardly fertile terrain for a rigorous phenomenological study - one that was heavily influenced by Sartre, Merleau-Ponty, and Husserl, but also by psychological research on perception (Albert Michotte van den Berck, Henri Wallon) and psychoanalytic conceptions of identification (Angelo Hesnard). Needless to say, on intellectual highways crowded by powerfully motored semiotic, psychoanalytic, and Marxist trucks that were headed in a decidedly political direction, Meunier's little vehicle did not gain much headway. Trying to retain the value of describing the subjective experience of viewers from the first person, it seemed outdated theoretically and outmoded politically.

And yet, some people did read the book and were impressed by it. Dudley Andrew, who discovered the book in a Parisian bookshop, was one of its first champions. In his influential article "The Neglected Tradition of Phenomenology in Film Theory" from 1978, Andrew was struck by how Meunier "describe[s], and account[s] for the peculiar fascination and momentum belonging to various types of film, from home movies through narrative features." In 1983, Jacques Aumont, Alain Bergala, Michel Marie, and Marc Vernet included Meunier in a list of recommended readings at the end of a chapter on the spectator in their L'Esthétique du film. ${ }^{3}$ Later, in Du Visage au cinéma (1992), Aumont described Meunier's book as an "authentically 


\section{Jean-Pierre MEUNIER}

\section{LES STRUCTURES}

\section{DE L'EXPÉRIENCE FILMIQUE}

\section{L'identification filmique}

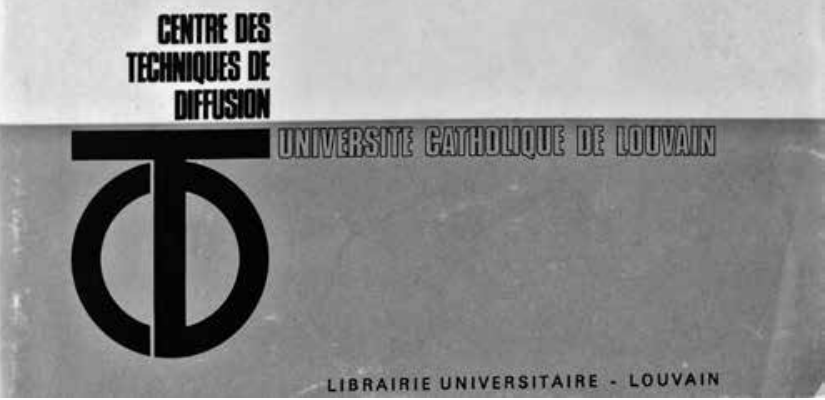

Fig. 1: Jean-Pierre Meunier's private copy of his book.

Sartrean attempt" to theorize the filmic spectator, an attempt that was so far removed in time for him, however, that it already seemed dated at the time of its appearance. ${ }^{4}$ At the end of the 1990s, Vivian Sobchack sat down with an English-French dictionary and slowly worked her way through the book to fully grasp Meunier's important contribution to understanding the viewer's relation not only to the fiction film, but also to the documentary film and the home movie (or film-souvenir, as the more specific term in French would have it). In her article "Towards a Phenomenology of Nonfictional Film Experience" (1999), Sobchack describes The Structures of the Film Experience as "an undeservedly neglected book" that "offers the premises and potential for an enriched understanding of how dynamic and fluid our engagement with the cinema really is." 5 Meunier's text also found resonances in other 
ways: for instance, it left a profound impression on the young Marie-Aude Baronian, who, as she recalls in her contribution to this volume, found the book in her father's private collection on cinema and philosophy, an encounter that resulted in a moment of epiphany for the future scholar.

Meunier's attention to home movies, highly unusual as it was for its time, is a good example of one of the most astonishing facets of his book: in some respects, The Structures of the Film Experience predates later research by decades. For instance, as Robert Sinnerbrink shows, Meunier came up with very similar categories of character identification to those devised by Murray Smith more than 25 years later in his influential book Engaging Characters (1995). ${ }^{6}$ Long before Hans Jürgen Wulff rejected the notion that viewers empathize with single characters and instead suggested the idea of an "empathic field," "Meunier had described characters in the cinema as "relational nodal points" or "characters-for-other-characters": "They define themselves with respect to other characters and the objective elements (or rather 'objectifiable' elements), which characterize them, only have meaning in the social context specific to the film" (p. 137). Moreover, much like Noël Carroll many years after him, Meunier rejects overblown ideas of a total fusion with characters in identification (even while insisting on a certain loss of the self):

I must act 'as if' I were in the place of the characters, 'as if' I possessed their bodies and possibilities. And yet, this 'as if,' imposed by the insurmountable distance between that behavior which remains inexorably before my own self, remains implicit for consciousness, and renders the realization of the relationship impossible. This is because 'acting' at being like another person implies that, at the same time, I deny that I simply am this other person (p. 134). ${ }^{8}$

Similarly, his brief but incisive remarks on film stars, although following in the footsteps of Edgar Morin's Les stars (The Stars, 1957), a book Meunier knew, predate Richard Dyer's more extensive work on that topic from the late 1970 s and 198 os. $^{9}$ This alone would justify devoting closer attention to Meunier's study.

Here, we publish The Structures of the Film Experience for the first time in English translation, and complement the text with a collection of essays that historically locate it, critically discuss its merits, and extend it into territory far beyond its original habitat. This is more than a philological favor to those interested in the history of film theory (particularly in film phenomenology, but also in cognitivism, filmology, and psychoanalytic film 
theory). For various reasons, Meunier's book remains a fascinating read, a quality that has to do with its assured tone and reasoned argumentation, an argumentation refuting contemporaneous positions as convincingly as it smoothly incorporates scholarly findings. While the book, except for a few references to filmologists like Michotte van den Berck, Jean-Jacques Rinieri, or François Ricci, contains hardly any footnotes referencing the film theory of its time, the young author shows a profound familiarity with the phenomenological literature of Sartre and Merleau-Ponty.

Meunier's book, and this is not the least of its qualities, demonstrates film phenomenology from its most intriguing and convincing side. The work does not limit itself to a subjectivist account of an idiosyncratic viewer response, but provides a description of the recurring structures of the film-viewing experience. As Meunier unmistakably defines his own phenomenological description of identification: "It is not a matter, of course, of elucidating particular forms of behavior - for example, a given identification of a given subject with a given person - through the concrete modalities of their realization, but, rather, of unveiling the invariable aspect in these particular forms of behavior" (p. 34, emphasis added). Implicitly distancing himself from the subjectivism of what today often goes by the name of 'film phenomenology,' Meunier sets out to describe from a generalized first-person perspective the invariable differences between three modes of spectatorial engagement: the home-movie attitude, the documentary attitude, and the fiction attitude. As the contributions to this volume show, these distinctions are as stimulating for further phenomenological explorations as they are in need of amendment and further differentiation.

If not every detail of the book survives equally well after 50 years, this was entirely expected, even hoped for by the author. At the end of his introduction, Meunier writes modestly but with an unabashed belief in the progress of scholarly insight:

Inevitably, the views expressed here will be criticized, corrected and even refuted with scientific progress in the field. Unavoidably, too, some (possibly important) aspects of the problems occupying us will escape us or will not be given the space they deserve. But what we do hope will come out of this work is that, beyond its imperfections, it shows some contours of the truth, some new insights, some interesting perspectives and that, above all, it provides a source of inspiration for new hypotheses conducive to advancing the cause of filmology" (p. 36/37). ${ }^{10}$ 


\section{Notes}

1. Jean-Pierre Meunier, Les Structures de l'expérience filmique: Lidentification filmique (Louvain: Vander, 1969).

2. Dudley Andrew, "The Neglected Tradition of Phenomenology in Film Theory," Wide Angle 2:2 (1978), p. 47.

3. Jacques Aumont, Alain Bergala, Michel Marie, and Marc Vernet, L'Esthétique du film (Paris: Nathan, 1983), p. 203.

4. Jacques Aumont, Du Visage au cinéma (Paris: Cahiers du cinéma, 1992), p. 61.

5. Vivian Sobchack, "Toward a Phenomenology of Nonfictional Film Experience," in Jaine M. Gaines/Michael Renov (eds.), Collecting Visible Evidence (Minneapolis: University of Minnesota Press), pp. 241-254, here p. 242.

6. Murray Smith, Engaging Characters. Fiction, Emotion, and the Cinema (Oxford: Clarendon, 1995).

7. Hans J. Wulff, "Empathie als Dimension des Filmverstehens: Ein Thesenpapier," Montage/AV12:1 (2003), pp. 136-161.

8. See, for instance, Noël Carroll, The Philosophy of Horror, or Paradoxes of the Heart (New York: Routledge, 1990), pp. 88-96.

9. Richard Dyer, Stars (London: British Film Institute, 1979) and Heavenly Bodies: Film Stars and Society (New York: St. Martin's Press, 1986).

10. The editors would like to thank Jeroen Sondervan and Maryse Elliott, the former and current commissioning editors of Amsterdam University Press, for their strong interest in this project. Thanks also to the editors of the Amsterdam University Press series "Film Theory in Media History" - Vinzenz Hediger, Weihong Bao, and Trond Lundemo - for their endorsement and helpful comments. Another important person was Nina Yakimova from the University of Groningen, who diligently supported the editing process. Not least, we wish to thank Jean-Pierre Meunier himself for his dedication to this volume. Not only did he reserve generous time during two conversation sessions for the interview that follows this introduction, but he also took a close look at the translation and helped improve it with his comments. 


\title{
"Every Theory Needs a Reference to Lived Experience": An Interview with Jean-Pierre Meunier
}

\author{
Julian Hanich/Daniel Fairfax
}

Your book came out in 1969 when you were still a veryyoung scholar. Canyou tell us a bit about the years leading up to your writing of The Structures of the Film Experience? ${ }^{1}$

Jean-Pierre Meunier: From 1960 to 1964, I did a degree in psychology at the Catholic University of Leuven/Louvain. At that time, the teaching of psychology was very diverse. It naturally included many courses of so-called scientific psychology, like experimental psychology and psychometrics. But, on the other hand, often in opposition to the pure and hard experimentalist tendency, many teachings gave a relatively important place to psychoanalysis and phenomenology. These currents of thought that emphasized the lived experience and existential problems interested many students. The "spirit of the time," to use an expression that served as the title of a beautiful book by Edgar Morin, was still strongly marked by existentialism and very little by Marxism. ${ }^{2}$ In this context, individual existence gains more attention than the systems and structures of which it is a part. Hence, the interest in the relations with others and the relation with oneself, and also the interest of many - and, in any case, me - in the notion of identification. I remember our interest in Freud's concept of narcissism, and toward the end of my studies in 1964, in a text by Jacques Lacan, still little known at the time, about the mirror stage.

This is something today's psychology students might be very astonished to hear: that in your psychology lectures and seminars you were reading Freud, Lacan, and phenomenology.

JPM: Belgians are very eclectic. During my studies, there were courses on experimental psychology, but also courses that presented Jean-Paul Sartre and Maurice Merleau-Ponty. And, at this time, they also began to give some attention to Lacan. There is a good Belgian author, Alphonse de Waelhens, 


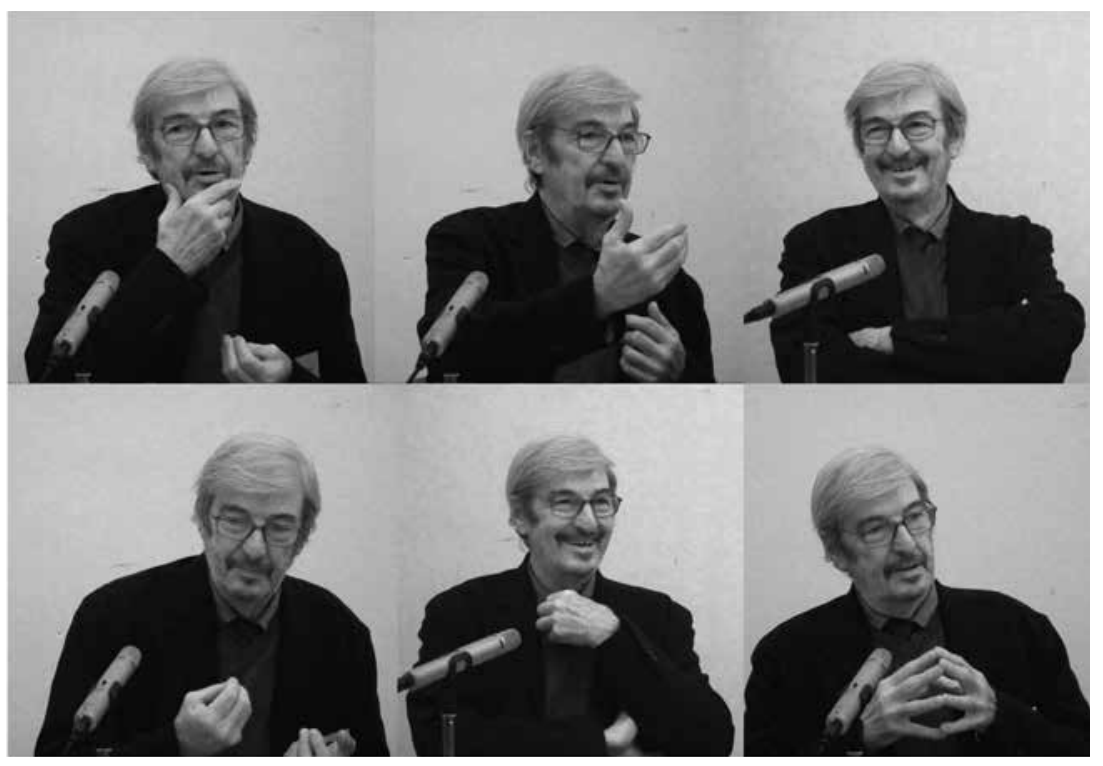

Fig. 2: Meunier during the first part of the interview on 23 November 2017 in Frankfurt am Main.

who wrote an interesting book, La philosophie et les expériences naturelles, in which he merged phenomenology and the theory of Lacan. ${ }^{3}$

After your studies and before writing The Structures of the Film Experience, you worked on a study of a single film: La Vie conjugale (Anatomy of a Marriage, 1964) by André Cayatte. ${ }^{4}$

JPM:Yes, this was an empirical research project about the reception of the film, and I was employed as assistant to Professor Victor Bachy from the institute of political and social sciences in my university, who had set up a media research center, the Centre des techniques de diffusion. Its intention was to bring together researchers from different backgrounds to develop an interdisciplinary approach to media. I arrived in 1964, at the right moment, to occupy one of the positions he reserved to psychologists to finish empirical research dealing with the reception of Cayatte's film. It would be too long to talk about this study in detail, but suffice it to say that it allowed me to point out in the responses of the film's spectators obvious traces of identification with the characters, because the responses given by men and women were noticeably different. And it also helped me to convince Professor Bachy of the interest of the notion of identification. 
Where did the importance of phenomenology in your work come from?

JPM: What I learned from phenomenology during my studies convinced me that the phenomenological approach to the lived experience of the spectator constituted the best approach to the film experience. When I was a student, I read Sartre's The Imaginary, and when I was employed by the Centre des techniques de diffusion, Professor Victor Bachy invited me to work on my ideas in one of his courses on film. It is within the framework of this course that I developed a phenomenological approach to the cinematic imaginary: I remembered the importance of the distinctions Sartre made between different ways of paying attention to reality, as existent or nonexistent. In fact, I had three frames of reference to orient my reflection. First: the description of image consciousness proposed by Sartre in The Imaginary, whose different forms of image consciousness seemed to me to correspond to the main types of cinematic representation: home movies (films-souvenir), documentary films, fiction films. Second: the concept of identification proposed by psychoanalyst Angelo Hesnard, who wrote on the phenomenological conception of intersubjectivity. Third: a number of articles from the Revue internationale de filmologie, which I had just discovered in the faculty library - mainly articles by psychologists like Henri Wallon and Albert Michotte van den Berck as well as Gilbert Cohen-Séat.

That's the beauty of serendipity: you go to the library, you browse, and you find something you have never looked for. How did you come across Angelo Hesnard, a psychoanalyst who is lesser known today?

JPM: Also by accident, when I was walking through the library. I knew that Hesnard tried to compose a phenomenology focusing on human relations, intersubjectivity, and psychoanalysis.

Didyou also read the texts of André Bazin back then?

JPM: No. I was mostly unfamiliar with Bazin. I only knew a little of his work.

But filmology was important for your work?

JPM: Yes, I was really inspired by Cohen-Séat, Morin, Michotte van den Berck, and some of Jean Mitry's writings. Certainly by Michotte and Cohen-Séat, because they highlighted the role of mimesis in spectatorial participation: there is a correspondence between the body of the character and the mimetic 
body of the spectator. For Cohen-Séat, this implies that the spectator no longer truly has awareness of himself. As for Michotte van den Berck, he said that, at bottom, the spectator no longer has his own sensations - he forgets them. For the spectator, the character has become his external aspect. So there are two complementary aspects: the spectator forgets himself, and, for him, the character has become akin to his external aspect. This is what impressed me the most, because here we find the entire problem of filmic identification, as I tried to explain in The Structures of the Film Experience and, a fortiori, in my second book Essai sur l'image et la communication. In The Structures of the Film Experience, the home-movie attitude was not really important for me. It was just a way to find my bearings: to show that, in the fiction attitude, protention and retention are so strong that the spectator effectively forgets himself, whereas in documentaries and home movies there is still some relationship with the real.

You mentioned the three main influences of your work that structured The Structures of the Film Experience. You also have the triple structure in your distinction between fiction attitude, documentary attitude, and home-movie attitude. Is there an importance of the number three for you?

JPM: For me, at the time, the triptych fiction attitude/documentary attitude/home-movie attitude was especially interesting for highlighting the experience of the viewer of fiction. My interest was in the fiction-film, and only in the fiction-film. But Sartre's distinctions allowed me to show that, in the home movie, we are looking for people in general, for the style of the person, but we still stay within reality. When you look at a photograph of somebody you know, you are situated in a certain time and place; when you follow a fiction film, you are not in the real world. It seems to me that it is the home-movie attitude that has come to the fore now. Perhaps it is due to technological change, which has allowed for an unprecedented multiplication of image-memories and representations of oneself.

What were the fiction films that you were predominantly interested in at the time?

JPM: Fellini, Godard, Truffaut, of course. The nouvelle vague. But also comedies like Georges Lautner's Les Tontons-flingueurs (Monsieur Gangster, 1963). I went to the cinema very often and I saw a lot of movies at that time. The period was rich in outstanding films: $\grave{A}$ bout de souffle (Breathless, 1960) by 
Godard, L'Avventura (1960) by Antonioni, La Dolce Vita (1960) by Fellini - all films which testify to the phenomena of empathy and identification that the cinema arouses, and that interested me in The Structures of the Film Experience.

What was the cinema scene in Louvain like?

JPM: Louvain is a city with a big university. At the time, there were cinemas, whose programs were like in other big cities, but there were also ciné-clubs for the students, with a special choice of experimental films, etc.

Didyou also frequent the famous Cinémathèque belge in Brussels?

JPM: At this time, never. I was a student in psychology, not cinema. I simply had the chance to be employed by a communications department as a psychologist.

In the late 196os, you then wrote The Structures of the Film Experience as a research assistant for Victor Bachy.

JPM: Yes. The book came out as part of a new collection launched by Professor Bachy to publicize the work of our research center. It was put out by a modest Louvain publisher called Vander. But the collection was too discreet to be known beyond a very narrow cycle of researchers, especially because, since 1969, attention had already shifted significantly towards structuralism in its various forms. In this new intellectual context, the image in general became a sign and the cinema became a special kind of language. Suspected of subjectivism and even of idealism, phenomenology as a method disappeared, to give way to the formalism of semiology. I believe that without the attention that Vivian Sobchack and a few others gave to The Structures of Film Experience, the book would likely have fallen into oblivion. It seems that it is now enjoying a new life fifty years after its release.

What was your first reaction when you heard that your book was coming out in English translation?

JPM: I was indeed very surprised, because for me it was a text that had been buried by several layers of structuralism, pragmatism, etc. It was something that I did not think would have been interesting to return to. But 
on the other hand, I feel like there is a broader groundswell of interest in the phenomenological approach. This aspect did not surprise me so much. I was quite happy, in the end, to see this newfound interest in an old work that had been rarely cited in the French academic literature.

Did you know Vivian Sobchack's essay “Toward a Phenomenology of Nonfictional Film Experience" from 1999, in which she introduces the ideas of The Structures of the Film Experience to non-French speakers?

JPM: Not at all.

There was no dialogue between you and Sobchack?

JPM: None whatsoever. It was only later that I encountered her work, in the special issue of Studia Phaenomenologica on "Film and Phenomenology" that Christian Ferencz-Flatz and Julian Hanich published, for which we both wrote an article. ${ }^{5}$ Before that, I didn't know her at all.

Were you aware of other resonances your text had in the English-speaking world?

JPM: No. It's astonishing, but perhaps it was because this all took place in film theory, and I have mostly abandoned this terrain. For me, it turned into a marginal area. I became a professor of general semiology and the general theory of communication, so problems relating to the image were no longer specific for me. I understood them in a more general framework, relating to audio-scripto-visual communication. So I was focused on the image only within complex messages, and I was no longer occupied with the specific literature on the cinema.

Before you became a professor in general semiology, you had to write a dissertation. It was entitled Image et perception: essai de description phénoménologique de l'expérience filmique and was later published as your second book under a different title: the still untranslated Essai sur l'image et la communication. ${ }^{6}$

JPM: Indeed. I wrote it in the early 1970s, and in the 1970s nobody in my department was interested in phenomenology anymore. It was the time for semiology, for narratology, for Lacan and Althusser. I wrote my thesis because I was obliged to have a thesis to continue my career at the university, and of 


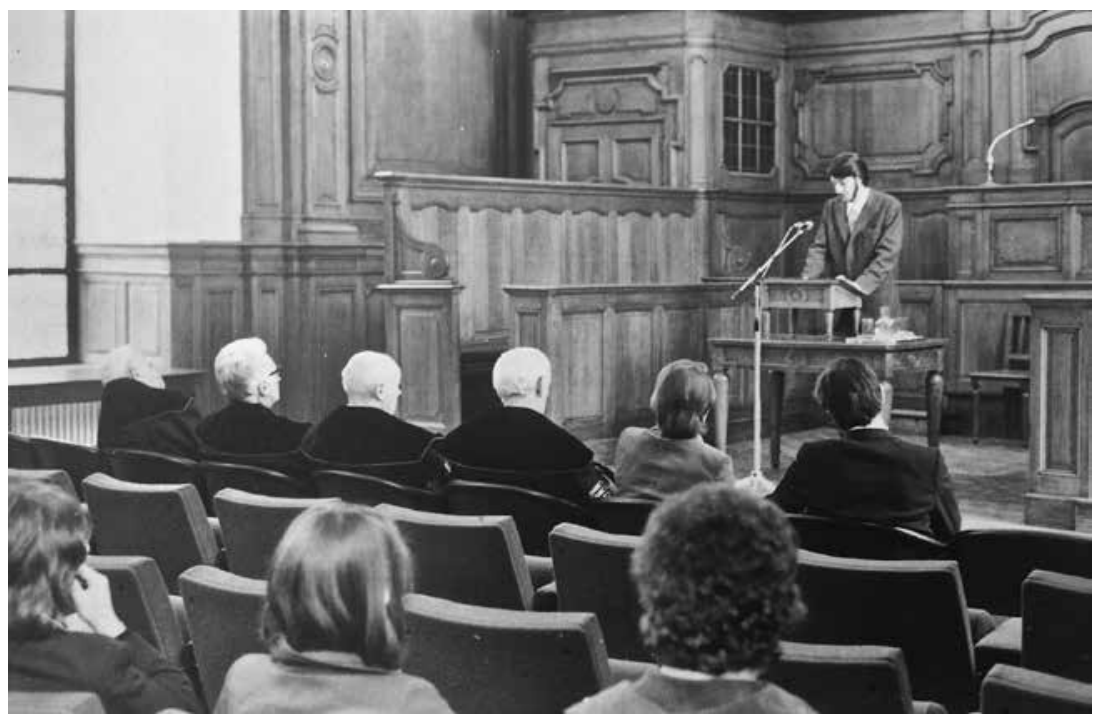

Fig. 3: Meunier in 1972 during a public lecture that was part of the requirements to acquire the doctoral degree in his faculty.

course I continued with what I knew: phenomenology. I was also interested in semiology, but it was easier for me to go on with what I knew. In The Structures of the Film Experience, I had taken Sartre as the framework, but the second book was based on Merleau-Ponty: namely, his books Structure of Behavior (La Structure du comportement) and Phenomenology of Perception (La Phénoménologie de la perception), two works which I studied deeply at that time. It seemed to me that what Merleau-Ponty said about perception, which is inspired by Husserl, what is called the perspectivism of perception, was a very interesting way to comprehend the fiction-attitude. In my book, I compared the real and the unreal.

The thesis was finished in 1972, but the book only came out in 1980. Why did it take so long?

JPM: There were no more publishers ready to publish a book of phenomenology at that time. It was very difficult. In France, it was not possible, nor in Belgium. I myself was rather uncertain about the value of phenomenology at that time. So I delayed the publication for a few years, until the day that my thesis supervisor told me that I must publish my thesis. So I found a very little publisher in Louvain, whose name was Cabay, which has since become a big publisher (but not thanks to me...). 
Even more than The Structures of the Film Experience, the second book was overshadowed by new intellectual currents.

JPM: Yes, indeed. Let me briefly go through the history of this: interest in phenomenology had completely died out as a result of the waves of structuralism, Marxism, materialism, which served to rediscover the materiality of language. For these studies (semiology, narratology, and other types of formalism), there was nothing but codes. Nonetheless, there was also the famous special issue of Communications on psychoanalysis and cinema, with articles by Christian Metz, Jean-Louis Baudry, and others, who were inspired by Lacanian psychoanalysis. ${ }^{7}$ Here, you can indeed find an interest for the lived experience. They weren't doing phenomenology in a Husserlian, Sartrean, or Merleau-Pontian vein, but they did pay heed to lived experience. And when, for example, Metz in The Imaginary Signifier described the film-viewer as an all-perceiving subject, it goes without saying that I saw the relationship with what I had written in Essai sur l'image et la communication. We were both concerned with perspectivism.

As I said, in The Structures of the Film Experience, my point of departure was Sartre and his different imaginary attitudes. Essai sur l'image et la communication was based more on Husserl and Merleau-Ponty and on their description of the perspectivism that characterizes perception. This notion, fundamental for phenomenology, takes account of the fact that, in our experience of the real, what we perceive is mediated by its perspectival aspect, and that, therefore, it always exceeds our vision. This is true both for the perception of objects and for the perception of other people. Perceiving a cube (to take the classical example) involves perceiving a volume through a profile that can only show us three sides - the other sides are merely anticipated. As Merleau-Ponty put it: "The 'things' in naïve experience are evident as perspectival beings: it is essential to them, both to offer themselves without interposed milieu and to reveal themselves only gradually and never completely [...]; I grasp in a perspectival appearance, which I know is only one of its possible aspects, the thing itself which transcends it." ${ }^{8}$ It is the same for other people. I can only perceive certain forms of behavior, but understanding them is akin to slipping into a life grasped as a totality (as a general manner of being or as a style of behavior) since the perceived gestures become meaningful for us from a mass of other possible gestures - possible but not immediately accessible, and which thus remain hypothetical. As with objects, the other person always transcends our vision.

On this basis, I tried to show that unreal objects and people do not have this transcendental character. They do appear to us in perspective, as in 
reality, but we know that the perceived profiles (the perceived aspects of objects, or the behavior of the character) only have an imaginary existence, that they do not really imply other possible profiles, and that the totalities that we aim for through them are entirely constituted by us, by our gaze. By slipping into the gestures of a fictional character, we bestow them with a life and an imaginary interiority which is wholly the result of our projections.

Here you show some similarities to other film theorists from this period.

JPM: Yes, indeed. From this derive some of the major characteristics of the filmic experience described by film theorists: the sentiment of being an "all-perceiving subject" (to adopt Metz's expression), as well as the forgetting of the self (the "absence of reflexive duplication" noted by Cohen-Séat) and identification such as described by Michotte (in the cinema, the character "becomes, so to speak the external aspect of the person of the spectator"). In the end, it is the extent to which what is perceived no longer has any real (transcendental) alterity that we lose a sense of difference and of our own identity. I can't delve any further, here, into the details of this explanation, nor into the nuances that arise from it. I will simply add that, as opposed to Metz, who was inspired by Lacan, I do not conceive of the cinema as an ideological apparatus, but as a dispositif that allows for many different forms of identification, empathy, comprehension, projection, etc. In Metz, the idea of the all-perceiving subject is based on an identification with the camera; I based it on the perceptive characteristics of the image. So Metz and I had similar ideas about an all-perceiving subject. But in contrast to Metz I didn't conceive of the cinema as an ideological apparatus. Metz used this idea to condemn the cinema. For Baudry, too, and especially for him, the cinema is an ideological apparatus, as he wrote in his famous 1970 article for Cinéthique. ${ }^{9}$

Did you have any contact with Roger Odin, who later developed a semiopragmatic approach in which, in a somewhat similar way to your triptych, he distinguishes modes of reading a fiction film, a documentary film, and a home movie?

JPM: I have never met Odin. I noted with interest that he made distinctions similar to those that I proposed (between the fiction film, the documentary, and the 'family film'), but his semio-pragmatic approach (founded on the notions of the institution and the corresponding reading) is noticeably different from mine, which is more psychological in nature. 
You had done this already ten to fifteen years earlier.

JPM: In a way, yes. But I'm not saying he got it from me! He took a different path.

Afteryou became a professor of general semiology, you gradually lost interest in phenomenology and film?

JPM: When I was writing Essai sur l'image et la communication, I was still using phenomenology, and we could still speak in those terms, because structuralism was not yet dominant. Then people lost interest entirely, and took to speaking of structures, codes, etc. And I followed this movement. Also, film courses in the strict sense practically disappeared from my department after Professor Bachy left. I had a filmology course that was canceled, because the department oriented itself more towards journalism and public relations. I was in this department and I became more interested in semiology, pragmatics, and educative messages. At bottom, I followed two orientations: the general theory of communication, and more specifically, educational communication, that is, documentary, pedagogical communication, museology, and the like. So the cinema disappeared from my field of interests. But I have always kept a phenomenological thread, because in my courses on semio-pragmatics, I have taught the pragmatics of Austin, Searle, Grice, and others, but also certain works relating to messages combining images, writing, speech, etc.

It's interesting that you mention that phenomenology remained important for you. Already in The Structures of the Film Experience, you voiced a strong critique of positivism in filmology, from a phenomenological point of view. You argued that there are things that quantification cannot take account of-such as subjective experience.

JPM: To tell the truth, I am not aware of that many positivist attempts at quantification in the cinema. For Michotte, phenomenology was very important, and I wanted to take this even further. Phenomenology was important even for anthropologists like Morin. They were a little outside of Husserlian phenomenology and philosophical questions in the strict sense, but they made reference, in some way or another, to lived experience. Semiology evacuated this entirely and saw everything in terms of language, while forgetting that, even in Saussure, there are references to lived experience. Lived experience was eliminated, except in psychoanalysis, where there 
is a recourse to lived experience through the concept of the Imaginary as conceived by Lacan.

I don't know if you know Dan Sperber and Deirdre Wilson's book Relevance..$^{10}$ The writers wanted to show that when you understand someone, it's like a proposition, you place what they say in a propositional logic, in order to discover what they meant to say. Sperber and Wilson understand the mind as a simple machine, a computer. But how can they say that if they did not have the feeling of actually having to reason, at a given moment, in order to understand what someone has said? There is always a reference to lived experience in order to elaborate any theory whatsoever - even in theories that deny lived experience. For a major part of cognitivism, the mind functions in a non-conscious way, like a robot. But in order to say this you have to have feelings... By this I mean that, even in the cognitivist current, which has said very interesting things, personally, I have always maintained that theoretical elements rest on an implicit lived experience being made explicit, and that we should not make implicit lived experience a purely unconscious, automatic thing, which is what Sperber and Wilson do.

Resorting to a computational model of the mind does not seem adequate anymore, even in cognitive science where ideas of the embodied mind have long replaced the so-called first-generation cognitivism. Does your critique also hold for contemporary neuroscience?

JPM: Yes, just take the problem of mirror neurons. This is an important problem for identification. It was discovered that, when a macaque watches another macaque doing something, the activated neurons of the one who watches correspond to those of the one who acts. So scholars like Giacomo Rizzolatti and Corrado Sinigaglia, who are perfectly respectable figures, say: we are now finally understanding the comprehension of other people. But phenomenologists like Merleau-Ponty (and Hesnard, who took inspiration from Merleau-Ponty) have long understood that, in order to comprehend someone else, there is a mimesis which makes one's own body capable of resonances with a perceived body, which allows me to understand someone else. It is not reasoning that allows us to understand someone else, it is the resonance of bodies. The neuroscientists have only been able to give this explanation because they themselves, in their lived experience, feel that we are capable of resonating with the bodies or actions of other people. Without this lived experience, it is impossible to understand the functioning of mirror neurons. 
There's a primacy of experience - only then can we go on to formulate scientific explanations?

JPM: Exactly. The neuroscientists think that they have found an explanation. But they only show electric charges, and that's it. They don't know how to give meaning to them, they don't get any closer to lived experience. You can't ascribe any meaning to the activation of neurons if you do not relate it to lived experience.

If we move away from a critique of other methods and look at phenomenology itself: what would you say are criteria for good phenomenology?

JPM: There must be an intersubjective accord, the only confirmation can be an intersubjective recognition! This is an old philosophical problem that goes back to Husserl, the problem of the transcendental subject, the transcendental ego. Why did you ask this question?

Because it is extremely vital for the whole film-phenomenology movement: there are certain strands that have a different understanding of phenomenology than others, and it would be helpful to know from someone who has practiced film-phenomenology what one could say to people how you can discover that this is good phenomenology - and that is not. What are your criteria?

JPM: It's a question I've also asked myself. There are first-person approaches, of course, but there is also a second-person approach, which relies on questionnaires, etc., and whose goal is to revive lived experience. The problem of all phenomenology is to let lived experience come to the surface in order to explain it, to render the implicit explicit. But it is true that we never did this in an entirely satisfactory manner.

In France, Claire Petitmengin has done interesting studies on second-person phenomenology. ${ }^{11}$

JPM: Also Natalie Depraz, who is a Husserl specialist, wrote an article with Francisco Varela and Pierre Vermersch which I found very interesting, "La réduction à l'épreuve de l'expérience" ("Reduction to the Feeling of Experience"), in a journal called Études phénoménologiques. ${ }^{12}$ Methodologically, it's interesting, because the writers try to explain how to let the implicit surface and make it explicit. I think that this is still a problem. Merleau-Ponty went beyond the dogmatism that you find in Husserl and Sartre. But the 
language you use to make the implicit explicit remains marked by layers of culture. In the end, I think that rendering lived experience explicit is an infinite work, which has numerous intersections with intersubjective experience. Second-person phenomenology can be useful, but it still doesn't exhaust the problem.

Many feminist film phenomenologists take as a point of departure the difference of the female experience. For you, this was not so crucial in The Structures of the Film Experience.

JPM: In our empirical investigation of Cayatte's La Vie conjugale, it was quite obvious that male and female viewers did not have the same projection on the characters: what they resonated with in the character's bodies was not exactly the same. Here we have a difference. But the common point is that both project something, and the fictional character of fiction lends itself to putting oneself into the other much more than a real being. Here we have a point in common.

Hence you are saying the structure of identification is the same?

JPM: Yes, the common point is that we all constitute - by projection and identification - the experience of a character via our own experience. The difference is that we do not project the same thing, because, depending on whether we are a man or a woman, we do not have the same background.

Just like Merleau-Ponty and Sobchack, you are saying that phenomenology is never complete. If you go back to The Structures of the Film Experience, what would you say is incomplete about it?

JPM: There's something I'd like to do, but I'm not sure if I will end up doing it. In the article that I wrote for Julian Hanich and Christian Ferencz-Flatz's Studia Phaenomenologica issue, I began a kind of synthesis between the earlier and the later book. I would try to begin, very simply, with the phenomenology of the unreal. I would not begin with Sartre's different attitudes or ways of positing existence. I would say: how does the unreal appear? And I would try to graft onto that the problems of the home movie and the documentary, the reference to the real. I would invert my procedure somewhat. Instead of beginning with the three attitudes, or ways of positing existence, I would start with the phenomenology of the unreal. I would try to better understand what happens when, instead of simply letting myself 
believe in the unreal, I target someone who exists. What does generalization, in the sense in which Sartre spoke about it, mean? What is a generalizing gaze, as compared to a gaze that remains in the singular? This is a question that has stayed with me, and that I would like to develop.

Likewise, what I would like to develop much more is the question of fictional emotions. If a character is fictional, what is the emotion that is projected? In Essai sur l'image et la communication, I said that we project all the schemas of existence of the fictional person we see. But as Merleau-Ponty said, in reality the rage of my friend is not really my own rage, I just feel it. Whereas in the cinema it is my rage that I project. What, then, does a rage that is unreal, played at, mean? What is an unreal rage, an unreal fear, etc.? This is a problem that I think it is necessary to go deeper into. We should not simply limit ourselves to saying 'play at.' What does 'play at' mean? A phenomenology of emotion seems very important to me.

So when you have the feeling of rage or fear as a film-viewer, it is not a real sentiment, but it is a sentiment that is played at by the spectator?

JPM: It is played at. It is projected by the spectator.

You are claiming that we don't really have these feelings? We do not leave the cinema in terror, for example?

JPM: Right. It's all play. There is a gap in phenomenological descriptions of viewer emotions.

There is already this importance of play in The Structures of the Film Experience when you speak of child's play, role-play. When children play 'cowboys and Indians,' for instance, they don't totally believe in the game. They are also in reality. They are not totally subjugated to the illusion that they truly are 'cowboys and Indians.' There is a kind of double existence at this moment, which is comparable to watching a film.

JPM: This is something I wish to describe better. What does it mean to be afraid through a character? It means being double, as you said. It's the "I know very well... but all the same...," as another psychoanalyst, Octave Mannoni, said. But there is a powerful sense of forgetting, otherwise it would have no interest. If you were simply double, there would not be much interest. You are double because you know that you play, but all the same, you get lost in 
the game. Sartre called it fascination. I read a novel, and I am fascinated by it. I can't let go of it. But at the same time you know that you are fascinated.

Does the fact that we are faced with images make this phenomenon more powerful in the cinema than when reading a novel, where the images are purely fictional or imagined? In the cinema, the images are real.

JPM: Yes, when you read a novel you have to construct images. But Metz said interesting things on this topic. For instance, he critiqued the notion of film grammar: There is no grammar in the cinema. Nouns, verbs, the subjunctive, etc. - there is no need for them. It is language that needs nouns and verbs and so on, in order to construct an image, but not the cinema. There is certainly a much stronger level of participation. This is what makes the cinema interesting. But to say it is stronger is not saying much. How is it stronger? How can we distinguish belief in literary characters from belief in the characters of a fiction film or a graphic novel? My grandchildren get lost in comic books. They really get inside them, but at the same time they know they are reading.

There is a remarkable passage in your book when you say that there are moments in films where the emotion produced by a scene - such as the scene from Mikhail Kalatozov's The Cranes Are Flying (Letyat zhuravli, 1957) - is so strong and intense that it produces a refusal in the spectator, who has a kind of defense mechanism against the emotional intensity of the on-screen world. The spectator doesn't withdraw from the film because the emotions are unreal and therefore weak, but because they are too strong.

JPM: When this happens, the viewer refers to a possible reality.

Soyou refer to your own experiences of having a similar emotion to that which you see on the screen?

JPM: Look at news images. When we saw the little Syrian boy dead on the beach, it was atrocious, because we experience this boy as a real kid. We knew that he really played with toys, that he really had parents, and this is what was unbearable. If you see the same thing and you know that it's a fiction, it's the same thing but there is less intensity. But if, at the moment that you see the fiction, you think that it is possible, then it can be just as intense. When I saw the image of the Syrian boy, I was completely overwhelmed, and when I see fiction films, in which horrific 
things happen, then this can evoke real images, and then it too becomes unbearable. But it is not the fictional image as such, it is because it refers to the real, because we know that somewhere in the real it is possible. Or take another example: not long ago I saw a film on the round-up at the Vel d'Hiv in 1942, La Rafle (The Round Up, 2010) by Roselyne Bosch, and in one of the scenes you can see a French cop separating a child from its mother. This is fiction, but for me it was very disturbing, because I said to myself that it must have been possible in reality. If you only see the fictional side, it's much less intense. But if you think that it is possible, that there really were children separated from their parents, then the emotion becomes much more intense. It's a problem of interference between the unreal and the real.

In fiction, you need to have a certain verisimilitude.

JPM: There is a great American film, Jeremiah Johnson (Sydney Pollack, 1972), where you see Robert Redford living with an Indian woman and child. He had profaned a sacred Indian site, and he returns home to his cabin, where he finds that his Indian wife and child have been killed. This is pure fiction, but when I saw it, it really touched me, because the dead wife and child made me think that things of this nature really do happen. It almost became a documentary, a quasi-documentary, and the emotion became much stronger. These fiction films are so evocative of real dramas that our emotions become charged. And there is yet another problem of emotion in the cinema: the problem of collective emotions. Even if it is played at, it becomes strong from the fact that many people are constructing it together. There are mimetic resonances.

This brings us to one thing missing in your book: You accept that the film spectator is a spectator in a cinema, whereas even in 1969 films were seen on television. Today, we can say that the majority of films seen by people are watched on screens that are not cinema screens. Does this change the nature of the film experience for you if we no longer have this collective experience?

JPM: The question is: are there fundamental differences in structure or meaning or is it more a matter of degree? If I am sitting at home with my wife and we watch TV, it's not the same thing as if I were watching the film in a theater with others on a big screen. But in the end, I think that this is a question of intensity, a question of degree. It's the same thing but lessened. 


\section{Notes}

1. The interview took place on two occasions. The first part was conducted in Frankfurt am Main on 23 November 2017; the second conversation was held in Louvain-la-Neuve on 12 April 2018.

2. $\quad$ Edgar Morin, L'Esprit du temps (Paris: Grasset, 1962).

3. $\quad$ Alphonse de Waelhens, La philosophie et les expériences naturelles (La Haye: Martinus Nijhoff, 1961).

4. See Jean-Pierre Meunier, "Limpact du film sur le public: 'La vie conjugale' d'André Cayatte," Centre des techniques de diffusion, Document no. 2, Université Catholique de Louvain, 1965.

5. Jean-Pierre Meunier, "Le problème de l'identification filmique reconsideré," in Christian Ferencz-Flatz/Julian Hanich (eds.), "Film and Phenomenology," special issue of Studia Phaenomenologica 16 (2016), pp. 241-268.

6. Jean-Pierre Meunier, Essai sur l'image et la communication (Louvain-laneuve: Cabay, 1980).

7. See "Psychoanalyse et cinéma," Communications 23 (1975), eds. Raymond Bellour, Thierry Kuntzel, and Christian Metz.

8. Maurice Merleau-Ponty, The Structure of Behavior, trans. by Alden L. Fisher (Boston: Beacon Press, 1963 [1942]), p. 187.

9. Jean-Louis Baudry, "Ideological Effects of the Basic Cinematographic Apparatus," trans. Alan Williams, in Philip Rosen (ed.), Narrative, Apparatus, Ideology (New York: Columbia University Press, 1986), pp. 281-298. Original in Cinéthique, no. 7-8, 1970.

10. Dan Sperber and Deirdre Wilson, Relevance: Communication and Cognition, $2^{\text {nd }}$ ed. (Oxford: Blackwell, 1995).

11. See, for instance, Claire Petitmengin, “Describing One's Subjective Experience in the Second Person: An Interview Method for the Science of Consciousness," Phenomenology and the Cognitive Sciences 5 (2006), pp. 229-269.

12. Nathalie Depraz, Francisco Varela, and Pierre Vermersch, "La réduction à l'épreuve de l'expérience," Etudes phénoménologiques 5 (2000), pp. 165-184 . 


\title{
Part I
}

\section{Jean-Pierre Meunier}

\author{
The Structures of \\ the Film Experience: \\ Filmic Identification
}

Translated by Daniel Fairfax 


\title{
Introduction
}

\author{
Jean-Pierre Meunier
}

\section{The Structures of the Film Experience: Filmic Identification}

Today, insisting on the importance of the cinematic fact has become a banality. Certainly, if we had to list the various technologies that have, to varying degrees, transformed our contemporary lives, the cinema would occupy a privileged place. The breadth of cinematic production and the large audiences it attracts among the mass public make cinema a veritable 'institution' of our era.

Film, as has been amply stated, exerts a considerable hold over both the individual and the crowd. The literature on this matter is abundant, yielding various results with an uneven success rate, which usually stigmatize rather than analyze this phenomenon. For the most part, this discussion has focused on the phenomena of 'fascination,' the 'outsized control of the image,' spectatorial enchantment, and even the 'magic of the movies.'

Theoretical analysis, whose role has been to provide an explanation for these phenomena, has for its part had recourse to the Freudian mechanism of identification. This is a convenient concept, which furnishes a descriptive, explicatory principle that is particularly well adapted to the filmic situation. It has inspired numerous analyses and endowed scholarship with a precious guiding thread. We only have to flick through specialized academic journals to notice the already considerable volume of studies dedicated to deepening our understanding of the nature of filmic identification - which, depending on the subjacent theoretical conceptions or the nuanced considerations of the process, also goes by the names of 'emotional participation,' 'projection' or 'empathy' - as well as its repercussions for individuals and the masses.

And yet, this book proposes to once more take the process of filmic identification for its object, despite the fact that it has been studied so often. What are the reasons motivating this new approach? First, it seems essential to us to constantly rework and perfect the general principles of a discipline, in this case filmology, whose most legitimate aspiration is to become a genuine science.

But to this theoretical reason we can add another, more profound reason, whose delineation may permit us to recognize the perspective in which the present study is situated. 
In their rush to apply the process of identification to the filmic situation, the majority of studies dedicated to the problem have, it seems, abusively simplified the data. Often, the original form of the Freudian mechanism has been 'transplanted' into the filmic situation without any changes. But this neglects the fact that the mechanism in question, in the framework of developments in psychoanalysis and other theoretical tendencies, had itself undergone various retouches, and nourished numerous controversies, and that it was thus rather hasty to utilize the notion of identification without subjecting it to a prior critical examination. In order to bear fruit, the notion must be envisaged in the framework of more recent currents of thought that have developed either as an extension of psychoanalysis, or in disagreement with it.

Furthermore, it also seems that filmological research has sinned through an excess of positivism. It was too quick to adopt the approach of a certain scientific attitude, an approach that consisted of objectivizing, or, better, externalizing, in the domain of objective realities observable from the outside, phenomena whose reality is to be found internally, in the experience of the subject.

Thus, filmic identification came to be considered in its objective form, that is, as a psychic mechanism (a mechanism of projection and introjection) or as a function (an empathic function) destined to comprehend or explain the functioning of the objective models of the personality constructed by scientific theory.

It is easy to see the reasons for this position to be adopted. Aside from the fact that it could be expressed in terms that were seductive by dint of their scientific allure, it seemingly justified submitting these phenomena to observation and quantification. It is, after all, generally admitted that the psyche can be regarded as an object, a slice of the perceptual world, or even an externally observable apparatus, if not in and of itself (the psyche has never been observable as an object), then at least by means of its manifestations, or through the objective representations that we construct of it.

But, in adopting this point of view, which it often did, filmology exposed itself to the same reproach that, in the last few years, phenomenological thinking has addressed to the scientific attitude in general, and which has done much to weaken it.

By transposing psychic phenomena to an external objectivized form, that is, by reducing them to the state of simple functions or mechanisms, their very nature was altered, and their meaning or signification was thereby lost. This meaning or signification can only be perceived if we place ourselves 
on the terrain from which these phenomena have been extracted - namely, lived, first-person experience.

It is therefore appropriate to study what the scientific attitude generally starts out by ignoring: the experience of the subject. We must explore, describe, and explain phenomena such as they are immediately lived, and not such as they are conceived by virtue of some pre-established objective schema. In other words, we must make the effort to discover the meaning of phenomena as they present themselves to the subject who experiences them.

It is also appropriate, however, to clarify what we mean by 'description of lived experience.' It is not a matter, of course, of elucidating particular forms of behavior - for example, a given identification of a given subject with a given person - through the concrete modalities of their realization, but, rather, of unveiling the invariable aspect in these particular forms of behavior. In other words, we must abstract real forms of behavior and the structures that we can locate in all forms of the same kind of behavior, which themselves are their specific, concrete realizations.

Could it be said that, by effectuating this kind of abstraction, we slip back into the impasses of the scientific attitude?

In effect, elucidating the invariable structure of a psychic phenomenon supposes that we consider this phenomenon, that we take a distance with respect to it, and that we have an experience of the experience in a consciousness of consciousness, which, we might justly say, constitutes a certain form of objectivation.

But at least by operating this kind of objectivation, we do not escape the experience of the subject - that is, the reality of the phenomena studied. The scientific attitude, in contrast, proceeds from a double objectivation. It also starts out from the formal structure of experience and, in doing so, it must accomplish an initial objectivation similar to what we have just spoken about. But it does not remain on that level. Instead, it accomplishes a second objectivation by placing in the external world what it has internally abstracted, by situating it in an objective, externally observable model, and thus, as we said above, by losing its meaning for the subject and real nature. This is why, we may say in passing, scientists always speak of intuition, because for them, the data of primary abstraction - bearing on their experience as a subject - are only ever presumptions or hypotheses that can serve to comprehend the objective model of psychism which they have constructed, and which, while it is supposed to represent it (they are themselves psychisms), are nonetheless exterior to it, and indeed rather alien to it.

As for the right to treat phenomena scientifically, to submit them to evaluation and quantification, we think that it will not be contested if, 
rather than beginning with objective representations of phenomena, we start with the description that an internal reading can deliver. Simply put, instead of drawing its hypothetical intuitions from objective models, which sometimes do violence to the most evident data of experience, such a description would formulate them on the basis of this very experience, explained in descriptive terms.

Thus, the basis for research must not be any kind of conception of man as an object of observation, but an explanation of man as a subject of experience.

The problem touched on here is evidently vaster and more complex than what we have just allowed it to seem. Unfortunately, the developments that it calls for cannot fit into the framework of this short introduction. Here, we can only affirm our conviction that, in matters of human science, reflection on the experience of phenomena is primordial, and normally precedes that which it must inspire and towards which it must orient itself - to wit, a scientific approach to these phenomena.

Thus, it seems to us that the point of departure for filmological reflection, as is the case for all reflection on human phenomena, consists of the description and explanation of this new and undoubtedly original experience that is the film experience.

The present study constitutes an attempt in this direction.

For us, it will not be a question of objectively representing to ourselves the experience of the spectator-subject, but, of placing ourselves within this experience, of attempting to describe and reveal its meaning, and specify its fundamental structures.

Here, sketched rapidly, are the major stages of this research. First, we will locate, using the texts of important filmmakers, what the notions of perception and identification relate to, notions which are evidently fundamental for the study of the problems occupying us. Let us note that, apart from a few rare personal considerations, this first part will not convey anything particularly novel. Indeed, it may even be seen as a rather pointless reminder of notions that are already familiar in philosophy and psychology. However, if we consider the particular status of filmology, we may understand the reasons for this long overview.

In fact, in the current state of things, filmology is not an autonomous science, but more a site of reflection situated at the intersection of the major human sciences. It can be of interest to the philosopher, the psychologist, the pedagogue, the sociologist, and even the philologist and the linguist. 
This is why any reflection on its object necessitates that those who embark on this reflection must clarify their perspective and recall the notions of the disciplines from which they draw.

The first part of our work has been conceived as a response to this demand.

Its essential goal is to present certain specifically psychological notions and problems to the reader unversed in the field. Let us note that, upon rereading our work, some of the chapters in this first part strike us as not a little superfluous (this is the case, notably, for Chapters V, VI, and VII), with respect to the whole. We have nonetheless retained them, with the thought that they could help some of our readers to be more familiar with the language and, above all, the problems specific to psychology. Those for whom psychology is a foreign domain will perhaps find the means to better recognize the perspective in which this work is globally situated.

The second part consists of the more original component of this study. We will try, with this modest contribution, to sketch out a description of the essential structures of the film experience, conceived as a specific mode of relating to the world and to other people. We will also try to define and explain the fundamental attitudes that this experience solicits on the part of the subject-spectator. Subsequently, in the same descriptive spirit, we will try to clarify the modalities of comportment (identification) that support the various attitudes described.

Finally, in the third part, we will endeavor to open certain perspectives in the study of the extensions of the film experience in the existence and the comportment of the spectator.

As is customary, it is appropriate to conclude this brief introduction by formulating the usual reservations that stand in for any possible rectifications and underscore the incomplete character of the proposed study.

But we would like to do so in more convincing terms than those generally deployed. In our case, these reservations are dictated much more by reality than by a conventional sentiment of modesty.

Thus, to preserve the valuable, or ever so slightly original, aspect of this research, we feel the necessity to highlight its relative, incomplete character.

This limit is tied to two things: on the one hand, there is our own lack of experience in the subject, and on the other hand, there is filmology's own relative lack of experience. Filmology is, indeed, a new discipline, and every reflection concerning it is exercised on a terrain that has still received too little recognition to not be uncertain and effectively partial.

We should not, therefore, expect definitive conclusions from this study. Inevitably, the views expressed here will be criticized, corrected, and even refuted with scientific progress in the field. Unavoidably, too, some (possibly 
important) aspects of the problems occupying us will escape us or will not be given the space they deserve.

But what we do hope will come out of this work is that, beyond its imperfections, it shows some contours of the truth, some new insights, some interesting perspectives, and that, above all, it provides a source of inspiration for new hypotheses conducive to advancing the cause of filmology. 


\section{Part One: Introduction to the General Structures of Experience}

\section{Chapter I: Perception}

The study of perception constitutes one of psychology's major preoccupations, and it is easy to see why: perception is indeed a primordial faculty that underpins our insertion in the world and all of our relations with other people. No attempt to understand any phenomenon of relations between humans and the world (and the film experience is precisely such a relation) can do without a general theory of perception. Whence the primary position reserved to the present chapter.

We will first see how the faculty of perception was conceived by the psychological tradition. More precisely, we will try to clarify the principles or, rather, the prejudices which have presided over the elaboration of certain classical theories.

This preamble will then help us to better recognize the phenomenological perspective, a perspective in which this study in its entirety is situated, and which, we suggest, will allow us to discover the true meaning of perception.

\section{The Point of View of Traditional Psychology}

Traditional thought unreservedly acknowledged the distinction between the world and the individual. It placed the individual between parentheses and bestowed it with the necessary functions for its integration into an environment. In this perspective, the world was always presented first, as an existing reality external to the individual, and whose truth the individual had to conquer.

As a victim of this prejudice, psychology posited the notion of sensation - an impression corresponding to a sensory excitation issued from a fragment of external reality - and made of perception a cognitive operation destined to procure for us, on the basis of a mosaic of sensations, the most adequate representation of this world in itself, present before anything else.

Perception, as Piéron's dictionary of psychology indicates, had become a "moment of sensory awareness of external objects and events which have given birth to sensations of varying number and complexity."

As for the perception of other people, traditional psychology was also incapable of conceiving it without the support of a cognitive operation. For this psychology, totally impregnated by the classical distinctions between 
mind and body, individual and world, the 'psychic fact' appeared as an internal reality accessible only to the subject who feels it, thanks to a process of introspection. Consequently, in order to apprehend this same 'psychic fact' in other people, we had to establish, by means of a totally intellectual operation, a relation between the 'psychic fact' and its external manifestations, manifestations which we have also experienced ourselves, and which constitute the only reality accessible to other people.

Finally, when this same psychology had to take stock of the communications existing between people, it had to have recourse to some motivation, function, or even instinct of sociability. The individual, conceived of as an individualized entity, an interiority closed in on itself, could not logically communicate with its kin without the intervention of these hypothetical internal forces. Thus, understanding other people involved intelligently reading the objective signs of their comportment, and communicating with them involved responding to a motivation strong enough to break the solitude of an otherwise quite self-sufficient being.

We can see that the conceptions that we have just briefly recalled are so many theoretical constructions built on what the phenomenologists have called the 'prejudice of the world.' There was still, at the origin of all reasoning, the individual and the objective world, the closed consciousness of the subject and the others. All the efforts of psychology consisted, then, of linking the terms thus defined, and explaining the de facto relations existing between individuals and the world, as well as among individuals themselves.

And yet, we should ask ourselves whether it was arbitrary to thus dissociate the terms. Was there not a way of relating to the world, and to other people, that was more fundamental than what traditional thought could define?

Is the human being, conceived of as an individualized entity, not a pure abstraction, an invention of the scientific attitude with no bearing on lived experience?

In the past, psychologists ignored these questions, but they have since been revealed to be of major interest in modern psychology, which has been considerably revitalized by the contributions of phenomenological reflection.

A quick analysis of the positions of phenomenology will enable us to understand the most important facets of perceptive phenomena.

\section{The Findings of Phenomenology}

Born in Germany with Edmund Husserl and disseminated in France by Jean-Paul Sartre and Maurice Merleau-Ponty, phenomenology is above all 
a method aimed at describing our immediate experience. Renouncing, at least provisionally, the theoretical explanations that reason or scientific intelligence have been able to construct, it represents a return to the lived experience of phenomena, an effort to recover a direct contact with the world such as it is, before any analysis that we can make of it, and any explanation that we can give of it.

As Merleau-Ponty has noted:

It is the attempt to provide a direct description of our experience such as it is, and without any consideration of its psychological genesis or of the causal explanations that the scientist, historian, or sociologist might offer of that experience... ${ }^{2}$

To return to the things themselves is to return to this world prior to knowledge, this world of which knowledge always speaks, and this world with regard to which every scientific determination is abstract, signitive and dependent, just like geography with regard to the landscape where we first learned what a forest, a meadow, or a river is. ${ }^{3}$

The lessons gained by the phenomenological method are so important that they have profoundly renewed our understanding of what it means to be human. Psychology and psychoanalysis, such as they are presently conceived by numerous practitioners (Angelo Hesnard, Jacques Lacan, etc.), have been considerably enriched by this new mode of thinking.

From the point of view that occupies us here, it is the contribution of the method concerning perception - perception in general and, more specifically, the perception of other people - that is of primary interest to us. In this regard, how does phenomenological reflection proceed when it comes to perception?

Rather than postulating, as premises for analysis, the individual and the world as separate entities, and trying to explain how one can represent the other to itself, we are concerned here, before anything else, with locating the experience of the perceiving subject in order to describe it and make it explicit.

In this perspective, the perception of the world is revealed as something totally different from the mental organization of a sum of sensations. The very notion of sensation seems unjustifiable in the face of experiential data.

Gestalt psychologists had already shown that what we perceive in a concrete and immediate manner is not the accumulation of sensations, but forms and structures of the whole, which are organized without the 
involvement of our intelligence. Let us quote, here, some particularly enlightening lines from Merleau-Ponty:

Broadly speaking, we should think of it [perception] not as a mosaic but as a system of configurations. Groups rather than juxtaposed elements are principal and primary in our perception. We group the stars into the same constellations as the ancients, yet it is a priori possible to draw the heavenly map many other ways. Given the series:

ab cd ef gh ij

we will always pair the dots according to the formula a-b, c-d, e-f, etc., although the grouping $\mathrm{b}-\mathrm{c}, \mathrm{d}-\mathrm{e}, \mathrm{f}-\mathrm{g}$, etc. is equally probable in principle. [...]

The same type of analysis can be applied to hearing: it will simply be a matter of temporal forms rather than spatial ones. A melody, for example, is a figure of sound and does not mingle with the background noises (such as the siren one hears in the distance during a concert) which may accompany it. The melody is not a sum of notes, since each note only counts by virtue of the function it serves in the whole, which is why the melody does not perceptibly change when transposed, that is, when all its notes are changed while their interrelationships and the structure of the whole remain the same. On the other hand, just one single change in these interrelationships will be enough to modify the entire make-up of the melody. Such a perception of the whole is more natural and more primary than the perception of isolated elements. [...]

Therefore analytical perception, through which we arrive at absolute value of the separate elements, is a belated and rare attitude - that of the scientist who observes or the philosopher who reflects. The perception of forms, understood very broadly as structure, grouping or configuration should be considered our spontaneous way of seeing. ${ }^{4}$

We can see, with the collapse of the notion of sensation, that there is also an abandonment of the idea of the intervention of the intelligence in the perceptive act. To perceive is not to think, reason, or judge. Far from being the sketch-outline of a knowledge that is elaborated on the basis of a sum of elementary data, perception attests, on the contrary, to a form of relating to the world that is more immediate and more primitive than 
that described by analytic thought, basing itself on supposedly objective elements.

As Merleau-Ponty, once more, writes:

I do not think the world in the act of perception: it organizes itself in front of me. When I perceive a cube, it is not because my reason sets the perspectival appearances straight and thinks the geometrical definition of a cube with respect to them. I do not even notice the distortions of perspective, much less correct them; I am at the cube itself in its manifestness through what I see. [...]

Perception is not a sort of beginning science, an elementary exercise of the intelligence; we must rediscover a commerce with the world and a presence to the world which is older than intelligence. ${ }^{5}$

At the end of the day, perceptive consciousness can no longer be conceived of as a closed entity that reasons in order to give itself a reality that is external to itself. When we return to first-person lived experience, perceptual consciousness first appeared as a relationship with the world, and the world perceived as that which is primordial in our existence, as a datum, given no thought, which is always 'already there,' and from which all knowledge is drawn. The primary element, however, is not the outside world, on the one hand, and the individual, on the other hand; it is perception itself as a primordial relationship with the world.

What we have just said about perception in general reveals itself to be just as correct when we look at the particular problem of the perception of other people.

Indeed, a return to lived experience evidently shows us that, no more than perception in general, the perception of other people is neither an operation nor a function of our intelligence, but an immediate datum. It is because the old psychology had conceived of the psychic fact as an internal reality only accessible by introspection that it had been obliged to carry out an intelligent reading of the external signs of the perception of other people, referring to a signified that is in itself inaccessible.

And yet, what does the introspection on these claimed internal psychic realities teach us, given that they are buried deep within the individual consciousness?

At the very most, there are some indications of a physiological nature, or certain qualitative nuances relating to a psychological state. We can say, for example, that emotion is an affective reaction of a certain intensity normally 
accompanied by vegetative manifestations. We could equally distinguish different types of emotion and nuance them by qualifying them according to their intensity or their quality. Thus, we speak of joy or sorrow, love or disgust, rage or fear (intense fear or quiet fear). But once we have said all this, we have still not understood the significance of emotion, for nothing, in these objective descriptions, gives us its meaning.

On the contrary, emotion becomes clearly intelligible when we envisage it as a form of behavior or comportment, a modification of our relations with other people. Rage, for example, as Jean-Paul Sartre has shown, is nothing but symbolic behavior destined to accomplish in the imaginary what we are incapable of accomplishing in reality. ${ }^{6}$

We can see that, to grasp the meaning of emotion, we must think of it as a form of comportment. In other words, we must think of it in the same manner as the emotion of another person whom we can observe. This signifies that the emotion is immediately perceptible in our bodily attitude, and thus that other people, and their comportment, are always clearly shown to us.

The psychic fact as a fundamental internal reality whose bodily manifestations would only be epiphenomena does not exist. Once again, consciousness is not an entity withdrawn from the world, one of whose possibilities would be to secrete psychic facts, which only have an external appearance through a collection of signs to be intelligently decoded. What is primordial is the beings who are in the world from the start, and who have this quality in common with each other, beings who are always placed on the same terrain of activities, and whose comportment is given with all their signification as figures detaching themselves from the background.

These considerations concerning the perception of other people are of fundamental importance for the comprehension of the problems posed by the relations between individuals and, on this basis, the problem of identification.

Indeed, if the perception of other people is an immediate given, if it has no need for any involvement of the faculties of knowledge to be realized, and if it is the primordial datum for a consciousness thrown into the world and no longer withdrawn from it, we can see that there is no longer any need for having recourse to a hypothetical function or motivation to explain the interactions between individuals. The link to other people no longer poses a problem because it now appears as a primary datum, as one of the dimensions of our existence. Once again, it is because it had conceived of man as a consciousness isolated from the world that the old psychology had been obliged to make the link with other people the result of an internal drive and thus make social relations a secondary formation. 
In reality, as Merleau-Ponty states, "our relation to the social, like our relation to the world, is deeper than every explicit perception and deeper than every judgment. [...] We return to the social world with which we are in contact through the simple fact of our existence, and that we inseparably bear along with us prior to every objectification."7

Man is above all a social being, a node of relations, a being ineluctably linked with other people, and the nature of this link, in its original form, is what we call intersubjectivity.

Let us make some comments on this last notion.

The perception of other people, we said, is an immediate given. That is to say, in any encounter with another person, I directly grasp the signification of their behavior, not through a cognitive operation, but through an immediate apprehension of their comportment. I grasp their intentions and, in a way, they become my own. Correlatively, in this same encounter, I appear to the other person in the same way that they appear to me. The other person reads my behavior. My intentions become, in some way, lived by another consciousness and cease to belong only to me. This kind of conscious coexistence of several subjectivities is first sketched out in every encounter. This is what we call intersubjectivity, the primordial link by means of which I am to other people as they are to me.

Regarding the philosophical problem posed by the dialectic of "the Alter and the Ego," Hesnard wrote the following lines, which have much to teach us about the nature of intersubjectivity:

In order for the dialectic of the Ego and the Alter Ego to be possible, they both must be defined by their situation. Discovering not only my presence for-myself, I must also discover the possibility of an alien actor "through a kind of internal weakness that prevents me from being absolutely individual and exposes me to the gaze of others" (Merleau-Ponty). It is only when the Cartesian cogito is thus clarified, that is to say, revealed to be in a situation, that, as Husserl puts it, "transcendental subjectivity could be an intersubjectivity." It is then that the Ego and the Alter Ego appear to each other, because both he and I have the primordial world in common. On the same level, there is my own vision of myself, just as there is the vision of the other person on himself, at the same time as there is my vision of the other person and his vision of me. My body of natural knowledge - my perceived body - finds in the body of the other person a kind of extension of its own intentions: our two bodies are inhabited by the same anonymous existence. Furthermore, our two bodies realize, or at least give a hint of, expressive and significative movements, 
and form a single system by completing each other, since they are both forms of comportment, or (as Freud said before the phenomenologists) forms of existence or psychic life that signal themselves to each other... I watch the other act: the objects that surround him thereby receive new significations; my world is modified by it, and, as if attracted by it, it ceases to be uniquely mine, present to me. It becomes present to the other, to this other behavior which is destined for my eyes. Its own body is no longer an object, or some kind of fragment of the world, but the site of a certain vision of the world: it is reciprocally engaged with me and becomes, to a certain extent, another me. ${ }^{8}$

As revealed by phenomenological reflection, intersubjectivity appears self-evident. But it is important to note that it responds to a factual truth confirmed to a large degree by a good number of observations realized in the domain of child psychology. Indeed, Henri Wallon and other psychologists have frequently described that stage of infant development in which the child, not yet possessing an awareness of itself or of other people as singular beings, lives in a kind of syncretic sociability, in a perfect lack of distinction between the self and other people. This syncretism of primary relations that intersubjectivity illustrates in a concrete manner as a primordial link to other people is defined by Wallon as "an exclusive and global consciousness that the child has of every situation at the moment when he experiences and imagines it."

Let us also cite Hesnard:

Syncretism is not a nascent personal psychism, but a confused intersubjectivity, that is to say, one's very relationship with the human world, such as it preexists any differentiation, within oneself, of the progressively structured attitude that will clarify one's link to other people.

It is on the basis of this indistinct, intersubjective syncretism that selfawareness, and the awareness of others, is structured in the child. Moreover, it is remarkable that the recognition of other people always precedes the awareness of oneself as a singular being.

This removes any credibility we may give to the formulation of the problem of the relations with other people in the language of traditional psychology. Human relations cannot be thought of in terms of cognitive functions, drives of attraction or repulsion, residing deep within the individual. The link to other people is provided with existence in the form of a co-existence of consciousnesses. As such, it precedes the formation 
of people as private subjectivities and is even the precondition for this process. There is also the question as to how to conceive a differentiation of people - of the 'I,' the 'you,' the 'he' - other than on the basis of an originally global structure in which the terms can be differentiated from each other. To suppose the pre-formed person as a distinct being before any dealings with other people, as traditional thinking had postulated, is just as absurd as abstractly conceiving the right-hand side without any reference to the left-hand side.

The terms of a system - such as, for instance, the system 'me, you, him...' - have never had any sense other than as members of this system that necessarily pre-exists them.

At the end of the day, it appears that intersubjectivity constitutes the terrain in which the multiple forms of relations between individuals are rooted.

We will see further how identification is founded on primordial intersubjectivity in order for it to be structured in relation to private intersubjectivity. We will also see the extreme importance of the notion of intersubjectivity for the comprehension of the specific problem of filmic identification.

This is, in any case, the reason for which we have tarried at such length with a description of it.

\section{Chapter II: Identification}

\section{The Origins of the Concept}

Freud, of course, had the merit of having emphasized the importance of the process of identification in the psychic development of the child. He saw this as the first manifestation of an affective attachment to another person, and assigned it an important role in the formation of the Oedipus complex.

But although Freud assigned the principal role to identifications intervening into the Oedipal conflict, he never excluded the idea of other forms of identification. Certain of his writings prove that he had glimpsed the essential role that identification plays in the totality of our social life, and more particularly in the domain of the awareness of other people.

Let us cite a short extract that serves well to illustrate Freud's point of view on this subject:

What we have learned [...] may be summarized as follows. First, identification is the original form of emotional tie with an object; secondly, 
in a regressive way it becomes a substitute for a libidinal object-tie, as it were by means of introjection of the object into the ego; and thirdly, it may arise with any new perception of a common quality shared with some other person who is not an object of the sexual instinct. The more important this common quality is, the more successful may this partial identification become, and it may thus represent the beginning of a new tie. We already begin to divine that the mutual tie between members of a group is in the nature of an identification of this kind, based upon an important emotional common quality; and we may suspect that this common quality lies in the nature of the tie with the leader. Another suspicion may tell us that we are far from having exhausted the problem of identification, and that we are faced by the process which psychology calls 'empathy' [Einfühlung] and which plays a major role thanks to the possibilities that it opens up in penetrating the soul of people foreign to our ego. 9

These few lines are of fundamental importance, since they allow us to glimpse the richness and significance of the concept of identification. But they equally appear interesting because they contain, at least implicitly, the traditional prejudices which we discussed earlier, and which constitute, we think, an obstacle to the comprehension of these phenomena.

The words "penetrating the soul of people foreign to our ego" effectively show that the idea underpinning Freud's theoretical formulations is that of an ego closed onto itself. Identification with other people should then be conceived on the basis of the perception of common traits, the only means for penetrating and attaching oneself to a psychic reality that is, in principle, foreign to ourselves.

Such a conception, however, engenders a certain number of difficulties.

In effect, if the term 'identification' signifies 'affective attachment,' then the number of common traits is doubtless, if not the precondition for identification, then at least a factor favorable to its development. But if, as Freud indicates immediately afterwards, it also constitutes a means of penetrating other people, we cannot conceive of it on the basis of the perception of common traits. We can see, indeed, that the perception of a common trait, that is, the apprehension of a 'like me,' necessitates, at the very least, the sketch-outline of an identification, without which this trait would not be perceived as common. In order to recognize, in other people, a trait that is common to me, I must have perceived its meaning. We should not say that identification is founded on the recognition of a certain number of common traits - the term 'trait,' incidentally, only corresponds 
to an abstraction without relating to an experience. Rather, through a sketch-outline of identification, which the meaning of the 'ways of acting' of another person already gives me, I can recognize the characteristics that we share.

The difficulties contained in Freud's text drop away if we take the identificatory relation as our starting point - not isolated egos but subjects who are, from the very start, open to the world and to other people. We will then see that it is not traits, variable in number and quality, which are shared between individuals, but the intersubjective link. We will also observe that identification is a mode of behavior that is structured on the basis of this primordial intersubjectivity, and, finally, we will recognize that comprehension and the affective attachment towards others are rooted in identification itself.

Here we return to the theories of Hesnard, who, by rethinking the concept in the framework of a psychology enriched by the gains of phenomenological thinking, has unveiled its true meaning.

Thus, we will now make principal reference to Hesnard, with the goal of optimally pinpointing the signification of identificatory behavior.

\section{Identification as the Behavior of Private Intersubjectivity}

Phenomenological reflection on the one hand, and child psychology on the other hand, have revealed to us the nature of the interhuman link such as it is presented in its origins: an intersubjectivity, a kind of generic co-existence of multiple consciousnesses.

At the beginning of any encounter, this primordial intersubjectivity may be qualified as anonymous because it is elementary, unstructured, and simply inherent to the human condition. As Hesnard points out:

We must insist on the fact that this generic and universal coexistence is anonymous, that is to say that it precedes all forms of identity, personalization, individuation and any other psychic function. With respect to this analysis, let us retain the idea that, given that the world, the primordial world before human knowledge, is not an object for man and that it is in this world that man knows himself. We must be wary of objective psychology and psychoanalysis when they study what they call object-ties.

An object-tie, defined as objectality in the Freudian sense, is already poorly defined. If it is defined by intersubjectivity then it is incomplete, since intersubjectivity is given to the anonymous human being. We must 
therefore endeavor to consider every link between defined, singular, or individual subjectivities as hatching from a soil common to everyone within an intersubjectivity, but structured, that is to say endowed with meaning and value, at the same time as relating to a particular, identified or personalized subjectivity. ${ }^{10}$

In this perspective, identification appears when, against the backdrop of anonymous intersubjectivity, more singular relations are developed and structured - in other words, when anonymous intersubjectivity is transformed into private intersubjectivity. As Hesnard writes:

Here there is a psychic structure, an appearance in the field of intersubjectivity of a posture, or, more generally, a behavior that fashions in each individual, or group of individuals, a disposition towards knowing, and then understanding, other individuals. This often complex or subtle postural disposition presents itself in two often distinct forms: an identification of a given individual with another (or several others), with a we, or a somewhat more anonymous one, and a collective or communal identification, whose sociability largely predominates over its individuality or duality. ${ }^{11}$

Let us make some comments on these lines by following, in the course of our lived experience, the manner in which identificatory behavior is formed in its simplest case - that is, the relationship between two people.

A given individual appearing in my visual field is perfectly unknown to me as a person (that is, as a singular being), but, because this being is structurally similar to me, because they appear to me in a given situation, their behavior already has meaning for me, for the simple fact that I perceive it.

At the same time, they have seen me, and due to this, my behavior no longer belongs to me, strictly speaking, by dint of the fact that it no longer has meaning for me alone. Instead, it also has meaning for this other person, who can read my intentions just as I can read theirs.

First of all, there is the intersubjective link. But, at this stage of the encounter, this link is still impersonal. The individual who I see is still not given to me as a person, but simply as a human being, similar, in this quality, to all other human beings.

It is only when my perception, becoming more active, is structured into an active behavior of apprehending other people that the relation becomes personal. Having been anonymous, the intersubjective link becomes private. 
This active behavior of apprehending another person as a singular being is realized by me through a kind of incorporation of the behavior of the other. In other terms, I identify myself by sketching out the movements of other people in order to comprehend them and grasp them from within. If they speak, I sketch out, while listening to them, the vocal gestures through which they express their thoughts. In extreme cases, it can even happen that, unconsciously, my lips exactly reproduce the movements traced out by the lips of my interlocutor. This quasi-muscular behavior of apprehending other people constitutes the principal aspect of identification. If we are to give an even more striking example, it suffices to think of the movements executed by the spectators when following the twists and turns of an acrobat or the motion of the participants in a sporting contest.

Identification, as a link of private intersubjectivity, is thus that postural behavior by means of which I surpass the simple apprehension of the behavior of other people to actively revive it, through incorporating it or, as psychoanalysts put it, through introjecting it. It is an active fusion of two or several subjectivities entering into a relationship with one another.

We can equally describe it as a complex of projection (or putting oneself in the place of the other) and introjection (putting the other in one's own place), on the condition that we consider this 'other' and the 'self' thus defined, not as already personalized entities but as subjectivities that, at the beginning, are still anonymous and simply opened to each other. It is precisely through the identificatory relation that the 'self' and the 'other', by fusing, mutually appear to each other as personal, singular beings.

At the same time, the relationship thus initiated takes on signification in the domain of affectivity, and is structured according to the multiple nuances of sympathy and antipathy. It is, in fact, on the basis of identification that the feelings of sympathy and antipathy towards other people emerge.

We must not say, as certain theorists think, that it is sympathy that gives rise to identification, or, at least, that sympathy is one of the essential preconditions for its realization. Sympathy, indeed, is nothing other than the affective dimension of the comprehension of other people, and this, as we have seen, is realized in and through identification. Sympathy would thus be unable to exist independently, outside of the behavior of identification of which it is one of the essential aspects.

It might be objected that many instances of sympathy have been born, or at least traced out, spontaneously, as the result of a momentary glance or even upon listening to a mere description, and that it is this initial and sudden sentiment that engenders a disposition that is favorable to comprehension and identification. But, upon taking a closer look, we can see that, if such 
spontaneous feelings exist, then this is because, through this momentary glance that initially gives me a sense for the behavior of others, or through this mere description that informs me of certain ways of acting, I have already been able to apprehend, by means of a barely sketched out identification, a certain manner of being or a certain style of existence. Subsequently, following the signification that this style of existence provides to me, feelings of sympathy or antipathy will be born in an apparently spontaneous fashion. It is very possible, then, that, having been solicited by these initial feelings, identification is extended and structured in a narrower relation. But, in any case, it is certainly because it finds itself traced out that the initial affective reactions have poured forth.

At the end of the day, it does appear that the multiple nuances of sympathy and antipathy are both the affective reflection and one of the factors structuring identificatory behavior.

We would like to illustrate here this final proposition through the examination of a very particular form of nascent sympathy or antipathy: that which emerges from the simple observation of a photograph. This phenomenon indeed arises very frequently, and it might be asked what, in a mere static image of another person, can engender a reaction of an affective nature. In order to understand, we should shift focus to the experience of the observer. When I look at a photograph, the face of the person who is represented to me appears to me with a certain gaze, a certain allure, in a certain position and with a whole series of other elements which I am able to analyze after the fact, but which, the instant that I see them, together form a structure, a structure which immediately gives me the sense of a certain comportment. Thus, I can immediately say of people who are photographed that they are smiling, or speaking, or that they are afraid or serious, etc.

But my knowledge of photographed comportment can go further still. As little as I observe it, a sketch-outline of identification is fashioned in my behavior, a barely traced out postural attitude by means of which I incorporate the behavior observed by reproducing it in a mimetic manner. Thus, I can grasp from within, a little as if it were mine, the attitude taken by the person photographed. I apprehend its meaning as a particular social behavior that is nonetheless revelatory of a more general style of carrying oneself.

Let us note, by the way, that this sketch-outline of the mimetic attitude through which I grasp the meaning of the behavior photographed sometimes finds a more manifest expression. For example, I may instinctively mime the position of the body that I observe, or the severe pout of a person with a particularly austere physiognomy. These are rather rare but highly revelatory manifestations of this incipient identification born from the observation of a mere photograph. 
We can now glimpse the depth with which it is possible for me to comprehend a person of whom I only possess the image. Through this incipient identification that impregnates me with the sense of someone's behavior, a whole style of existence is conveyed to me, a structure or a certain particular manner of being in the world. I may thus say of the person photographed that he appears kind, pretentious, likable, or foolish. Many other qualifiers may nuance my judgment, and they are so many attempts at explaining the form of social existence that it is possible for me to perceive.

At the same time, and in an entirely natural manner, sentiments of sympathy or antipathy spontaneously gush forth. A given countenance, on which I may read amiability, spontaneity, etc., will inspire sympathy in me, while another countenance on which transpires a social attitude that I find unpleasant will arouse antipathy in me.

All these considerations allow us to glimpse the subtlety and astonishing complexity of the process of identification, when we envisage it on the level of lived experience.

Structured on the basis of intersubjectivity, it is above all a postural behavior with multiple, complex, and structural affective repercussions. Its role in the comprehension of other people is essential, and we can thus understand that it is both the origin and the fermentation of multiple relations between individuals and groups, and, subsequently, that it plays a fundamental role in the great and small dramas in the daily life of every individual and every social grouping. Among other things, it allows sympathies to be forged, antipathy and aggression to be formed, social groupings to be constructed, and alliances to be sealed or dissolved. Here, we touch on what Hesnard called the 'dramatic aspect' of identification, and which is, in sum, simply its social dimension.

To refine these notions and clarify these ideas, it is now appropriate to specify the three aspects of identification that we have just evoked: its motor or postural aspect, its affective aspect, and its dramatic aspect. With this goal in mind, we will permit ourselves to cite Hesnard at length. Since this writer has furnished very precise descriptions of these three aspects, we can do no better than simply convey them to the reader.

\section{The Principal Aspects of Identification}

a) The Motor Aspect

We have seen that identification is elaborated on the terrain of private intersubjectivity, in which the motor or postural aspect appears essential. 
As Hesnard explains:

It [identification] is above all a form of motoricity or, if it is observed in a specific situation, a segment of comportment or behavior. But this motoricity is very particular: it is postural. We have here a tonic and durable muscular contraction which affects the muscular systems destined by their functional structure to plastically imitate or copy, in a more or less silent manner, the attitude or the action of another person; to reproduce it in its own way by personally reacting to it, rather than servilely imitating it. This is because the apparent immobility of the subject that visually identifies itself with another person is an immobility full of muscular tension. This tension is felt by the subject by approximatively localizing it, and it can be objectively observed in the form of weak, undulatory expressive movements (in the physiognomy, attitudes, gesticulations) made by the observer. We can say that the observer who identifies interprets the movements of the person with whom they identify while sketching them or tracing them out. ${ }^{12}$

We should clarify that the motor aspect of identification is not a process of simple imitation. On the contrary, it is an interpretative mode of behavior correcting, in a way, the attitude incorporated. The attitude of the spectator whose gaze follows the movements of the acrobat and, while 'miming' them, also corrects them, in a way, is a good example of the interpretation and rectification of the behavior apprehended.

Another example: think of the fleeing gesture we spontaneously make when, at a distance, we see someone who is not reacting to an evident menace.

These examples allow us to glimpse the role that motoricity plays in behavior associated with spectacular identification and filmic identification. But we will return later to these problems which are of particular interest to us.

b) The Affective Aspect

Hesnard writes:

In a normal state, identification is initially - as much in the history of the individual as in the restricted cycle of these durable relations - affectively ambivalent. It is so in the sense that it can orient towards sympathy or love, or it can evolve in the direction of antipathy or aggression. ${ }^{13}$ 
As we have already tried to explain, it is precisely in and through the process of identification, which gives us the 'social mode of being' of other people, that an ambivalent relation finds its initial affective coloring, and is structured according to the multiple nuances of sympathy and antipathy.

\section{c) The Dramatic Aspect}

Man, we said at the beginning of this work, is an essentially relational being. His existence is naturally linked to that of other people by love, friendship, sympathy, aggression, etc., which form a whole spectrum of relations amounting to a vast number of variations of identification.

From the gossip about romantic affairs to the tragedies of hateful, despairing co-existence, from a tiff between friends or joking banter about one's love life to divorce, all-consuming hatred, unexpected suicides and unexplained crimes, all these dramatic events, with their often spectacular outcomes, belong to the dialectic of the couple, that of the master and the slave, the accuser and the accused, that is to say, the intensifications, variations and failures of the links with other people, of identification. Thus is the dramatic nature of identification revealed. ${ }^{14}$

These three aspects of identification, so well described by Hesnard, are far from exhausting the complexity of the phenomenon. There are many others, undoubtedly less important, but whose utility for the comprehension of certain forms of behavior warrants our attention. Such is the case, we would hazard, with the phenomenon of the valorization or devalorization of other people, a phenomenon whose significance can be perceived when we tackle the particular case of filmic identification. It is this aspect that we would like to discuss in greater detail.

d)

Identification as the Basis for the Valorization (or Devalorization) of ther People

As is the case with the affective aspect, nascent identification is, we think, ambivalent on the level of the value attached to a person. It is subsequently oriented either towards a valorization of the people with whom we identify, or towards their devalorization. We can illustrate this aspect by considering the nature of friendly relations.

Friendship doubtless constitutes a stable and profound identification, structured in the course of a durable, recurrent relationship. At the same 
time that it sustains a mutual, highly elaborated comprehension, it finds itself supported by strong feelings of sympathy. Between the members of such a relationship, a common system of thoughts and interests is often established, a similar manner of envisaging people and objects, in short a largely shared mode of existence. At the same time, there is, on the part of each of the members of the amicable relationship, a valorization of the other that advances insofar as the relationship is well-structured. Each friend, to the extent to which they see themselves in their counterpart, forming a community of ideas and feelings with them, attributes to them an unconditional value, a value that they will want to defend in the eyes of others, and which they will not hesitate to exaggerate if necessary.

Alternatively, if this relationship deteriorates, or rather, if the identification that links the friends is destructured, the inverse phenomenon often arises. This mutual devalorization is all the more aggressive when each friend is diminished in the eyes of the other.

This manner of valorizing or devalorizing other people, patent in amicable or amorous relations, exists on the least structured levels of the identificatory relationship, but in a more discreet manner. Identifying with someone, even if this is in a fleeting or barely traced out manner, signifies apprehending a manner of existing which initially appears endowed (or not endowed) with a certain value. Little contact is needed in order to tell whether people are interesting or not, whether they are valuable or not, or whether they possess a remarkable or mediocre personality. In such contact, no matter how brief it may be, there is time for understanding other people, apprehending a certain social manner of comporting themselves, and thus for a confrontation, on the level of lived experience, of the structure of their comportment with one's own. This confrontation of two modes of existence leads to a valorization, or a devalorization, of the people we come across.

It could be thought, upon reading the preceding lines, that this confrontation consists of rational mechanisms of comparison and judgment. In our opinion, however, this is not at all the case. It is quite possible that these mechanisms act on the level of verbal thought, when, for one reason or another, we have been led to explain, even if just to ourselves, our attitude of appreciation or depreciation towards other people. But this is a secondary rationalization. The appreciation of people, their valorization or their devalorization, initially acts on the level of lived experience, before rational thought. Nor should we understand by 'confrontation' a simple process of filtration, through which that which, in the other, is similar to ourselves would be valorized, and that which is not similar would be devalorized. This would abusively simplify the phenomenon. More generally, it is better to 
consider that the sense and the behavioral style of other people, to which I have access via identification, are affectivized, in the field of my own mode of existence, in the sense of a valorization or a devalorization. In other words, the behavior of other people, to whom I have access via identification, endows me with a certain affective signification, which is given a certain affective value.

We are aware that we are touching here on an extremely complex and subtle phenomenon, one which warrants deeper attention and closer description.

We could study, for example, the phenomenon of valorization-devalorization in its relations with affectivity and sympathy, or even rational thought. We could also attempt a classification of different kinds of valorization, and study their effect on human personalities.

Unfortunately, we can only point to these problems, whose analysis would take us too far away from the subject at hand. However, we would still like to evoke, here, certain types of pronounced valorization, whose role in the structure of the personality reveals itself to be particularly effective. Let us think, for example, of the value that parents assume in the eyes of their young children, or the value of particularly brilliant teachers in the eyes of their pupils.

In a general manner, it can be considered that, in these cases, there is, within the identification that links the child to the parent or the disciple to the master, an apprehension of a privileged mode of being of the lived world. This mode of existing will then be valorized to such an extent that it will often become a behavioral model, and thus a factor in the formation of the personality.

We will return to such phenomena of extreme valorization when we envisage different aspects of filmic identification. It will then become evident that this particular type of identification can engender a valorization of the film character that goes as far as excessive idealization and even 'divinization.'

The few aspects of identification that we have just summarily sketched out are far from exhausting its complexity. We can perceive how useful it would be to pursue its analysis at length. We should hope, however, that this exposition is sufficient to glimpse the importance of identification in our psychic lives.

Identification, as we know, is of interest to the totality of the human being. It is the fundamental wellspring of the apprehension and comprehension of other people. It is both the fermentation and the structuring factor of our social relations. It appears in the first hours of our existence and continues 
to act on a permanent basis, sometimes in a patent manner easily observable from the outside, but most often in a discreet, interiorized manner.

It is even present when, withdrawn into isolation, we give free reign to our imagination. Often, the dream is merely the identification of the self with a dreamed ego, projected in a more or less chimerical universe which reorganizes reality in the sense of our projects and desires.

Let us note that, in the reality of our daily relations, identification, as the behavioral form of comprehending other people, is most frequently structured in a relation of reciprocity, a relation through which each of the subjectivities in interaction, while impregnating their counterparts, conserves their own autonomy and self-consciousness. In such a relation of reciprocity, other people are present in my consciousness, as well as my view of them and their view of me, which constantly refers to my behavior, and which has the result that I am incapable of forgetting myself.

But when, outside of any reciprocity, we are only the remote spectator of the actions of other people, identification can become absorbing to such a point that it abolishes almost all self-awareness. As we will see, this phenomenon attains its highest degree of realization in the identification with a spectacle, and above all, in filmic identification, a kind of fusion of the actor and the spectator in the same behavior, represented in an effective manner by the former and posturally experienced by the latter. We will return to this problem later.

As we can see, identification subtends the most diverse types of interhuman relationships. Whether this is in the spectacle, in direct contact with other people, or even in our imagination, identification is what allows us to psychically live with other people.

As Hesnard writes:

Identification with another person, which can be complicated by identification with oneself, and which extends within itself the concrete, external drama of existence, results in there being nothing of any importance in the thought or action of each of us that is not what we take from other people, what we give them, and what we believe to be the judgment of others on us. Obscure and without any effect when it comes to other people with whom we are only linked by generic intersubjectivity, this presence of the other person in us is formulated or appears reflexively to us with respect to all those who we have loved or desired: parents, friends, teachers, those who inspire our intellectual or social activity. [...] If nothing of what is human is foreign to us, this is because, as subjectivities who are separate but in communication with each other, we identify ourselves with all the actors in the drama of our existence, up to the 
testimonies that they leave on events. We could almost say that man is an anthropomorphic animal - an anthropomorphosis, if you will - and is born from the projective element of natural identification. This can be understood if we admit that identification, as a generalized style of comportment, is only the private aspect of anonymous intersubjectivity that the primary behavior of man expresses. And it is also what conditions in each human being their comprehension of those who are akin to them. ${ }^{15}$

\section{Fleeting and Structuring Identifications}

The forms of social relations are too numerous for us to attempt, within the limits of this work, a systematic exposition of the multiple variations of identification. Such an attempt would doubtless lead to an abusive and rather artificial schematization of reality.

However, in light of the goal of furnishing this book with the means for studying identification as a form of influence, we can distinguish, from among the different types of identificatory behavior, those which are fleeting and most frequently without any effect on the personality from those which are stable and structuring. The former are sketched out in the multiple contacts of our daily life. The latter are realized through shared life and recurrent encounters with other people. Among them, we can cite identification with one's parents, which contributes in a determinant manner to the formation of the personality, and the assimilation of moral and cultural norms. We could also cite the identification of pupils with teachers and the more prevalent identification of adolescents in search of privileged models of behaviour.

In short, in a general manner, we can qualify as 'structuring' those identifications which, in one way or another, exercise an influence on the personality. We could also note that stable identification can still be variously qualified according to the modalities of its realization. It can be alienating or liberating, successful or failed, or even healing. But here it is a question of nuances introduced by psychoanalysis, and which are only of distant interest to the preoccupations of the present study.

\section{Identification, Projection, Introjection}

The terms identification, projection, and introjection have often been employed in a confused way, or in different senses by different authors.

In order to avoid any confusion, we would now like to precisely clarify the meaning of each of the terms in the framework we have adopted. 
Our point of view on this subject does not question the aptness of the concepts in the framework of psychoanalysis, or the definitions that they have received in this same framework. It does not enter into our competence to judge either this aptness or these definitions.

But, with the goal of avoiding the equivocations that may arise in the rest of this work, we believe it is useful to define our opinion, and to clarify the exact meaning that we will give to the terms under examination here.

In a very general manner, it could be said that projection and introjection are two aspects of a single phenomenon: identification as a form of private intersubjectivity. In our view, we should not see in these terms two distinct phenomena that together form identification by succeeding or completing each other in a simple synthesis.

If we have used, with respect to a single phenomenon, the apparently opposed concepts of projection and introjection, then this is because, for those who experience it, identification, as the behavior of actively apprehending other people, can also be qualified as a placing of the self in the other (projection) or a placing of the other in the self (introjection). The two terms refer to this same behavior of apprehending other people. They are simply two ways of expressing one and the same behavior.

Identification is a form of intersubjectivity, that is, a coexistence of consciousnesses, or a fusion of subjectivities, in a behavior of mutual apprehension. Thus, to speak of the self and the other, of a projection of the self or of an introjection of the other, no longer has any significant meaning. In our view, they only amount to two different ways of shedding light on one and the same phenomenon, the subject who, having been liberated, and having been able to recuperate its identity, is forced to express itself by making reference to the two terms in the relationship - the self and the other person - and must therefore make its choice between the two possible combinations: 'placing of the self in the other' and 'placing of the other in the self.'

We could, however, oppose to this point of view the observed existence of certain phenomena whose explanation seems to necessitate the distinction between the two components: projection and introjection.

Thus, the existence of different appreciations of the subject of a single person or a single form of behavior seems to be able to justify a conception of identification, conceived of as a composite of two processes - projection and introjection - with projection being the cause of the multiple distortions that the appreciation of other people can suffer.

How to respond to this objection? If we initially reflect on the different ways of appreciating a person, we can observe that the explanation advanced neglects to think that the personality is not a stable object, identical with 
itself, and that a good part of the differences between the perceptions and interpretations of the different ways that people have of behaving comes from the fact that these people take on variable attitudes and structure their comportment differently depending on the interlocutors they meet and the types of relations that they establish.

Subsequently, having abstractly considered the malleability of other people, we should still consider that the behavior apprehended by identification is interpreted in different ways according to our personalities, or, rather, the specific mode of being of each individual.

To explain this, it is not necessary to have recourse to the complex interplay of the mechanisms of projection and introjection, whose respective parts in the behavior of identification would condition the value or the objectivity of the comprehension of other people. Simply put, the comportment with which we identify in order to understand it is given a specific perspective, which depends on our own manner of structuring our existence, and thus, on our system of values. Hence, a given behavior, which I apprehend, and which appears to me, against the backdrop of my own system of values, as intelligent, or valid, or nonsensical, might appear to other people as ill-adapted or without value, etc. And yet neither this other person nor myself are mistaken on the meaning of this behavior.

It is only because we each categorize the real according to a system that is specific to us, that this behavior receives, for each one of us, a particular signification.

Alternatively, we can consider by attribution, occasionally observable in certain particular situations, very different meanings in the same behavior. A good example of this phenomenon is provided to us by the examination of responses given to projective tests (the Thematic Apperception Test, Rorschach tests, etc.). The same image arouses responses that perceptibly vary according to the subjects tested. For example, we sometimes say of people who have an ambiguous attitude that they are dreaming, crying, or sleeping, etc. Is identification, in these cases, reduced to its mere projective component? This would, evidently, confirm the idea of identification as a composition.

In order to understand these supposed pure 'projections,' we must take into account the fact that, in these cases of identification, reciprocity and exchange are lacking. There is, on the one hand, a neutral behavior (simply visualized in the case of projective tests) and, on the other hand, a subject who identifies in an active behavior of apprehension encountering no reciprocity or exchange. Thus, when we demand that the subject express what they have perceived in the other, it is self-evident that aspects of their 
own subjectivity appear. Is this to say that there has been a projection of subjectivity in the other, and thus that we have managed to isolate the 'projection' component of identification? It seems to us that this is not the case, since nothing, in the experience of the subject who identifies, allows us to conclusively determine the autonomous existence of this kind of transferal of the self into the other. On the level of lived experience, identification is a form of intersubjectivity (that is, the fusion of subjectivities). But, precisely, because one of the elements of the relationship is neutral, and identification is unilateral, this fusion of subjectivities is a one-way process and only lets one of the subjectivities transpire, that of the subject who is actively apprehending. We can then speak of projective identification, signifying by this that it is conducive to revealing the personality of the subject who identifies. But we can in no way speak of 'projection' and 'transferal' as autonomous processes. These terms may well designate the result of 'projective identification,' but they do not imply anything about nature, or its composition.

In the same manner, we can designate with the term 'introjection,' not a process, but the result of what we may call introjective identification. In order to illustrate this last type of identification, let us recall the situation of the psychological interview. In this situation, the interviewer, whose goal is to understand the interviewee, effaces himself in order to better enable the subjectivity of the other to transpire. There is introjective identification, with a one-way intersubjectivity brought about, in which only one of the subjectivities in the relationship, that of the interviewee, expresses itself.

We will conclude by saying that identification can be projective or introjective to the extent that the intersubjectivity that characterizes it is fixed on only one of the subjectivities in the relation.

From the point of view of the subject who identifies, we can speak of projective identification when intersubjectivity is crystallized around one's own subjectivity, and introjective identification when intersubjectivity is fixed on the subjectivity of the other.

Thus, when we speak later of filmic identification, it should not be considered as a mechanism of the projection of the spectator, or introjection of the character, but only as a relation of intersubjectivity linking the spectator and the character.

\section{Identification, Mimicry, and Imitation}

The concepts of mimicry and imitation can also give rise to diverse interpretations. In order to eliminate any confusion, it is important to clarify what they refer to in the perspective that governs this study. 
By 'mimicry,' we understand the posturo-motoric behavior that constitutes the principal aspect of identification. We have already had the occasion to clarify the nature of this aspect. Let us simply recall that mimicry is the active behavior through which the subject who identifies tends to posturally reproduce the comportment of the person with whom they identify. This is a motoric behavior, sometimes patent but usually discreet, and occurring in an unthinking way.

We have given several examples of rather manifest mimetic behavior. In order to illustrate the phenomenon one last time, let us recall the example of spectators who trace out and reproduce the gyrations of acrobats whose movements they follow when identifying with them.

Contrary to mimicry, which is an apprehensive comportment, imitation can be characterized as reproductive comportment.

We could define it as follows: a comportment seeking to consciously reproduce, with various goals, the behavior that is apprehended through identification. Following the goals sought after, we can distinguish several forms of imitation.

Some forms of imitation take place within spectacles: their objective is to caricature a character. Others simply strive to reproduce the behavior of an individual or a group of individuals, to better explain or depict it. Still others aim to reproduce in reality modes of comportment with which we can identify, and which are highly valorized. These more important forms of imitation warrant our focus for a while.

Anticipating the second part of this study, we can illustrate this type of imitation with the numerous examples that are offered to us by what we can call the extensions of the cinematic spectacle in our individual and social life.

We know all the phenomena provoked by the cult of the movie star. An actor or an actress encounters the favor of the mass public, and the manner, the bearing, the facial expressions, and even the clothing of this actor or actress are immediately copied by a significant section of their admirers.

How can these facts be explained?

Briefly put, we can sketch out this genesis as follows: on the screen, the star presents a comportment, or rather, a privileged mode of social existence. The spectators who identify with the star during the screening valorize this exceptional mode of existence, whose advantages on the social level appear self-evident. Thus, in order to valorize themselves, they tend to appropriate the characteristics of the star, to reproduce their mode of existence, to embody the same signification. In other words, they will try to present themselves in the eyes of other people an image of themselves similar to that of the valorized actor or actress. 
This intentional appropriation of the behavior of other people can also be called imitation.

The question remains open to know if there exists, alongside such fleeting imitations, more structural imitations. We can ask ourselves if, in extreme cases, structural imitations are not equated with what we called structural identifications.

Probably, at a certain level, the vocabulary becomes uncertain and the distinctions become rather artificial. Whatever the case may be, in a general manner, we will reserve the term 'identification' for the active behavior of apprehending other people, the term 'imitation' for the intentional behavior of reproducing the comportment of other people, and the term 'mimicry' for the posturo-motoric aspect of identification.

\section{Identification and Personality}

We have tried to study some of the major principles concerning the very nature of the phenomena of perception, intersubjectivity and identification. We have also spoken of 'personality' in terms of the 'mode of existence,' the 'manner of being in the world' or the 'manner of structuring one's social relations.'

It has thus become easier to sketch out a more systematic definition of the personality. This will be the object of the present section. We will try to present a certain conception of the nature of the personality, a conception which, we think, could be useful to filmological reflection, and to show the preponderant role played by identification in the formation of the personality.

What, then, is the personality? The concept of the personality evokes a whole series of other concepts, with a rather widespread usage in psychology, as in everyday language: 'temperament,' 'character,' 'Ego,' 'characteristics' or 'personality traits,' etc., so many terms which all, aside from a few nuances, refer to a reality situated within the individual.

Often, indeed, the personality (or the temperament, etc.), is considered as one of the internal entities or psychic objects, and we can then ask ourselves what, in these objective realities, can be attributed to heredity or to the environment.

Since the problem cannot be solved scientifically, a compromise is often established. Heredity is ascribed to the original nucleus, and the environment to the modification and reorganization of this nucleus. In this perspective, we often call 'temperament' that which is innate, and 'character' what this temperament becomes in the environment that has modeled it.

In any case, reference is always made to a kind of internal entity, an objective reality inscribed in the psychism as a biological trait. 
It may well be true that the depiction that we have provided here of a certain classical conception of the personality is rather caricatured. But, in spite of the nuances that we have neglected to expose, there remains the fact that, in everyday thinking as well as in the great majority of theoretical conceptions, the term of the personality almost always designates an internal, objective, and therefore relatively stable entity.

And yet, as with the old conception of perception evoked at the beginning of this study, such a mode of thinking derives from what the phenomenologists have called the 'prejudice of the world.'

To posit, as the starting point for this reflection, the world as a reality external to the individual, and the latter as an individualized entity closed in on itself, leads us to think of the personality as an internal, objective reality, one that is given from the very beginning, whose function it is to give form to comportment in general and, more particularly, to social comportment.

And yet, what does this lived experience teach us about these supposed internal realities?

First of all, the personality appears much less stable than we would often like to imagine. 'Comportment,' such as it is experienced, is a fluid, changing reality. In order to take stock of it, it suffices to think of the changes in attitude and comportment of an individual according to the milieus in which they are successively inserted, and the different people with whom they associate. Of course, there is a constancy to comportment, a general manner of conducting oneself, which constitutes, precisely, what we call the personality. But the suppleness of this general manner of conducting oneself already underlines the relational signification of the personality. Behavior is always, in fact, formed on the basis of specific relational situations.

The relational character of the personality will be even more apparent if we interrogate the nature of the constant aspects of the personality. Let us take as an example the well-known phenomenon of paranoia. In order to understand the paranoid, or paranoiac, individual, it is necessary to refer to the insertion of the individual in the interhuman world. Paranoia, even in its attenuated forms, is essentially a social mode of comportment. Its signification can only be understood in and through the network of interpersonal relations of the individual.

We could doubtless say that paranoia, as a mode of social comportment, did not develop by chance, and that something needed to exist within the temperament in order to provoke it. It is quite possible that this something exists, that there is a biological structure favorable to the onset of paranoia. But, in any case, this structure cannot be considered as the sketch-outline of paranoia: it cannot even constitute its cause. It is only one of the numerous 
elements that, in the field of the social relations of the individual, have contributed to the structuring of paranoiac or paranoid behavior.

Another example would allow us to better understand this idea.

Biometric and typological studies have established a correlation between the mental structure and the anatomic structure. Thus, it has appeared that malingering individuals are usually schizothymic, closed off, and introverted. Does this mean that asthenics (as they are called) bear, inscribed within themselves, at the same time as their bodily structure, the germs of schizothymia and introversion? This would amount to saying that, prior to any social insertion of the individual, the form of one's social comportment is already structured. It appears more reasonable to think that, having taken account of a certain anatomo-physiological substrate, the manner in which individuals structure their comportment within the multiple social interactions will normally be oriented towards schizothymia and introversion, or towards cyclothymia and extroversion. Thus, to focus on anatomic structure alone, it is evident that physical asthenia, which is experienced by the asthenic individual as a certain mode of being in the world and a certain way of appearing to other people, contributes, in the fields of interpersonal relations, to the formation of a certain behavioral structure oriented towards timidity and introversion.

In short, all this shows us that we should consider the personality not on the basis of the isolated individual, but rather on the basis of the insertion of individuals in their interhuman milieu. What is primary in man is the need for relationships. We thus come back, here, to what perception and intersubjectivity have taught us.

Perception, indeed, has shown that man is, from the start, a 'being-inthe-world' and a 'being-with-other-people.'

Intersubjectivity, as a generic co-existence of consciousnesses, has revealed to us that the nature of man is to be a relational being, that the individual can only be understood as a node of relations. We thus understand that the personality is none other than a certain singular mode of being in the world and with other people. It is the manner in which each individual structures their interpersonal behavior. Born within primordial intersubjectivity as a generic link to other people, it is the manner in which each subjectivity is constructed in and through the complex interplay of multiple identifications that link the individual with others: identification with one's parents, identification with one's mentors, identification with cultural or moral models, group models, etc., as well as identification with oneself and the image one offers to other people. 
In short, the personality is a singular manner of social existence, which is structured within the multiple interpersonal relations in which identification plays a preponderant role.

Having admitted this, we can now clarify what we mean by the notion of the interpretative system of the personality.

In this optic, any system of interpretation or evaluation of the personality essentially consists of a systematic set of categories and notions serving to specify the modalities of being in the world.

We can also better clarify the role of research when it has the goal of studying the modifications of the personality when subject to the influence of various factors.

Hence, to ask ourselves whether a given factor can modify or influence one's personality or comportment, first means seeking the lived signification of this factor, and then seeing how the apprehension of this signification can modify the social manner of being, or the social mode of existence of the individual.

Thus, asking whether filmic identification can influence a personality initially involves attempting a description of the lived meaning of the phenomenon of filmic identification, and then seeing if this phenomenon, whose lived repercussions and affective resonances we know well, can contribute to the structuring of the personality, or rather, to the structuring (or restructuring) of social modes of comportment. We will return to this problem later.

\section{Identification, Communication, and Information}

Specialists in the social sciences have often characterized communication as the simple transmission of a message from a sender to a receiver. The stages of the process presented in this fashion are: formulation of the message, its encoding or translation in a system of signs, and the emission, transmission, reception, and finally decoding which provides the receiver with the meaning of the message.

Such a schema offers, of course, a convenient tool for thinking of communication in scientific terms. But this apparent scientific objectivity can only, unfortunately, be obtained by neglecting an important element. It is indeed often forgotten that communication is just as much an affective as a cognitive phenomenon.

Let us cite Lagache:

If communication is that through which an individual influences another individual, and is influenced by another individual, then it is not only the 
cognitive content that constitutes the essence of the message, but also the affective halo that accompanies it.

And yet, in the particular case of verbal transmission, what exactly does this affective aspect of communication consist of? It essentially relates to the identification in the relation that links individuals through communication - that links, that is, the listener (or listeners) to the speaker.

We all know by experience that an adequate understanding of the discourse of an interlocutor or lecturer can only be attained by mobilizing a certain degree of identification. We 'put ourselves in the shoes' of the person speaking in order to adopt their comportment and better understand the lived experience of the words they utter. If there is any need to convince ourselves of this point, it suffices to recall the example (cited earlier) of the listener who, in certain pronounced cases of identification, unconsciously repeats the vocal gestures of the interlocutor.

It thus appears that communication, far from being reduced to a cognitive operation, is only realized to a high degree of perfection in a climate of intersubjectivity.

Pushing this analysis further, we can even perceive that the relations between identification and verbal communication, and even communication in the more general sense, are much more profound that we might think.

Is it not, in fact, in the primordial and generic intersubjectivity which initially links people to each other, that we should seek the first form of communication and the terrain on the basis of which the most structured modes of communication (like language, for example) are elaborated?

Hesnard answers this question in the affirmative. Speaking of primordial intersubjectivity and of primary identification, he writes:

Expression through language is the culmination of the concrete gestural expression, born of a primary mimetic identification and expressed through the muscles, then becoming structured in thought, which is incarnated in the laryngo-vocal gesture. ${ }^{16}$

In this perspective, not only does identification appear necessary to the realization of verbal communication, but also, reversing the terms, we can even say that language itself, through the immense possibilities it offers to expression, is a tool at the service of the interhuman link of identificatory behavior.

What we have already said concerning the role of identification in verbal communication can also be applied to all forms of communication, 
beginning with writing. To understand, to discover the significations in written words, is not simply a process of decoding, but involves apprehending, through writing, the significations experienced by a particular subjectivity. It involves, that is, identifying with the author. Hence, any lack of understanding of a text, unless it is written in an unknown language, is not linked to the shortcomings of a decoding grid, but is usually due to an incapacity for identifying with the author of the text, of 'putting oneself in their shoes,' and thus grasping the living significations of the words employed. We are thus confronted with an incoherent assemblage of phrases that are incomprehensible because they are lacking in any affective resonance.

In the end, identification equally has a word to say about what could be termed 'artistic communication.' Understanding a work of art, a painting or a musical work, involves apprehending, through colors, forms, or musical movements, an affective structure specific to a certain subjectivity.

Here again we identify with and relive the experience of the author, and this is what permits the spectator to then affirm, of a painter or a musician who has never been met, that they are passionate, sad, tender, or sentimental, etc.

As for the cinema, we will soon see that it is indisputably the art form which permits the highest degree of identification and that, by dint of this fact, its possibilities in the order of the comprehension of humans are considerable.

To conclude this section, let us cite some lines from Merleau-Ponty, conducive to giving us a presentiment of the virtualities of filmic identification:

This is why the movies can be so gripping in their presentation of man: they do not give us his thoughts, as novels have done for so long, but his conduct or behavior. They directly present to us that special way of being in the world, of dealing with things and other people, which we can see in the sign language of gesture and gaze and which clearly defines each person we know. If a movie wants to show us someone who is dizzy, it should not attempt to portray the interior landscape of dizziness, as Daquin in Premier de cordée and Malraux in Sierra de Terruel wished to do. We will get a much better sense of dizziness if we see it from the outside, if we contemplate that unbalanced body contorted on a rock or that unsteady step trying to adapt itself to who knows what upheaval of space. For the movies as for modern psychology dizziness, pleasure, grief, love, and hate are ways of behaving. ${ }^{17}$ 


\section{Part Two: The Film Experience}

\section{Chapter I: Filmic Consciousness Faced with Its Object}

We have tried to explain the major principles that should guide our understanding of the general phenomena of perception and identification. It has thus become easier to broach the problems relating to the particular case of the film experience.

We should rapidly recognize the path we are going to take. Film presents itself above all as an object of perception and, as such, it is a structure, a perceptual 'gestalt.' It is thus as a form, or a 'gestalt' that we will initially envisage film. But we will not linger very long on this point because we will soon perceive that film solicits a different attitude in our consciousness than the pure perceptual attitude. We will see that, in order to clarify this particular attitude, certain writers have made of the film experience something situating itself midway between the real and the unreal. These considerations, and others, will lead us to see filmic consciousness as a variation of the major category of consciousness that constitutes the imaginary consciousness. This idea will constitute the guiding thread of our whole work.

We will attempt a description of the major aspects of the filmic attitude conceived of as an imaginary attitude and, pushing this analysis further, we will then try to explain the particular variations or modalities of this attitude.

In the end, on the basis of what this description will have taught us, we will broach the problem of spectatorial behavior, or in other words, of filmic identification.

\section{The Film as an Object of Perception}

Film is first presented as an object to be perceived. Thus, we can already apply to the perception of film what we have said of perception in general.

In perception, as we have said, the object always presents itself as a structure, a form, or a 'gestalt.' The same goes for film, which, as an object to be perceived, presents itself first as a temporal form.

Film is not, in fact, merely a sum of elementary images placed in a temporal contiguity. If we envisaged each image in particular, independently of its context, we would perceive that these isolated images do not have the same signification as when they are perceived inside a film. This is because the meaning of an image always depends on those that precede it and those that follow it - in a word, on its surroundings. 
The succession of images thus creates a new reality, irreducible to the sum of the elements employed. This means that the construction of each shot and the organization of shots into scenes, and of scenes into sequences, creates a complex visual form.

A film, as Merleau-Ponty writes:

seems to be an extremely complex form inside of which a very great number of actions and reactions are taking place at every moment. The laws of this form, moreover, are yet to be discovered, having until now only been sensed by the flair or tact of the director, who handles cinematographic language as a man manipulates syntax... ${ }^{18}$

What is valid for images is equally valid for sound. The sounds and voices that accompany a film are evidently not presented as a sum of elements more or less independent of one another, but form a sonic 'gestalt,' a sonic totality in which the elements draw their signification from their assemblage. In the end, it is still necessary to consider that, inside a film, the visual form and the sonic form are not simply juxtaposed but are composed to form an even more complex ensemble.

Merleau-Ponty continues:

A sound film movie is not a silent film embellished with words and sounds whose only function is to complete the cinematographic illusion. The bond between sound and image is much closer, and the image is transformed by the proximity of sound. This is readily apparent in the case of dubbed films, where thin people are made to speak with the voices of fat people. [...] And the union of sound and image occurs not only in each character but in the film as a whole. ${ }^{19}$

The film, as an object to be perceived, thus appears as a structure, a complex organization of visual and sonic elements which draw their signification from the ensemble that they compose.

Hence, the deeds and the gestures perceived on the screen assume meaning or signification through the contexture of the film. Each event, each gesture or comportment, appears with a signification that comes to it, in addition to its own signification, from the relations that it entertains with everything that precedes and follows it.

But we should also point out that these significations are grasped from the start. Here, we come back to one of the major characteristics of perception: its immediacy. Perceiving, we noted at the beginning of this work, does 
not involve intelligently interpreting the world in order to reconstitute its meaning. Rather, it has a presence alongside the objects of the world.

And yet, by giving us events and gestures, the cinema is essentially addressed to this capacity for co-existing with things that is proper to perception in general.

It may be that the cinema is equally addressed to reflection, but this can only be a secondary aspect. As is the case with perception in general, the reflection that necessitates taking one's distance from the object can only be carried out after this immediate apprehension of the meaning of things, deeds, and gestures, which characterizes our first dealing with the filmic world and with the world tout court.

Let us summarize what we have said. The film, as a perceptual object, constitutes a 'gestalt' or a complex spatio-temporal structure in which the elements draw their meaning from their internal organization. These significations, which are significations of deeds and gestures, are initially grasped without the aid of the intelligence.

Now, we must say that if filmic comprehension - or, rather, filmic consciousness - borrows from perceptual consciousness its capacity for co-existing with things, it is nonetheless differentiated from it by many aspects. This is because the cinema is only a representation of the world. It does not give us the world, but only images of the world. And yet, if images of the real, like the real itself, offer themselves to us in the same manner as our unmediated sensations, they nonetheless solicit a different attitude.

Let us explain ourselves. Perceiving real behavior or perceiving represented behavior is, in both cases, grasping the meaning of this behavior. But what changes from one case to another is our manner of considering this behavior, of relating to it. In the case of visual representation, we know that the behavior under consideration, despite presenting all the characteristics of perception, is not physically present. Whence what we could provisionally call a vague sentiment of mingling two different registers: the real and the unreal. Whence also this behavioral difference when faced with an image or with reality. Many writers have tried to describe this intermediary position, specific to the cinema, between the real and the unreal.

Let us cite the titles of some very important articles in this respect: "Le cinéma entre l'imagination et la réalité" (François Ricci), ${ }^{20}$ "Limpression de réalité au cinéma" (Jean-Jacques Rinieri), ${ }^{21}$ "Le caractère de réalité des projections cinématographiques" (Albert Michotte van den Berck). ${ }^{22}$

Some writers believed that they were able to specify the nature of the real-unreal mixture on the basis of the objective characteristics of the 
image. The last article cited constitutes without doubt the most interesting attempt in this direction.

In order to orient this analysis, we can take this article as a point of departure.

\section{Film, Real, and Unreal}

Michotte begins with the following observation: the cinema gives a very vivid impression of reality, and yet, the reactions of spectators are very different from those of everyday life. They barely exceed the emotional stage. Does this mean that there are two different types of reality? This obliges us to distinguish between a belief in the reality of an object and the intuitive character of reality.

He states that "the movement perceived is real, and yet we know that nothing takes place on the screen apart from the rapid succession of immobile images." The conflict thus expressed is resolved, according to Michotte, by the introduction of the concept of 'illusion,' which is dedicated to the divorce between what we believe to be reality in itself and what merely seems to be real.

As Michotte writes:

This is an important distinction for the psychologist because in general, the reality of our beliefs rather than our intuition of the situation determines how we act. The cinema is again characteristic here, since our general attitude to film is that of a belief in unreality, despite the apparent reality of represented events, and this probably goes some way to explaining the difference in behavior just mentioned. But it would be wrong to imagine that this explanation completely resolves the issue. On the contrary, the psychological relation between belief and the impression of reality sets up for the cinema, and indeed for the theater, extremely tricky problems about which we know very little. For example, we must realize that the attitude of belief in the non-reality of perceived objects, permanent though it may potentially be, is neither constantly in operation nor ever able to be suppressed entirely by the impression of reality. Audience reactions to $3 \mathrm{D}$ cinema prove this when they are presented with a ball that looks as if it has been thrown into the auditorium. Even in conventional cinema, apparent reality cannot but impose itself in an absolute manner at certain moments. There are probably numerous oscillations of this kind over the course of a screening and what determines them should be investigated. ${ }^{23}$ 
This way of posing the problem is doubtless remarkable in many respects, even if, in our opinion, it is a little absurd to have apparent reality and a conviction of unreality co-exist in our consciousness. We will soon see that this mode of thinking likely derives from an effort to explain psychic realities on the basis of objective realities external to the spectator. Whatever the case may be, we will retain the following fundamental remarks for our reflection:

1. In real perception, there is a belief in the reality of the object, whereas in filmic perception, there is the appearance of reality and, at least potentially, the conviction of unreality;

2. Depending on whether there is belief or the impression of reality, our comportment takes on a different allure.

We now see how Michotte explains what he calls the "psychological relation between belief and the impression of reality." In his view, the method consists of "examining to what extent the laws known to govern perception allow us to theorize an impression of reality, and how such an impression differs from the one we assign to real things and events."

We can see that Michotte places his investigation on the terrain of objective realities. These are relations between the systems of excitation specific to everyday life and those governing filmic perception, which, according to him, impose on consciousness the impressions of reality and unreality.

He begins by examining the divergences between the systems of excitation envisaged. Let us briefly summarize them. Firstly, there are the changes in the setting that intervene in the cinema and remove from the perceived world the continuous character and phenomenal permanence that it possesses in real perception. Subsequently, there is the difference in the visual field: while the limits of the visual field in everyday life do not belong to the objects perceived (we always have the impression that space extends beyond what we can actually see), in the cinema, the visual field finds itself considerably reduced: the portion of space it encloses appears closed and strictly limited.

Analyzing the image in itself, we can observe that, as opposed to what happens in the real perceptual field, where the objects that we see are constituted by shadows, the realities that we project on the screen are patches of light, with the darker parts considered from the physical point of view as a sort of negative corresponding to the regions of the object that do not excite the retina.

Finally, one last divergence is the fact that the perception of shapes and sizes finds itself perceptibly altered in the cinema. The fact is that, due to 
its inability to reproduce the third dimension, the cinema does not entirely respect the principle of size consistency.

All these perceptual anomalies are, for Michotte, so many determinations of the impression of unreality. If it was necessary to focus on them alone, the cinema would be nothing but a set of a data imposing themselves on consciousness as unreal. But the film possesses other properties which, according to Michotte, perceptibly bring filmic data close to real data.

First of all, cinematic projection ordinarily allows us to see perspectival images. As Michotte explains:

The opposition between the moving figure and the still screen acts to segregate and liberate the object from the plane it had been in. The object somehow 'substantializes' itself and takes on an autonomous existence, becoming a 'physical thing.'

A second, powerful factor of reality is constituted by movement as such.

Finally, a third and final factor of reality would be the fact that the film, almost always, induces emotional reactions. For Michotte:

One final aspect of the question should be considered. Watching a film usually brings about numerous powerful emotional reactions in the audience and these obviously possess an immanent character of reality. $[\ldots]$ These emotions are intimately tied to what we see and above all to its apparent reality because it is not generally the image of the character which evokes our sympathy or admiration but rather what makes up their real personality, as constructed from their physiognomy and behaviour. Furthermore, there is empathy, that projection of our own emotions into the characters on the stage or screen which is well known to psychologists and aestheticians. Wouldn't all of this bring about a kind of return shock, a 'circular' process of reciprocal interaction, stronger than we might at first imagine, one which would confer a veritable resurgence of reality on people and the things they move around?

This last argument is differentiated from the others by the fact that it no longer exactly concerns objective realities. The views that it expresses are of a greater interest - this is, incidentally the reason for which we have reproduced this passage in its entirety - but we do not understand why Michotte introduced it into his reasoning. Emotion, in his view, is a tributary of the impression of reality, itself determined by objective properties. It could well be supposed that a circular process of emotion-empathy engenders 
a recrudescence of reality. But, in any case, in the final analysis, they are the only objective properties which, in Michotte's logic give the cinema its attribute of reality.

In any case, this is what transpires in his conclusions: "Now," he writes, "cinematic experience appears to be a peculiar conjunction of the 'real' and the 'artificial."

And what, for him, creates this 'peculiar conjunction' is none other than the conflict between a determined perceptual organization and our acquired experience, a conflict that is resolved through the impression of distance. As he points out:

We think, in short, that the cinematic situation may be described as one which makes us feel we are actually perceiving real beings and events, but that this reality is more or less distorted, since it belongs to a world which is psychologically speaking not exactly ours and from which we feel, in spite of everything, rather distant.

Michotte's analysis, as rich as it is in descriptive elements, nonetheless strikes us as rather dissatisfying in the explanations he gives.

His argumentation contains certain weaknesses that are necessary to analyze if we want to grasp the fundamentals of the film experience. First of all, if, as Michotte thinks, the impression of reality is a direct tributary of the relation between habitual perceptual elements and unusual perceptual elements, then we need to take into account the fact that, as a general rule, this relationship is rather constant. How can we thus explain these considerable variations of belief in reality which Michotte himself speaks about at the beginning of his article, of which a striking example is given to us by certain spectacular reactions during the very first film screenings? Indeed, if we are to believe film historians, these first representations sometimes engendered, among the spectators, manifest behavioral acts such as fleeing in terror.

Such behavior would be unthinkable today, and yet, the objective conditions of the representation of the real have been considerably ameliorated.

We can understand these facts if we admit that there is, in filmic consciousness, a certain knowledge: the spectators know that the reality unfolding on the screen is merely represented to them. And yet, this knowledge, well-structured today, was without doubt still ambiguous during the first film screenings. For the first fans of the cinématographe, who still had little familiarity with the screen, this knowledge was still too uncertain of itself to be effectively maintained in the unreal images whose apparent reality remained disarming for our minds. 
It could be objected that the knowledge of which we speak nonetheless stems from the objective conditions of representation, that it is the perceptual anomalies that engender the awareness of a certain unreality of the projected images. The schema proposed by Michotte would then remain entirely valid.

We should first note, however, that Michotte never refers to knowledge. He only mentions a conflict, and we are quite justified in thinking that this conflict is only exercised on the simple level of impressions. Consequently, is it certain that perceptual anomalies are the cause of the sentiment of unreality? If this were the case, many things would appear unreal to us. Let us take an example. Let us suppose a subject who is suddenly placed before an unpolished, misshapen pane of glass, behind which people move about. It is certain that the people perceived would appear to our subject as bizarre, because they would be particularly misshapen. But it would be no less true that they would remain just as real as they would be if they were seen in normal conditions.

Of course, our subject could, if they so desired, posit that these strange forms had come from some outlandish world. But this would necessitate an attitude of consciousness, an intention to interpret the shapes in question, since, in any case, the observing subject knows that they are real individuals actually existing in the real world.

Let us take another example, borrowed, this time, from the world of cinema. It happens that, during a film, in the middle of a succession of events unfolding in an apparently real world, a sequence appears to be thoroughly unreal. This is the case with sequences intended to represent the dreams (or daydreams) of characters in the film. It is also the case with animation films and films with fantastic settings.

How can we account for the two examples mentioned in the framework of Michotte's theory?

On the one hand, we have a very deformed vision, but posited as real without any equivocation, and on the other hand, we have a vision of an unreal world detaching itself from a world that is, in theory, midway between the real and unreal.

Can we still, after examining these two examples, affirm that what has been filmically perceived draws a certain unreal character from the objective deformations to which the representation of reality subjects it?

Such difficulties posed by Michotte's theory are surmounted if we make a distinction between unreality and absence. Unreality is what consciousness poses as being incapable of existence. Hence, the film experience, when the film limits itself to representing lifelike events, would not be capable 
of inducing an impression of unreality. By contrast, when the content of the film has, as its object, dreams or unrealistic events, the filmic consciousness evidently becomes an awareness of something unreal.

We can see that the qualities of the real and the unreal essentially depend on the manner in which we are given the content of the filmic representations, and bear no relation to the objective conditions of perception. There are some kinds of filmic content that solicit our consciousness to take them for reality, and others to take them for unreality, and the deformations of the perceived world are not responsible for any impression of unreality.

Let us now envisage the notions of absence and presence, and resurrect the example of perception through an unpolished, misshapen plane of glass. What radically distinguishes this example from the film experience is the fact that, although it is considerably deformed, the reality observed through the glass remains actually present.

The cinema, by contrast, only gives a reality that we know to be absent, or existing elsewhere, or not existing at all.

We touch, here, on a fundamental phenomenon. We can now see to what the knowledge we have just discussed refers. It is not, in the end, the knowledge of a certain unreality of the perceived world that is in question, but the knowledge possessed by the filmic consciousness that the reality it perceives, even though it has all the appearances of actual reality, is not present in its bodily physicality.

We can also see from where this impression of 'psychic distance' spoken of by Michotte stems. It cannot only be the consequence of a supposed mixture of the real and the artificial, since it is included in the filmic consciousness. The filmic consciousness indeed gives its object as not being there. So what would be so astonishing about the spectator feeling distant from the filmic world?

In fact, it now appears that Michotte has committed a double error. Firstly, by bringing together the impression of unreality and objective data, he ignores the fact that, in the final analysis, reality and unreality, absence and presence, essentially derive from knowledge, from a position of consciousness. Subsequently, he makes no distinction between unreality and absence.

Until now, we have been able to keep separate an essential aspect of filmic consciousness: it is a relationship with the world, but a world that is not present. Furthermore, this absence emerges from a position of consciousness.

And yet, the absence of the perceived world constitutes one of the essential characteristics of the imaging consciousness, such as it is described by Jean-Paul Sartre in The Imaginary. ${ }^{24}$ Thus, in order to discover more about the filmic consciousness, we must now try to situate our problematic in 
the general framework of the theory of the imaginary, such as it has been developed by the French philosopher.

\section{The Imaginary Consciousness}

Let us begin by offering a brief summary of Sartre's thinking. A quick overview of his reflections will help us to better pose our problems.

Reflecting on the imaginary consciousness, Sartre observes this supremely important fact: in all cases in which the imaging function of consciousness is active, it renders present an object that we know is not there. He writes:

The image is an act that aims in its corporeality at an absent or nonexistent object, through a physical or psychic content that is given not as itself but in the capacity of 'analogical representative' of the object aimed at. ${ }^{25}$

This phrase undoubtedly calls for some commentary.

With regard to the object targeted by the imaging consciousness, we can cite this interesting passage from The Imaginary:

To produce in me the image consciousness of Pierre is to make an intentional synthesis that gathers in itself a host of past moments, which assert the identity of Pierre across these diverse appearances and which give this same object under a certain aspect (in profile, in three-quarters, full size, head and shoulders, etc.) This aspect is necessarily an intuitive aspect: what my present intention aims at is Pierre in his corporeality, the Pierre that I can see, touch, hear, were I to see him, touch him, hear him. It is a body that is necessarily at a certain distance from mine, necessarily in a certain position in relation to me. Only, the Pierre that I could touch I posit at present as not being touched by me. My image of him is a certain manner of not touching him, not seeing him, a way he has of not being at such a distance, in such a position. The belief, in the image, posits the intuition, but does not posit Pierre. The characteristic of Pierre is not to be non-intuitive, as one might be tempted to believe, but to be 'intuitive-absent,' given as absent to intuition. In this sense, one can say that the image has wrapped within it a certain nothingness. Its object is not a simple portrait, it asserts itself: but in asserting itself it destroys itself. However lively, appealing, strong the image, it gives its object as not being. This does not preclude our then reacting to this image as if its object were present, before us: we will see that it can happen that we try, with all our being, to react to an image as if it were a perception. But the 
ambiguous and false state at which we thus arrive only throws into relief what has just been said: in vain we seek by our conduct towards the object to give rise to the belief that it really exists; we can ignore for a second, but cannot destroy the immediate consciousness of its nothingness. ${ }^{26}$

In any case, the imaging consciousness posits its object as not being present in its bodily physicality. But this 'positional act' of consciousness, as Sartre calls it, can take, in his view, four different forms.

The act can take four and only four forms: it can posit the object as nonexistent, or as absent, or as existing elsewhere; it can also 'neutralize' itself, which is to say not posit its object as existent. Two of these acts are negations; the fourth corresponds to a suspension or neutralization of the thesis. The third, which is positive, assumes an implicit negation of the natural and present existence of the object. These positional acts - this remark is crucial - are not superimposed on the image after it is constituted: the positional act is constitutive of the image consciousness... ${ }^{27}$

That is to say, the imaging consciousness includes, within its constitutive targeting of the imaginary object, the modality of existence according to which it is given as an object. This also implies that this modality of existence only depends on the imaging intention and not on the object imagined. We could, for example, neutralize the thesis - that is, not posit anything concerning the existence of the object - with respect to the image of a dragon or even view this dragon as being existent. Childhood consciousness, for example, views as existent beings (such as Father Christmas) which adult consciousness normally considers to be nonexistent.

But, if the imaging consciousness has as its essential and constant characteristic a positing of its object as not being present, there are other characteristics that can be modified and even disappear according to the objective matter on the basis of which the imaging function is exercised. In the case of the pure mental image - that is to say, when there is no material basis, beyond the fact that consciousness gives its object as non-present - it also appears as a creative spontaneity.

Let us return to Sartre:

A perceptual consciousness appears to itself as passive. On the other hand, an imaging consciousness gives itself to itself as an imaging consciousness, which is to say as a spontaneity that produces and conserves the object as imaged. ${ }^{28}$ 
Finally, we must still consider that, contrary to what takes place in perception, where we can observe and apprehend the object, in the mental image, the object is given en bloc, it is entirely determined, and nothing can let us know more about its nature.

Indeed, there is no sense in trying to enumerate the elements of an imaginary image. An image of this kind is what it is. We do not apprehend it - we constitute it.

As Sartre writes:

In a word, the object of perception constantly overflows consciousness; the object of an image is never anything more than the consciousness one has of it; it is defined by that consciousness: one can never learn from an image what one does not know already. ${ }^{29}$

In the intention produced by the absent or nonexistent object, there is a certain knowledge that is indissolubly linked with it, and which focuses on the determinations of the object.

In the case of the image that has a material existence, we can nonetheless note certain variations concerning the knowledge of the imaging consciousness.

Between the pure mental image and the portrait, the objective matter of the image is far richer and, correlatively, the knowledge about the object targeted evidently plays a less and less important role. Indeed, while in the case of the pure mental image, or in the case of the image created through a schematic drawing, or even more so in the case of the image created through an imitation, there is nothing in the image above and beyond what we put into it (the image is entirely penetrated with the knowledge we have of it), in the case of the portrait, for example, or the photograph, the rich, even perfect nature of the material basis of the image, its quasi-perfect resemblance with the intended object, does not solicit the intervention of knowledge to the same degree. Furthermore, we must also note that the portrait or the photograph can equally be an object of perceptual consciousness or of an imaginary consciousness.

The matter of a portrait is a quasi-face. No doubt it is first of all a neutral element that could just as well function as support for a perceptual consciousness as for an imaging consciousness. But this indifference is mainly theoretical. In fact, the spontaneity of consciousness is strongly solicited: these forms, these colors, strongly organized, almost impose themselves as an image of Pierre. If it takes my fancy to perceive them, 
they resist. A picture spontaneously offers itself in relief to the imaging consciousness, and the perceptual consciousness would have great difficulty seeing it as flat. This quasi-face, moreover, is accessible to observation: of course, I do not refer the new qualities that I see there to the object that I have before my eyes, to this painted canvas. I project them far beyond the picture, to the real Pierre. As a result, each judgment that I make is given as probable (whereas in genuine observation judgments are certain). When I say "Pierre has blue eyes," I imply: "At least, if the picture represents him faithfully.”

The matter of my image is a strictly individual object: this painting is unique in time and space. It should be added to this that the features of the quasi-face also have this inalienable individuality: that quasi-smile is the same as no other. However, this individuality appears only to perceptual consciousness. In passing from perception to image, the matter acquires a certain generality. We say: "Yes, it is just as he smiles," implying that the smile represents a mass of Pierre's individual smiles. We apprehend the different qualities of the matter as representatives that are valid for each of a mass of qualities that appear and disappear on Pierre: this pink color becomes the pink of his cheeks; this green gleam is the green of his eyes. What we seek through the picture is not Pierre such as he could have appeared to us the day before yesterday or on such-and-such a day of last year: it is Pierre in general, a prototype that acts as a thematic unity of all the individual appearances of Pierre..$^{30}$

Let us summarize. In the pure mental image where objective matter is lacking, the knowledge that we have of the intended object is alone responsible for the determinations of the object. Here, we have what Sartre calls the phenomenon of quasi-observation: we observe the mental image, but this observation teaches us nothing. In the case of the portrait, wherein the objective matter possesses an almost perfect resemblance with the intended object, such knowledge barely intervenes at all. Furthermore, the matter of the portrait can, at least theoretically, be the object of a perceptual consciousness or an imaging consciousness. In the end, the portrait is offered as a quasi-person accessible to observation.

It goes without saying that the elements that we have just recalled will be extremely useful for our own analysis. There is, however, one point that we would like to deepen, a point that has little importance in Sartre's theory, but which will have great significance on the problems occupying us. 
Regarding the portrait, Sartre's examples almost always related to an image representing an absent object, or an object existing elsewhere, but still having been the object of a pre-existing perception. The 'Pierre' of the portrait constitutes a concrete, known being for Sartre. With this in mind, Sartre passes quite rapidly over the phase preceding the appearance of the intention that constitutes matter into an image. He even seems to indicate that the observation of the quasi-face is still on the side of the perception ('seems,' that is, because at other moments the observation of the face constitutes an imaging consciousness for Sartre.)

Let us read these lines:

The matter of our image, when we look at a portrait, is not only that tangle of lines and colors that I just called it in the interest of simplicity. It is, actually, a quasi-person, with a quasi-face, etc. At the museum in Rouen, suddenly entering an unfamiliar room, I happened to take the people in a large picture for actual men. The illusion was of very short duration - a quarter of a second, perhaps - it remains nonetheless that I did not have, during this negligible lapse of time, an imaged consciousness, but on the contrary, a perceptual consciousness. [...] It is the case that, in the picture, there is the appearance of a man. If I approach it, the illusion disappears, but the cause of the illusion persists: the picture, made to resemble a human being, acts on me as would a man, whatever attitude of consciousness I took towards it in other respects. [...] The composure of this figure moves me directly whatever interpretation I may give it. In brief, these elements in themselves are neutral; they can enter into a synthesis of imagination or of perception. But although they are neutral, they are expressive. [...] The person in the painting solicits me gently to take him for a man. [...]

The portrait acts upon us - almost - like Pierre in person and, because of this fact, it solicits us to make the perceptual synthesis: Pierre of flesh and blood.

Presently my intention appears; I say: "This is the portrait of Pierre" or, more briefly: "This is Pierre." Then the portrait ceases to be an object, it functions as matter for an image. This invitation to perceive Pierre has not disappeared, but has entered into the imagined synthesis. ${ }^{31}$

We can see the difficulty that these lines contain. On the one hand, Sartre underscores the manifest difference between the appearance of a present 
object and the appearance of a quasi-face (the illusion was shortly lived...) and seems to indicate that this difference is that between perception and the imaginary ("I did not have, during this minute lapse of time, an imaged consciousness, but on the contrary, perceptual consciousness"). On the other hand, he suggests, at least implicitly, that the observation of the quasi-face remains on the side of normal perception by waiting for an intention to appear and be directed towards something other than the quasi-face, towards, that is, the real person. "Presently my intention appears... Then the portrait ceases to be an object, it functions as matter for an image."

Let us note here that criticizing Sartre's theory does not enter into our project. Doubtless, the difficulty that we raise is only a minor difficulty. But, by noting it and by trying to resolve it, we simply hope to be able to extract certain elements conducive to advancing our comprehension of our own problems.

How can we resolve this difficulty? Let us first interrogate its cause. It does seem that the ambiguity on which rests the perception of the quasiface derives from the fact that the example introduced by Sartre concerns the case in which the intention targets an already perceived object. The Pierre of the portrait is known elsewhere, and from the moment when the intention appears, it is brought towards someone whose existence is situated elsewhere. The matter of the portrait and the quasi-face then totally disappear from the background of the object targeted, of the true Pierre existing elsewhere, and are shifted, so to speak, to the side of perception.

And yet, if it is correct that the objective matter (forms, colors, etc.) of the portrait is indisputably situated on the specific terrain of normal perception, the apprehension of the quasi-face contains an element that radically differentiates it from perception, and which leads us to place it on the side of the imaginary, of non-presence.

Let us take an example. I have before me a photograph of a person I do not know, who I have never seen and, thus, who has never been the object of my perception. The person represented thus appears to me as a quasi-person with a quasi-face; he solicits me to take him for a real person, and I can observe him at leisure, as I would do of a true person, but the fact remains that I cannot see him, at any moment, as being present. There is, in the apprehension of the quasi-face of a photograph or a portrait, a positing of absence. The portrait or the photograph may well be lifelike and expressive, but I know that the person is merely represented, and I posit him as being non-present. It is simply that there is no positing of his existence, or, rather, there is a neutralization of the thesis as to his existence. 
Let us cite a passage from The Imaginary illustrating a case in which there is no positing of an existence:

If I look at the photos in a magazine, they can very well 'say nothing to me,' which is to say I look at them without positing their existence. Thus, the people whose photographs I see are indeed reached through these photographs, but without my positing their existence, just as the Knight and Death are reached through Dürer's engraving, but without my positing them..$^{2}$

We could also cite these lines from Husserl:

Let us suppose that we are observing Dürer's engraving, "The Knight, Death and the Devil."

We distinguish here in the first place the normal perception of which the correlate is the 'engraved print' as a thing, this print in the portfolio.

We distinguish in the second place the perceptive consciousness within which in the black lines of the picture there appear to us the small colorless figures, 'knight on horseback,' 'death,' and 'devil.' In aesthetic observation we do not consider these as the objects [Objekten]; we have our attention fixed on what is portrayed 'in the picture,' more precisely, on the 'depicted' realities, the knight of flesh and blood, and so forth. [...] This depicting picture-object stands before us neither as being nor as non-being, nor in any other positional modality; rather, we are aware of it as having its being, though only a quasi-being, in the neutrality-modification of Being. ${ }^{33}$

In short, to 'have' a quasi-person or a quasi-face indeed amounts to having an imagined consciousness, but one in which there is no positing of existence, and thus one in which the existential thesis is neutralized.

Now, it also seems that it is not enough to say that the observation of the quasi-face does not bear a positing of existence in order to exhaust its characteristics.

Rather, it must also be added that, in the case of the consciousness of the portrait, the neutralization of the thesis (that is, the absence of a positing of existence) is often conducted by an undecided consciousness, which has still not clearly established the existence of its object - or, in other words, of an imaging consciousness which has just emerged and still remains unfinished. The correlative of such a consciousness can only be a quasi-being. 
Or, to take another example: at the very moment in which a portrait appears to me (let us suppose it is life-sized in order to facilitate understanding), the person represented still finds himself at the edge of perception. He is almost a present person, and solicits our consciousness to make a perceptual synthesis. However, this absence is already included in the consciousness of the portrait and prevents it from being realized in the domain of perception. In short, we are in the presence of a form of consciousness that is still uncertain, an undecided attitude of consciousness floating between perception and the imaginary. On the one hand, although the quasi-face first appears absent, its resemblance with a face is such that I have a tendency to take it for a real, present face, presenting itself in a singular and unique attitude.

On the other hand, through its very absence, I have a tendency to take it as the matter of the image - that is, to target, through the portrait, a being existing elsewhere (or not existing at all), but which, due to this positing of its existence, would gain in generality, since each trait observed in the quasi-face is no longer valid for what it is in itself, but refers to a quantity of the traits of the person depicted in the portrait or the photograph.

We can now return to and clarify the genesis of the consciousness of the portrait.

In the first place, the portrait can be the object of a perceptual consciousness as much as of an imaging consciousness. We can, indeed, observe the colors and forms by themselves.

But the portrait, through its resemblance with a human face, barely permits the perceptual consciousness to be realized. In fact, we are immediately solicited to consider the person and the face, rather than the portrait as an object. At this stage, we have before us a quasi-person with a quasi-face. Resemblance can be such that we have a tendency to take the portrait for a real person.

The gaze of a portrait can sometimes be so lively that it happens that, at least for a brief instant, we have the sensation of being seen by a person in flesh and blood. And yet, in spite of the apparent reality of the object, there has already been a negation of the presence of the person. There is a quasi-person, that is, a quasi-presence, but we already vaguely know that this quasi-person is not there. At this point, the attitude of consciousness is still rather undecided. On the one hand, consciousness is already in the imaginary, in that it posits the non-presence of the object, and on the other hand, it remains on the side of perception through the tendency it has to take the portrait for a real person, quasi-present and fixed in a singular attitude.

But this relative instability of consciousness does not last for long. The awareness of the portrait as a portrait is soon made more explicit. The 
imaging intention appears more clearly and we tell ourselves: "that is a portrait." Thus, the portrait ceases to be ambiguous. Consciousness resolutely slides into the imaginary, and clearly poses its object as not being there. This does not mean, however, that there is already a positing of existence.

We know that a person existing beyond the painting is depicted, but we cannot posit anything about his existence.

In other words, the person is indeed targeted by the portrait, but without any positing of his existence from our part. It even happens that we let ourselves fall into the trap of resemblance, that we almost enjoy believing in the presence of the person. In any case, we still aim at nothing other than the singular aspect or the unique attitude that the person in the portrait presents. In short, at this moment, what we see in the portrait is not a person-in-general, but a fixed person with a particular attitude.

Now, should someone tell us that it is a portrait of such-and-such a person (a parent, perhaps), then there is a positing of existence. We posit the person as existing, or having existed, elsewhere.

Thus, consciousness ceases to adhere to the object in its singularity. The qualities perceived are projected beyond the painting, onto the real person of whose existence we are assured. We target a person-in-general, since each quality perceived in the portrait is valid for a quantity of others that we presume have appeared on the face of the person. We then say that the person has a friendly smile, or that he possesses a severe gaze, wishing to designate by this a smile in general or a gaze in general. But we must remark here that everything that we can say of the person-in-general, consists of presumptions on our part. Each individual trait of the portrait refers to a trait in general by the intervention of a sort of hypothesis on our part. It is actually given to us to see a unique attitude of the person in the portrait, and if the imaging consciousness is generalizing, it nonetheless remains connected only to the characteristics of the portrait, which remains in the foreground of our attention.

If, on the contrary, we find ourselves faced with the portrait of a person we know, then there is no presumption of a person-in-general, but rather recognition.

Our attention extends well beyond the portrait, to the multiple characteristics perceived in the real person.

Everything that we have known about the person flows from the face of the portrait whose singularity fades in favor of the generalities that become the center of our attention.

This final analysis of the consciousness of the portrait appears of interest due to the fact that the portrait, and the photograph, doubtless constitutes the matter of the image closest to the cinematic image. 
It is on this cinematic image that our attention will now be focused. It is now for us to ask how the imaging function is exercised in the specific case of the cinematic image. In other words, we must extract the specific structure of the filmic consciousness, with respect to all the other types of the imaging consciousness.

\section{The Attitudes of Filmic Consciousness Faced with Its Object}

In the first place, we can already affirm, recalling what we said about Michotte's descriptions, that filmic consciousness possesses at least one characteristic shared with all the other forms of the imaging consciousness: it posits its object as not being there. In other words, we know that filmic reality is not physically present and we posit it as such.

Once this point has been ascertained, we need to interrogate the different functions of the cinematic image, or, alternatively, the internal modifications of filmic consciousness.

Let us note that, for reasons which will come to light in the rest of this study, we will follow a procedure that is the inverse of that followed for the analysis of the consciousness of the portrait. We will begin with a case in which the object is existent and known (the home movie [ film-souvenir $])^{34}$ in order to head towards the study of a case in which the object is unknown and non-existent (a fiction film) by passing through the intermediary case, in which the object is existent but unknown (a documentary film).

\section{a) The Home Movie}

It can happen that the cinema, like the portrait, offers to my vision images relating to a person who is known but absent or existing elsewhere. We can immediately see that this particular case of cinematic projection supposes a conscious attitude very different to that which engenders the fiction film.

Let us take an example: I want to recall the face or the whole physiognomy of a person I know. In order to do this, I can produce a mental image of this person, but I will only ever reach an imperfect representation. I can also take a photograph or a portrait of this person, and then I will find all the face's details. Photography, as we have seen, functions as an analogical representation of the absent person. But it lacks life. It gives all the characteristics of the face, but remains incapable of rendering expressions, looks, and familiar gestures which have been seen countless times on the person in question. If I desire to rediscover these known gestures, I can then, if I am an amateur filmmaker, project a film that represents the person in 
question, if they have been filmed on a certain occasion. The cinematic image, more than the portrait or the photograph, restores life. This time, I really do find the person.

In the three cases that we have evoked, the intention remains identical: every time, I render present to myself a person I know who is not there. In all three cases, there is a positing of existence. The person who I seek to render present to myself is posited as existing, or having existed, elsewhere. In all three cases, too, the goal is to find a person-in-general.

Thus, the matter of the home movie, like that of the portrait, acquires a certain generality. As for each of the gestures that I see on the screen, I do not apprehend them in their own individuality, but as representations of multiple gestures in reality. It matters little whether the person represented carries out a given particular activity. The activity in itself is of no interest. What interests me is to find, through the manner in which this particular activity is accomplished, a more general mode of behavior, repeatedly perceived in the absent person.

In short, what I seek to render present to myself is the person-in-general, such as I knew him in the multiple real perceptions that I have had of him. Thus, as in the case where I gave myself a known person through a portrait, our attention carries well beyond the cinematic image. The person-ingeneral, who is known in real perception, is the center of our attention. We can also say that, in the case of the home movie, the cinematic image truly plays the role of medium. It serves as an intermediary between the reality perceived and my current consciousness of this reality.

With the characteristics that we have just enumerated, we must still add that the consciousness of the home movie appears as a constitutive activity: it looks beyond the image, to the person-in-general that it depicts, in order to produce and maintain his existence even during the screening.

If this activity ceases, the person sought after gives way to an anonymous character on the screen carrying out equally anonymous and singular gestures, since they no longer refer to any general comportment.

Let us summarize. In the case of the home movie, there is, on the part of consciousness, a positing of existence, a generalization of the matter of the image that refers to a person-in-general, who constitutes the locus of our attention, and, finally, the creative activity.

\section{b) The Documentary Film}

We can now envisage the case of the documentary film, a case similar to the home movie in that it seeks to render present objects and people existing 
or having existed elsewhere, but which is nonetheless differentiated from the home movie due to the fact that (at least theoretically) the objects and people represented are not the object of any real perception.

Included in this category of films are biographical films - that is, documentaries on people. But fictionalized representations of the lives of historical celebrities (for instance, most films treating the Napoleonic era) are eliminated. These are hybrid productions halfway between fiction and reality, between myth and historical truth.

In order to facilitate our analysis, we will begin with a rather pure case of modest films - generally short or mid-length films - seeking to render, as faithfully as possible, individuals who are relatively little known to the public, or even completely unknown.

Cinéma-verité offers us some specimens of this type of film. We will find others still in certain works of new Canadian cinema (Lonely Boy, for example). 35

What takes place in these specific cases? As with the home movie, there is, of course, a positing of existence. We know that the person proposed by the film exists, or has existed, elsewhere, and we posit him as such.

As with the home movie, there is a certain generalization of the matter of the image. In other words, through the specific attitudes and comportments of the individual presented by the film, it is the general attitudes and comportments that the spectator considers, with the goal of rendering present the person-in-general who is the object of the film, and whom we know to exist elsewhere.

In the film Lonely Boy, for example, a film which seeks to give an overview of the life of the young Canadian singer Paul Anka, the behavior of the singer in question is not generally apprehended in its individuality, but as representative of a quantity of other types of behavior referring to the general comportment of the singer-in-general.

We should also note that in this type of film, the director usually chooses the most typical fragments of behavior, which are supposed to be the most representative of the mode of behavior of the filmed person.

Until now, the biographical film has not appeared any different from the home movie. In both cases, there is a positing of existence and the targeting of an object-in-general. For this reason, in both cases, there is a constitutive activity on the part of consciousness.

But we should also note that in this type of document, contrary to what occurs in the home movie, the knowledge about the person-in-general is contemporary to the viewing of the film. In the home movie, the image functions as a representative of a sum of real perceptions, which, in each of 
the specific appearances, flowed out of the person depicted. Thus, we have been able to say that our attention was focused on these real perceptions. The image, in other words, slid to the background of our attention and lost all singularity. Here, the process is quite different. We have not had any real perception of the character represented. We only have a vague idea of the character or no idea at all. Thus, if the perceived comportments gain in generality, or better, if they essentially serve as a representative for a general comportment, then it must be said that this generality is only acquired through a hypothesis or a series of presumptions whose point of departure can only be the particular behavior relayed by the film. No prior perception can precede the current filmic image, and this remains the center of attention.

We can illustrate this last affirmation by a new example.

With the goal of rendering present to myself a person who is a friend of mine, I have projected a home movie onto the screen. The first images present this person to me taking a cigarette and lighting it up. I perceive this unique gesture, but soon I also see something else: a familiar gesture that has really been perceived on the multiple occasions on which I have seen this friend light a cigarette. Or rather, the gesture in itself loses all signification, and I only retain fragments of particularly representative gestures of a general behavioral style that I have had the opportunity to perceive when faced with the multiple and diverse actions made by my friend. The cinematic image is filled with earlier perceptions. Its effective content ceases to be apprehended for itself. It is dissolved, so to speak, in the multiple real perceptions which it calls to my mind, and which flow into the structural elements of the behavior presently perceived. It is not my friend lighting a cigarette that I see, but my friend-in-general, such as he appeared to me through the multiple gestures of his which I have perceived, and which constitute the focus of my current attention. Now, let us suppose that another person watches this home movie at the same time as me. As he does not know my friend, this person finds himself in the same condition as the spectators of a documentary or biographical film. I tell him that the person on the screen is one of my friends. At this point, for this casual viewer, the individual on the screen is posited as existent. What is more, there is a search, by both him and by myself, for a being-in-general, and the matter of the image acquires a certain generality. But, for the other viewer, the cinematic image constitutes the only point of reference for this search for the person-in-general. Through the representation of my friend lighting his cigarette, this viewer aims for a structure of the entirety of his comportment, but this structure is simply presumed, and his attention continues to adhere to the cinematic image in its singularity. Whereas for 
me, there is a certain knowledge about my friend, which constitutes the pole of attention, and which flows into the image, for the casual viewer, there is the trace outline of a general knowledge about the film character on the basis of the particular characteristics of the images, which remain at the center of attention.

We can see, by passing from the home movie to the biographical film, that the cinematic image gains in autonomy with respect to the level of real perception. It further polarizes our attention, but nonetheless remains situated (as an intermediary) with respect to an unknown reality, posited as existing elsewhere.

Let it be noted that what we have just said applies to the documentary in general. It suffices to replace the film character by a group of individuals. The majority of documentaries indeed seek to take stock of the activities or the history of a defined social group (a working group, a sports group, etc.), or of a collectivity. In these cases, as in the biographical film depicting a single individual, there is a positing of existence (we pose the group as existing, or having existed, elsewhere), a generalization of the matter of the image (the group-in-general, its general style of activity, is targeted), a constitutive activity and a fixing of the attention on the image as a point of departure for the trace outline of a general knowledge.

We can now move on to a study of fiction film. As we will see, this last category of film (the largest) solicits, on the part of consciousness, a different attitude, in many aspects, from that which it adopts with respect to the home movie or the biographical film.

\section{c) The Fiction Film}

Let us envisage the case of the film relating an invented story - this case is all the more important in that it concerns the majority of film production - and refer once again to the same experiment.

This time, the images do not refer to anything existing. The characters who perform the action are indeed attained - it is perfectly evident that it is not the image in its objective reality that I see - but I do not posit that they exist (or have existed) elsewhere, and, moreover, I do not posit their non-existence, at least in the majority of cases. Rather, I am faced with a world of quasi-people, totally independent of the world known through real perception. We can thus say that, in the fiction film, the imaginary closes in on itself in some way: the characters seen are indeed posited as being absent, or rather, as not being there in their concrete bodily existence, but their physical appearance and actions do not refer to anything really 
existent, the filmic world is cut off from the world existing in perception in order to erect itself in an autonomous reality.

It follows that our attention is entirely centered on the screen. It also follows that the matter of the image no longer acquires any generality, but on the contrary, it is apprehended in all its singularity. In other words, the image no longer serves as a medium between a perception and a person-in-general or a group-in-general, it ceases to be valid as a representative sign of a larger signified, and solicits our consciousness to take it in its individuality.

This last remark already anticipates a modification in the form of consciousness's activity. In the home movie and the documentary film, we have been able to extract a certain constitutive activity that seeks and maintains the existence of the object-in-general that it targets.

This is not entirely the case in the fiction film. Here, the consciousness of the fiction film appears more passive, in the sense that it submits more to the object that it targets in its individuality, and that it follows in its particular evolutions. If there is activity, it is doubtless situated more at the level of retention, which integrates past events into present action (and of protention, which prolongs present action into the future), than at the level of the constitution of the object.

But we will have the opportunity to deepen this point when we study the function of movement more particularly. Before this, there remain several important remarks to make. First of all, if the fiction film no longer has any relation with existing reality, what is its status for consciousness? In other words, if the fictional world is purely imaginary, how should we characterize the degree of consciousness's belief in this imaginary world?

Let us examine our attitude when faced with the fiction film, and compare it with what we adopt in normal perception, and then, when faced with the documentary film.

In perception, we do not have to believe what we see. The perceived world initially gives itself as real. Sartre explained this well in the following lines:

When I perceive a table, I do not believe in the existence of that table. I have no need of belief, since the table is there in person. There is no supplementary act by which, in addition to perceiving that table, I confer a believed or believable existence on it. In the very act of perception, the table is discovered, disclosed, given to me. [...] The evidence peculiar to perception is therefore in no way a subjective impression that would be assimilable to a specification of belief: evidence is the presence for the consciousness of the object in person; it is the 'fulfillment' of the intention. [...] An evidence is a presence. Where evidence is given, belief is neither useful nor even possible. ${ }^{36}$ 
In perception, therefore, the objects are not 'believed,' but are immediately apprehended as existent.

In the documentary, or, more generally, in the case in which an existent object is targeted through an analogical representation (photography, film, etc.), the object is evidently not present to our intuition, but we know that it exists, and it is, in any case, its concrete existence that we try to attain through the image. Regardless of whether or not we have actually felt this existence, we posit it. In other terms, the awareness of the documentary is not disconnected from the real. It is simply their relationship that has changed. From now on, no more than for perception, we cannot say that the objects are 'believed.' They do not depart from the category of the real, and we apprehend them as real objects.

On the contrary, the objects, characters, and events of the fiction are not posited as existing in reality. They form part of an unreal world, the closed world of the film, which has no more relation with reality. It can, of course, be objected that a given object that appears in a film (an item of furniture, for example) really does exist, and that the spectator can, if they so wish, set their sights on this existence. But we must then note that the object, while recovering its place in the category of the real, ceases to belong to the world of the film. It is entirely one or the other. Either we think of the object in its reality, and consider it to be a studio prop, or we think of it in relation to the events of the film, and it appears as an unreal object in an unreal world. The same, obviously, applies to the characters of the film. Either we consider the actor and we are in the category of the real, or we consider the character and we are in the category of the unreal.

But if the objects, characters, and events of the fiction film are not posited as existing - that is, if they are not immediately apprehended as being real - we must still admit that they are 'believed.' The spectator believes in the unreal, and is fascinated by it. This phenomenon of belief that we find each time we let ourselves be 'taken away' by a fictional story has been characterized by Sartre, with respect to a problem close to our own: reading. Take this passage:

Reading is a kind of fascination, and when I read a detective story I believe in what I read. But this does not signify in the least that I cease to hold the detective's adventures to be imaginary. Simply, an entire world appears to me as imaged through the lines of the book [...] and this world encloses my consciousness, I cannot disengage, I am fascinated by it. This is the kind of fascination without positing existence that I call belief. ${ }^{37}$ 


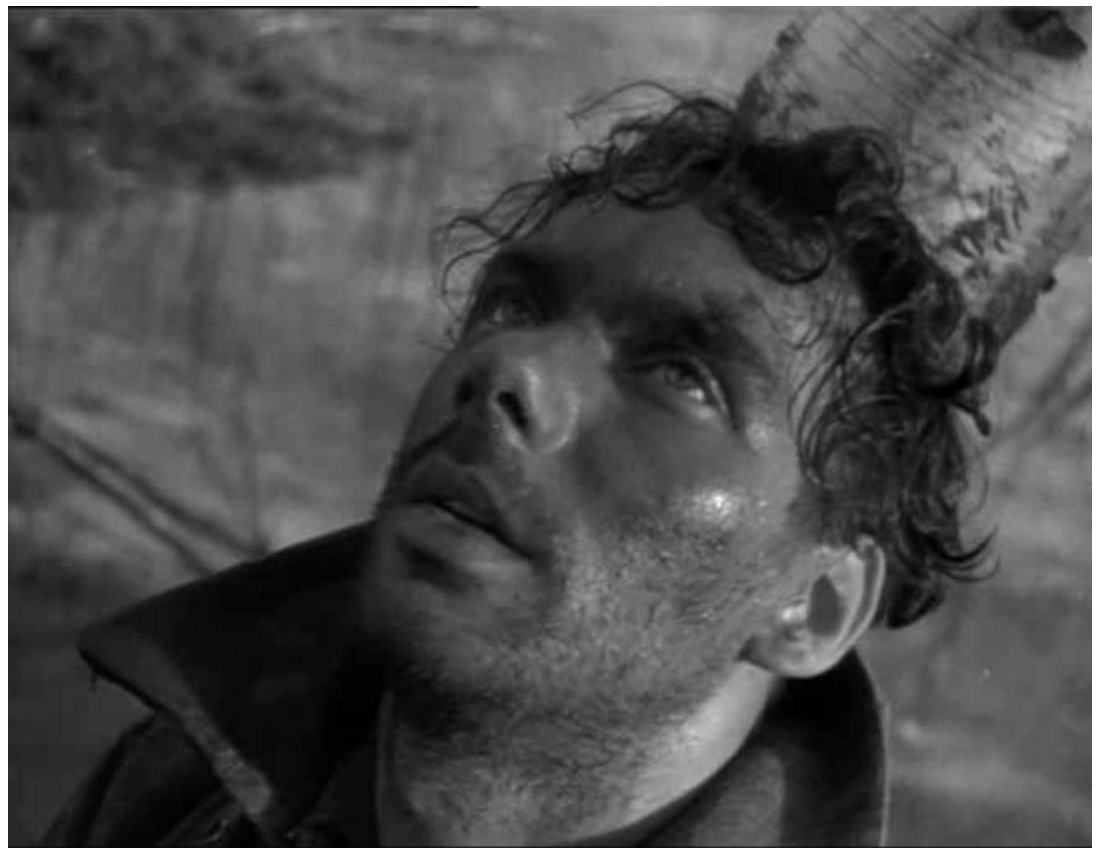

Fig. 4: The unexpected death of Boris (Aleksey Batalov) in Mikhail Kalatozov's The Cranes Are Flying.

What is true for reading is even more so for the cinema, since the latter, rather than offering us signs on the basis of which we 'imagine' an unreal world, directly gives us this unreal world in images, with an appearance of reality which, even though we are never deceived (when reading and when watching films, we never cease regarding the adventures as imaginary), solicits belief and fascination to a very high degree. We can better understand the phenomenon of fascination if we take note of the cases wherein the spectators, by themselves, break their belief in the adventure and the heroes of the film.

These breaks sometimes happen when the events presented by the film become unbearable, or when the hero finds himself in an excessively awful situation. In order to escape the unpleasant feeling instilled by a belief in the film, the spectator says, "It's just a film," thereby refusing to believe in the story unfolding on the screen.

To be more precise, let us examine a concrete example of this break. In doing so, we can shed more light on the nature of the phenomenon of belief.

On the screen, the young hero of Letyat zhuravli (The Cranes Are Flying, 1957) by Mikhail Kalatozov is mortally wounded, and his tragic end is described with such dramatic intensity that the scene becomes too awful 
for me to continue consenting to it. I tear myself away from my fascination and say: "It's just a film."

From this point, I leave behind the 'believed' world of the screen and return to my real situation as a spectator among other spectators, following an imaginary adventure. In other terms, I re-enter the category of the real, which I had momentarily evaded in order to consent to the unreal. The filmic world loses its density, it annihilates itself: for a moment, I have ceased to believe in it. This is not an act of denial. We do not deny that which is imaginary. We either consent to it or we do not. In order to deny an object or an event, the object or event must impose itself as such, as occurs in perception.

In the example given, I do not deny that the hero has died - this act of denial can take place, in a real situation, before a real death that I do not want to accept - but rather, I cease to consent to the imaginary world, I withdraw from it, as it were, in order to recuperate my function of the real and to enable me to consider the death of the hero as an unreal event. I acquire a certain distance with respect to this fact, which now merely appears to me as a product of the imagination, a shadow without any substance. In short, I stop believing in the imaginary world.

We can now see more precisely what belief is. It implies that we depart from the category of the real, in order to be fascinated by an unreal world, a world that we posit as neither existent nor nonexistent, that we never cease to regard as imaginary, but to which we consent, or rather, which we let ourselves believe in. Belief, in the cinema, is rather comparable to belief when playing. The child who plays 'cowboys and Indians' never ceases to regard his behavior as imaginary, but this does not negate the fact that during the game - that is, until the moment when he decides to stop playing - the child 'believes' that he is a 'cowboy' and 'believes' that his fellow players are 'Indians.' He is fascinated by the unreal world created by the game, just as the spectator is fascinated by the unreal world of the screen. Both act 'as if' the unreal were real. In other terms, they confer a 'believed' existence on objects that they never cease to regard as imaginary.

Such is the status of objects in a fiction film.

A second important remark concerns those cases in which, contrary to what we said above, certain characters are apprehended, not in their singularity, but as representatives of people-in-general, or, rather, charactersin-general. The popularity of certain actors is often the cause of such phenomena, above all when these actors remain confined to playing a specific type of character. James Dean, Jean Gabin, Sean Connery (as James Bond), and Fernandel are just a few examples of actors who generally restrict 


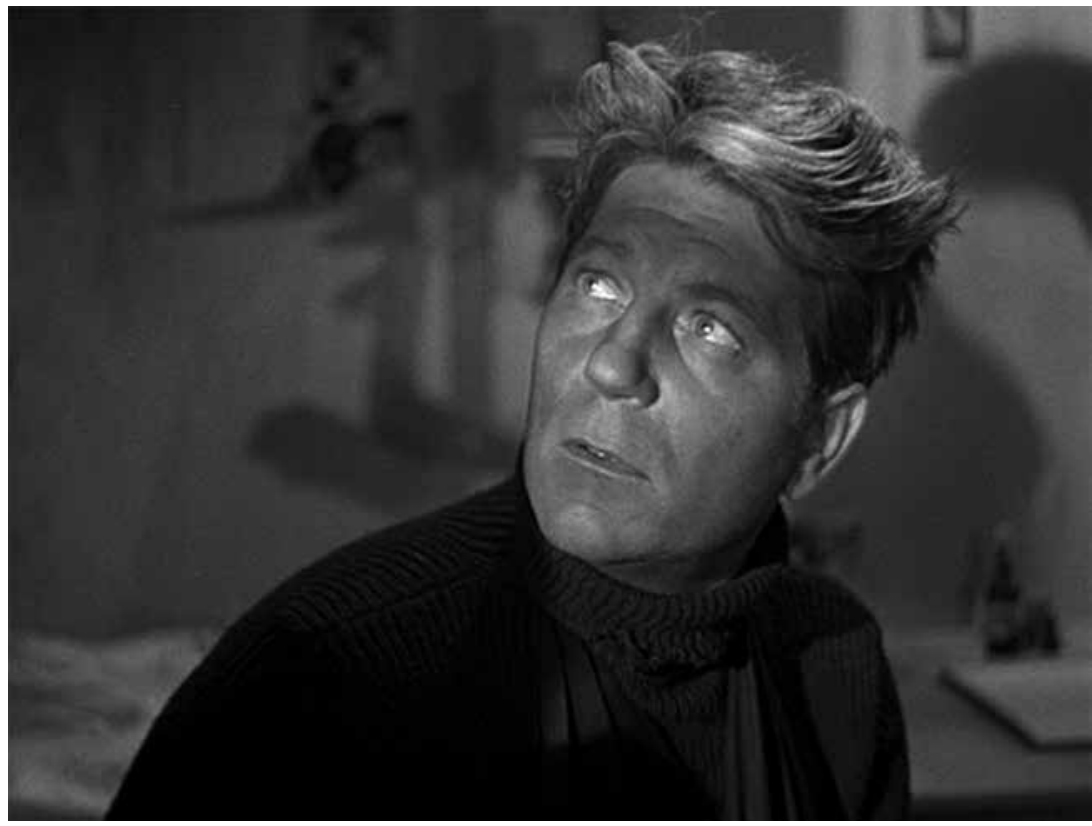

Fig. 5: Jean Gabin as the Lieutenant Maréchal in Jean Renoir's Grand Illusion.

themselves to certain roles. Let us suppose a fiction film in which the central character is played by a popular actor who generally appears as the same kind of character: for example, Jean Gabin. It then happens that our attention is diverted from the meaning of the specific action of the character, and focuses instead on the image of the actor's broader personality. We then say "that's Jean Gabin all right" or "that sure is how he acts," and we thus consider, via the present character he is playing, a certain general personality that we have seen in numerous other films. When such phenomena arise, we can see that the fiction film distinctly plays the same role as the home movie.

But it is important to note two things. Firstly, these phenomena are generally short-lived. The fiction soon takes over again and we forget Jean Gabin, in favor of the police detective or the businessman he is incarnating. Secondly, if such generalizations about the perceived being occur, and even present themselves frequently, it is essential that the character-in-general that we perceive does not leave the filmic world. Thus, in our example, we obviously do not seek Jean Gabin such as he is presented in real perception, but a certain film personality recognized in multiple films. Or rather, if it is true that our attention has been detached for a short moment from the specific character incarnated by Jean Gabin in order to focus on Jean Gabin in general, then this process in our consciousness paradoxically leads to 
a growing focus on the particular action of the character played by Jean Gabin. Indeed, at the same time as we think of Jean Gabin's specific film personality, there often forms within us a disposition to find and follow this same personality in his actions, once again incarnated in a singular character and action. The difference with the home movie is easy to discern. In the latter, the image essentially served as a medium, and its particularities fused into the ensemble of the characteristics of the person-in-general regarded by us, whose reality is located elsewhere. Here, the reality that we regard is not the Jean Gabin of real perception - there is no attempt to render Jean Gabin present as such - but a film personality, a manner of being known only in the filmic world, of which we expect a new manifestation in this same filmic world.

Another important remark concerns the modifications internal to the attitude taken when faced with a fiction film, modifications which derive from certain relations that the fiction has with the real.

We have said that, in the case of the fiction film, the image does not refer to anything that exists or has existed elsewhere. And yet, there is a nuance to add to this proposition, a nuance that may be suggested to us by the expressions of certain spectators frequently heard when they leave the cinema, the object of which is to underscore the 'truthful' character of certain films. We say, for example, "that sure is how things happen," etc. The reason for this is that the fiction often maintains closer relations with the real than might seem to be the case at first sight. If we wish to be complete, it would be apt to study the changes in attitude that this implies.

Let us first distinguish between the purely fictional film, such as we find in heroic and fantasy genres, and this other category of films closer to the real, whose action unfolds, as Cohen-Séat has explained, at the level of the 'resembling-ego' [semble-moi].

In the heroic film or the fantasy film, there is, of course, no search for a reality existing elsewhere. The filmic world is perfectly autonomous since it is totally independent of all perceived reality. Sometimes, even, the lack of any verisimilitude in the story is such that it clearly solicits a positing of its non-existence. The characters we see are indeed perceived through the image, and we do indeed continue to follow them in their actions, but we do not think that they exist, or rather, we do not think that they can exist, which further seals the divorce between the filmic world and the real world.

In the second category of films, wherein the action unfolds at the level of the 'resembling-ego,' the story told - while often banal or representing familiar events from daily life - has the particular quality that it is lifelike, 
or at least possible. The action it recounts often refers to slices of lived experience, and the human conflicts and problems it illustrates can, to varying degrees and in various forms, be found in the common lot of mortals. This type of film is perceptibly close to the documentary genre - think of Italian neorealist cinema, for example - but is distinguished by the fact that it does not convey, beyond the image, a specific, existent, concrete reality. We can choose an example of a realist film that approaches the limits of the documentary: Vittorio de Sica's Ladri di biciclette (Bicycle Thieves, 1948). This film is presented almost as a social observation; beyond the characters it depicts, it invites us to consider a certain social reality. The film, therefore, refers to something other than itself, a specific reality existing elsewhere. But, contrary to what takes place in the documentary, this reality remains indistinct, vague, and undifferentiated. Thus, the bicycle thief is not posited as existing in his specific reality, that is as a personal being, but he is valid as a representative of a number of anonymous beings existing in a certain period and sharing the same problems with him.

What should we make of this?

As in the pure fiction, our attention remains fixed on the particular behavior of the character in particular, since this behavior is valid for itself. Indeed, we do not search for a certain general personality of the bicycle thief in the image, in the same way that we searched for a being-in-general beyond the behavior of Paul Anka in Lonely Boy, which, in any case, we posited as existent. Here, the behavior is not generalized, and is followed for itself. But, from the fact that it is inspired by existing events, it is, in a certain manner, impregnated with reality. The bicycle thief as such does not exist, but the existing reality that it illustrates confers on it a power of existence that gives it a certain substance of reality.

We should shed more light on this 'substance of reality.' We have seen that, in the fiction film, we confer on the objects and characters a 'believed' and 'credible' existence. The bicycle thief, as a fictional character, receives this 'believed' existence, and I may, if I wish to (or if I feel too uncomfortable with the situation he experiences), break my belief in him just as easily as I can break my belief in James Bond, or the hero in L'Homme de Rio (That Man from Rio, Philippe de Broca, 1964).

But if I do this, contrary to what takes place with James Bond or the 'Man from Rio,' there remains a residue of authenticity in the character that I cannot eliminate: the real man, or, rather, the possible real man, who is hidden behind the bicycle thief, and who I know exists in the anonymity of a certain social layer in postwar Italy. All of a sudden, at the same time 
as I break my belief in the bicycle thief as a fictional character, I must also, in order for this act to be complete, deny a certain social reality that this fictional character illustrates, and whose major characteristics he reproduces.

We can now see better what is meant by 'substance of reality'. It derives from the fact that a character, because he is the reflection of a certain category of real people, acquires this potential existence that the authentic quality confers on him.

\section{From the Home Movie to the Fiction Film}

There still remains for us to apprehend the film experience, but, before going further, it will be useful to briefly summarize the few conclusions that our thinking has provided us with.

In all the cases we have examined, we have been able to recognize this characteristic common to all types of filmic attitude: it is still a matter of being presented with an object that is not there, or that is not present in its corporal physicality. But if this characteristic has not changed, there are others which have been modified as a function of the knowledge that we have of what is represented, and correlatively, of the positing of existence that derives from it. Let us quickly refer to the different cases studied. From the home movie to the fiction film, via the documentary, we have seen that the existence of the intended object, posited and known in the first case, posited but unknown in the documentary, ceased to be posited in the fiction.

From one end to the other of this spectrum of possibilities, we have been able to note a progressive, increasingly structured adhesion of our attention to the reality on the screen, which was gradually constituted as a reality autonomous from the reality existing in perception.

At the same time, and corresponding with the increased attention given to the filmic object, the matter of this object ceases to be generalized. It even progressively ceases to be regarded as a more general object, and is instead increasingly considered for itself, in its individuality.

On the other hand, passing from the home movie and the documentary to the fiction film, we have also been able to discern a change in the mode of activity of the filmic consciousness. Beginning as a constitutive activity seeking a general, existing object, it then slides into a kind of submission when it is more attached to the particularities of the individual object that it targets and follows in the fictional world. 
Furthermore, we have also seen that, when passing to the category of the fiction film, the objects change their status for our consciousness: they are provided with a 'believed' existence, correlating with the act of belief that the fiction postulates.

Finally, even within the fiction, we have been able to highlight an important variation. In the pure fiction, above all the heroic film and the fantasy film, the filmic world is perfectly autonomous because it is totally independent of any perceived reality. In the realist fiction - whose content is inspired by existing reality or slices of lived experience - the behavior of the characters, even if they are fictional and thus individualized, also acquires a real substance through the power of existence that a certain existing, but general and undifferentiated, reality confers on them.

In conclusion, we should also note that the positing of existence does not essentially depend on the type of film. In the end, it is consciousness alone which is responsible for this positing of existence. It is quite evident that a home movie generally solicits a home-movie attitude, and that a fiction film demands that we comprehend it as a fiction, but this is not necessarily always the case. We can indeed posit a purely fictional character as existing, and we can also posit the Paul Anka of Lonely Boy as not existing.

In any case, it is probable that such phenomena take place and that the consciousness of the child can teach us a lot on this subject. But this is not our concern. We have only sought to determine certain general attitudes of filmic consciousness, particularly with respect to the evident manner in which each type of film solicits consciousness to comprehend it, outside of any deviation.

It is now important to shift our focus to an essential characteristic of the objective matter of the film: movement.

\section{Movement}

Up until now, everything that we have said about filmic consciousness has been said with respect to the different attitudes that consciousness can take towards the portrait or the photograph. The analogies are striking. We have above all highlighted the resemblances, on the one hand, between the portrait of a familiar person and the home movie, and, on the other hand, between the portrait of an unknown person and the documentary film.

We can even add another analogy, which we will not analyze, but which appears quite evident: that between the fiction film and the photo-novel or the comic book, which also show us invented stories. 
And yet, none of the types of photography envisaged possess this characteristic that is specific only to the cinema: movement. Moreover, none possess this power so often recognized in the cinema. It is this properly cinematic aspect that we are now going to look at. But if we do not wish to engage in empty discussion and lose ourselves in useless commentary on movement's power of attraction, we must first attempt a description of the perceptual experience of movement in order to highlight all the implications on the level of the attitudes of the filmic consciousness.

\section{The Experience of Movement}

The effectiveness of movement has often been underlined by numerous writers. The theories and descriptions of this are abundant, and we may, as a point of departure for our study, take a remarkable analysis by Wallon, which appeared in an article entitled "Lacte perceptif et le cinéma." 38

Wallon highlights two essential aspects of movement: its power of attraction and its power of life.

Let us cite the most significant passages:

From the point of view of perception, movement is also what happens first; we detach moving objects from their background, and detach from that the 'environment' in which this action occurs. The movement in itself has a power of effectivity.

Illustrating this 'power of effectivity;' Wallon evokes the example of onlookers whose gaze is attracted by the rapidly flashing letters of neon street signs.

Then, passing to the analysis of film movement, he adds:

In cinema there is something similar: we cannot take our eyes off the film whose images flash past one after another, because we would lose the thread of the story and would no longer understand what is going to follow, but also because as the images follow one another, there is a sort of attraction, a sort of induction working on us, on our attention, our senses, and our sight, to ensure that we retain everything. The movement is therefore something attractive and captivating in itself. I was telling you just now about the details in a film that attract our attention more by moving: that is the proof of this law of perception. You know that in order to discern extremely subtle things which wouldn't be visible if they were immobile, you give them some movement: in this way you manage to distinguish very slight tendencies, simply because of their movements. 
All these examples demonstrate something in movement that induces greater subtlety of perception and which stimulates the desire to perceive.

Finally, in addition to this power of attraction, and correlating with it, film movement, according to Wallon, possesses a veritable power of life:

But beyond this, movement possesses the power of life, a power of attraction which makes film subjugate our senses' ability to keep and attract this power, whereas in fact we are in an atmosphere completely foreign to the series of images passing before our eyes.

The power of attraction and the power of life: these are the two essential elements which, in Wallon's view, characterize film movement.

We will further see that these two 'powers' of movement function very differently according to the cases envisaged in the preceding section (the home movie, the documentary film, the fiction film). But first it would be best to analyze, in a deeper manner, the properties of movement such as they have been described by Wallon.

We should first try to illuminate the characteristics of movement in its most elementary nature - that is, the movement of a point.

Imagine an immobile point on a screen. This point, endowed with a certain luminosity, is clearly detached from the darker background. As such, it already has the power to solicit my attention. I can then fix my gaze on it and it will appear to me as a figure detached from a background, and one that maintains a series of fixed relations with the elements of the background, which entirely determine the position that it occupies. Imagine, for example, that the point is placed to the right, a little bit above the middle of the screen. But as such, and unless I willingly adopt an attitude of concerted observation, this inert and entirely determined point will be incapable of retaining my attention for any significant period of time. Now let us suppose that this point begins to move on a background that otherwise remains immobile. In this case, there is, in my visual field, the appearance of an overturning of the structure, in the sense that, losing its stability, the point constantly changes its relations with its surroundings. There is an indeterminacy of the object with respect to the background, which poses the problem of its destination, and orients in the observer an attitude of expectation. In principle, this attitude will only be relaxed when the object attains a new stable position.

Let us explain this matter in greater detail. When the object was immobile - that is, when it constituted, along with the background, a stable 
structure defined by a series of fixed relations - the act of perception was in a certain fashion completed once this ensemble of relations is perceived. I would naturally turn away from the object, and if, exceptionally, I had maintained my observational attitude, this could only be as an effect of my will, since nothing (or not much) in the object solicited my attention to further explore it. In other words, the immobile point, or, more generally, the immobile object, if it can momentarily attract our attention through its luminosity or some other characteristic, can only mobilize our gaze in a more prolonged manner through the intervention of our will deciding to further explore the structure of the perceived object. We should also note that this exploration is itself accomplished through a series of ocular movements (our gaze wanders around the object in order to deepen its relation with its surroundings), which are themselves accomplished in all directions, but following the manner in which I have decided to explore the object (from left to right, from top to bottom, etc.).

But when the object begins to move, when the stable relations it maintains with its surroundings are broken up, a new spatio-temporal structure appears. This is a structure that unfolds in time, whose starting point is well-known, but whose endpoint remains problematic.

And yet, it is the question of the becoming of the structure that solicits our consciousness and mobilizes our attention. There is an incomplete aspect in the perceived object, which induces an attitude of expectation based on the defined position of the observed point.

It is important to note that what consciousness focuses on is not the object as such, nor the different positions that this object can take when moving, but the whole structure that unfolds, the trajectory.

In this case, not only does movement mobilize the gaze through the question of its becoming, but it also implies that our attention is only detached from the object once the movement has been completed. Indeed, since consciousness focuses on the totality of the movement in progress, it must adhere to each particular position of the point as the only trace of its becoming. If it momentarily distances itself from the moving object, it loses the structure of the whole. Hence, consciousness must not be distracted. It attaches itself to each particular position of the point as the culmination of the movement that flows out of it, and that it retains, and also as the starting point of the future movement that it anticipates. With each position, there is an act of 'retention' and 'protention.' This absorptive, exclusive activity has no other goal than prefiguring what consciousness is focused on: the totality of movement.

With respect to a different problem than the one we are concerned with, Sartre, taking inspiration from Husserl, gave a very illuminating description 
of these acts of 'retention' and 'protention,' which constitute one of the essential aspects of the perception of movement.

He writes:

Husserl has given a remarkable description of these particular intentions which, starting from a living and concrete 'now,' are directed towards the immediate past to retain it and towards the future to grasp it. He calls these 'retentions' and 'protentions.' This retention, which itself alone constitutes the continuity, is not itself an image. It is an empty intention which is directed towards the phase of the movement that has just been annihilated; we say, in psychological language, that it is knowledge centered on the present visual sensation, and which makes appear that now as also being an after of a certain quality, an after that does not follow any sensation except precisely the one that has just vanished. The protention, on its part, is an expectation and this expectation gives the same sensation as also being a before. Naturally, this latter is not as strictly determined as a 'before' as it is as an 'after,' since [...] the sensation that will follow is not entirely known [connue]; but this sensation is already pretraced by a very precise expectation. [...] Retention and protention constitute, in every way, the sense of the present visual impression: without these synthetic acts, one could hardly speak of an impression at all; this before and this after that are correlates of these acts are not given as empty forms, as homogeneous and indifferent structures: they are the concrete and individual relations that the current sensations sustains with the concrete and individual impressions that have preceded it and that will follow it. ${ }^{39}$

A focus on the structure of the whole unfolding in time, an attention towards the indefinite becoming of the moving object, acts of 'retention' and 'protention' - these are the characteristics of the perception of movement, and we can now see what produces the 'power of attraction' of movement discussed by Wallon.

Whereas the observation of a static form (a form entirely determined in space and time) usually relates to a voluntary decision which is maintained for the duration of the observation, and which can be suspended at any moment without losing anything of the object (I can always come back to it), the observation of the temporal structure is solicited in a constant manner by questioning the becoming of the object, and can only be relinquished, in principle, at the end of the movement.

Correlatively, whereas consciousness, during the observation of the static object, is master of itself, of the points of view that it takes towards 
the object under consideration, and of the manner in which it decides to deepen a consideration of the qualities of the object, in the attention given to the dynamic object, consciousness is not in possession of itself to the same extent. It awaits the structure that is progressively discovered and that it therefore does not yet entirely possess. It is only when the movement is completed that it can recover itself and perhaps return to the attitude of voluntary observation of the perceived form that it then possesses in its totality, and that it can then represent to itself as a static ensemble: the trajectory or the totality of the path taken.

We can thus say that the perception of movement, or rather, the awareness of a form in becoming, is, owing to the fact that it is in the course of being realized and that it situates itself before its total completion, a pure expectation, or even an empty intention which expects to be filled by the object on which it is focused. In this sense, it must alienate itself in its attention to the various successive positions of the moving object, as the only traces of the global form that it contemplates. Such an attitude rules out taking any distance from the object. Our attention must coincide with each present position of the object insofar as this position is given as the culmination of the immediate past that it must retain, and as the starting point for the immediate future that it is projected to follow up to the conclusion of the spatio-temporal form in progress. We have thus been able to speak of a genuine 'attraction' of movement, a formula that is a little incorrect but highly suggestive.

Wallon has similarly spoken of a certain 'power of life' associated with movement. This second great characteristic of movement flows, according to Wallon, directly from the first characteristic, namely, the attraction exercised by movement. The two phenomena are doubtless correlative, but, in our opinion, what confers this power of life is the real or apparent autonomy of the moving object.

We should also note that when any moving object immediately appears not to be the cause of its own movement - for example, an object that I move about with my hands - it does not possess this power of life, and continues to appear to me as an inert object.

On the contrary, when an object moves inside my visual field, without an extrinsic cause for its mobility also appearing, this object appears to me as autonomous and draws from this autonomy its quality of a living being.

Let us return, for example, to the case of the luminous point moving on a screen. As long as this figure is immobile, it remains integrated with the background surrounding it as an inert object. But once the point moves, there is a segregation between the point and the background, and since nothing seems to give rise to this segregation, the point appears to us as 
being granted an autonomous being, and thus with life, because what we usually understand by the word 'life' is none other than this quality of being able to autonomously generate one's own movements.

There are plenty of other things to say on movement in general, and on its particular characteristics, but such a project would distance us too much from the subject at hand. We have, we believe, the essentials of the matter, and we can now focus on a study of movement in the cinema.

\section{Movement in the Cinema}

What we have just said about movement in general can also be applied directly to the cinema.

A film is, in fact, an extremely complex spatio-temporal structure, which presents us with action and behavior in becoming. Each shot is presented as a spatio-temporal structure integrated in broader structures, which we call sequences, and these sequences are integrated in turn into the whole spatio-temporal form constituted by the film.

On all levels (shot, sequence, film), the filmic consciousness awaits a becoming-in-progress, a total action that it considers in its entirety, and that it will only possess once the film is over. This is an empty intention which expects to be filled, and which must therefore adhere (and alienate itself in its attention) to the various successive moments of the film, in the sense that it must cling onto each one of these particular moments of the action, as the only visible points of the whole, and on the basis of which it can make its way towards the past or the future.

It is only when the film is over that consciousness can be distanced from it. At this point, it possesses the structure in its entirety, and can take a point of view on this structure. In fact, it can then be given or represented as a static form, because it is now conclusively finished.

To adopt a more figurative way of putting it, we could almost say that the filmic consciousness, during the screening, must coincide with or plunge itself into each present moment, as the only location from which it can perceive the moments that pass by and those that will follow. On the contrary, when the film is over, and consciousness possesses the whole, this whole can be given or represented 'from a distance,' as an object that it can handle, and on which it can take any point of view that it likes.

What we have just said about movement in the cinema is particularly applicable to fiction films, and we will later have the opportunity to return to this matter. First, however, it would be beneficial to quickly examine the role of movement in the other cases previously studied - namely, the home 
movie and the biographical or documentary film. This quick examination will not be useless: not only will it permit us to deepen the attitudes of our own consciousness in these two particular cases, but also, furthermore, it will allow us to better understand and explain the role of movement in the case of the fiction film.

\section{a) Movement in the Home Movie}

Here, as also, but to a lesser degree, in the documentary film, we will see that movement, by being subordinated to a specific attitude of consciousness, takes on a rather different signification from that which we have recognized on a general level.

Let us quickly recall what we said about what we can now call the homemovie attitude' [attitude-souvenir].

In this attitude, the intention is to render present a person who is not there, but who we posit as existing or having existed elsewhere. Since the goal is to rediscover the person-in-general, there is a generalization of the matter, in the sense that each gesture seen is not apprehended in its individuality, but as a representative of multiple gestures perceived countless times in reality. Moreover, our attention goes well beyond the image, extending to the real person we are focusing on, and, finally, there is a constitutive activity on the part of consciousness. In short, consciousness constantly exceeds the image, which serves precisely as a medium between the reality perceived in the past and my present consciousness of this reality.

In this perspective, therefore, the role of movement is largely reduced to being a factor of the liveliness of the represented reality. Indeed, the progressive becoming of the filmed action, or, more generally, the spatiotemporal form constituted by the entirety of the home movie, is of barely any interest to the spectator.

Hence, for example, if, in order to summon the memory of one of my friends, I screen a home movie representing various actions carried out by this person, the endpoint of these actions is of no interest to me. My intention is not to be given all of these actions in their entirety, but only to rediscover, in each shot, or in the various moments of the action in progress, familiar attitudes or gestures, specific to the person-in-general I am thinking of, and which have been perceived in reality on several occasions. In other words, each particular moment of the film is in some way isolated from the whole. The preceding moments do not interest me and I do not anticipate the following moments. Rather, each moment serves as the basis for the constitutive activity of consciousness to seek and find, beyond each specific 
image, the typical allures of a certain person-in-general who truly exists in reality. Unconcerned with the result of the actions it observes, consciousness is not an empty vessel waiting for reality to materialize. On the contrary, at every moment it is full of the object that it considers by means of the image, an object which appears to it in different aspects (my friend is walking, he is reading, etc.), but wherein each of these aspects contains the whole of the person (my friend has a certain way of walking, or reading, etc.).

We could almost say, in figurative terms, that the home movie gives rise to a longitudinal consciousness, which makes its way, via each present moment of the film, towards the real and distant object that it has in mind. On the contrary, when our mind focuses on a spatio-temporal structure in progress, consciousness is, in a way, 'lateral,' in the sense that it makes its way, via each present moment, towards both the past and the future. This is indeed what takes place in the fiction - but we will return to this point later.

Hence, in the home movie, movement is subordinated to the primary intention, which is to call to mind a real person existing elsewhere. Then, the total action that it sketches out is not (or almost not) taken into consideration, but, on the contrary, each present moment is forcefully detached to serve at each moment as a point of application for consciousness, which does not cease to regard a general, existing, and known object.

Our analysis, such as it has been expressed, is in all likelihood not entirely correct. Indeed, if we pushed our reasoning right to the end, we would end up claiming that our attention focuses on each specific moment, which would end up being isolated content pure and simple (that is, mere photographs).

And yet, in movement no present moment is ever given as an isolated content. It always appears as the succession of that which preceded it, and the starting point for what will follow it. In other words, each visual impression is always given as the basis of a retention and protention, which determine its place in the continuity of movement.

However, and this is important to note for the case that we are presently concerned with, retention and protention appear here as subordinated to the present moment, to the concrete, current impression on the basis of which I consider a general object.

Let us illustrate this last affirmation by returning to our example. In order to evoke the presence of one of my friends, I can try to imagine the person, but I will only end up with a very imperfect image. I can also take a photograph, and now the representation will be more convincing. If this photograph represents the person undertaking a certain action (for example, walking in the street), then I can seek and find, via this fixed representation, my friend's general mode of comportment. But this representation lacks 
life. So let us suppose that I possess a home movie representing this same person undertaking this same action. By following this action, which now unfolds in time and space, there are, of course, retentions and protentions that, at every point in time, give me the place of each present impression in the continuity of movement, but my attention, far from making its way towards the becoming of the observed act, or towards the past, as that which can illuminate the whole of the acts, is instead centered at every moment as the continually visible incarnation of a certain mode of comportment that I constantly call to mind in its generality.

We can see the difference between the photograph and the home movie: both restitute the specific mode of existing of the person considered, but, in addition to what the photograph provides, the home movie restitutes this mode of existing in action. The home movie shows us life, and we should also note that this characteristic has affective repercussions that are often more perceptible than those that are engendered by the fixed form of the photograph. To a far greater extent than the photo, the home movie, by means of the life that movement confers on it, is conducive to inducing a high degree of nostalgia, regret, or other sentiments in us.

We can also get a glimpse, here, of the difference between the home movie and the fiction film. In the latter, retention and protention, instead of accumulating in each present moment, project beyond the present moment, both towards the past and the future, in order for consciousness to take in the action in its entirety.

But, before elucidating this last point, it is apt to study in greater detail the intermediate case between the home movie and the fiction film, namely, the documentary film.

\section{b) Movement in the Documentary Film}

In the 'documentary attitude,' as we saw earlier, there is, as is the case with the home-movie attitude, a positing of existence, a generalizing of the matter of the image, a constituting activity, and a fixing of the attention on the image as a starting point for the sketch of a generalized knowledge.

When passing from the home movie to the documentary film, the cinematic image gains in autonomy as far as the level of real perception is concerned. It further centralizes our attention, but nonetheless remains situated (as an intermediate case) with respect to an unknown reality.

To say that the image further centralizes our attention already implies that movement takes on a different meaning from that which it assumes in the home movie. 
In the documentary film or the biographical film, all we know about the object under consideration is that it exists elsewhere, and nothing else.

Our intention is precisely to know more about it. Consequently, our attention is not focused only on each present moment, but on the ensemble of actions that are proposed to us. There is a knowledge that is formed by the projection, and that requires us to provide ourselves with a set of successively presented events. However, despite the fact that it comes very close to the signification that it takes in the fiction film, movement in the documentary film is distinct from it in several respects. These differences reside, we think, in the relationship that exists between retention and protention.

Let us take a concrete example.

Say I am watching a documentary film about a foreign country, and I am shown a group of indigenous people engaged in a typical activity, which, most of the time, has a symbolic, representative, and generalizing signification. Hence, if I am shown the indigenous people in question hunting or farming the land, I immediately know that I am seeing a people who are hunters or farmers.

Incidentally, the voice-over commentary is often there to confirm this generalizing opinion.

By means of each of these particular activities presented to me, I am always focused on a general style of existence. What is more, each particular activity brought to the screen gives me, in some sense, the totality of the object under consideration.

If I am shown the indigenous people hunting, farming, or devoting themselves to some other activity, it is always a general style of comporting themselves that I aim for, and that I attain through the multiple aspects given to me.

In short, in the documentary film, there is a knowledge that is formed on the occasion of each particular event, a knowledge that is constantly generalized and related to the reality that is aimed for.

Each particular shot appears as a particular perspective on a general comportment. That is to say that, in the documentary, movement does not engender this expectation of the future that we see in the fiction film. In general, we can cut the film after any sequence, or even right in the middle of a sequence, without the spectator being truly frustrated by it. This is because, at every moment, it possesses a general reality that presents itself on each occasion as a whole by means of the multiple, particular points of view given about it. No moment really summons any other moment. It is integrated with the preceding moments for the formation of an accumulating knowledge, but does not create any expectation of a future, because this 
future never appears as being truly necessary - at least before it appears - in order to illuminate the preceding moments.

Of course, one could reply to this that there exist all sorts of documentaries, and that certain among them come close to the fiction film, such that the attitude that we have just described finds itself modified to a great extent. Nanook of the North by Robert Flaherty (1922) is a good example of this.

Nanook, a real character chosen to illustrate the life of the inhabitants of the Arctic Circle, is indeed 'personalized' to the extent that we follow him more as an 'individual' than as a representative of a category of people, and that the 'becoming' of his actions has as much importance as those that precede them. When watching Nanook of the North, the attitude we take is almost the same as in the fiction film. But this is a particular case. On the other hand, since our project no longer involves describing the multiple variations and compromises within attitudes, but tries to describe rather pure types of these attitudes such as they are solicited by equally pure types of films, we will not dwell on marginal or ambiguous cases. These cases could, in any case, easily be understood on the basis of the major characteristics that the description of pure cases will have delivered us.

To conclude: in the case of the documentary or biographical film, there is firstly retention, in the sense that each present moment is integrated with past moments, while the whole constitutes itself into an additional knowledge on the object under consideration, and a generalization in the sense that, at any moment, the perceived object finds itself related to a general object that exists elsewhere.

In figurative terms, once more, we can see that the documentary gives rise to a consciousness that is both lateral - in the sense that, on the basis of each present moment, it makes its way towards the past in order to retain it and integrate it with the present - and longitudinal, in the sense that, on the basis of each present moment, it makes its way towards a general object that exists elsewhere.

In the documentary film, movement is what allows for a progressive, cumulative knowledge of an existing object. In this case, protention, or rather anticipation, is reduced.

\section{c) Movement in the Fiction Film}

Here, as we have seen earlier, there is no positing of existence. In a way, the imaginary is closed in on itself, in the sense that the filmic reality does not refer to any other existing reality. 
The filmic world is erected as an autonomous reality: there is no generalization of the matter of the image, which is apprehended in its singularity. Hence, our attention remains centered on the screen.

All this is to say that, in the case of the fiction film, movement ceases to subordinate itself to an intention that remains connected with existing reality.

On the contrary, it possesses the function that we recognized it had on a more general level. The film is presented as an autonomous spatio-temporal structure with respect to the reality of perception, and the intention is evidently to give oneself this structure in its totality.

The fiction film, therefore, creates an expectation, an empty intention that waits to be filled by the totality it takes into consideration.

The successive events are no longer a sum of independent points of view on an existing general object. Rather, they are linked in the whole structure that consciousness considers. Detached from existing reality, the only meaning they have is in relation to all the events that precede and follow them.

Consequently, retention and protention constitute the essence of consciousness's activity, which projects, beyond each present moment, towards the whole that is under consideration.

In other words, consciousness must dive into every present moment, as the only place from which it can perceive the past and project the future. In the figurative language we used earlier, we could say that the consciousness of the fiction film is a 'lateral' consciousness.

There follows a certain number of consequences, some of which will allow us to better understand the meaning of certain expressions currently utilized in filmological literature, which all underscore the hold exerted over us by the fiction film.

Thus, it now appears that the fiction film excludes almost any attitude of detachment.

In fact, in the other cases examined (the home movie, the biographical film, the documentary film), there remains a form of constituting activity on the part of consciousness which means that it remains the master of its object, from which it nonetheless keeps a certain distance. In other words, it is consciousness, in this case, which holds, 'at arm's length,' the general object that it projects at every moment on the basis of the individual events and characteristics that are given for it to see.

In the fiction film, by contrast, consciousness is constantly in an attitude of empty expectation that leads it to totally coincide with each present moment in order to lose nothing of the past or the future. Its project is, indeed, to possess the object it considers (the film in its entirety) and it 
can consequently take a step back once the action is over, that is, when it possesses, and can represent to itself at a distance and in its entirety, the total series of events represented on the screen.

This is doubtless one of the reasons for the 'fascinating' nature of the fiction film that has been so often noted by film specialists.

Let us note here that we prefer, instead of the term 'fascinating,' which we have reserved for the description of the phenomenon of belief, the term 'captivating,' which is more descriptive as it underscores the retention or 'capturing' of our attention by fictional events in their becoming.

If, to the preceding remarks, we can add the fact that the material conditions essentially aim to abolish the ambient reality in favor of the filmic reality alone (the darkened room, the comfort of the spectator, the big screen, the luminosity of the screen), then we have the essence of fictional filmic reality: an imaginary world (that is to say posited as non-present), which is autonomous, which imposes itself on consciousness by substituting itself for the real world, and which, thanks to its movement, solicits consciousness to coincide with it with barely any possibility of distanciation.

It is important to note here that, owing to the resources at its disposal, the cinema can on occasion provoke in the spectator a certain 'distanciation' with respect to filmic reality. The likes of Godard and Varda have honed a certain number of procedures aiming to break the spectator's enchantment, and to invite them to take their distances. But these are, when it comes down to it, rather artificial and rarely used procedures. The phenomena they provoke doubtless warrant a deeper description, but do not form part of our project, which, let us recall, is above all to highlight certain general types of attitudes.

We should also note that this 'captivating' character we have spoken about above is not found to the same degree in any other genre of fictional expression, such as the novel or, to take an example even closer to the fiction film, the photo-novel. We will now examine this latter case.

In the photo-novel, as in the cinema, a fictional story can very well engender in the reader a strong attitude of expectation for the becomingin-progress such as it unfolds by means of successive photographs. We will then see the reader excitedly leaf through the volume in a single sitting, even though the photo-novel is no more than an attempt to represent a story in motion that is artificially broken down into static fragments.

Contrary to what we can observe in the case of the film, however, there remain sequences of voluntary movements in the photo-novel, which prevent our total adherence to the story, or rather, a perfect coincidence with it. We must indeed pass from one image to another, turn the pages, etc., and what is more, we have, at every moment, the possibility of stopping and 
distancing ourselves from the passing sequences in order to envisage them in their entirety, while in no way losing anything of the future sequences.

In the cinema, by contrast, the spectators not only can but must submit to the unfolding of the story. They can never relieve themselves from their attention and can therefore only distance themselves from their object with much greater difficulty.

It follows that movement reinforces the autonomous nature of the fiction film we recognized earlier. Not allowing any withdrawal or relaxation of our attention, which must be focused on the succession of events, it impels a belief in the events and characters on-screen, even if this belief is brought into question once the film is over. Any relationship with reality is generally only considered afterwards. During the film, a belief in the specific reality of the film is customary, at least as far as the fiction film is concerned.

This last consideration leads us to formulate a very short and final remark on the differences between the filmic and theatrical situations. Although somewhat digressive, this remark will perhaps furnish us with a supplementary element for understanding the 'hold' a cinematic film has on us.

In the cinema, we said, belief is customary, a belief not in the authenticity or inauthenticity, or the existence or non-existence, of the object represented on-screen, but simply a belief in a quasi-world populated by quasi-presences which impose themselves on consciousness, and to which consciousness adheres without any detachment.

Theatrical scenes, by contrast, present events played by people present in their bodily physicality, but acting as analogical representatives of absent characters, who are posited as existing or having existed elsewhere (or even as not existing at all). In any case, we have in the theater the paradoxical situation wherein a physically present being stands in for a non-present character.

There ensues a certain segregation between a world of presences (the real people) and an absent but represented world.

Let us suppose, for example, a staging of Le Cid by Corneille. Rodrigue and the other characters are indeed attained via the actors, but we never lose sight of the fact that these characters are merely being played by actors. In fact, we are aware of an actor playing the role of Rodrigue. In other words, there is a certain constituting activity on the part of consciousness, which posits the fictional characters represented via the actors.

In the cinema, there is no segregation between the people who represent and the represented characters. There is not a world of fictional characters considered via a cast of present people. As a general rule, the fictional characters initially appear as fictional people in a fictional world. Hence, in Laurence Olivier's Hamlet [1948], Hamlet and the other characters are 
immediately registered as being fictional characters, posited as being nonpresent and evolving in a world equally non-present. Of course, we know the names of the actors, and certain acting personalities are sometimes so powerful that we cannot forget them (such as Orson Welles).

But it remains no less true that, in the majority of cases, filmic reality invites us to believe in the characters of the film without any distance, while in the theater a certain complaisance or disposition on the part of the spectator is necessary. We must 'play the game' and posit the fictional characters via the physically present actors.

In the theater, there is a constituting activity and the belief in the character is in some way feigned. The spectator remains in control, and is responsible for the belief in the characters, a belief that they 'play' under the effect of a sort of 'good will.'

In the theater, the spectator posits the fictional reality under consideration. In the cinema, this reality directly imposes itself.

We can see that this direct, submissive adherence to the filmic reality has no equivalent in any other mode of expression. This is undoubtedly one of the most essential traits of the film experience.

\section{Conclusion}

To conclude this section is not merely, we should think, to summarize what has been said, but rather to take some distance, and cast a critical eye on the text and its contents. Any theory necessarily contains lacunae and imperfections which it is good to examine with an overriding concern for being constructive. This is what we wish to do here.

Let us first note that we are far from having exhausted the problem. This banal remark, which can be found at the end of every study as a necessary precaution, nonetheless here keeps its full meaning.

The attitudes that the filmic consciousness can take when faced with its object are indeed rather more diverse and complex than it seems upon reading our all-too-short analysis. We have indeed tried to specify three major types of attitude corresponding to three major categories of film, but it must be said that we have taken these attitudes in a pure state, such as they are solicited by equally pure cases of the home movie, the documentary film, or the fiction film. What is more, through a concern for the specification and the differentiation of attitudes, a concern that often thwarts the possibility of an exhaustive description of the multiple nuances which every phenomenon contains, we have doubtless framed or abusively crystallized each of these attitudes, thereby neglecting the subtle relations that they can have with 
the others, and the multiple intermediate modalities that scale from the pure 'home-movie attitude' to the pure 'fiction attitude.'

And yet, when looking closer, we can see that the attitudes described can succeed each other or intertwine with each other during the viewing of a single film, that a fiction film of a certain genre can solicit a home-movie attitude, or that a documentary film can be presented as fictional and engender a corresponding attitude.

Incidentally, it is important to note that the three attitudes described correspond to three possible positions that consciousness can take, and not necessarily to three objective categories of film. If it is true that the objective category of the 'fiction film' normally solicits a 'fiction attitude,' this in no way precludes the possibility of the 'home-movie attitude' or the 'documentary attitude' from appearing.

Whatever the case may be, by specifying three modalities of the 'filmic attitude,' we hope to have been able to furnish an adequate frame of reference, and, consequently, a verbal tool useful for the explanation of the nuances evoked above.

Finally, a second remark: we have also neglected those cases in which a voluntary, premeditated attitude gives a very special allure to the spectator's attitude. This is above all true for the fiction film. For example, it goes without saying that the critical attitude brings about a type of perception that is quite different to that of the naïve spectator. For the latter, we can observe this adherence without any distance, which we have spoken about at length. In the first case, a willed distanciation and a taking into consideration of the film as an aesthetic object thwarts this coincidence with the perceived object that the fiction film solicits, and brings about a more complex attitude whose description warrants its own chapter.

Finally, it goes without saying that the personality of the spectator and their particular interests can have a major influence, not on the type, but on the quality of the attitude taken. A film that is boring for one person because they see no interest in it will evidently not induce this intense expectation for the future that we have described as constituting the pure 'fiction attitude.'

In the same mode of thinking, certain technical procedures (or, more generally, the aesthetic aspect of the film) influence in their own way the type and the quality of the attitude taken. For example, we can think of certain successful suspense films whose technical qualities are all mobilized to engender, to a high degree, an expectation of the future and a passive and intense adherence to the perceived object.

In short, there exists a complex web of factors whose impact on the attitudes that the filmic consciousness can take is certainly not negligible, 
but whose detailed analysis would require at least one if not several volumes. Such a detailed analysis could not find any place in our own study, but it is necessary to signal its possibility, as well as the principal elements that it ought to envisage.

This said, it seems useful to summarize in a short synthesis the various aspects of the film experience that we have been able to unearth.

The filmic consciousness, we have seen, consists of a certain manner of referring to an object, a manner that is different from that which we encounter in real perception, and also different from that which defines the pure imaginary, but which nevertheless comes close to this last, in the sense that it targets an object not physically present, or, to adopt Sartre's language, an object that we posit as a nothingness [néant d'être].

The filmic consciousness is thus a relation to the world, but to a world posited as non-present.

Now, we have seen that the object of the filmic consciousness, an object always posited as non-present, can refer either to an existing and known object or an existing but unknown object, or indeed to nothing existing at all. In both of these different cases, the attitude of the filmic consciousness varies considerably. Correlatively, movement, an essential element of the filmic datum, has a diverse array of functions.

When the object is posited as existing or having existed elsewhere (which is generally the case for the home movie), there is a constituting activity on the part of consciousness, in the sense that, via the individual matter of the film, it seeks and finds the object-in-general which it knew, which exists elsewhere, and on which all its attention is focused.

Movement, in this case, has the essential function of giving life to the perceived object. Retention and protention appear as subordinated to the present impression, an impression which constantly serves as the basis for consciousness to seek out the general object known from elsewhere.

When the object is posited as existing but was not known in real perception (which is generally the case for documentary and biographical films), there is also a constituting activity on the part of consciousness, which constitutes a general object on the basis of the individual matter of the film. But since our knowledge of the object is contemporary with the screening of the film, our attention must be more attached to the image as a starting point for the sketch of a general knowledge.

Movement here has as its principal function the progressive unveiling of certain aspects of the object, necessary to the formation of an additional, generalizing knowledge. The activity of retention thus appears more important than the activity of protention. 
In one word, the activity of consciousness consists above all of retention - which makes it submit more to the filmic datum than it does in the home movie - and generalization, and it remains a constituting activity which keeps it distant from the filmic reality as such.

When there is no longer any positing of existence on the part of consciousness (this is generally the case for the fiction film), or, in other words, when the filmic reality no longer refers to anything existing in the real, and finds itself bestowed with a 'believed' existence correlative with an act of belief on the part of the subject spectator, there is of course no longer any generalizing activity. Our attention remains fixed on the perceived object in its individuality and must submit to it. The activity of consciousness is exclusively realized in retention and protention, which, this time, have the goal of integrating at every present moment the ensemble of past events, and projecting future events on the basis of these same moments.

Here, there is no longer any possibility of a detachment or a distanciation with respect to the filmic reality. The coincidence with the perceived object is customary, and this reinforces the autonomous character specific to the fiction film.

At the end of the day, it appears that our attitude towards the filmic reality is not only radically different from our attitude towards real (present) objects, but that it can also adopt very different forms according to the modalities of existence of the object under consideration.

By describing these variations in our attitude, we hope to have been able to explain some aspects of the film experience, but also, we believe that we have sketched out a useful framework for the study of our behavior when encountering a film.

To define certain types of attitudes according to their structure and their specific particularities was indeed necessary for the comprehension of filmic behavior, which necessarily draws its form from the attitudes that underpin it.

It is this behavior that we will now discuss.

\section{Chapter II: Filmic Behavior, Identification}

At the beginning of this study, we defined identification as a behavior of private intersubjectivity, understanding by this that it is a question of the comportment rooted in the terrain of anonymous intersubjectivity - a sort of generic coexistence of subjectivities - but subsequently structuring itself in a personal relationship, that is, in the behavior of private intersubjectivity. 
The analysis we have carried out on identification related principally to real situations in which the members of the relationship are both present to each other. Now, it is a question of examining how identification in a filmic situation is realized, that is, when one of the members of the relationship is presented as not being present.

There is no doubting that the essential structures of identification are not modified - in both filmic situations and real situations, we find the same postural apprehension of other people, as described earlier - and it would be wrong to make filmic identification a privileged form of behavior without any equivalent in real situations. Too many writers have begun with this false premise in order to then make our identification with a character (which also goes by the name of 'participation' or 'empathy') a unique mechanism, one that is comparable, as much on the level of its form as on the level of its possible influence, with an identification with certain particularly structuring forms of behavior such as parental identification or the phenomenon of identification in a psychoanalytic situation.

For us, there is no question of positing filmic identification from the start as a privileged form of behavior.

Following the principles that we have detailed at the beginning of this work, identification is a general mode of behavior that is traced out in every encounter, and that is structured according to different modalities depending on the type of relationship at issue.

In this conceptual framework, filmic identification is a variation of identification as a general mode of behavior, a particular type of identification corresponding to a particular type of relationship, one in which the object, although presenting almost all the characteristics that it possesses in perception, is presented as absent in its bodily physicality.

Provisionally leaving to one side the question of the choice of characters with whom the viewer identifies, and what determines this choice, we will now try to specify the major characteristics of this particular type of identification, filmic identification, while taking into account, of course, the internal modifications that it can undergo in line with the types of attitude that we were able to distinguish earlier.

\section{The Types of Filmic Identification}

\section{a) Identification in the 'Home-Movie Attitude'}

We know that, in the home-movie attitude, the image functions as a representative of a known but absent person, that the matter of the image is 
generalized, that there is a constituting activity on the part of consciousness and that, in the end, since our attention remains centered on the object existing elsewhere and known in real perception, it is not the series of events presented that is targeted but only each present moment.

All this leads us to presume a particular form of identification, a very special manner of entering into intersubjective relations with other people. In order to explicate this, we will once again refer to lived experience, and imagine a concrete example.

Say I project a home movie showing people I know in various activities.

At one point in the film, one of them appears to me in a close-up, smiling. I then happen to smile with him, or rather, like him - that is to say, I reproduce the smile that I apprehended in another person. We can recognize here the postural aspect of identification Hesnard spoke about, which, although it is manifest in our example, is customarily more silent and almost undetectable from the outside.

But we must note that here it is not the specific smile shown by the film that is the object of identification.

We know, in fact, that in the home-movie attitude, the acts perceived are not focused on for themselves, in their individuality, but as a representative of a certain general manner of acting such as it has been experienced through multiple real perceptions.

In the same manner, the acts 'reproduced' or 'mimed' by identification are not reproduced or mimed on an individual basis, but on a general level.

Thus, in the smile that I mimed upon seeing my friend smiling in the film, there was more than a simple reproduction of the individual act that has been perceived.

It did indeed involve miming a certain general manner of smiling apprehended through the specific smile shown in the film. In other words, the smile reproduced by identification constitutes a kind of synthesis of all the smiles apprehended on the occasion of numerous identifications in real situations.

There is an entire knowledge that is incorporated with the postural attitude of reproduction, a knowledge which bears on a behavior-in-general and which largely exceeds the individual act reproduced on the screen. These individual acts are, incidentally, only a means for the actualization of this knowledge. Hence, the smile that I saw on the screen was only, for me, the opportunity to remake the experience of a smile known for having been perceived and apprehended over the course of numerous circumstances.

We can already glimpse the meaning or the role of identification when it is developed within the home-movie attitude. 
But beforehand, let us look at the role it does not play.

Such an identification, it can be seen, is not a participation in the acts perceived on the screen. In order for this to be the case, these acts would have to be considered on an individual basis and thus perceived 'in situation.'

Let us explain this point further. If, for example, in a home movie, I perceive a friend running, it is not, of course, the act of running itself that I apprehend - the meaning, that is to say the origin and the goal of this act does not, in fact, interest me in the slightest - but rather, as we have seen, a certain general manner of running which itself reflects a general manner of acting which is that of my friend. It would be another thing entirely to see a character from a fiction film running. In this case, identification would indeed have the act itself as its object, in its individuality and with its meaning. This identification would then often assume the guise of a participation. If, for example, the running of the character in question has the meaning of an escape, then it is the comportment of escaping which we apprehend, and with which we identify, with all that this implies.

But this presents the opportunity of deepening the genre of identification when we study the fiction film more precisely.

The identification in the home-movie attitude is not a participatory behavior. Nor is it, however, understanding in the general sense of the term. There is, in fact, nothing to understand in the observed acts. In other terms, the identificatory behavior as applied to the home movie teaches us absolutely nothing about the person under consideration. On the contrary, as we clarified above, it is the actualization of a certain intuitive knowledge bearing on a general behavior which is formed on the terrain of real perception on the occasion of previous contacts.

But why is this actualization realized? What is its meaning?

In our opinion, it essentially involves a kind of 'incantatory' behavior intended to 'presentify' the person under consideration, and evoke their presence.

Let us explain this further. In the example given above, there was on the one hand my intention to render a friend present to myself, and on the other hand, a film sequence showing me this friend smiling. Since my attention does not focus on the individual smile on-screen, but on a certain mode of smiling specific to my friend who I know exists elsewhere, my postural attitude was fashioned as a function of what I know about the mode of smiling possessed by my friend-in-general who exists elsewhere.

It is therefore a matter of identifying with an absent person who is realized through the intermediary of the image, a vicarious identification. My goal was therefore to enter into intersubjective relations with an absent 
person through his image. Thus, the smile of the screen was given as the 'phantom' of my friend's real smile such as I have seen it in perception, such as it is presently realized elsewhere, and which I regard in its most essential aspects.

But to state that, in the case of the home movie, identification is a form of vicarious identification says much about the meaning of this behavior. This amounts to saying that we are dealing with an empty identification, a behavior that is realized as if the person under consideration were present in flesh and blood, and which even incorporates everything that it knows about the absent person, who is not directly perceptible on the image. This is a behavior that 'plays' the presence of the object. In short, it is an effort to apprehend a real but absent comportment which remains out of range. This is why we say that it is a kind of 'incantatory' behavior.

Incidentally, it may be apt to remark that the feelings accompanying this behavior are also sentiments that are 'played,' simulacra of feelings that could inspire in us the effective presence of the person under consideration. Hence, the sympathy felt for a 'presentified' friend in the home movie is evidently not inspired by what the screen shows us. It draws its origin from the real contacts that we have seen with the friend sought after. What is more, it is linked to the presence of this friend and, even when it functions for no purpose, as is the case with the image of my friend, it must also be interpreted as an attempt at 'presentification.' In fact, in order for these sentiments of sympathy that I feel for a determinate person to be produced, we must have the presence of this person or, absent this, a substitute for this presence. The cinematic image offers us this substitute and allows us to feel this sympathy linked to presence. At no moment do we lose sight of the fact that the image is only a substitute, a simulacrum of presence. And yet we continue to feel sympathy, even when it functions for no purpose. More precisely, we realize this sympathy within us in an effort to join the real person from whom we remain irremediably cut off. As we can see, the affective aspect and the postural aspect are merged in a single, unified behavior which is essentially defined as an effort to evoke the presence of the object under consideration. But we must also say that this behavior always fails. We 'play' at believing in this presence, but we never get there since we are always aware of the absence of the object.

We might even add that the more the characteristics of the substitute are close to the real characteristics of the object such as it can be perceived, the more the failure of our behavior is felt. We can, in fact, try to render a person present by different means. For example, we can produce a mental image, or utilize a photograph or home movie. In all three cases, the behavior has 
the same meaning. In all three cases, too, this behavior is doomed to failure, but we can observe that this failure is generally felt with more violence for the home movie than for the photograph, and with more violence for the photograph than for the mental image.

The fact is that, from the mental image to the film, the image gains in precision and vivacity. It thus becomes more apt to evoke the presence, and more apt to render the object such as it can be seen in perception. At the same time, and paradoxically, it expresses absence with much more clarity, quite simply because, by further resembling the real object, it lets us better take stock of what the effective presence of this real object would be. Consequently, this 'absenteeism' is all the more clearly felt, and the resulting disappointment is all the greater.

In the home-movie attitude, our behavior consists of a vain effort to 'presentify' the object, an attempt to enter into intersubjective relations with other people, which necessarily leads to disappointment.

All this leads us to make a final observation. At the same time as the absence of the object is felt, and correlatively with this fact, the presence of the spectator is experienced as useless, without any meaning. This is because, by wishing to render a person present, it is often our presence to the person that we try to evoke. In sum, we seek a relationship of real intersubjectivity. But, once the object is irremediably revealed to be out of our grasp, this will for a personal engagement in the relationship is experienced as being absurd.

It is confronted with the void, and remains suspended, without any possible outlet or any real signification.

To conclude: in the home-movie attitude, our own presence is constantly felt insofar as it is one of the poles of the relationship that we would like to see realized, and it is felt all the more for the fact that, since it is incapable of being engaged, it remains entirely preoccupied with itself.

This situation is comparable to the situation in which we have attempted to take hold of an object that is out of our grasp. Insofar as the object can be grasped, we simply have the awareness of an object to be held, and the gesture to take hold of it barely attracts our attention. By contrast, when it is out of our grasp, our attention focuses on these gestures. We are then aware of carrying out useless, symbolic gestures which embarrass us in their absurdity.

We could speak at much greater length on the behavior we have just studied. There would be a great deal of nuance to add, and numerous specific cases to examine. In any case, we believe we have touched on the essence of the structure and meaning of this behavior, an essence that we can summarize in the following terms. 
In its structure, identification in the home-movie attitude essentially consists of the actualization of an intuitive and synthetic knowledge of the object under consideration, an actualization which is realized thanks to the perception on the screen of behavior that is objectively individual but generalized by the spectator. In its meaning, this type of identification consists of a vain effort to evoke a presence that remains irremediably out of our grasp.

\section{b) Identification in the 'Documentary Attitude'}

In the documentary attitude there is, as we clarified in the preceding chapters, a positing of existence, a generalization of the matter of the image, a constituting activity and a fixing of the attention on the image as a starting point for the sketching of a general knowledge. In the end, the essential function of movement is to permit the formation of a progressive, cumulative knowledge in the object presented by the film. In this sense, the activity of consciousness consists, above all, of a retention and a generalization of the perceived object.

Within this attitude, how is identificatory behavior structured, and what is its meaning?

Let us first of all note that here the quality of identificatory behavior depends to a large extent on the interest felt by the spectator for the subject of the documentary. This remark is, incidentally, very general, and applies just as much to identification in the home-movie attitude as it does to identification in the fiction film. However, it is appropriate to formulate it in specific relation to the documentary film, since, in this case more than in the other two cases, our attention risks being distracted. This is because the documentary aims to procure a certain knowledge about a certain object, and if this object does not interest us, we will experience the film in a very distracted manner instead of following it attentively.

But since our project is to explain certain characteristic attitudes and forms of behavior, we envisage the case wherein the spectator is interested and follows the film attentively.

In order to orient our analysis, we will once again refer to a concrete example. Take one of the numerous documentaries about medicine. For example, take a documentary whose goal is to teach the spectator about the lifestyle of country doctors, and the difficulties they face. The film shows one of these medical practitioners in some of his most representative activities: talking with patients, taking their pulse, difficulties in moving around, emergency cases, etc. 
If I am interested, I will apply myself to the task of grasping the sense of this doctor's behavior by identifying with him. But here, as with that form of identification that develops within the home-movie attitude, his behavior is not apprehended on a strictly individual level. We know, in fact, that, in the documentary attitude, the perceived object is generalized, in the sense that it refers to a more general reality existing elsewhere. Thus, the particular manner that our country doctor has of conducting himself with a patient at a given moment in the film, presented as a general style of his comportment with his patients, proper to the real-life doctor and, through him, to country doctors in general. Consequently, what we try to apprehend through the individual behavior with which we identify is a general style of comportment, such as can be observed in numerous country doctors. We can see the difference with fiction. In a fiction film, the comportment of a doctor does not refer to anything existing. It would have no meaning with respect to existing general reality. Its only meaning relates to the story told by the film, an individual story made up of individual forms of behavior interacting with one another. This comportment would then be apprehended in its singularity.

Within the documentary attitude, identification therefore has a generalizing nature. It involves apprehending, on the basis of particular behavioral acts, typical or general modes of comportment.

But if this behavior is generalizing, it is not generalizing in the same manner as that which is developed in the home-movie attitude. In this case, there is a whole knowledge that incorporates the postural attitude of reproduction, a knowledge which is naturally intuitive and formed in the course of earlier perceptual acts.

Here, by contrast, knowledge is contemporaneous with viewing the film, and is formed precisely during the film screening.

Briefly put, in the documentary attitude, identification teaches. This is its precise meaning and function. It targets the formation of an intuitive knowledge about an existing and general reality considered through the intermediary of the image. The postural attitude is here one of 'comprehension.' It is, therefore, radically different from the behavior of evocation specific to the home-movie attitude, and also different, in many aspects, from the behavior of 'participation' that we will have the opportunity to study with respect to the fiction film.

Identification in the documentary attitude thus constitutes a kind of apprenticeship. We grasp and understand a certain number of typical behavioral forms with the explicit or implicit goal of knowing the 'how' and the 'why' of these representative modes of behavior belonging to a certain category of comportment. 
The individuals represented on the screen thus have little value as individuals, unless of course they are 'personalized' as in certain documentaries that have fictionalized elements or that relate to a specific person (such as Nanook). But, as a general rule, the individuals of the documentary film are anonymous beings who are seen as representing broader categories of individuals. Thus, in our example, the country doctor is not taken as a singular person but as one doctor among many, chosen from the group of country doctors as a representative sample of this group. It is therefore an anonymous being whose anonymous behavior we grasp, and who we relate to a set of individuals.

That is to say that, in this case, identificatory behavior does not imply any 'ego transference.' The 'ego' of the spectator and the film character remain in a relation of pure exteriority. In other words, we identify with the character to understand their behavior, but in no way do we try to be this character, who has no, or almost no, 'personality' for us. We remain ourselves in the process of grasping the modes of comportment illustrated by one or more anonymous, merely representative individuals. There is nothing similar, in this type of identification, to that by which we try to substitute ourselves for the other person, to become united with the other person, because it is another character, a hero, whom we have strongly 'valorized.' We will encounter this type of identification when we have to envisage a certain genre of fiction filmmaking.

Here it is only a question of apprehending impersonal behavior merely illustrated by an anonymous individual.

This is why we said that the spectator and the character remain in a relation of pure exteriority.

We have the structure and the meaning of identification in the documentary attitude. We also know that this identification does not imply an engagement of personal 'ego' in the character of the film. But above all, we know that, in the case that occupies us, it is a form of apprenticeship. We must now ask ourselves about the particularities of this form of apprenticeship, taking into account the non-presence of the object. In other words, what differentiates the formation of knowledge in a filmic situation from the formation of knowledge in real situations? Here, we can only give a tentative response to this rather marginal question, but it may nonetheless be suitable to address it, given the importance that it can take in the framework of the problems that audiovisual pedagogy poses to us.

Two elements retain our attention.

Firstly, let us note that, in a real situation, in contrast to what takes place in the filmic situation, our presence alongside the people with whom we identify implies a certain reciprocity in relations. 
We are always situated in a relationship with other people, and, at the same time that there is our view on another person, there is also the view of another person on us. Our presence alongside the other person is felt, and hones our attention as well as that of the other person. In short, we are in the midst of a real situation, and are concerned by other objects and people.

In a filmic situation, there is nothing of the sort. We apprehend reality 'from a distance' and our presence is absolutely not under question. It follows that we can develop a purer behavior of comprehension, because it is extracted and centered exclusively on the object.

On the other hand, however, we must also consider that, since we are not in a concrete, real situation - or rather, since we are not physically engaged in this situation, and since we are therefore not physically concerned by it, the reality considered through the intervention of the image does not have the density for us that its actual presence would, with all that this implies (particularly on the level of affectivity). We all know through experience that following dramatic events on the screen makes less of an 'impression' on us than seeing them in reality. This is because, in the cinema, we see things and events 'from a distance,' without truly being concerned by them. The reality targeted remains distant, and becomes 'disaffectivized.'

Thus, in our example, we can well understand the difficulties faced by the country doctor, we can even see them, but in a manner abstracted from reality. Consequently, we imagine what they are more than we really feel them. By 'imagine' we do not mean an intellectual operation, by which we represent to ourselves what these difficulties are. Rather, since we are not in a real situation, we can only 'play' what we would feel more deeply if we were present at the events and directly concerned by them.

It follows that this modality of apprenticeship that is identification in the documentary attitude offers the advantage of a comprehension that is more 'objective,' because it is extracted from the situation. Moreover, it remains impotent to render in all their density the affective resonances that are engendered by real contact with these events.

\section{c) Identification in the 'Fiction Attitude'}

We here reach the most important point of our analysis, since it is quite evident that the behavior that will be under discussion is by far the most characteristic of the filmic fact.

Along with identification in the home-movie attitude and identification in the documentary attitude, we have studied the forms of comportment 
corresponding to cinematic functions that are, when it comes down to it, rather secondary, if not de jure, then at least de facto.

Through the importance of its on-screen representation, as well as through its consumption by the broader public, fiction evidently constitutes the principal sector of film production. This is why we will accord special attention to the behavior solicited by fiction films.

Let us briefly recall the essence of what we have said with respect to the attitude taken when faced with a fiction film.

We know that, in the fiction film, the filmic datum does not refer to anything that exists. The filmic world, we said, closes in on itself in order to constitute itself as an autonomous reality. It is a quasi-world populated by quasi-presences, which we believe in without positing its existence. Our attention focuses on the image in its individuality. Correlatively, the activity of consciousness almost exclusively consists of acts of retention and protention, whose goal is to integrate at every present moment the set of passing events, and to project, on the basis of these present moments, future events. Thus, as we have seen, there is no longer any possibility of a detachment or a distanciation from the filmic reality. Consciousness is led to follow the story and cannot be detached from it.

How is the apprehension of perceived behavior realized within this particular attitude?

In other words, what is the meaning and the function of identification with the characters of a fiction film?

We know that, here, the perceived behavior is almost entirely cut off from existing reality. It only has meaning inside the film, within the action in the course of being shown. Thus, for example, when we follow the behavior of the hero in a Western, we obviously do not seek to represent what heroes in general do. Their existence is not even presumed. Simply, we wish to follow a story concerning a certain number of characters who interest us to the extent that they are significant to the imaginary story we wish to follow.

It is thus above all a matter of understanding the behavior perceived, not for what it is conducive to teaching us (as is the case in the documentary) but because it has a meaning within the story being told. This is the first function of identification. It exerts itself on all the characters, but is almost exclusive when it comes to secondary characters or, more precisely, characters who remain little 'affectivized.'

Let us explain this. We know that, in the beginning, identification is affectively ambivalent but that it is then oriented either towards sympathy 
or towards antipathy. The same, by the way, goes for the valorization or devalorization of characters.

And yet, in the cinema, there are characters who are strongly 'affectivized' - generally, they are the main characters - and others who are barely 'affectivized' at all (who are generally secondary characters). We will later discuss the manner in which this 'affectivization' is structured. For the moment, we will limit ourselves to describing the meaning of this identificatory behavior according to whether it is attached to characters who are 'affectivized' to a greater or a lesser degree.

When it comes to less 'affectivized' characters, identification is, as we said, exclusively a behavior of 'comprehension.' The behavior of these characters is simply apprehended for its signification in the action taking place. This is the case, for example, in the behavior of the German sentinel when the prisoners try to escape. This comportment is grasped insofar as it has a meaning in the unfolding of events, but we in no way 'participate' in it. On the contrary, this type of comportment remains 'external' in the sense that it is situated with respect to a character who we follow more particularly.

Thus, when we are dealing with secondary characters affectivized to a lesser degree, identification simply grasps the individual behavior on the basis of its meaning in the context of the film, and the relationship of the spectator to these characters is a relationship of pure exteriority.

The same, obviously, does not apply when we are dealing with more strongly 'affectivized' characters. In this case, identificatory behavior takes on more of an allure of 'participation.' But it will be useful to distinguish several levels of participation.

To schematize somewhat, we can distinguish participation in the modality of 'being-with' from participation in the modality of 'being-like.' It is hardly possible to differentiate the objective filmic content susceptible to inducing one or the other of these modalities. The personality of the spectator remains the principal determinant of the type of participation. Nonetheless, without any presumption of reality, it seems to us that certain categories of film, such as so-called 'psychological' films, do more to solicit our participation in the mode of 'being-with,' whereas the heroic genre and so-called 'adventure' films appear to induce a greater degree of participation in the mode of 'being-like.' We will refer to concrete examples.

Thérèse Desqueyroux by George Franju (1962, adapted from a novel by François Mauriac) offers us a typical example of the psychological film. Thérèse Desqueyroux, the title character, does not have the typical qualities of the hero of an adventure film. She is a character the likes of whom we 
often meet in daily reality, someone who finds herself confronted with real psychological and moral problems, such as they occur in real life.

In the course of the film, a certain sympathy is formed for the character of Thérèse Desqueyroux, a sympathy which derives from an understanding of her behavior, and which in turn solicits this understanding even more. This sympathy for Thérèse Desqueyroux results in our participation in her problems, her state of mind, and her behavior. In other words, identification here takes the allure of participation. I am 'with' Thérèse Desqueyroux in the sense that I share her life and her psychological troubles. But what is important to underscore is that, while participating in her existence, I remain situated with respect to her. In other words, I do not engage my personal 'ego' in the character. Thérèse Desqueyroux remains before me, in a relationship of exteriority. I live in connivance with her, in a sort of sympathetic complicity, but I remain a center of reference. As such, the story of Thérèse Desqueyroux does not become my story, since I do not have a tendency to fuse with her, to be 'like her.'

Rather, I am in solidarity with her behavior and her state of mind. I am with her, while remaining myself. This is what we fittingly call participation in the mode of 'being-with.'

In films presenting a 'hero,' or, in a more general manner, characters who are highly idealized or magnified - the hero of a Western, James Bond, etc. - participation can sometimes take on an entirely different allure.

Think, for example, of certain Western heroes, super-men who triumph over all obstacles and succeed in all their endeavors, both on the level of action and on a romantic level. This type of character offers to the audience the spectacle of a comportment, or rather, a highly idealized manner of being.

Not only do these characters provoke our sympathy, but, more than this, they are valorized to a very high degree.

We should clarify that valorization should not be understood as proceeding from a moral judgment, but rather as flowing from an intuitive apprehension of privileged comportment on the level of relations with another person. We have here the affective valorization of a comportment that appears as an ideal form of behavior.

It follows that participation in such comportment is often much more than mere solidarity. This is because participation takes on the allure of an attempt to 'be like' the hero. Here, there is identification in the narrow sense of the term. In other words, there is an attempted fusion with the highly valorized character. The ego tends to establish with the personality of the hero a relation not of exteriority but of belonging. The center of reference is no longer the ego of the spectator but the personality of the hero, and 
participatory behavior consists of an effort to be this personality. This is, therefore, participation in the mode of 'being-like.'

But we must maintain that this genre of participation brings with it certain limits that it is important to specify if we wish to avoid wasting our breath by producing a caricature of reality. This attempt to incorporate the hero leads, in effect, to an extremely complex state in which the spectator has a tendency to become another person while nonetheless remaining himself.

Let us try to elucidate this ambiguity and begin by further clarifying the link established through participation.

We said above that participation in the mode of being-like tends to establish a relation of belonging. But what, precisely, does this relation consist of? Here, we must be wary of abuses of language, because certain expressions - which we ourselves have utilized - such as 'fusion with the character,' 'transference of the ego into the character' or even 'forgetting oneself to live inside the character,' expressions which are frequently used in the literature dedicated to cinema, are only a very imperfect reflection of reality, exaggerating it or deforming it due to the words used to describe it. It thus appears necessary, lest we lapse into committing certain errors, to nuance the global meaning that these expressions contain. The problem is thus to specify the exact nature of the relations between the self (the spectator) and the other person (the character) which are established through participation.

First of all, what do we mean when we speak of 'forgetting oneself' with respect to the spectator?

This question requires us to clarify what we mean by the 'self.' We know that subjectivity is not closed in on itself, but is a relationship with the world and other people, that it is constitutionally intersubjective.

We also know that, in such conditions, it is in and through intersubjective relations that the 'self' and the other person reciprocally constitute each other through the interplay of identification and opposition. But this means, among other things, that, what I am for myself is, at the same time, necessarily what I am for other people, that the 'for-me' is indissolubly linked with the 'for-another.' When it comes down to it, this means that, in the process by which I constitute myself as a personal ego, I must constantly take into account what I signify for other people, through 'appearance' or exteriority, as well as through my position within a sociocultural milieu, which confers on me a signification in the eyes of other people that I have not chosen but that I must accept, and either take responsibility for or overcome.

These remarks will allow us to better understand what is meant by 'forgetting oneself.' 
Although constituted interiority must also accommodate exteriority (or being-for-another) within itself, because they are indissolubly linked with one another, this does not prevent it from sometimes escaping itself, at least on the imaginary level, and taking refuge in another exteriority, another being-for-another.

It is in the imaginary realm, indeed, that we can, for a certain length of time, abstract ourselves from the concrete conditions of our existence, and free ourselves from this signification for the other which we must always assume in real life, and it is in the imaginary realm that we can consequently try to install in our interiority another being-for-another linked to another apparition and other conditions of existence. The expression 'forgetting oneself' means nothing other than the bracketing of one's social being. We are now in a position to further clarify this 'relation of belonging' which we evoked earlier, and which we admitted was specific to participatory identification. This relationship is established between the interiority of the spectator and the exteriority of the character, between the for-oneself of the spectator and the being-for-another of the character.

The attempt to be 'like another person' is, in the end, an attempt to let dwell in one's interiority another apparition, another signification for another person. Correlatively, what the spectator targets in participatory identification is not the other person as a being endowed with an interiority, but as an exteriority, a being incarnated in a certain body realizing certain possibilities within a certain historical and social milieu. In a word, it is a special manner of being-in-the-world-and-with-other-people that the spectator seeks to integrate. In this behavior, the essential function of mimicry (posture) is precisely to make the external behavior of the character dwell in the interiority of the spectator, thereby constituting a link of belonging between the being-for-another of the latter and the being-for-oneself of the former.

It may be useful to illustrate all this with a concrete example.

On the screen, the standard Western hero - we are referring here to classical Westerns with a simple structure, and not to certain films of the same genre which have ambitions that more evidently reside on the psychological or social level-imposes his law on the evildoers, his strong personality on his posse, and his seductive powers on the heroines. Each of his actions reflects a privileged mode of being, a kind of mythical style of existence, which is consequently enviable in many aspects. As such, if the character seduces me, the intersubjective relation that makes me coexist with him is structured in the direction of a belonging of his conditions of existence to my interiority. I try to appropriate to myself his behavior 
and his manner of being. By mimetically imitating him, I try to feel the exteriority of the hero in my own interiority. If he vanquishes an enemy, I act as if I have overcome the bad guy. It can even happen that I anticipate his behavior, reacting to events before he does or correcting his actions.

In short, I participate in a privileged manner of being-in-the-world by making it my own.

We can now see what distinguishes this mode of participation from that which we have defined as a "participation in the mode of being-with." In this latter category, we do not only aim for an exteriority. Through the exteriority, we try to feel the interiority of the character, even while we maintain a distance from it in order to comprehend it. Simply put, there is a co-existence with the other person, who remains other in terms of their personal consciousness. By contrast, with participation in the mode of being-like, there is no co-existence with another person, but an attempt to make another behavior exist for us. We should also note in passing that heroic characters, those who encourage participation in the mode of beinglike, do not impose themselves as individuals, that is, as personal beings possessing their own interiority, but rather as pure behavior or, if you like, as pure exteriority. They provide us with ideal schemas of comportment more than inviting us to consider them as personal consciousnesses. Think of Tarzan or Zorro, to take the simplest cases, or even James Bond or Matt Helm. On the other end of the spectrum, those characters who do more to solicit our complicity, connivance, or comprehension (participation in the mode of being-with) impose themselves as individuals, and invite us to enter deeper into the mysteries of their interiority, rather than live vicariously through their actions. These characters include Thérèse Desqueyroux, Cleo (from Cléo de 5 à 7 [Cléo from 5 to 7 , Agnès Varda, 1962]), the hero from Bicycle Thieves, or St. Vincent de Paul from Monsieur Vincent (Maurice Cloche, 1947).

All these considerations put us in a good position to elucidate the limited and ambiguous aspects of the relationship established by participation in the mode of 'being-like.'

If, as we believe, this participation is an adherence of the personal ego to the exteriority of another person, we can understand that the link thereby established cannot be totally realized.

If he finds himself favored by the filmic situation - a situation which is, we must clarify, advantageous for the bracketing of my own conditions of existence - it remains the case that the character under consideration is still before me.

An insurmountable distance remains between him and me. Fundamentally, for participation to take place, I must be able to transport myself 
into the filmic world. But I cannot do so, and so I remain condemned to mime from my seat the role that I try to occupy in the universe of the film. This means that, no matter how much I may realize the belonging of my interiority to the exteriority of another person, I can only make it act from afar. I must act 'as if' I were in the place of the characters, 'as if' I possessed their bodies and possibilities. And yet, this 'as if', imposed by the insurmountable distance between that behavior which remains inexorably before my own self, remains implicit for consciousness and renders the realization of the relationship impossible. This is because 'acting' at being like another person implies that, at the same time, I deny that I simply am this other person. In other words, this means that the 'participating' ego who can only 'pretend' remains implicitly conscious of its exteriority, since 'pretending' implies that we cannot forget but only feign to ignore our proper conditions of existence, and that feigning to ignore implicitly means recognizing.

Thus, escaping from the self is never total. It is only ever a game requiring a share of bad faith, an attempt to deceive oneself about one's own reality and make oneself believe something else.

In what we have called participation in the modality of 'being-with,' there is nothing of the sort, since this behavior is a form of co-existence - that is, the simple coming together of the self and the other person as different beings.

Hence, the difference between the two types of participation appears still more clearly, and this difference, we believe, deserves to be elucidated, since it indicates to us that the experience of the film is neither simple nor singular, that it moves, at times, in the direction of the understanding of the other person, and at other times in the direction of an escape into the other person, and that any psychological or sociological study of the function of film in the life of individuals and societies must necessarily take into account this diversification of experience.

\section{The Differentiation of Identification According to Different Characters}

Until now, we have spoken of filmic identification in general, without worrying too much about the manner in which it is differentiated according to the different characters of a film. And yet, we all know from experience that our identification with a character varies greatly depending on whether the character is central or secondary, strong or weak, moral or immoral, etc. How is this differentiation brought about? 
In other words, what is it that makes our relation to certain characters, in the course of a film, take on the allure of an intense participation, whereas for others, it is reduced to mere understanding?

We already partially responded to this question when we envisaged the problem of the different modalities of filmic identification, but it is doubtless apt now to return to this issue, by further systematizing the elements of an answer.

We have sometimes posed the problem of the structuring of identification according to different characters in terms of a choice, by the spectator, of a privileged individual who is identified with in an almost total manner. Subsequently, to justify this choice, it sufficed to appeal to one or another objective characteristic, discernible in the personality (or the character) and conducive to inviting the spectators to 'escape' or 'project' themselves into this character. Thus, we have invoked the physical beauty of the onscreen figure as an invitation to live for a time with the ideal appearance that we do not possess. Sometimes, too, we attributed the role of enabling intense participation to certain traits held in common by the actors and the spectators. If they find themselves faced with the physical or moral image that actors present to them, spectators have the opportunity to 'project' themselves into a cinematic 'alter ego.' Of course, the objective elements which, like physical beauty, arouse our escape into an ideal personality, or which, like the resemblance between the spectator and the actor, invite our participation through connivance or complicity, intervene, to a certain extent, in the choice that the spectators make.

On this matter, we should signal that, during a study aiming to clarify the impact on the audience of the film La Vie conjugale by André Cayatte (Anatomy of a Marriage, 1964), we were able to observe that certain spectators, having gone through problems similar to those encountered by the characters, took the side of one or the other of the characters, and stood up for them. Thus, everything leads us to believe that during the course of the film, these same spectators had 'projected' themselves, more than is normally the case, in what appeared to them as their own image.

We do not deny the importance of the objective elements which have here been in question, but, what seems erroneous to us, or in any case abusive, is the idea that we turn these elements into 'factors of identification,' that we establish a direct link between these elements and the choices of spectators.

First of all, this would considerably reduce the act of identification. As we have seen, it is not only a behavior of intense participation, but intervenes on every level of relational behavior. We therefore need to describe the 


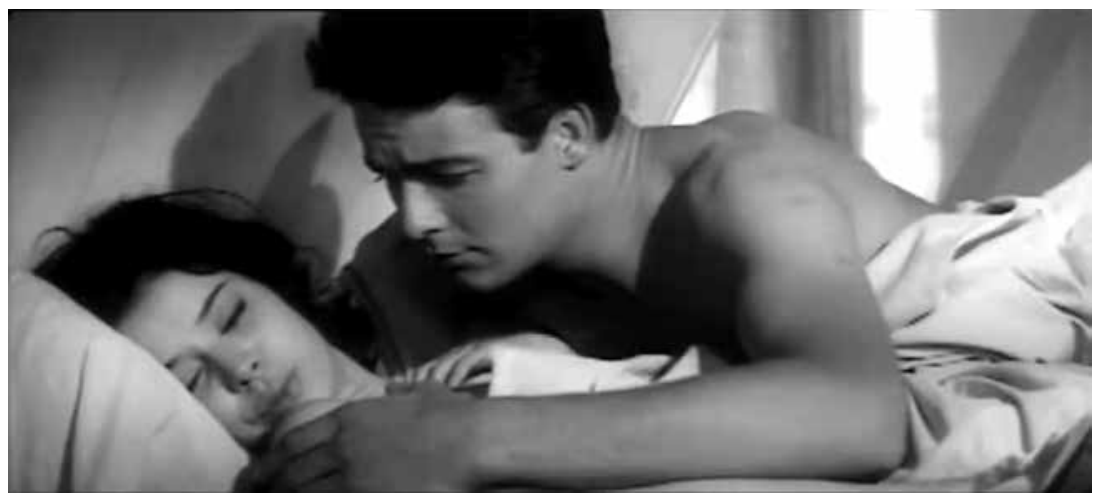

Fig. 6: Françoise (Marie-José Nat) and Jean-Marc (Jacques Charrier) in André Cayatte's Anatomy of a Marriage.

modalities of identification, more than defining privileged cases where it is realized to a high degree.

Subsequently, if there was a direct link, if physical perfection or resemblance automatically induces participation, it is hard to see why these elements do not function in an equal manner for characters who are apparently equal on the level of beauty, or on the level of possible similitudes with the spectators. For example, among the secondary characters gravitating around the main characters, there are often those whose physique or conduct might inspire the spectator. In the same manner, it is also hard to see why, in the hypothesis of a direct link between physical perfection and participation, certain stars do not exert the same hold from one film to the next. The cases are numerous wherein a star, who is generally adulated by the public in the majority of his films, loses, as a result of playing a new role in a situation that is unusual for him, his power of fascination. Thus, in Lost Command (Mark Robson, 1966), Maurice Ronet plays, alongside Alain Delon and Anthony Quinn, and in opposition to these two actors, a particularly antipathetic character, barely conducive to soliciting the participation of the spectator.

The manner in which we here discuss the attractive value of the 'objective' elements under consideration, can appear a little simplistic, but nonetheless shows that it is vain to try to establish direct links between participation and a visible trait of the characters independent of the context in which they are perceived. If the traits of the characters have any influence on identification, this cannot be in the absolute, but in relation to a certain context. This is why we find it illegitimate to pose the problem of the differentiation of identification in terms of the choices motivated by certain characteristics of the characters envisaged as isolated beings. 
In reality, if we attentively examine the film experience, we will see that the characters of a film are always perceived in relation to one another. They are characters-in-relation-to-other-characters. As we expressed at the beginning of this work, we do not perceive isolated subjectivities, but social beings perpetually in relation to one another and drawing their very definition from these relations. Likewise, characters perceived in the cinema are perceived as relational nodal points. They define themselves with respect to other characters and the objective elements (or rather 'objectifiable' elements) which characterize them, only have meaning in the social context specific to the film.

In fact, one of the reasons why we have sometimes sought the direct causes of intense participation in the objective traits of characters was very probably the constancy with which certain actors garnered the admiration of spectators. It was consequently tempting to attribute only to the elements that are apparently invariant from one film to another - the physique and the temperament taken by themselves - the direct reasons for the constancy of the fascination they exert on the crowd. But, when looking more closely, we can see that, what principally remains invariant, from one film to another, is the character played by these actors, a character who is always ratified by the social context of each of their films. Thus, in almost all films, Jean Gabin presents the image of a strong, slightly gruff personality, admitted as such and confirmed by his entourage.

Likewise, Brigitte Bardot, who has never ceased, since the beginning of her career, to play beautiful, erotic, and amoral young women, has always found herself in filmic situations from which she has drawn this signification of amoral and erotic beauty.

We can also say that her physique and temperament predispose her to this signification, but this is possibly because she plays the same role in life as she does on the screen, or, in other words, that, taking into account her innate physical attributes, the human relations of her real existence have been structured in a certain manner, and that it is this manner that has been reproduced on the screen in situations that confirm it.

In any case, we are still dealing with roles and situations, and with characters drawing a certain signification from a certain context, and not isolated personalities drawing from themselves, like a secretion, a certain power of attraction or repulsion.

Moreover, in contrast to actors restricted to a single persona, there are many others whose various appearances on the screen are so many compositions of characters having little or no relationship between them, and they acquire from this fact very different significations. 
In short, as we have said, film characters are always characters-in-relationto-other-characters who receive their signification from the social situations in which they are involved. It seems that it is on this basis that we must envisage the problem of the differentiation of identification according to different characters.

We must consider that, at the beginning of the film, all characters are simply apprehended by the spectator in roughly the same manner. We grasp this behavior and understand its meaning, but nothing is as yet well structured, since the relations between characters are still too imprecise. If, at this point, certain characters already appear as more sympathetic than others, we are still only dealing with a barely sketched out sentiment. This sentiment is doubtless predicated on a style of behavior that makes us presume an appearance that has either been glimpsed or, in the case of a well-known actor, valorized in other films, and that we are prepared to once again find a familiar role for them. But, up to this point, differentiation has only just been initiated. It is only later, in the course of the film, that identification is structured and differentiated into an intense participation, in the case of certain characters, or a simple comprehension, in the case of others.

The fact is that, during the unfolding of a film, that is, as the interactions between characters are intensified and specified, each one of them reveals their signification within the pattern that the ensemble of these characters constitutes.

Let us clarify things a little. As we have underscored, the spectator does not perceive isolated characters, but beings in relation with one another, characters-for-other-characters, or, alternatively, the manners that these different characters have of structuring their relations with other people.

In the course of the action they undertake, these manners of comportment are specified, and each one of them takes on a signification in relation to the others.

As this apprehension of significations is realized, the intersubjective relations between the spectator and the character are modified and concomitantly diversified.

In fact, the affectivity which, as we have seen, plays an essential role in identificatory behavior, invests the characters in a very different manner according to the significations that they reveal. Certain behavioral styles appear sympathetic, while others are apprehended as indifferent or antipathetic. Certain of them are valorized, while others are devalorized.

And yet, this affectivization and valorization of the characters will orient the form and intensity of identifications. We espouse the cause of 
sympathetic, valorized characters. Identification is crystallized around them, it is intensified and takes the allure of participation. As for the other characters, they are soon only apprehended through the main characters, to which we adhere almost exclusively. We grasp their behavior as having a meaning with respect to the chosen characters, and we often feel for them the same sentiments as those that they inspire in these same chosen characters.

At the risk of gross schematizing, we could summarize the complex process that we have just described in three successive phases, which can be delineated as follows:

1. Understanding of different characters.

Here, identificatory behavior merely grasps the meaning of on-screen behavior. Following this comprehension, each character takes on a certain signification with respect to the others.

2. Affectivization and valorization of the characters.

Certain modes of behavior are affectivized in the direction of sympathy and others in the direction of antipathy and indifference. Likewise, the same behavior is valorized or devalorized and remains indifferent on the level of its value.

3. Identification fixates on the sympathetic, valorized characters. It becomes participation.

The other characters are now only grasped through the main characters.

Let us try to illustrate this process by means of a concrete example chosen from a genre that is rather simple as far as the signification of characters is concerned: the Western. High Noon by Fred Zinnemann (1952), a Western that has become a classic, tells us the story of an aging sheriff at the end of his career, who finds himself suddenly constrained to carry out an imperative but dangerous task.

The drama begins at 10 o'clock in the morning. Will Kane, the sheriff, has just married, and is ready to once and for all leave the town in which he has conscientiously carried out his duties for many years. However, at this very moment, Kane learns that the train from the south will bring a dangerous outlaw (Frank Miller) to the township, whom Kane had earlier condemned to death. Already, three accomplices wait for Miller at the station. Up to this moment, and although the ensemble of characters has already begun to organize itself around Kane, the spectators limit themselves to understanding the situation and grasping the meaning of behavior specific to the different characters, who still have barely any signification on the affective level. 
But the rest of the action will increasingly orient our attention and affectivity on Kane: the sheriff, in the absence of a successor who will only assume his functions the following day, vainly tries to rustle up a posse of men to welcome the four 'desperados.' One by one, and for various reasons, his friends desert him. Even his wife abandons him. Everything is against him, and he will have to fight alone.

We can see how the identificatory behavior of the spectator is differentiated. Through the situation and the interaction between the characters, Kane's behavior is bestowed with a signification that induces affectivization and valorization, which results in identification being transformed into participation. On an affective level, we take his side, stand up for him. Our state of mind coincides with his own, and we 'experience' his behavior.

As for the other characters, they are primarily apprehended through Kane. Many of them (the townsfolk) are felt to be mediocre or cowardly, and Miller is seen as a mortal danger. Of course, even for these other characters, identification can move in the direction of a deeper comprehension. Kane's wife, for example, can certainly be the object of identification-comprehension. For proof, take this extract from a newspaper review, which can only be the result of enhanced identification:

Kane's wife. Her character is like that of the pastor. She belongs to the Quaker religion which forbids violence of any kind. She pushes her religious convictions to the extreme and coldly imagines leaving her husband, resorting to threats in order to put pressure on him. We should adopt a very nuanced judgement in the analysis of her behavior if we take into account, on the one hand, the depth of her religious convictions, and on the other hand the obligation she has, owing to her marriage, to understand and admit the point of view of her husband, who values doing one's duties.

We should also underscore that she was not born a Quaker, but had embraced the pacifist religion following a murder in her family, committed right before her eyes. This atrocious vision provoked a psychological shock in her. She sees nothing strange in the fact that a new shock (seeing her husband on the verge of being killed) should provoke a profound, instantaneous change in her feelings, and lead her to use violence in her turn in order to defend the man she never stopped loving...

Evidently, this type of analysis can only come from identificatory behavior which is based on comprehension, and which has been developed during 
a viewing of the film. But it is still the case that, for the vast majority of spectators, Kane's wife remains a 'peripheral' character understood through her relationship with Kane, the central character who not only solicits our understanding but also our participation.

Let us note that this participation will attain its culmination when Kane heads off in search of his enemies in order to do battle with them, a battle which he miraculously wins despite being greatly outnumbered.

We can now see more clearly how identification is structurally and functionally differentiated according to the various significations with which the different characters are endowed within the situation in which they are inserted.

We can also see the precise importance that we must attribute to the objective, isolable elements in the physical and moral personality of the actor. It is only in a situation or a social context in which physical beauty is valorizable that this beauty can intensify identification or orient it towards participation.

In the same manner, a possible resemblance between actor and spectator only acquires importance in and through its context. If we are dealing with a moral resemblance - that is, a resemblance that is translated through a similarity in comportment - this is evident. If we are dealing with a purely physical resemblance, everything depends, in our opinion, on the signification that the character in question takes in the context of the film. If the character is favorably situated, that is, if they are valorizable and conducive to inspiring sympathy, there is every reason to believe that this element of resemblance will orient our identification towards more intensity or participation. If, on the contrary, this same character is disadvantageously situated, it is rather certain that the element of resemblance will not in any fashion influence identificatory behavior.

In a word, the primordial element on the basis of which we must understand the type of identification that a character solicits is the signification that this character draws from their position in relation to the other characters.

Now, to avoid any confusion, it is essential to note that the process by which each of the characters draws their signification from the context is not something objective that would be uniquely situated within the film, and to which the spectator is simply subjected. In fact, in the final analysis, it is the spectator who attributes significations, and who projects these significations onto the different characters in order to subsequently affectivize them and valorize them in one sense or another. But what we have simply wanted to show is that this bestowal of signification is realized not 
through a direct effect of some kind of characteristic objectively readable in the personality of the actor or, more generally, the character taken in isolation, but rather through the apprehension by the spectator of a series of interactions between the characters, interactions that permit him to situate the characters with respect to one another and thus to attribute significations to them.

To put it differently, it is the spectator who, entering into intersubjectivity with each of the characters during the initial emergence of identification, and thus perceiving in each of them a certain mode of comporting themselves in relation to other people, or a mode of being for the other characters, will give a certain signification to this manner of being for other people.

This last remark elicits another question that will make us pose the problem of an objective approach to audience reactions. If it is true that it is definitively the spectator who is alone responsible for the significations accorded to the characters, do we not fall into a pure subjectivism, and are the reactions of the spectators not too individual, and thus too diverse, for the possibility of synthesizing them ever to be glimpsed?

We do not think so, since subjectivism does not necessarily signify a heterogeneity of perceptions and a dispersion of behavioral forms.

In fact, if the perception, identification, and attribution of significations essentially belongs to the subjective activity of the spectator, we must say that this subjective activity is largely guided by the author of the film.

In other terms, it is the director who solicits, to a large degree, the manner in which spectators structure their behavior.

When he makes a film, a director incarnates in behavior significations that he wants the spectators to recognize. He structures the relations between characters in such a way that each one of them is grasped by the spectators. He composes each behavioral act in such a way that it is perceived and felt by the spectators, just as he desires it to be. What is more, he disposes of numerous technical procedures conducive to highlighting the significations that he translates to the level of comportment (the scale of shots, rhythm, the soundtrack, etc.), so much so that, at the end of the day, he is the one who solicits and orients the manner in which the spectators must apprehend the characters and structure their behavior. Moreover, we should also remark that this solicitation of the author is exerted not through a critical consciousness, but, as we have seen earlier, through a 'captivated' consciousness, led to coincide with the filmic reality and thus without any distance from it.

It follows that the solicitation of the author takes the allure of a real shaping of the spectator's behavior and manner of perceiving. The psychological 
conditions of filmic perception are such that, in the course of viewing the film, a narrow relationship is established between the subjectivity of the director and the subjectivity of the spectator, with the latter being led to find the significations incarnated by the former, by means of the filmic content.

This is why subjectivism does not signify a dispersion of reactions. On the contrary, we now understand that, between the spectators of one and the same film, there exists a community of comportment and, extending our reasoning further, we can ask whether this behavioral community reinforces each individual's behavior through what they have in common. Indeed, everyone knows that the reactions of the isolated spectator seem rather different, and in any case timider, with respect to those of the spectator within a group, and it is easy to understand this. In the midst of other spectators whose reactions are perceptibly similar, every individual is confirmed in their own reactions, and gives free rein to them. Thus, within the group of spectators, there is a mutual reinforcement of reactions through what they have in common. We can say that, in addition to the intersubjective link tying each spectator to the author, and thanks to this link, there forms among the spectators in a single theater an anonymous intersubjective link, drawn from a contagion of reactions, and through which each individual has a vague feeling of solidarity with the crowd.

It is now important to note that the solicitation of the author can be exerted to different degrees. While particularly powerful in the majority of action films, it is often less spellbinding when it comes to films inspired directly by daily reality, 'psychological' films, or social-issues films.

Action films (the Western, the cloak-and-dagger film, the spy film, the adventure film, etc.) often only recount a story involving characters with a simple and clearly differentiated psychology (there are 'good guys' and 'bad guys,' brave men and cowards, etc.). Such films generally arouse in the spectator simple reactions, which are exactly those anticipated by the author, all the more so given that these films address a well-disposed audience, who only wish to be distracted by the antics of purely fictional heroes. But for other films, those in which characters with more complex psychologies bring with them a measure of ambiguity, it is obvious that the relationship between the spectator and the character, although it is broadly oriented by the author, is also nuanced according to the personality and the history of each party. We can think, for example, of the characters in films such as Hiroshima mon amour by Alain Resnais (1959), Jules et Jim by François Truffaut (1962), Thérèse Desqueyroux by Georges Franju, 81/2 by Federico Fellini (1963), Moderato Cantabile by Peter Brook (1960), and many others. The equivocal nature of these characters, with their complicated 
psychology rich in contradictions, leaves greater room for the initiative of the spectator, above all when the ambiguity is willfully maintained by the author (e.g. Anatomy of a Marriage by Cayatte).

In the end, we can see that the behavior of the spectator is organized in a very complex manner. We could now begin an analysis of the way in which, within a single subjectivity, the personal urges and the solicitations of the director are articulated. This analysis would doubtless require an elaboration that would be too long to be included in the present study.

Our project was to describe the broad outlines of spectatorial behavior, and to thereby furnish a useful canvas for a global comprehension of phenomena.

This said, we believe it is useful, as much to clarify our ideas as to form a conclusion, for us to briefly summarize the ideas developed in this chapter.

Identificatory behavior is structured in different ways according to the different characters of a film, and this is a function of the different significations that the spectator attributes to these characters. The attribution of signification is a subjective matter, but it finds itself broadly solicited by the author. Finally, this solicitation of the author can exert itself to varying degrees, depending on the type of film or, more generally, the will of the director.

\section{Chapter III: Towards Post-Filmic Behavior}

After studying the structures of the film experience, we would like to hazard a few hypotheses relating to the influence of filmic identification.

Here, of course, we can only summarily paint the broad brushstrokes of a tableau showing the principal repercussions of a film on the mental life and personality of the spectator. To put it simply, as much to manifest the possible utility of the preceding discussion as to initiate further study of the problem, we would like to open up certain perspectives to the analysis of the influence of the cinema. More precisely, based on what we have said of the film experience, we will try to explain the manner in which this experience can be prolonged in psychic life and, on this basis, formulate hypotheses about what it would be fitting to call post-filmic behavior.

We have seen that, in the case of fiction films, identification can take, at least when it is focused on the central characters, two rather different forms: participation in the mode of 'being-like' and participation in the mode of 'being-with.' 
We can take this observation as a starting point and formulate the hypothesis, which is a certitude for us, that the film will produce different effects according to whether one or the other of these modalities is realized.

Let us first envisage the case wherein the film has solicited participation in the mode of 'being-with.'

Let us recall that this modality of identification is not presented as a form of escape into the other person, but as a complicity, a connivance with the other person. In this specific case, the self and the other remain in a relationship of exteriority, in the sense that the spectator participates in the other person while still remaining the same self, and that they 'experience' the other person as different to their own self.

We could also say that the spectator takes possession of the other person in order to assimilate them, to live inside them even while their self remains the center of reference. What would remain of this participation?

It goes without saying that if the effects of this behavior are prolonged, then this will take place on the same level as participation itself, that is to say, on the level of the being-with-other-people, or, more generally, the comprehension of other people as others.

Can we see how?

If we interrogate the spectators upon exiting a movie theater, we can observe that, in general, they are incapable of saying much of any interest about the films and the characters they have just been following. At the very most, they can express a few vague impressions or sentiments, but they cannot clearly explain the film experience through which they have just lived.

We could thus say that, with respect to the characters and, on this basis, the film, they possess an intuitive knowledge, and this can be understood if we recall the specific nature of identification.

In its participatory form, as in all its other forms, identification is in fact motoric and mimetic in nature.

And yet, mimicry, we can recall, consists of a postural or psycho-muscular attitude that aims to reproduce the behavior of the other person in order to understand it.

What the spectator possesses at the end of the film is, therefore, not a conceptual knowledge situated on the level of rational thought, but a knowledge that is somehow 'bodily' in nature. In figurative terms, we can say that the spectator remains impregnated by the other person - possessing, that is, in the form of motoric or bodily traces, the behavior of the other person. 
If we add to this the fact that this behavior is now presented to the spectator as a complete whole, then we have the essence of the intuitive knowledge we spoke about earlier: a bodily knowledge relating to the global behavior of the other person understood as another person. Of course, we are here leaving to one side the possibility of a conceptual knowledge resulting from a possible reflection that takes place while the film is being screened. It is not very often that this type of reflection is realized and it is not, in any case, the habitual function of the film to induce it.

It now remains for us to examine how this intuitive knowledge will be resolved. In our opinion, it can follow two different evolutionary paths (not counting intermediary cases). In the first case, it can remain in a vague, intuitive state. In this case, although it is not reproduced at the level of conceptual thought, this knowledge can constitute an enrichment in the general framework of our real relations with other people. It can always re-emerge and serve as a point of reference in the understanding and appreciation of the other person. This intuitive knowledge, therefore, would be in addition to the traces left by the multiple identifications (in real or cinematic situations) taking place in the existence of subjectivity in order to constitute the complex interplay of intuitive references. Seeing the exact role and the relative importance of filmic references is, we believe, a fundamental problem of interest for reflection and research. This intuitive knowledge stemming from filmic identification can equally be the object of a more or less elaborated explanation. This happens when the spectator, for one reason or another, is led to conceptualize (that is, explain using verbal categories) the identificatory experience of another person.

The manner in which this conceptualization is realized posits numerous problems that are difficult to resolve.

How can a global knowledge of an intuitive nature flow into concepts? What is the role of the imagination and its power to refer to the scenes of the film in this passage from the intuitive to the verbal? What are the relations between the mimetic traces and the imagination within the process that leads to conceptualization? And what is the role of intelligence?

The solution to these problems would necessitate long analyses that are impossible to realize in the framework of this study.

Nonetheless, as nothing more than a pure suggestion, we can propose this: there is, initially, an intention to conceptualize, to translate into words the behavior about which we possess all the necessary data, but in an intuitive and thus globally undifferentiated state.

This intention produces an activity of conceptualization. In order to understand this activity, it is essential to note that the concept only ever 
teaches us about one aspect of the comportment to be explained. If we say, for example, that a given character is 'courageous' we only find one aspect of the behavior of the character in question, and we discard the rest of his personality. Moreover, the term 'courageous' is still very general and very vague. We would need other concepts to specify what type of courage we are dealing with. And others would be needed to explain other behavioral aspects. The conceptualization of behavior is thus progressively achieved by reviewing its different aspects, that is to say, by taking a wide range of perspectives on it - right until, if this is even possible, the globally intuitive knowledge we possessed in the beginning is exhausted.

We now have a better understanding of how the activity of conceptualization should be realized: it must proceed by stages, and successively envisage different levels of judgment (the moral level, the psychological level, the social level, etc.). That is, it must take different points of view towards the intuitive knowledge that it possesses.

But, having chosen the level on which they will pass judgment, the spectator must also be able to relate, in their imagination, to the behavior of the most significant characters, with respect to the point of view they have chosen, and they must relate this behavior to all kinds of other behavior which they have experienced, and which they will use as reference points, since, in fact, behavior only has meaning in relation to the behavior of others, to which it is opposed or with which it is identified. The meaning derived from these relations will then be explained with the use of a concept.

If we add to this the fact that speech is not a pure translation of what it signifies, but that it has a constitutive character, then we have an idea of the complexity of the problems that the conceptualization or, if you like, the accession to the explicit meaning of intuitive knowledge has. These problems - which, it must be said, we have only been able to briefly skim through from a distance - belong to general psychology rather than film psychology. If we have devoted a few words to general psychology, it is because we think that certain more specifically filmic questions closely relate to it, and that possible research into these questions should take it into account. This is the case, for example, with the problem of the specific qualities - if there are any - of the conceptualization of a datum of cinematic origin. On this matter, there are those who have expressed the opinion that film was conducive to revitalizing the conceptual apparatus, and to giving birth to more flexible verbal categories. Without fully subscribing to this hypothesis, we think that it would still be useful for research to focus on this question. 
In any case, whether it leads to conceptualization or not, it is in the domain of comprehending other people, or more generally on the level of being-withother-people that participation in the mode of being-with can prolong its effects. In all instances, this participation constitutes an enrichment, an experiential surplus. Defining the exact role and the manifestations of this experiential surplus is, in our opinion, a research perspective that could be of great interest.

We must now consider those cases in which the film has solicited participation in the mode of 'being-like.' Let us first recall that this modality of participation consists of an attempted escape into the highly idealized personality of the character. Between the self and the other person, there is no longer a relationship of exteriority, connivance, or complicity, but one of belonging. The other person (the character) is presented as an ideal behavioral schema, and the ego installs itself into this ideal schema. In short, the ego tends to escape into a highly valorized behavioral mode.

What might be the extensions of this escapist behavior in psychic life?

Here, as is the case when participation is realized in the mode of 'being-with,' it seems evident that post-filmic behavior will have the same signification as participation itself. In other words, it is the attempt to be like the idealized other person that the spectator prolongs beyond the limits of the film. We must now look at the manner and degree of this behavior. Lessons learnt from lived experience on the one hand, and some conclusions drawn from simple observation on the other hand incline us to distinguish, rather schematically, three major modalities of post-filmic comportment corresponding to three levels of behavior: oneiric behavior, ludic behavior and imitative behavior.

Let us consider the case wherein post-filmic behavior is situated on the oneiric level. We know from experience that a major part of the life of the imagination consists of dreaming, wherein the dreamer identifies with an unrealized self whose very unreality allows for the accomplishment of ideal actions usually made impossible by the contingencies of real life.

In other words, the imagination is often the favored site for the behavior of escaping the self.

What, therefore, should be so astonishing about the fact that filmic identification prolongs its effects in the imagination? It is indeed normal that the spectator who, for more than an hour, has vicariously experienced an ideal comportment, contrives to reproduce it in their dreams or fantasies. This is all the more true given that escapist film characters have something unreal or mythical about them, in perfect accord with the world of daydreaming. It is also all the more true given that the dream offers the dreamer the possibility 
of experiencing idealized filmic comportment with their own physical traits. The dreamer, in fact, places their own self in their daydreams, but in an unreal form. We can thus say that the cinema constitutes an aliment for oneiric activity. It is also a powerful stimulant, since the identification that is repeated for the multiple heroes who populate the cinematic universe constitutes a powerful inducement to daydreaming.

Filmic behavior can thus be continued and completed in oneiric behavior. But this is not its only extension. Participation in the modality of being-like can sometimes engender more active forms of behavior, even if they are still bracketed off from reality. This is true for ludic forms of behavior, which are a compromise form between pure oneiric comportment and comportment in reality. Such behavior can be primarily observed in children. It is expressed in child play, and can be interpreted as an attempt to incarnate, to play in real life, that which has a purely imaginary character. Like dreamers, 'players' project themselves into an unreal, often idealized 'ego,' with the difference, however, that they realize their unreal 'ego' in manifest and apparently real comportment. In a word, they act 'as if' their 'dreamed ego' was a 'real ego.' To the same extent and in the same manner as the dream, the cinema constitutes a kind of aliment for ludic activity. We only need to consider the enthusiasm with which children contrive to reproduce in their games all kinds of situations illustrated by fiction films. Childhood games are replete with cowboys and Indians, cops and robbers, heroic soldiers, and numerous other characters born from the mythology created, at least in part, by fiction films.

As active and manifest as it may be, ludic behavior nonetheless remains without any great relationship with real life. Play rests on a convention, and the player who acts 'as if' they were a hero, even if they are fascinated by this character, never forgets that it is simply an enjoyable diversion. In other words, players never confuse themselves with the characters they play. Once the game is over, they come back to their own selves without any difficulty.

This amounts to saying that, as in oneiric behavior, ludic behavior in no way participates in reality. It is a pure escape from reality.

The same goes for the behavior of imitation, whose most perceptible manifestations can be observed in fashion styles. The 'Brigitte Bardot look' was often spoken about during the time when her popularity was such that, among the female public, many believed they could gain the same powers of seduction by donning the same long, unkempt hair as the star. Likewise, the myth of James Dean resulted in a wider uptake of wearing blue jeans. More recently, we have been able to note in men's clothing all kinds of details borrowed from James Bond. The examples of this kind are 
numerous. In fact, throughout the history of fiction filmmaking, there is practically nothing in fashion that has not felt the influence, in one way or another, of the major stars, who are both loved and envied by the public.

Fashions borrowed from film stars incontestably attest to the existence of imitative behavior, but they are only a socialized and, all in all, a rather superficial manifestation of this phenomenon.

If we question the meaning of imitative behavior on the purely individual level, we can propose this: imitation consists of behavior aiming to reproduce the idealized behavior of others, with the goal of appropriating the signification attached to this behavior. Thus defined, imitation is not fundamentally different from oneiric behavior and ludic behavior. In all cases, we still find the same desire to be like the idealized other. However, whereas dreams and play realize this desire in an imaginary manner, within the sectors of activity operative in real life, imitative behavior, for its part, attempts to realize it in reality.

In other words, imitation tends to realize the dreamed ego in the real ego. The dreamer or the player still kept in mind the distinction between the imaginary ego and the real ego. Or rather, their activity was based on this distinction. The imitator, by contrast, contrives to fuse the two.

The problem is thus to know whether this fusion is capable of being realized, whether it is structuring or destructuring.

This is not the place to treat this problem, which requires a discussion that would be too long for this study. Nonetheless, out of a concern for being even a little bit complete, we can, as a pure hypothesis, try to sketch out an answer.

If it is true, as we have maintained throughout this book, that man is a being who is relational right from the start, and that it is in and through intersubjective relations that the personal ego is constituted, if, in other words, we are nothing other than what we are for other people, then we can say that imitation can be structuring, insofar as the modifications of behavior that it engenders are conducive to being ratified by the gaze of the other. Conversely, it would be destructuring if the signification that the imitator tries to incarnate does violence to the signification constituted by other people.

In the latter case, imitation can doubtless have dangerous consequences for the mental equilibrium of the individual. In fact, it is constantly experienced as a vain endeavor unavoidably doomed to failure. Taking refuge in a character is a form of alienation that cannot be approved by other people. It can consequently result in aggression towards other people, or a detachment from reality, a withdrawal into the self and an escape into the 
imaginary. In short, it is divorced from real intersubjective relations. We can glimpse the consequences of this, but this is not the place to talk about them. In any case, if there is a place to elaborate a pathology of post-filmic behavior, it seems that we should look in this direction.

By relying on what we have been able to discern of the film experience, we have tried to highlight certain interesting perspectives for the study of post-filmic comportment.

In doing so, we have occasionally indicated certain problems that should, in our opinion, arouse the attention of the researcher. But we are also aware that the number of these problems undoubtedly exceeds what we have been able to discuss. The forms and consequences of these manifestations will doubtless be more clearly elucidated with the aid of multiple, painstaking observations.

Whatever the case may be, we think that it is on the basis of a reading or sufficiently elaborated description of the film experience as such that research in the field of cinema should formulate its hypotheses and construct its methods of observation. In the end, this is what we have wished to show in this last chapter. 


\section{General Conclusion}

When beginning this work, we announced that it would include a number of gaps and imperfections, and now that we are concluding this study, we can see how necessary this precaution was.

When making our way through the different parts of this book, we would doubtless have taken note of the fact that there are aspects of the problem that have escaped our attention, or that have not been given the space they warrant.

This is why, having come to the end of this study, we believe it is useful, and even necessary, to take another quick look at the path we have taken. This will permit us to measure the limits of our analysis, but also to become aware of the place that it occupies in the general framework of filmology.

We had proposed to reveal certain important aspects of the process of filmic identification, but it has appeared to us that, for this goal to be realized, our project must be based on a rather detailed description of the fundamental structures of the film experience. We have thus applied ourselves to the task of explaining this experience, and what we have been able to conclude from this can be summarized in the following terms: the film experience is a perceptual experience that underpins the imaginary attitude of consciousness.

This imaginary attitude is not univocal. We have seen that it can be differentiated by assuming several different possible forms, of which the three main ones seemed to us to be the 'home-movie attitude,' which considers its object to be known and existing elsewhere, the 'documentary attitude,' which considers its object as existing but not known, and finally the 'fiction attitude,' by means of which we let ourselves become fascinated by an object that we know does not exist.

Depending on which one of these three forms the imaginary attitude takes, the manner in which subjectivity is constituted in its own turn as an interpersonal relationship can also be differentiated. From this point derives the problem of identification, and the structure and particular meaning that it assumes when it is held up by the different forms of the imaginary attitude.

When it is realized within the home-movie attitude, identification is the actualization of an intuitive knowledge relating to the person under consideration, and can be interpreted as an attempted 'presentification,' or evocation of the person known elsewhere. 
When it is developed based on the documentary attitude, identification has a didactic effect. It is the behavior of understanding, aimed at the formation of knowledge relating to an existing and general reality illustrated on-screen by anonymous forms of behavior that are representative of a general type of behavior.

Finally, when it takes shape within the fiction attitude, identification often becomes a participation in the behavior of other people, a participation that can be realized according to two modalities, that of 'being-with' when the character is followed in the mode of solidarity or connivance, and that of 'being-like' when there is an attempted escape into this character.

In short, the imaginary attitude specific to the film experience differentiates itself in various different forms, and each one of these forms underpins a particular modality of identification. This is what we hope to be the principal lesson taken from this study.

Having said that, we must now more explicitly come to terms with the limits of this analysis. These limits are of two kinds. The first are of an internal nature and concern the imperfections and the incompleteness that we have been able to discern in our own descriptions. The others are of an external nature, and result directly from the fact that we have had to make a methodological choice. We will have to explain this choice later. In the meantime, let us try to shed a little light on what remains incomplete in our analysis.

Every theoretical exposition requires that we retain from reality only the most pertinent aspects, that we simplify them and exaggerate them. Owing to a concern for introducing clarity to the topic, this results in the neglect of details and the lack of nuance that was bound to have marked our study.

We have signaled these imperfections on several occasions. Broadly speaking, they can be boiled down to the following remark: while abstracting some well-characterized attitudes from the film experience, we have neglected, alongside the modifications capable of supervening within these attitudes, their possible interaction. Additionally, we have left to one side the detailed analysis of the relations between the attitudes and objective elements of the film or, if you will, the particulars of filmic language. Finally, while considering the film experience as an isolated experience, the aspects that we have been able to elucidate have not been envisaged in their integration within the general experience of the subject, an experience that is intellectual, perceptual, and affective, etc.

We have said all this over and over again. In fact, these limitations have been dictated to us by our intention to draw out only the most fundamental structures of the film experience. 
What we desire is that these overly clear and precise descriptions nonetheless contain enough truth to inspire the wish to complete them.

The external limits of our study essentially derive from the choice that we have made in terms of our methodology. In the vast spectrum of methods recommended by the various disciplines of the human sciences, we have resolutely opted for the one that has permitted us to read the meaning of these phenomena, such as they are immediately experienced. From the very start, we have tried to justify this choice. A reading of the lived meaning of the phenomena to be studied indeed appeared to be the natural starting point for filmology, just as it is for any of the other human sciences. We have thus provisionally put aside the more properly scientific methods in order to consider the film experience such as it is proffered to the subject in a filmic situation. We have tried to understand this experience 'from within' in order to describe and explain it.

Of course, filmological research should not remain at this point. By uncovering some aspects of the film experience, we have simply surveyed the terrain for other disciplines and other methodological approaches.

Hence, the conclusions that we have reached should serve to nourish thinking inspired by other methodological approaches (scientific psychology, sociology, linguistics, etc.).

All that remains, then, is to wish that this should take place, since, in that case, our modest reflection will not have been useless. It will have shown its fecundity and contributed to creating unity within the science of filmology.

\section{Notes}

1. Henri Piéron, Vocabulaire de la psychologie (Paris: Presses universitaires de France, 1957), p. 264.

2. Maurice Merleau-Ponty, Phénoménologie de la perception (Paris: Gallimard, 1945), p. I [Phenomenology of Perception, trans. Donald A. Landes (London: Routledge, 2012), p. lxx].

3. Ibid., p. III [p. lxxii].

4. Maurice Merleau-Ponty, Sens et non-sens (Paris: Nagel, 1948), pp. 86-87 [Sense and Non-Sense, trans. Hubert L. Dreyfus and Patricia Allen Dreyfus (Chicago: Northwestern University Press, 1964), pp. 48-49].

5. Ibid., pp. 92-93 [pp. 51-52].

6. Jean-Paul Sartre, Esquisse d'une théorie des émotions (Paris: Hermann, 1939) [Sketch for a Theory of the Emotions, trans. Philip Mairet (London: Routledge, 2002)].

7. Merleau-Ponty, Phénoménologie de la perception, p. 415 [p. 379]. 
8. Angelo Hesnard, Psychanalyse du lien interhumain (Paris: Presses universitaires de France, 1957), pp. 26-27.

9. $\quad$ Sigmund Freud, Essais de psychanalyse (Paris: Payot, 1963), pp. 129-130 ['Group Psychology and the Analysis of the Ego,' in Sigmund Freud, The Standard Edition of the Complete Psychological Works of Sigmund Freud, vol. XVIII (1920-1922), ed. James Strachey (London: Hogarth Press, 1955), pp. 106107. Translation modified.]

10. Hesnard, Psychanalyse du lien interhumain, p. 28.

11. Ibid., p. 29 .

12. Ibid., p. 39 .

13. Ibid., p. 42.

14. Ibid., p. 45 .

15. Ibid., p. 46.

16. Ibid., p. 100.

17. Merleau-Ponty, Sens et non-sens, p. 104 [p. 58].

18. Ibid., p. 98 [p. 55].

19. Ibid., p. 100 [p. 55].

20. François Ricci, "Le cinéma entre l'imagination et la réalité," Revue internationale de filmologie 2 (September-October 1947), pp. 101-105.

21. Jean-Jacques Rinieri, "L'impression de réalité au cinéma," in Étienne Souriau (ed.), L'Univers filmique (Paris: Flammarion, 1953), pp. 33-45.

22. Albert Michotte van den Berck, "Le caractère de réalité des projections cinématographiques," Revue internationale de Filmologie 3-4 (October 1948), pp. 249-261 ["The Nature of "Reality" in Cinematic Projections,"' in Vinzenz Hediger and Guido Kirsten (eds.), Filmology: Selected Writings from the Revue internationale de filmologie (Amsterdam: Amsterdam University Press, forthcoming)].

23. Ibid.

24. Jean-Paul Sartre, L'Imaginaire (Paris: Gallimard, 1940) [The Imaginary, trans. Jonathan Webber (London: Routledge, 2004)].

25. Ibid., p. 45 [p. 20].

26. Ibid., pp. 32-33 [pp. 13-14].

27. Ibid., p. 30 [pp. 12-13].

28. Ibid., p. 34 [p. 14].

29. Ibid., p. 25 [p. 10].

30. Ibid., p. 105 [p. 50].

31. Ibid., pp. 49-50 [pp. 21-22].

32. Ibid., p. 54 [p. 24].

33. Edmund Husserl, Idées directrices pour une phénoménologie, translated into French by Paul Ricoeur (Paris: Gallimard, 1950) [Ideas: General Introduction to Pure Phenomenology, trans. W.R. Boyce Gibson (London: Routledge, 2002), p. 283].

34. Translator's note: The original term used by Meunier, le film-souvenir, refers to films made for private purposes, with the goal of acting as a keepsake or 
record of an event in the individual's life, such as weddings, vacations, family gatherings, etc. The English term 'home movie' comes close to this meaning, and its usage as an equivalent term has been established by Vivian Sobchack. As Sobchack reminds us, however, the original term has a close relationship with the role of memory (le souvenir), which is absent in the term 'home movie,' and this should be kept in mind throughout Meunier's discussion of the home movie (le flm-souvenir), and its corresponding attitude, the 'home-movie attitude' (l'attitude-souvenir). See Vivian Sobchack, "Toward a Phenomenology of Non-Fictional Film Experience," in Michael Renov and Jane Gaines (eds.), Collecting Visible Evidence (Minneapolis: University of Minnesota Press, 1999), pp. 241-254.

35. Lonely Boy (1962) is a reportage on the singer Paul Anka, directed by Wolf Koenig and Roman Kroitor and produced by the National Film Office.

36. Sartre, L'Imaginaire, p. 316 [p. 163].

37. Ibid., p. 327 .

38. Henri Wallon, "Lacte perceptif et le cinéma," Revue internationale de filmologie no. 13 (April-June 1953), pp. 97-110 ["The Perceptual Act and Cinema," in Hediger and Kirsten (eds.), Filmology [forthcoming)].

39. Sartre, L'Imaginaire, p. 149-150 [p. 75]. 


\section{Part II}

\section{Critical Essays, \\ Historical Assessments, Phenomenological Expansions}




\section{I: Placing Meunier IN THE}

History OF FILM THEORY 


\title{
Stages of an Encounter with Filmic Identification
}

\author{
Dudley Andrew
}

\begin{abstract}
Meunier wrote his major work in 1969 as phenomenology slipped under the sway of structuralism. His next book followed Edgar Morin from a phenomenology of identification with images to an anthropology of mass culture. But in 1969, Meunier ignored Morin and other contemporary theorists. He relied instead on Sartre, Merleau-Ponty, and the filmologists. His three-stage approach to experience derives from Husserl and echoes Paul Ricoeur's hermeneutics. This kept him at a remove from French film studies, though he gained some notice in the USA, especially after the return of phenomenology in the late 1980s. This English translation lets us rethink issues that film theory has engaged with for a century, and that came to a head in 1969 .
\end{abstract}

Keywords: Filmology; phenomenology; structuralism; Edgar Morin; Paul Ricoeur; Jean-Pierre Meunier

I ran into Jean-Pierre Meunier through his book The Structures of the Film Experience in the autumn of 1973. It was at La Minotaure, the mythical bookstore at 2 rue des Beaux-Arts in Paris, where I loved to go as it was just across from where André Bazin and Chris Marker had worked for years after the war in the offices of Travail et Culture, a communist outreach organization where cinema played a leading role among all the arts. Like all genuine encounters, I engaged The Structures of the Film Experience in three stages. The first stage found me instantly disposed to the book, wanting to understand its possibilities. It was very different from the semiotic studies that were then so fashionable. I was in Christian Metz's seminar that year along with ten others. Among these was Geneviève Sellier who, when I mentioned this book, told me, "Ah phenomenology: Merleau-Ponty. This is

Hanich, J. and D. Fairfax (eds.), The Structures of the Film Experience by Jean-Pierre Meunier. Historical Assessments and Phenomenological Expansions, Amsterdam University Press, 2019 DOI 10.5117/9789462986565_ANDREW 
what my parents used to read." Evidently, I had picked up Meunier when his way of thinking was on the outs.

A few years later, stage two set in, when I pulled away for a more analytical view, carefully examining the book's elements and composition. In completing The Major Film Theories, I determined to add a final section on the remnants of phenomenology in which Meunier is mentioned. ${ }^{1}$ No one who reviewed that book cared to talk about this chapter; so, in 1977, I wrote an article entitled "The Neglected Tradition of Phenomenology in Film Theory," in which I located Meunier's approach, lamenting that it had been ignored, a casualty of the era of 'Grand Theory.' Even if the word 'structures' appeared in his title, Meunier was obviously closer to Merleau-Ponty and phenomenology than to Lévi-Strauss and structuralism. My encounter now enters stage three with the appearance of this English translation. Re-approaching the book, I now aim, in Paul Ricoeur's schema, to 'comprehend' it, that is, to apply it as a map to clarify, and perhaps to re-view and re-traverse, the overgrown field of film theory.

\section{Tripartite Structures in Phenomenology}

Phenomenology and hermeneutics operate via stages like this, generally in threes. Merleau-Ponty overcame impasses in Sartre's thought by adding a third term to Sartre's binary categories. Where Sartre cleaved experience into being and nothingness, presence and absence, language system and personal style, Merleau-Ponty interjected an intermediary term. For instance, perception involves three stages that ramp up virtually together thanks to our body's rapport with nature: sensation, then recognition, and finally interpretation. ${ }^{3}$ First come light and shadow, colors and movement, forms and blurs; then bodies, objects, backgrounds, and a scene come into view; finally, in stage three, interpretation resolves a perception by inserting it in a larger sphere of orientation or action.

Each perception, retained at the ready, sets the stage for a subsequent triad. Retention of the immediate past is part of the current moment of perception, which involves protention of what likely comes next; hence, each instance (or instant) of perception chains the past to the future. ${ }^{4}$ Thanks to protention, the imagination enters perception. Sartre notoriously divided mental states into either imagination or perception; in the latter, consciousness is absorbed in what is present, whereas imagination consists of immaterial states of remembering, wishing, dreaming, or the like. MerleauPonty, following Husserl more closely than did Sartre, assumes that past 
perceptions, colored by their affect - including the experiences they were part of and the reflexes they triggered - constitute predispositions for new, current perceptions, which project themselves toward future perceptions. Retention and protention make room for temporal slippage in the same way that, in Merleau-Ponty's Phenomenology of Perception (Phénoménologie de la perception), slippage between background and foreground makes space both continuous and dynamic.

Inheriting phenomenology's description of (three-stage) processes, rather than binary states of being, Paul Ricoeur fought the structuralism of Saussure and Lévi-Strauss. The title of his brilliant 1964 riposte, "Structure-WordEvent," inserts a term between system and contingency. ${ }^{5}$ In Saussure, the a-historical permanence of language's rules grounds an indefinite number of everyday speech events; whereas, in Ricoeur, speech events occur within history. A third term is required for the vital dimension of meaning in history. This third term, 'Word,' does not have the logical necessity of grammatical 'Structure' but is more permanent than any 'Event' of speech. Its etymology points to the historical birth of each word, while examples (including their dates, in the OED) attest to the accretion of its meanings over time. Words have histories and provoke habits of speech, since prior speech events are drawn upon by every speaker who projects language for a purpose into a future. This schema lines up with Merleau-Ponty's view of history: the sedimentation of successive interpretations of events upon which new events play themselves out. ${ }^{6}$ Words, institutions, and ideologies exist as accretions of sedimented meanings.

When Meunier wrote this book on filmic identification, he thought to break it down in the mode of Husserl, Merleau-Ponty, and Ricoeur, whom he does not mention but who, more than the others, conceived of experience in explicit stages. Meunier planned to approach identification as a three-step process: description, analysis, speculation. But the richest sources he draws on in his account of filmic perception turn out to be taken less from phenomenology than from the filmology of the 1940 s and early 1950s. The last sentence of his book prays that he has "contributed to creating unity within the science of filmology" (p. 154). The lure of scientific objectivity led him to structural descriptions seemingly at odds with 'process-oriented' phenomenology.

The Structures of the Film Experience could appear to be a prelude to the topic Metz would soon take up on the psychoanalysis of identification. As Martin Lefebvre has thoroughly documented, Metz's starting point is also filmology. ${ }^{7}$ His first essays, written prior to, though not cited in, Meunier's book, including the important "On the Impression of Reality in Cinema" "Sur l'impression de realité au cinéma"), revolve within the orbit of filmology. 
Though this postwar institute had been forced to leave Paris for Milan in 1959, something of its scent emanates from the journal Communications, volume one of which dates from $1960 .{ }^{8}$ Filmology was sedimented at the École pratique des hautes études in the 196os under the administrative umbrella of Edgar Morin (a founder of Communications), whose two most illustrious figures were Algirdas Greimas (Metz's director of studies) and Roland Barthes, author of The Fashion System (Systèmes de la mode), "An Introduction to the Structural Analysis of Narrative" ("Introduction à l'analyse structurale des récits"), and Elements of Semiology (Éléments de sémiologie).

By 1969, structuralism had indisputably prevailed in the battle for intellectual hegemony in the Francophone world (indeed post-structuralism was well underway). In Anglophone film studies things were more in flux. When Meunier's book first met the world, I was at the University of Iowa arguing structuralism in my seminars on literary theory with Gayatri Spivak, Angelo Bertocci, and Robert Scholes. Disciplined film studies matured in the US at this time in a handful of institutions: Iowa, Northwestern, Wisconsin, NYU, UCLA. Peter Wollen's Signs and Meaning in the Cinema arrived in 1969, affecting the way we discussed auteurs, and initiating debates about the status of the image as 'sign.' In Paris, 1969 was when Jean-Louis Comolli and Jean Narboni delivered their manifesto classifying films according to ideological valence. ${ }^{9}$ This overriding political-ideological dimension was understood by Cahiers du cinéma, which I followed, to operate via forms of filmic identification that exerted inescapable force via distinct processes like those of suture. Jean-Pierre Oudart's essays on this most treasured concept appeared in this crucial year. ${ }^{10}$

Structuralists approach texts from systems external to them (linguistic, anthropological, psychoanalytic, ideological), whereas phenomenology, ever since Husserl, starts its inquiries from the natural attitude by describing interior processes. Meunier's starting point is mixed; he appears to work like a social scientist aiming to clarify and map the inner life of cinema, the transactions of a text with the spectator's capacities to see and to imagine. Predecessors such as Henri Wallon, and Albert Michotte van den Berck, whom Meunier cites (pp. 101-102 and 71-76), and especially Edgar Morin (whom he does not cite) shared this double heritage.

\section{Meunier, Morin, and the Filmology Movement}

Evidently, Meunier soon recognized that his ideas were part of an ongoing debate, for, right at the outset of his second book, Essai sur l'image et la 
communication, he does cite Morin's The Cinema, or The Imaginary Man (Cinéma ou L'homme imaginaire, 1956), alongside Metz's essays on the impression of reality and on the phenomenology of narrative. He also recapitulates Mitry's objections to Cohen-Séat's filmological notion of identification. These references support the book's first longer section, which he tells us was written as his 1972 habilitation and closely resembles The Structures of the Film Experience. The shorter part two, devoted to the image in mass communication, brings up Morin's later writings alongside references to Baudrillard, Deleuze, Foucault, Clastres, and Debord, all of whom forecast a new image society. ${ }^{11}$

Meunier's mix of interests, evident in the second book, closely resembles Morin's. Both men move from the phenomenology of imagination to the social anthropology of images. The early Morin was specifically interested in the state of 'fascination' that a spectator enters when dealing with the magic of 'the double' on the screen. Often deploying the language of phenomenology, The Cinema, or The Imaginary Man is an anthropological study of humans haunted by their shadows. In the protected space of the movie theater, associational dream logic is unleashed by what Morin calls the spectator's "projection-identification loop," in which shadows thrown on a screen return to the spectator through his identification with their quasi-objectivity. Morin's more openly sociological study, The Stars (Les Stars, 1957), examines not the fictional worlds of films so much as the post-fictional behavior of fans who imitate stars.

Meunier takes up both these directions of inquiry, concluding the first part of his second book with a chapter titled "Participation et Identification" that explicitly addresses the notion of fascination, and then embarking on part two, "Communications et Sociéte." Even in The Structures of the Filmic Experience, this dual approach is present in the idea of imitative behavior, though Morin's name is absent. Both men are rooted in filmology. Morin published in their flagship journal, Revue internationale de filmologie, and, like Meunier, he cites Michotte van den Berck. He would adopt much of filmology's mission in Communication, a journal that would become an abundant source for cine-structuralism in the UK and the US, where journals like Screen, Diacritics, and New Literary History echoed its topics and approaches. Barthes, Greimas, Todorov, Bremond, and Metz became well-known to us film scholars; whereas the couple of Italian semioticians who had any impact (Emilio Garroni, Giancarlo Bettetini) were associated neither with filmology nor with its Italian journal IKON; instead, they were linguists. Pasolini was a case apart; an important one for American film studies after his essay "Cinema of Poetry," ("Cinema di poesia") delivered 
in Pesaro in 1965, passed through Cahiers du cinéma and became available to the rest of the world. Meunier does not cite the Communications group (Metz, Barthes) until his 1980 publication; perhaps he felt closer to early filmology because some of the most significant figures were Belgian (such as Albert Michotte van den Berck and Alphonse de Waelhens), and their ideas were alive in the Université Catholique de Louvain, where Meunier studied, taught, and published his books.

Throughout the 195os in Paris, filmology appealed to philosophers, sociologists, and perceptual psychologists so as to be recognized as a legitimate university discourse. ${ }^{12}$ However, it never welcomed film historians, critics, or 'film theorists,' as they were already being called. And neither does Meunier, who turns his back on the French cinephilic discourse, never looking to Epstein, Bazin, or even Mitry. It is especially surprising that his book excludes Mitry (he rectifies this in the 1980 book), since Mitry, the co-founder of the Cinémathèque francaise and author of a five-volume history of cinema, was far more than a cinephile. He had been appointed a university professor and his formidable Aesthetics and Psychology of the Cinema (Esthétique et psychologie du cinéma) appeared in two large volumes from the Presses Univérsitaires de France (1963-1965). With minute analyses of such traits as cinematic rhythm, subjective camera, and reflexive montage, and with copious references to philosophies of perception and cognition, Mitry produced an informal encyclopedia of film theory. His eight pages on the question of identification directly respond to the work of certain filmologists. His is an effort to account for the film experience in a systematic, phenomenological manner. What does Meunier think of his insistence on the 'solidity of absence' established by the real movement of the shadows on the screen, against the immobility of the spectator enframed before it? Even Christian Metz, often considered a harsh opponent of phenomenology, embarked on his career with essays responding directly to Mitry's views of narrative and identification. Meunier does not acknowledge this tradition until 1980. The Structures of the Film Experience even ignores Albert Laffay's Logique du cinéma (The Logic of Cinema), a 1964 treatise that built on that author's impressive postwar essays published in a Sartrean vein in Les Temps modernes and La Revue du cinéma. Metz saluted Laffay in a 1965 review, published in the same issue of Communications, wherein he famously locked horns with volume one of The Aesthetics and Psychology of the Cinema. Metz pinpoints the concept of 'quasi-reality' as Laffay's most signal contribution, though he shows it to be insufficiently developed..$^{13}$ But any rendezvous one ought to have predicted between these French theorists and Meunier 
was missed, the fault lying on both sides. For Metz never said what he thought of Meunier's ideas about cinematic ontology and spectatorial identification, or about the experience of the image and of fiction - issues both men shared with Laffay at exactly the same moment, as they slipped from phenomenology toward structuralism. Later on, Meunier would acknowledge this moment. ${ }^{14}$

\section{Echoes of Sartre}

Given its title, Meunier's book could have served as jumping-off place for Metz's famous chapter on identification in the 1975 work The Imaginary Signifier (Le Signifiant imaginaire). ${ }^{5}$ Perhaps he wanted to avoid association with Merleau-Ponty through Meunier's reliance on this philosopher. Oddly, shortly after Metz wrote his psychoanalytic book, his friend Roland Barthes published Camera Lucida (La Chambre claire), which he dedicated to Sartre's The Imaginary (L'Imaginaire), the very book that is the explicit source for Meunier's reflections. You can feel how important The Imaginary is for Meunier when he accounts for the peculiar fascination and momentum belonging to the three distinct types of film he identifies: home movies, documentaries, and narrative fictions. Identification is the key with which he unlocks the inner dynamics of one mode after the next, by meditating on the viewer's shifting states of consciousness in digesting various types and organizations of images.

Bazin also drew heavily on The Imaginary. As I have previously detailed, a copy of the 1940 first edition of Sartre's book was on the shelf above Bazin's deathbed. ${ }^{16}$ When Janine Bazin let me select a book as a souvenir, this is the one I chose. It sat throughout 1973 and 1974 right next to my heavily marked-up copy of Meunier's volume. But I did not open Bazin's copy of Sartre for three decades. If I had done so right away, I would have seen that Bazin had underlined some of the same passages that appealed to Meunier. Furthermore, Bazin typed out a page of responses to Sartre that he left folded in the book, and which have guided my understanding of his difference from Sartre. He distinguishes three types of images (three again): photographic, filmic, televisual - all of them seen in relation to 'presence,' and thus to our way of absorbing them.

Leaning almost exclusively on early Sartre and Merleau-Ponty, and supplemented by filmological articles dating to 1953 , Meunier, as we have seen, skips over film theory and criticism. Taking his cue from Husserl (or even Descartes), he effectively starts from scratch on a difficult problem: how 
do spectators relate to films and the characters within them? Although he does not cite him, Meunier's position sometimes comes close to what Bazin (and Deleuze) would propose when, for example, he posits fiction films as quasi-real:

We can now see more precisely what belief is. It implies that we depart from the category of the real, in order to be fascinated by an unreal world, a world that we posit neither as existent nor non-existent, that we never cease to regard as imaginary, but to which we consent, or rather, which we let ourselves believe in. Belief, in the cinema, is rather comparable to belief when playing (p. 95).

Meunier's table of contents, as if modeled on that of a philosophical treatise, is leaner and more abstract than the one Morin constructed for The Cinema, or the Imaginary Man and Mitry for his two volumes. Those more verbose theorists try to corral their overbrimming thoughts and examples by organizing them post-facto. Meunier, however, began with a clean outline. In part one, he treats the general experience of perception and identification; then, in part two he narrows the target to the experience of filmic identification. Each of these parts is given in two large chapters with numerous subsections. Throughout, the symmetries and oppositions are easy to keep track of; indeed, they provide much of the book's pleasure, while making it easy to see where the argument is headed.

This table of contents echoes that of Sartre's The Imaginary, the explicit source for Meunier's chief premise: every filmic consciousness is a relation to a world, but a world that is posited as not there. This constitutive absence that operates in all films differs according to mode, of which there are three: home movies (le film-souvenir), documentaries, and fictions. Thanks to this absence, all films require an investment by the spectator, although the type and quality of that investment varies. Phenomenological description distinguishes each from the others.

Laffay and others may have addressed our investment in fiction films before Meunier, but the types of investment required by home movies and documentaries is original to this book. Meunier would not accept for home movies what Mitry wrote about fictional works: "the film image purports to be the same as the mental image [...] fixed inside our memories [...] with the one difference that memory in this case is a strip of celluloid."17 When Mitry then goes on to detach the image from the viewer since it is the product of someone else's memory bank, he ignores the case of home movies that individuals record and return to. The use of cinema to recall something of 
one's own familiar world (often one's family world) would not be studied comprehensively until the semiologist Roger Odin in the 1980 s. $^{18}$

As for documentary, Mitry has little to say. Although this mode had long been on the agenda in film studies, its distinct phenomenology had best been seized by Bazin in his reviews of films of exploration. Meunier's plan to examine the viewer's manner of processing documentary film was therefore novel; it would have been more revolutionary but for the paucity of his pool of examples. His documentary category comprises only films with a pedagogical function, ignoring essay films and experiential explorations. While most documentaries in the 1960 s were indeed produced by institutions rather than personally authored (as fiction films often are) or made as diaries (in the manner of home movies), many subcategories of documentary would seem to demand a different interior description. Meunier does use the example of Lonely Boy (Wolf Koenig and Roman Kroitor, 1963), a rather ambiguous portrait of pop singer Paul Anka, but overall he considers documentaries to be films made to instruct the spectator in the workings of a world beyond the spectator's knowledge. This is how the documentary film differs from the home movie, which presents the spectator with a world he already knows.

In restricting documentary primarily to a mode of instruction, Meunier misses the entire function of what I call "cinema of discovery." ${ }^{19}$ This tradition began with Flaherty, whose Nanook of the North (Robert Flaherty, 1922) Meunier does in fact cite. In my view, Flaherty spent years with his subjects so as to discover what the untrained eye, or even the human eye in general, could not see. The camera does better than the eye. And the film does more than instruct; it discovers and delivers an abundance of audiovisual information otherwise unavailable, challenging the viewer to adopt a different temporality. Such 'artistic documentaries' can be unpredictable, unlike most fiction films and unlike most pedagogical documentaries. Even the length of artistic documentaries is uncertain, whereas fiction films and commissioned documentaries come in at standard lengths. The shape of a film, like Chris Marker's Koumiko Mystery (Le mystère Koumiko, 1967) or Johan van der Keuken's Blind Child (1965), is impossible to predict, and this surely affects the spectator's attention, perception, and identification. Recent bold experiments in documentary - from Harun Farocki's work to that of Harvard's Sensory Ethnography Lab - comprise a rich repertoire and could include hybrid cases of fiction-documentary like The Act of Killing (Joshua Oppenheimer, 2012), which challenge Meunier's clean categories; but Meunier's methodology, especially had he applied it to complex documentaries available in 1969, could clarify the spectator's experience of such cases. With 
experimentation in mind, what about experimental or avant-garde cinema, a distinct mode Meunier does not address at all? Often without characters, such films explore not the world so much as perception, including cinematic perception. Do Stan Brakhage's films, like Dog Star Man (1964) or Scenes from Under Childhood (1967), invite identification with the filmmaker's eye, with the camera, or with some putative subjective center as in the romantic tradition of poetry?

At the conclusion of Concepts in Film Theory (1984), using the same notion of stages that Meunier draws, I suggest that the modes of film are tied to the level at which they "do their principle work." ${ }^{20}$ Experimental film operates at the level of sensation as it congeals into perception; documentary operates more at the level of perceived or recognized objects as these begin to constitute a complex world; and fiction films, which seldom challenge viewers at the level of perception or recognition, instead operate at the level of the values of the world once it has been recognized and put in dramatic motion. My aim was to take Meunier's structures and turn them into processes. One must work toward perception, in other words, and then, literally come to terms with what is perceived as a recognized situation, before one can proceed with higher-order processes of interpretation.

My ideas were informed at the time by a new stage in the phenomenology of the film experience that came into its own around 1980 in France. Mitry at this time was aggressively attacking semiotics in an effort to keep alive his 1960s aesthetics based on perception and style. ${ }^{21} \mathrm{He}$ felt he had established what might be called the terms of perceptual constraint operating in all theories (thus, both in Meunier's typology of identification and in Metz's structural psychoanalysis). Mitry had declared:

One thing is certain: the brilliance of the screen against almost totally black surroundings produces a sort of preoccupying fascination which confines the impressions of consciousness within a frame which is clearly circumscribed. During the projection of a film, nothing is (or can be) perceived except what is presented on the screen [...] we only appreciate the image content relative to what it presents to our eyes, though we never lose self-consciousness. ${ }^{22}$

In 1980, perhaps as a revolt against such constraints, yet still in a quite phenomenological tone, Roland Barthes insisted on decentering the viewing situation in the presence of the punctum. ${ }^{23}$ Whereas the studium controls the spectator's relation to the image, the punctum returns the image to the spectator's wayward and private memories, attachments, and instincts. 
Notably, Barthes felt this delicious possibility to belong to still images only. He needed to stop the film, so he could control the temporality of the experience of viewing, something he did in "The Third Meaning" as well, and something that Laura Mulvey does in Death $24 x$ a Second, too. ${ }^{24}$

But on the heels of Barthes came an even more radically phenomenological approach, one that does not arrest the film, but relishes its ceaseless movement as liberating an uncontrollable gush of images, some of which are interior and personal, others cultural, and all of which take place in a temporal vacuum, without duration. Jean Louis Schefer's The Ordinary Man of Cinema (L'Homme ordinaire du cinéma), a nearly impossible book to assimilate into the system of cinema studies when it appeared, changed the stakes of film phenomenology. I pointed to it in 1984 in Concepts in Film Theory; about the same time, Wide Angle published a section of it in English alongside an excellent introduction situating its importance by Paul Smith. ${ }^{25}$ Championed by many theorists on both sides of the Atlantic (Deleuze, Raymond Bellour, Jacques Aumont, Tom Conley), it was only in 2016 that it was translated in full. ${ }^{26}$ However, uncomfortably suited to the digital age that perhaps it anticipated too well, this book may have missed its moment. Whereas when it was published in 1980 (just when Meunier's second book appeared), it had the force of a completely new perspective, a description of 'the filmic experience' but without any structures holding it in place.

The 1980s, it should be recalled, found Betamax and VHS machines promising a new manner of watching film. No longer Mitry's "brilliant screen surrounded by black"; no longer Bellour's ineluctable, implacable unrolling of images beyond the viewer's control. ${ }^{27}$ Suddenly the spectator has come to be in control, to change speeds, change films, become a DJ of his own experience. We can now own films (purchase them like books) and own our own spectatorship. Cinema studies has yet to fully accommodate itself to this shift, though Vivian Sobchack's 1992 Address of the Eye: A Phenomenology of Film Experience and especially her 1999 article "Toward a Phenomenology of Nonfictional Film Experience" go a long way toward that goal, using Meunier's book more thoroughly and valuably than anyone before or since. ${ }^{28}$ And Schefer's ordinary man is now everyman at the cinema, awash in a sea of screens where identification operates so differently it must surely mean something quite distinct from what it did in 1980, let alone in 1969 .

It may be claimed that Jean-Pierre Meunier's book applies to a situation that no longer governs our relation to moving pictures; even if this is so, however, he has provided a model by which to clarify our situation, and he supplies the basic modes of experience from which our relation to newer forms of moving images derive. For, despite the mutations and explosion of 
spectating situations, film spectators still behave much in the manner he so clearly laid out. We still return to our personal worlds; we still come to terms with a world beyond ourselves that we believe is out there and must learn to meet; and we still involve ourselves in fictions, which belong neither to us, nor to the actual world but in the midst of which, through identification, we play out other possibilities in other circumstances.

\section{Notes}

1. Dudley Andrew, The Major Film Theories (Oxford: Oxford University Press, 1976), p. 183.

2. Dudley Andrew, "The Neglected Tradition of Phenomenology in Film Study," Wide Angle 2:2 (Spring 1978), pp. 44-49. Reprinted in Bill Nichols (ed.), Movies and Methods vol. II (Berkeley, CA: University of California Press, 1985), pp. 625-632.

3. Maurice Merleau-Ponty, "The Primacy of Perception and its Philosophical Consequences," in The Primacy of Perception (Evanston, IL: Northwestern University Press, 1964), esp. pp. 17, 25.

4. Husserl's view is laid out by Maurice Merleau-Ponty in Phenomenology of Perception (London: Routledge and Kegan Paul, 1962), pp. 416-435. He explicitly cites Husserl's Formal and Transcendental Logic (The Hague: Martinus Nijhoff, 1969), pp. 256-257 in the original.

5. $\quad$ Paul Ricoeur, "Structure-Word-Event," Philosophy Today 12:2 (1968), pp. 114129 .

6. See John O'Neill, "Institution, Language, and Historicity," in Perception, Expression and History (Evanston, IL: Northwestern University Press, 1970), p. 46.

7. Martin Lefebvre, "Christian Metz: entre sémiologie et esthétique," Recherches anthropologiques 32 (2012), pp. 247-272.

8. Dudley Andrew, "Edgar Morin," in Carl Plantinga and Paisley Livinsgton (eds.), The Routledge Companion to Philosophy and Film (London: Routledge, 2009), pp. 415-418

9. Jean-Louis Comolli and Jean Narboni, "Cinéma/Ideologie/Critique," Cahiers du Cinema 216-217 (October-November 1969), trans. by Daniel Fairfax as "Cinema/Ideology/Criticism," in Jean-Louis Comolli, Cinema against Spectacle: Technique and Ideology Revisisted (Amsterdam: Amsterdam University Press, 2015), pp. 251-259.

10. Jean-Pierre Oudart, "La Suture," Cahiers du cinéma 211-212 (April-May, 1969), trans. Kari Hanet as "Cinema and Suture," Screen 18:4 (Winter 1978), pp. 24-34. A full explanation of these issues is undertaken by Daniel Fairfax in his 2017 Yale dissertation, "Politics, Aesthetics, Ontology: The Theoretical Legacy of Cahiers du cinéma 1968-1973." 
11. Jean-Pierre Meunier, Essai sur l'image et la communication (Louvain: Cabay, 1980), p. 3 .

12. The most up-to-date history of the "filmologie movement" can be found in the double issue of Cinémas: revue d'études cinematographiques 19:2-3 (2009), edited by Francois Albera and Martin Lefebvre.

13. Christian Metz, "Albert Laffay: Logique du cinéma," Communications, no. 5 (1965), pp. 141-142. Laffay is also the first name cited in Metz's Essais sur la signification au cinéma, vol. I (Paris: Éditions Klinksieck, 1968), in a section called "Approches phenoménologiques au cinéma."

14. In addition to citing Metz in his second book, recently Meunier was interviewed on the occasion of the publication of his book Des images et des mots: Cognition et réflexivité dans la communication (Paris: Éditions Academia, 2015), where he places Metz in the history of film theory. See Daniel Paraya: “Entretien avec J.-P. Meunier," Communication 34:1 (2016), https://journals.openedition.org/communication/6955 (Last accessed: 30 April 2018).

15. Christian Metz, "Identification, Mirror," in The Imaginary Signifier: Psychoanalysis and Cinema, trans. Celia Britton, Annwyl Williams, Ben Brewster, and Alfred Guzzetti (Bloomington, IN: Indiana University Press, 1982), pp. 42-57.

16. Dudley Andrew, "The Ontology of a Fetish," Film Quarterly 61:4 (Summer 2008), pp. 62-67.

17. Mitry, Aesthetics and Psychology, p. 83 .

18. Roger Odin's works on home movies are collected in Le Film de famille (Paris: Klincksieck, 1999).

19. Dudley Andrew, What Cinema Is! (Malden, MA: Wiley-Blackwell, 2011), chapters 1 and 2.

20. Dudley Andrew, Concepts in Film Theory (Oxford: Oxford University Press, 1984), pp. 167-169.

21. Jean Mitry, Sémiologie en question (Paris: Éditions du Cerf, 1987), trans. by Christopher King as Semiotics and the Analysis of Film (Bloomington, IN: Indiana University Press, 200o).

22. Mitry, Aesthetics and Psychology, p. 82.

23. Roland Barthes, Camera Lucida, trans. Richard Howard (New York: Hill and Wang, 1981), pp. 26-27.

24. Roland Barthes, "The Third Meaning," in Image-Music-Text, trans. Stephen Heath (NY: Hill and Wang, 1977), pp. 52-68; Laura Mulvey, Death $24 x$ a Second (London: Reaktion Books, 2006).

25. Dudley Andrew, Concepts in Film Theory, pp. 189-190; Jean-Louis Schefer, "Schefer on Cinema," Wide Angle 6, no. 4 (1985), pp. 54-63; Paul Smith, who curated the Wide Angle piece earlier wrote an essay "The Unknown Center of Ourselves: Schefer's Writing on the Cinema," Enclitic 6:2 (1982), pp. 32-43. 
26. Jean-Louis Schefer, The Ordinary Man of Cinema, trans. Max Cavitch, Noura Wedell, and Paul Grant (Pasadena, CA: Semiotexte, 2016 [1980]).

27. Raymond Bellour, "The Unattainable Text," Screen 16:3 (October 1975), pp. 19-28.

28. Vivian Sobchack, The Address of the Eye: A Phenomenology of Film Experience (Princeton, NJ: Princeton University Press, 1992); and "Toward a Phenomenology of Nonfictional Film Experience," in J.M. Gaines and M. Renov (eds.), Collecting Visible Evidence (Minneapolis, MN : University of Minnesota, 1999), pp. 241-254.

\section{About the author}

Dudley Andrew is the R. Selden Rose Professor of Film and Comparative Literature at Yale University. He began his career at the University of Iowa with three books commenting on film theory, including the biography of André Bazin, whose ideas he continues to explore in What Cinema Is!(2010), and the edited volumes Opening Bazin (2011) and A Companion to François Truffaut (2013). He was named "Commandeur des Arts et des Lettres" by the French Ministry of Culture in recognition of his books Mists of Regret (1995) and Popular Front Paris (2005). His fascination with Japan led him to co-author a sourcebook on Mizoguchi Kenji (1981) and a monograph on his masterpiece Sansho Dayu (2000). His teaching and research are divided between questions of World Cinema and literature (such as translation and adaptation) and aspects of twentieth-century French intellectual life (especially theories of the image). His film analyses appeared in Film in the Aura of Art (1984) and he has authored introductions and video essays on French and Japanese classics for DVD editions. He is currently completing French Cinema: A Very Short Introduction and Encountering World Cinema. 


\title{
Between Phenomenology and Psychoanalysis: Jean-Pierre Meunier's Theory of Identification in the Cinema
}

\author{
Daniel Fairfax
}

\begin{abstract}
This paper aims to situate Meunier's The Structures of the Film Experience within the constellation of film theory at the time of its writing in 1969. More specifically, it argues that Meunier's text can, in retrospect, be seen as a 'missing link' in film theory, bridging the divide between phenomenological and psychoanalytic approaches to the study of cinema, which can be more profitably seen as complementing each other rather than existing in a state of mutual enmity. However, whereas apparatus theorists, such as Jean-Louis Baudry and Christian Metz, drew primarily on Lacan for the contribution of psychoanalysis to an understanding of filmic identification, Meunier is distinct in turning instead to the Freudian Angelo Hesnard for his take on the phenomenon.
\end{abstract}

Keywords: Angelo Hesnard; apparatus theory; Jean-Louis Baudry; Christian Metz; home movie

For historians of film theory, one of the most intriguing aspects of Jean-Pierre Meunier's The Structures of the Film Experience is the year of its publication: 1969. The last year of the 196os was one of the banner years in the history of film theory, on a par with 1925 (the year of Eisenstein's Strike and his first texts on montage), and 1945 (Bazin's "Ontology of the Photographic Image" and the dawn of the neorealist movement in Italy). Above all, 1969 has gone down as the birth-moment of the 'Marxo-Freudian' strand of film theory. This moment saw an abrupt shift in editorial policies on flagship film journals on both sides of the English channel - Cahiers du cinéma and Screen - as well as the founding of the explicitly radical journal Cinéthique.

Hanich, J. and D. Fairfax (eds.), The Structures of the Film Experience by Jean-Pierre Meunier. Historical Assessments and Phenomenological Expansions, Amsterdam University Press, 2019 DOI 10.5117/ 9789462986565_FAIRFAX 
In France, landmark articles such as Jean-Louis Comolli and Jean Narboni's "Cinema/Ideology/Criticism" "Cinéma/idéologie/critique") and Jean-Pierre Oudart's "Cinema and Suture" ("La Suture") appeared in 1969, and were quickly followed by Jean-Louis Baudry's "Ideological Effects of the Basic Cinematographic Apparatus" ("Cinéma: effets idéologiques produits par l'appareil de base") in 1970, while in the UK the first edition of Peter Wollen's Signs and Meaning in the Cinema was published, and Screen's turn to political modernism ensued shortly afterwards. ${ }^{1}$ Debates swirled around contemporary politicized films such as Jean-Luc Godard/Jean-Pierre Gorin's Wind from the East (Vent d'est, 1969), Jean-Marie Straub/Danièle Huillet's Othon (1969), Costa-Gavras's Z (1969), and Fernando Solanas/Octavio Getino's Hour of the Furnaces (La Hora de los hornos, 1968).

From these tempestuous discussions, out of whose cauldron the academic discipline of film studies as we know it today was born, Meunier's book seems singularly remote, whether geographically, institutionally, ideologically, or theoretically. Geographically, because he was based in the Belgian town of Leuven rather than in Paris or London, the 300-odd kilometers of distance keeping him safely ensconced from the critical combat of the larger metropolises. Institutionally, because, rather than the world of film criticism, he was operating in a university environment, with its more sedate pace of work and markedly different standards for the presentation of ideas. ${ }^{2}$ Ideologically, because, whereas the French and British critics saw the development of a theory of the cinema as an inherently political project, closely tied with a prospective revolutionary overturning of the capitalist system, Meunier's work is deliberately detached from political questions, preferring instead to probe deeper, more unvarying aspects of human experience and the cinema. And finally, theoretically, because the conceptual apparatus dominating the Cahiers-Cinéthique-Screen variant of film theory, with its combination of the structuralist semiotics of Saussure and Barthes, the historical materialism of Marx and Althusser, and the psychoanalytic theory of Freud and Lacan, was not one shared by Meunier, who predominantly drew, for his study on 'the film experience,' on the theoretical corpus of the filmologie movement and, more fundamentally, on the phenomenology of Sartre, Merleau-Ponty, and Husserl.

We could thus be tempted to firmly place Meunier's work on one side of a theoretical divide that has characterized film theory - particularly in the French-speaking world - since the 1940s: that between a phenomenological and psychoanalytic approach to film spectatorship. If the former was prominent in the postwar period, with the work of Amédée Ayfre, Henri Agel, and, above all, André Bazin, by the late 1960s, the latter was in the 
ascendancy, and came to overwhelmingly dominate the field in the $1970 \mathrm{~s}$ and 1980 s. $^{3}$ Often, proponents of the 'psychoanalytic' paradigm of film studies subjected earlier phenomenological accounts of spectatorship to ridicule - infused, in their view, with the musty stench of antiquated ideas (although, in reality, not much more than a decade separated their respective heydays), and prone to the twin (and contradictory) offences of metaphysical idealism and mechanistic scientism. Film phenomenology became, as Dudley Andrew termed it in his 1978 article, little more than a "neglected tradition" in film studies. ${ }^{4}$

By the end of the 1980s, however, the hegemonic position of the structuralist/psychoanalytic paradigm had been decisively overturned. Importantly, however, it was not supplanted by a new dominant theoretical trend, but by scholarly dispersion, a fragmenting of the field into multiple, jostling academic endeavors. Given that this dissipation coincided with a massive institutional inflation - both in the university system more generally, and in the discipline of film studies more specifically - a suitable allegory for this moment may be the Big Bang: from a dense, compact field of energy feeding in on itself, the study of cinema exploded, becoming an ever-expanding universe whose component parts have been rapidly moving away from one another, in a centrifugal process which, to this day, shows no signs of being reversed. Indeed, in retrospect, the period when this theoretical prism exerted a near-totalizing sway over the concerns and activities of the field can be seen as a fundamentally unique, never-to-be-repeated moment in the history of the discipline: film studies today is too vast, too polycentric, and too atomized to ever come under the dominance of a single set of ideas again. Among the constellation of theoretical schools to emerge in the wake of the structuralist/psychoanalytic moment, we can find the post-theory of David Bordwell and Noël Carroll, the 'new film history' of Tom Gunning, Charles Musser, André Gaudreault et al., cultural studies, media theory, and approaches inspired by Gilles Deleuze, Michel Foucault, Jacques Derrida and others. We can also, thanks to a large degree to the efforts of Vivian Sobchack from the early 199os onwards, observe a resurgence of the phenomenological investigation of film. ${ }^{5}$

It is thus that phenomenology-inspired and psychoanalytic approaches to the study of cinema, and more particularly the experience of the film spectator, have predominantly been contrasted with one another, and held to be in an antagonistic relationship, vying for conceptual supremacy within the institutional framework of academic film studies. This, certainly, is the textbook account of how these two theoretical tendencies relate to each other, and such a viewpoint can be evinced in certain passages from the 
proponents of these theories themselves. In The Imaginary Signifier (Le Signifiant imaginaire), for instance (one of the tutor-texts of psychoanalytic film theory), Christian Metz caustically refers to phenomenological film theory as "the main form of idealism in cinematic theory" and characterizes it as a "cosmophanic conception" of cinema that registers "the 'feeling' of the deluded ego of the spectator." At best, phenomenology can shed light on the functioning of the cinema in a symptomatic manner, because its "conceptual apparatus" is analogous to the "topographical apparatus" of film projection. But it suffers from a blind spot towards the "lure of the ego," and is only of interest if its theoretical premises are inverted. ${ }^{6}$ Conversely, Sobchack defends the phenomenological model of cinematic identification she develops (partly on the basis of Meunier's ideas) as an explicit alternative to the psychoanalytic model, and superior by dint of the fact that it "does not posit a single and totalizing structure of identification with the cinematic image, but rather differentiates among a variety of subjective spectatorial modes that co-constitute the cinematic object as the kind of cinematic object it is." It thereby offers "a more dynamic, fluid and concrete description of film viewing than does its psychoanalytic counterpart" and "discloses rather than discounts" the "charge of the real" in cinema (and more particularly, documentary cinema). ${ }^{7}$ Elsewhere, the antipathy between these two tendencies manifests itself in the form of stony silence: scour the pages of Cahiers du cinéma in its Marxist phase for discussions of the ideas of Husserl, Sartre, or Merleau-Ponty, even in the form of polemics against them - you will not find any. ${ }^{8}$

I would nonetheless like to push back against this idea of an irremediable state of enmity, or irreconcilable discord, between phenomenology and psychoanalysis in film theory. For a start, as two 'schools' of thought, their philosophical heritage is, to a large degree, shared - we are not talking about the kind of epistemological chasm that has separated continental and analytic philosophy for more than a century. Indeed, there is much evidence of a state of mutual influence between these two theoretical branches. The harsh words of The Imaginary Signifier notwithstanding, Martin Lefebvre and Dominique Chateau have demonstrated the importance of Metz's early phenomenological period for his later work, a debt that Metz himself readily recognized in interviews. ${ }^{9}$

That phenomenology and psychoanalysis are more intertwined than is commonly assumed is also evident in the work of another seminal figure. With its emphasis on the role of the gaze in the formation of the subject and its discussion of visual systems of representation such as painting, the significance of Lacan's Seminar XI: The Four Fundamental Concepts of 
Psychoanalysis (Le Séminaire XI: Les quatres concepts fondamentaux de la psychanalyse, 1973) for film theory can hardly be overstated. Often overlooked, however, is the fact that, in this discussion, Lacan makes frequent reference to phenomenological thinkers. Sartre's notion in Being and Nothingness (L'Être et le Néant, 1943), for instance, of the bidirectional nature of the gaze, and the element of surprise involved in the production of the gaze, are glowingly reiterated by Lacan, who states: "The gaze I encounter - you can find this in Sartre's own writing - is, not a seen gaze, but a gaze imagined by me in the field of the Other. ${ }^{10}$ Similarly, Merleau-Ponty is a recurrent point of reference for the psychoanalyst: his understanding of the function of the gaze in works such as Phenomenology of Perception (Phénoménologie de la perception, 1945) and the posthumous The Visible and the Invisible (Le Visible et l'invisible, 1964) strains against the very limits of the phenomenological method, in Lacan's view, by insisting that the subject is circumscribed by a gaze emanating from "the spectacle of the world."11

All this serves as contextual material for my main claim in this essay: that, in developing the notion of filmic identification by drawing on phenomenological and psychoanalytic theoretical foundations, Meunier's The Structures of the Film Experience represents a missing link in the 'family tree' of film theory, bridging the gap between two theoretical tendencies that, rather than being counter-posed to each other, should most profitably be related to one another in a complementary, compatible fashion.

\section{Identification in Film Theory}

Ironically, it was at the same time as Meunier published his account that the notion of 'identification' in the psychoanalytic sense made a spectacular entry into the working lexicon of film theorists. In 1970, Tel Quel writer and novelist Jean-Louis Baudry - whose work was not, it must be said, particularly focused on questions of film theory prior to this point - published his "Ideological Effects of the Basic Cinematographic Apparatus" article in issue no. 7-8 of Cinéthique, thereby effectively launching apparatus theory in film studies. There is much that we can find wanting in this brief yet dense article - most notably its reductive vision of the spectator's relationship with the filmic image, and its terminological slippage between 'ideology' and 'idealism' - but there is no denying its enormous influence (an outsized influence, perhaps, when compared with the confidential reception of Meunier's text), and the theoretical advances produced by the debates it 
incited. Few, today, would sign up wholeheartedly to the propositions Baudry articulates, but his text remains a vital point of discussion in the field.

Central to this article is a grand analogy between the cinema spectator and the infant, aged 6-18 months, in the midst of Lacan's 'mirror stage,' owing to the common presence of two physiological conditions: restricted mobility and heightened visual awareness. As with the child who, faced with their own mirror image, constructs a sense of a unified ego upon this basis, the film spectator develops a relationship of identification with the images projected onto the screen. But Baudry also distinguishes two levels of identification in this process, derived from the fact that, in the cinema "the reflected image is not that of the body itself but that of a world already given as meaning."12 It is only on a secondary level that the spectator 'identifies' with the characters portrayed in the film; the primary identification in cinema-viewing is with the machinery of image-production, the camera. By standing in for what Baudry, following Husserl (in another point of convergence between phenomenology and psychoanalytic film theory) calls the "transcendental subject," the camera fulfils the function of creating a unifying, centralizing meaning out of the perceptual shards of audiovisual imagery thrown onto the screen.

This gloss of identification in the cinema is widely known today. Its renown is partly due to Baudry's ideas being taken up by Metz in The Imaginary Signifier, who reiterated the distinction between a primary level of identification (with the camera/projector, the cinematic apparatus), and a secondary level of identification with the various characters of a narrative-representative film. Like Baudry, Metz highlighted the fundamental difference between the cinema screen and the mirror, and thus pinpointed the limit-point where the analogy with the mirror-stage breaks down: as opposed to the mirror, the cinema screen "returns us everything but ourselves, because we are wholly outside it."13 In Lacanian terms, whereas the mirror unambiguously exists within the order of the Imaginary, the cinema screen skirts the threshold between the Imaginary and the Symbolic.

This, then, is the model of identification that dominated considerations of film spectatorship in the 1970s and 1980s, and which continues to be one of the principal frameworks when questions of identification in the cinema are considered. In The Structures of the Film Experience, Meunier offers a markedly different theoretical model of filmic identification to that developed by Baudry and Metz. This is not to say, however, that there are not areas where the two overlap. Like Baudry and Metz, Meunier comes out against an overly positivistic account of film spectatorship, a shortcoming he ascribes to his predecessors in the filmologie movement, who were 
excessively preoccupied with submitting the phenomena of film-viewing to supposedly empirical observation and quantification. In doing so, they earn the same reproach that phenomenologists have addressed to the scientific method in general. Phenomena such as film-viewing can only be adequately analyzed if the immediate lived experience of the subject is considered, rather than being subject to a pre-established objective schema, and this was, in Meunier's view, the primary cause for the limitations of the research experiments carried out by filmologists such as Albert Michotte van den Berck, Jean-Jacques Rinieri, and François Ricci.

Although phenomenology is the main guiding light of Meunier's study, he is not reticent to acknowledge that his notion of identification is ultimately drawn from Freud. This he has in common with Baudry and Metz. But, whereas the proponents of apparatus theory adopted a Lacanian outlook in their account of filmic identification (most notably through Lacan's essay on the mirror stage), Meunier turned to another follower of Freud, one whose influence on film theory has been far less prominent: Angelo Hesnard, and more particularly his 1957 book Psychanalyse du lien interhumain [Psychoanalysis of the Interhuman Link]. ${ }^{14}$ Although they engaged in polemics with one another, Lacan and Hesnard were not personally hostile, and Hesnard, who was a co-founder of the Société psychanalytique de Paris in 1926, joined Lacan's École freudienne de Paris when the psychoanalytic movement in France split in $1964 .{ }^{15}$ But Hesnard's theoretical positions were still quite distinct from that of Lacan.

If we wish to map out schematically the conceptual lineages of the respective models of filmic identification offered by Meunier and Baudry/Metz, then we could give the following diagram:

Freud

$\longrightarrow \quad$ Lacan $\quad \longrightarrow \quad$ Baudry/Metz

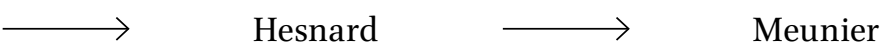

Meunier draws on Hesnard for rectifying what he sees as some of the limitations of Freud's own conception of identification, chiefly through, in Meunier's words "rethinking the concept in the framework of a psychology enriched by the gains of phenomenological thinking" (p. 48). Whereas Freud still held to a model of self-contained, atomized egos, which can only relate to each other through the perception of common traits found in their (equally self-contained and atomized) fellow subjects, Hesnard, by contrast, develops a model of identification fundamentally based on a "primordial intersubjectivity" (p. 48). This emphasis on intersubjectivity 
forms a significant demarcation point between Meunier's account of filmic identification and that espoused by the apparatus theorists, whose topological models of film-viewing invariably posit a lone, isolated spectator subjected to cinematic imagery, the affective content of which is essentially indifferent. ${ }^{16}$

Following Hesnard, Meunier highlights three aspects of identification: its motoric or postural aspect (our tendency to reproduce mimetically the movements or gestures of the person identified with), its affective aspect (eliciting either sympathy or antipathy in the subject), and its dramatic aspect (the fact that relations of identification are not stable and unchanging, but are subject to changes and events, which are frequently capable of altering the very nature of the relationship). Together, these three aspects contribute to the respective valorization or devalorization of the individuals identified with, thereby transforming anonymous intersubjectivity (the generic co-existence of subjects) into private intersubjectivity (the development of personal relationships founded on affective bonds).

Meunier's original move, then, is to apply a Hesnardian framework of identification, steeped in a phenomenological understanding of intersubjectivity, to the experience of film spectatorship, a step which distinguishes his project both from earlier studies of spectatorial empathy or emotional participation carried out by the filmologists, and from the contemporaneous Lacan-influenced view of identification developed by Baudry and others. For Meunier, identification in the filmic situation (the situation of the moviegoer) is a variant of the general mode of behavior that is identification. It does have one primary point of distinction from identification in day-to-day life, however: whereas, in 'real' situations, the parties of a reciprocal intersubjective relationship of identification are both present to each other, in filmic identification, one of the parties in this relationship does not assume the form of a flesh-and-blood human being, but is a spectral image projected onto a two-dimensional screen. They are, in Meunier's words, "presented as not being present" (p. 119). Moreover, unlike Baudry and Metz, Meunier's discussion of identification largely remains at the level of filmic diegesis - he opts not to take the step of locating an identification of the spectator with the mechanism of film projection itself.

\section{Meunier's Three Modes of Identification}

It is at this point in his discussion that Meunier makes what is perhaps his most theoretically stimulating move, and the one which seems to have 
elicited the most interest among followers of his such as Sobchack, as well as many other contributors to the present volume. Rather than consider the cinema as a unitary phenomenon, in which identification would play the same role regardless of the type of film under consideration, or tacitly take the traditional fiction film to stand in for all forms of cinema (a sin that can, not unjustifiably, be imputed to Baudry, Metz, and many others who have discussed filmic identification), Meunier proceeds to a tripartite typology of the different modalities of filmic identification, on the basis of the three overarching categories of film: the home movie, the documentary, and the fiction film.

In each of these three categories, the phenomenon of identification has markedly different effects on the film spectator. In the home movie, it serves primarily to evoke (or 'presentify') a person known to the viewer, enabling the viewer to recall past events or typical forms of behavior shown by the on-screen figure. In the documentary, identification has a didactic function: although we do not know the individuals shown in the film personally, they draw our interest by exemplifying a more general reality that is of concern to us, allowing us to deepen our knowledge of the world. Finally, in the fiction film, due to the fact that the filmic datum does not make reference to an existing reality, identification acts as a more individualized, affective relationship with the characters presented to us, which itself can take two forms: being-with (wherein we sympathize with the character but do not exhibit any tendency to transpose our own personality onto them) and being-like (in which a highly valorized, heroic character elicits a much more participatory mode of identification, beckoning us to 'step into their shoes'). The French New Wave, indeed, gives us an excellent example of an obsessive form of 'being-like': in Jean-Luc Godard's À bout de souffle (Breathless, 1960), Michel Poiccard, played by Jean-Paul Belmondo, happens upon a poster advertising the film The Harder They Fall (Mark Robson, 1956). Staring at the image of Humphrey Bogart emblazoned on the poster, Belmondo is transfixed by the image of a cinema icon on whose intra-filmic persona he has modeled his own behavior. Murmuring the name 'Bogie,' Belmondo motorically imitates the actor's signature tic of tracing his thumb over his lips, in an overt act of identification with Bogart's on-screen persona.

While the divide between fiction and documentary cinema is a mainstay of film theory, bringing in the home movie as a third category is a far more unusual move, and its inclusion is a major factor in the unique nature of Meunier's study. Here, it should be recalled that Meunier does not use the regular French word for home movie (film amateur or film de famille) but a different term, film-souvenir, which more directly evokes the role of 


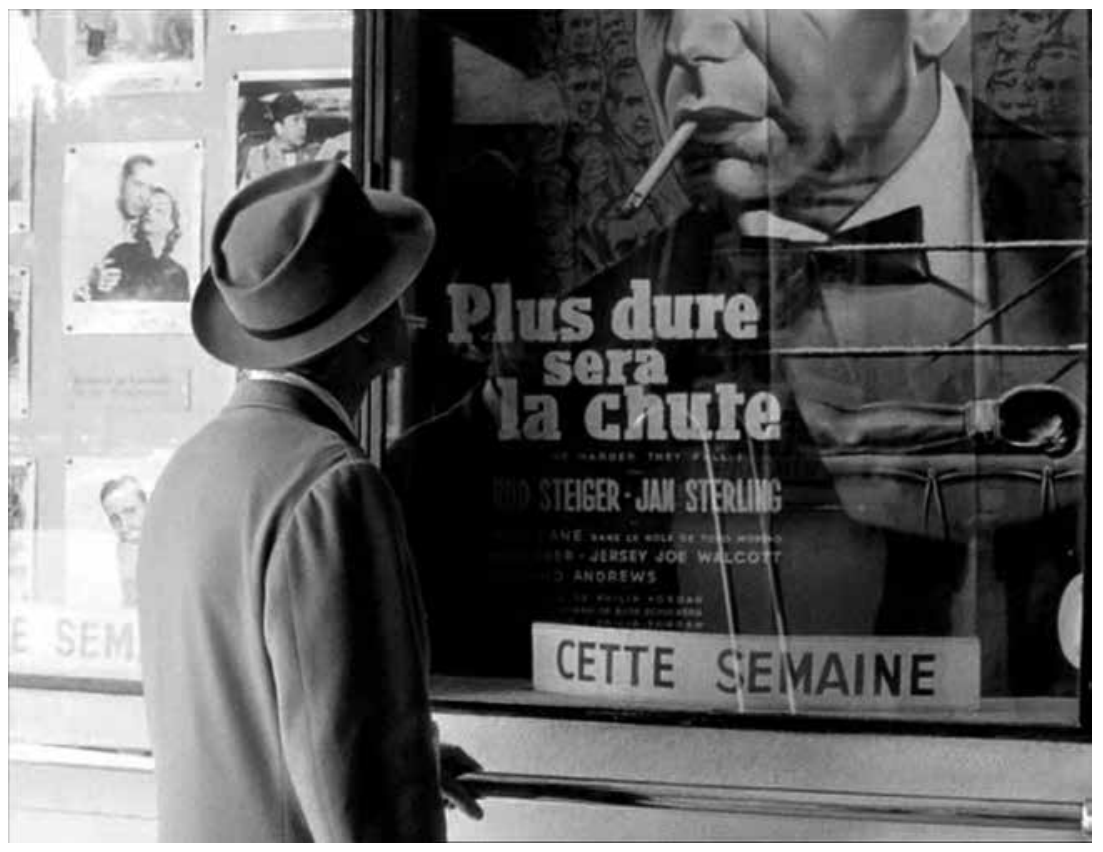

Fig. 7: Jean-Paul Belmondo admires Humphrey Bogart on a film poster promoting The Harder They Fall (Mark Robson), in Jean-Luc Godard's Breathless.

memory in home movies. If we were looking for a more exact equivalent, we could perhaps proffer the term "keepsake-film" (or even the direct cognate: 'souvenir-film'). A large part of the motivation for people to record, preserve, and watch home movies is precisely to retain a memento of key - or even mundane - moments in their lives. As such, the film-souvenir essentially functions as a fetish-object for the viewer. The film itself ends up standing in for a memory that - inherently unstable, unreliable, and ephemeral - resides just outside of our grasp. And yet, in attempting to capture a moment forever by recording it on film (or, more preponderantly today, digitally), we are always frustrated by its status as a pale substitute for the experience of the moment itself. This understanding of the film-souvenir as a fetish-object remains implicit in Meunier's text, and is not directly broached by the author himself, but, given the importance of the notion of the fetish in both Marx (the discussion of 'commodity fetishism' in Volume 1 of Capital) and Freud (his essay on the fetish), it suggests another point of potential contact between film phenomenology and Marxist/psychoanalytic accounts of the cinema. ${ }^{17}$

Although Meunier could be criticized for implicitly retaining a certain hierarchy of image forms, ascending from the 'base' form of home movies, 
through the intermediary of documentary cinema, to the more 'noble' art of fiction film, recognition should be given to the very gesture of including home movies as an independent category, and dedicating a significant portion of his study to the format. That he did this in 1969 is particularly precocious: although $8 \mathrm{~mm}$ cameras had been available for some time, it was only in the late 196os that the Sony Portapak, the first video-camera intended for the consumer market, became commercially available. From a relatively niche pastime only accessible to middle-class families in Western countries, the 'home movie' has become a globalized cultural practice, with the ability to produce and disseminate moving images of reasonably high quality available to anyone with a smartphone in their pocket. ${ }^{18}$

In fact, if in 1969 Meunier could state that "through the importance of its on-screen representation, as well as through its consumption by the broader public, fiction evidently constitutes the principal sector of film production" (p. 128), we could well ask if, in 2019, this pecking order has been reversed. When compared with the sheer mass of audiovisual material available online, the vast majority of which is essentially 'home movies,' and the amount of time that individuals in contemporary societies spend producing and consuming this material, is it not the commercial fiction film that has become a minor, secondary variant of the cinematic image, and the home movie that has become its primary, even hegemonic manifestation?

\section{Meunier in/and Film Theory: Further Questions}

This is only one of the many questions that Meunier's work inspires in the contemporary scholar of cinema. To end this essay, I want to raise a few scattered enquiries of my own, which were provoked as I consulted his book, and which I present now somewhat at random. The present preponderance of the home movie has, of course, been enabled by digital technology. While the technological conditions of image production are little discussed in The Structures of the Film Experience, we may well wonder if the transition from analogue home movies (whether Super-8 or VHS) to digital has had a significant effect on the function of identification for the viewer of such works. This can particularly come into play when watching home movies recorded many years earlier, in which their relationship to memory plays a particularly important role. I often tell my current crop of undergraduate students that they are the last generation who will know what it means to have a faded photograph of their childhood. 
An uncanny cognate of the 'fading' of our own memories, the way our mental images become progressively blurred and indistinct over time, the patina of the past produced by the drained colors or sepia tones of old home movies and photographs is lost with the rise of eternally crisp, eternally 'now' digital imagery. Does the advent of the digital home movie, then, change anything in what Meunier has to say about identification with the film-souvenir?

On an unrelated note, Meunier's discussion of identification often seems to evoke its flipside, denial (or Verleugnung in Freud's terminology). It is curious, however, that the only time he explicitly raises the question of denial, he refuses its pertinence. Belief in the cinema, as Meunier recognizes, is not a totalizing phenomenon. A film is not a hallucination; no matter how immersed we may be in the on-screen events, we never entirely lose sight of their status as images projected on a screen. As Meunier notes, we frequently provoke ruptures in our belief in the film, often when the situation presented becomes emotionally unbearable (he mentions the dramatic intensity of Boris's death in Mikhail Kalatozov's The Cranes Are Flying [Letyat zhuravi, 1957] by way of example). As a form of consolation, the viewers tear away from their fascination with the film and say to themselves: "It's just a movie." As Meunier notes, however, this moment of spectatorial rupture is not an act of denial: we are not denying a real event, but are instead withdrawing from the imaginary world of the film, in order to return to our real existence as a viewer sitting before a screen. On a broader level, however, I still wonder whether a phenomenon of denial is taking place in this process of spectatorial vacillation between a 'belief' in the on-screen world and a detachment from the film's diegesis. Again, a text contemporaneous with Meunier's seems to be of striking relevance here: in 1969, the Lacan disciple Octave Mannoni, in Clefs pours l'imaginaire ou L'Autre Scène, discussed Freudian Verleugnung in terms of a process whereby the patient under analysis says to themselves: "I know very well..., but all the same..." (Je sais bien..., mais quand même...). ${ }^{19}$ As Pascal Bonitzer and Serge Daney were quick to recognize, this formulation has particular pertinence for the mode of existence of the film-viewer, constantly prone to thinking, in essence, "I know very well that it's just a film, but all the same, it seems so real." ${ }^{20}$

At many moments in Meunier's text, this oscillatory mode of spectatorial behavior seems germane to his discussion. Indeed, it is notable that he rejects an equivalence between the film and the dream in favor of an analogy between cinema and child's play. Unlike the film, the dream exerts a total hold over the dreamer - we almost never tell ourselves during the dream 
that "it's all a dream", or when this does happen, it usually provokes us to wake up. By contrast, belief in cinema is rather akin to the 'belief' of the child during role-playing games such as 'cowboys and Indians' or 'cops and robbers.' As Meunier puts it:

The child who plays 'cowboys and Indians' never ceases to regard his behavior as imaginary, but this does not negate the fact that during the game - that is, until the moment when he decides to stop playing - the child 'believes' that he is a 'cowboy,' and 'believes' that his fellow players are 'Indians.' He is fascinated by the unreal world created by the game, just as the spectator is fascinated by the unreal world of the screen. Both act 'as if' the unreal were real. In other terms, they confer a 'believed' existence on objects that they never cease to regard as imaginary (p. 95).

I find this analogy to be a seductive one. Compared with the model of the cinema-viewer as equivalent to an infant in the mirror-stage, it at least has the merit of raising us from the level of a one-year-old baby to that of a six- or seven-year-old child! The flipside, of course, is that, unlike the child playing cowboys and Indians, who has no restrictions on their mobility during the game, the film-viewer pinned to their seat is still, as Baudry reminds us, motorically immature, and during the projection we are severely limited in the movements we can make in our mimetic identification with the on-screen figures.

Finally, while for the purposes of conceptual clarity Meunier presents his three "orders" of filmic identification as schematically divorced from one another, it is hard to dispute that it is the mixed cases, in which the documentary, fiction, and home-movie modes of identification interfere with and "contaminate" each other, that are of most theoretical interest for scholars today. Sobchack has already written at length on the experience of actress Cindy Williams when confronted with images of herself in the series Laverne \& Shirley - effectively responding to a fictional TV show as a film-souvenir, a "diary of her life," as the actress herself termed it. ${ }^{21}$ Sobchack's example also evokes a more canonical moment in film history, which would have been fresh in the mind when Meunier was writing The Structures of the Film Experience.

In the 1966 film Persona, Ingmar Bergman made the striking formal innovation of including a close-up in the film which merged the faces of its two main actresses (Liv Ullmann and Bibi Andersson), highlighting the (supposedly) more unflattering side of each of their faces. In Bergman's own telling, he showed this mongrel image to the actresses during the 


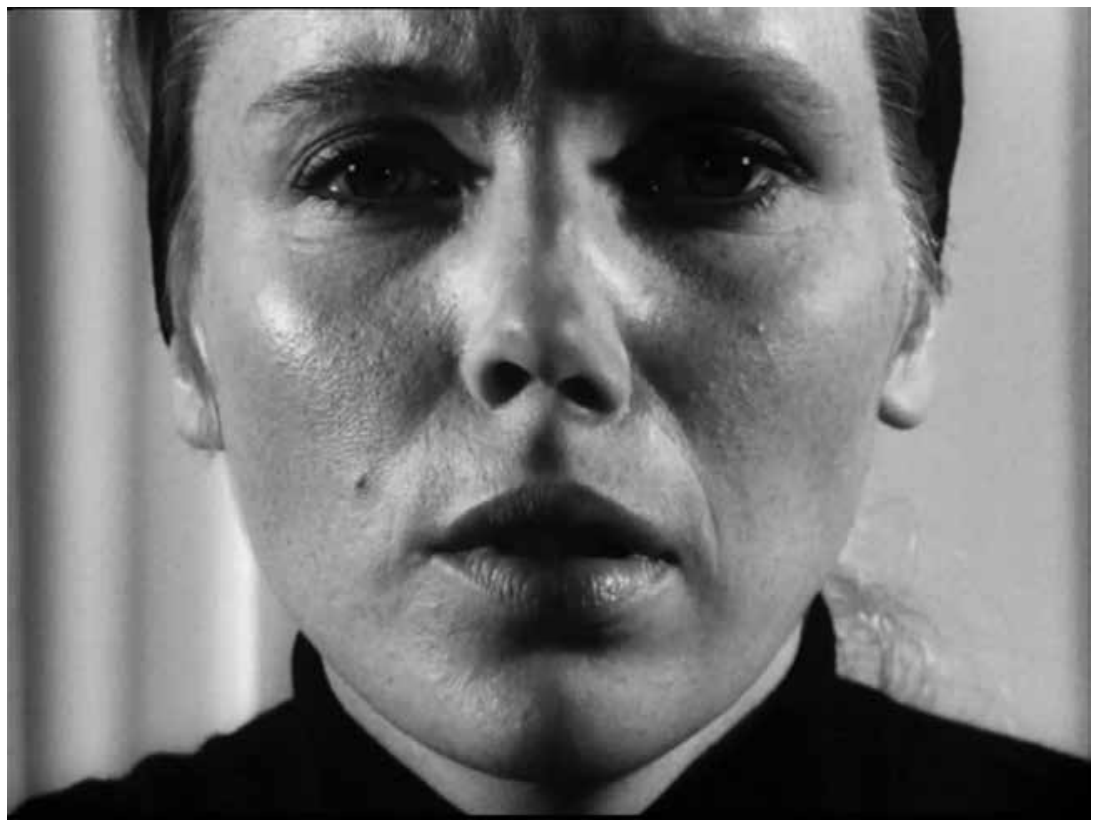

Fig. 8: The faces of Liv Ullmann and Bibi Andersson in a merged close-up from Persona (Ingmar Bergman).

editing of the film, and both of them thought the image was that of the other actress:

We set the machine running, and Liv said, "Oh look, what a horrible picture of Bibi!" And Bibi said, "No, it's not me, it's you!" Then the picture stopped. Everyone's face has a better and a worse side, and the picture is a combination of Bibi's and Liv's less attractive sides. At first they were so scared they didn't even recognize their own faces. What they should have said was: "What the hell have you done with my face?" But they didn't! They didn't recognize their own faces. I find that rather an odd reaction. ${ }^{22}$

In this anecdote - and there is no way of verifying whether such an exchange actually took place, but se non évero, é ben trovato - the oscillation between identification and denial, or what Hesnard calls the "dialectic of the alter and the ego" plays out in the most fascinating of ways. ${ }^{23}$ In forming a "missing link' between the psychoanalytic and phenomenological paradigms of film theory, the value today of Meunier's book, I would contend, lies precisely in providing us with a set of theoretical tools for grappling with such moments of sublime uncanniness in the cinema. 


\section{Notes}

1. See Jean-Louis Comolli and Jean Narboni's "Cinema/Ideology/Criticism," trans. Daniel Fairfax, in Jean-Louis Comolli, Cinema against Spectacle: Technique and Ideology Revisited (Amsterdam: Amsterdam University Press, 2015), pp. 247-259; Jean-Pierre Oudart "Cinema and Suture," trans. Kari Hanet, Screen vol. 18 no. 4 (1977-78), pp. 24-34; Jean-Louis Baudry, "Ideological Effects of the Basic Cinematographic Apparatus," trans. Alan Williams, in Philip Rosen (ed.), Narrative, Apparatus, Ideology: A Film Theory Reader (New York: Columbia University Press), pp. 286-298; Peter Wollen, Signs and Meaning in the Cinema (London: BFI Press, 1969).

2. It should be noted, however, that 1969 was also the year that the French university system, after the post-1968 restructuring, opened itself up to teaching film studies, with programs initiated at Paris-III and Paris-VIII. Many of the new film courses were instructed by present and former critics for Cahiers, Cinéthique, and Positif.

3. While Bazin himself was not, strictly speaking, a phenomenologist, his ideas were deeply influenced by Sartre, Merleau-Ponty, and Mikel Dufrenne, and he was in dialogue with other film phenomenologists of the era, such as Ayfre and Agel.

4. See Dudley Andrew, "The Neglected Tradition of Phenomenology in Film Theory," Wide Angle 2:2 (Spring 1978), pp. 44-49.

5. Indeed, Julian Hanich and Christian Ferencz-Flatz have persuasively argued for seeing the early 1990s as on par with the immediate postwar period as the two key dates in the emergence of film phenomenology. See Christian Ferencz-Flatz and Julian Hanich, "What Is Film Phenomenology?", Studia Phaenomenologica XVI (2016), pp. 11-61.

6. Christian Metz, The Imaginary Signifier (Bloomington: Indiana University Press, 1982), pp. 52-53.

7. Vivian Sobchack, "Toward a Phenomenology of Nonfiction Filmic Experience," in Michael Renov and Jane Gaines (eds.), Collecting Visible Evidence (Minneapolis, MN: University of Minnesota Press, 1999), pp. 241-254, here pp. 241-242.

8. For more on the theoretical implications of Cahiers du cinéma's Marxist phase (under the editorial direction of Jean-Louis Comolli and Jean Narboni), see Daniel Fairfax, "Politics, Aesthetics, Ontology: The Theoretical Legacy of Cahiers du cinéma (1968-1973)," PhD dissertation, Yale University, 2017.

9. See Dominique Chateau and Martin Lefebvre, "Dance and Fetish: Christian Metz's Epistemological Shift," October no. 148, pp. 103-132; Warren Buckland and Daniel Fairfax (eds.), Conversations with Christian Metz: Selected Interviews on Film Theory (1970-1991) (Amsterdam: Amsterdam University Press, 2017), pp. 295-296.

10. Jacques Lacan, The Four Fundamental Concepts of Psychoanalysis, trans. Alan Sheridan (New York: W.W. Norton, 1978), p. 84. The seminar was held 
in the 1964-1965 academic year. For the Sartre book, see Jean-Paul Sartre, Being and Nothingness, trans. Hazel E. Barnes (New York: Philosophical Library, 1948 [1943]).

11. Ibid., p. 75. For the Merleau-Ponty books, see Maurice Merleau-Ponty, Phenomenology of Perception, trans. Donald Landes (London: Routledge, 2012); Maurice Merleau-Ponty, The Visible and the Invisible, trans. Alphonso Lingis (Evanston, IL: Northwestern University Press, 1968).

12. Jean-Louis Baudry, "Ideological Effects of the Basic Cinematographic Apparatus," p. 295.

13. Metz, The Imaginary Signifier, p. 49.

14. Angelo Hesnard, Psychanalyse du lien interhumain (Paris: PUF, 1957).

15. Hesnard's biography, however, was far from immaculate, and his diminished reputation today may at least in part be due to his anti-Semitism and allegiance to Vichy France during World War II. See Élisabeth Roudinesco, Jacques Lacan, trans. Barbara Bray (Cambridge: Polity Press, 1997), p. 153.

16. This is not to say that intersubjectivity is conceptually alien to the structuralist Marxism that underpinned apparatus theory. In "Idéologie et appareils idéologiques d'état (Notes pour une recherche)" (written in January-April 1969), Louis Althusser's claim that the formation of subjectivity requires the "interpellation" of individuals as subjects has profound affinities with the phenomenological understanding of intersubjectivity. But, in contrast to Meunier's phenomenology, Althusser's notion of interpellation offers a profoundly political account of intersubjective relations. As his example of the police officer "hailing" a suspect on the street shows, the confrontation between subjectivities is invariably (in class societies, at least) an encounter between the dominant and the dominated, and is subtended by the latent threat of violence.

17. Indeed, one of the former writers for Cahiers du cinéma during its MarxistLeninist period, Pierre Baudry, would later devote a significant article to the distinction between home movies (which he calls "private cinema") and commercial films ("public cinema"), on the basis of the audience for which they were intended: that is, whether it consisted of people who were known or unknown to the filmmaker. Within the micro-field of home-movie studies, this text has some interesting parallels with Meunier's study. See Pierre Baudry, "Se voir," La Revue Documentaires no. 9 (September 1994), pp. 63-77.

18. Even as late as the early 1990s, the expense of video cameras meant that owning one was an impossible dream for a child from a suburban workingclass family in Australia, such as myself.

19. See Octave Mannoni, Clefs pour l'/maginaire ou L'Autre Scène (Paris: Seuil, 1969), esp. pp. 9-33. Meunier also mentions this text in the interview with him contained in this volume (p. 27).

20. See, in particular, Pascal Bonitzer and Serge Daney, "Lécran du fantasme," Cahiers du cinéma 236-237 (March-April 1972), pp. 30-40. 
21. Sobchack, "Toward a Phenomenology of Nonfiction Filmic Experience," p. 247 .

22. Ingmar Bergman, in Stig Björkman (ed.), Bergman on Bergman (London: Secker \& Warburg, 1974), pp. 31-32.

23. Hesnard, Psychanalyse du lien interhumain, p. 26. This is also discussed by Meunier, p. 44.

\section{About the author}

Daniel Fairfax is Assistant Professor in Film Studies at the Goethe-Universität Frankfurt, having completed his PhD in Film Studies and Comparative Literature at Yale University in 2017. His research focuses on French film theory in the post-1968 period, and for the University of Amsterdam, he has been responsible for editing and translating Cinema against Spectacle: Technique and Ideology by Jean-Louis Comolli (2015) and Conversations with Christian Metz: Selected Interviews on Film Theory (1970-1991) (2017, with Warren Buckland). His monograph The Red Years of Cahiers du cinéma (1968-1973) will be published by Amsterdam University Press in 2019. Daniel is also an editor of and regular contributor to the Australian online film journal Senses of Cinema (www.sensesofcinema.com). 


\title{
The Missing Link: Meunier on Imagination and Emotional Engagement
}

\author{
Robert Sinnerbrink
}

\begin{abstract}
In this chapter, I consider the originality and applicability of Jean-Pierre Meunier's phenomenological account of cinematic identification. I focus in particular on the key role assigned to imagination in his account of spectator identification, and describe some suggestive parallels with contemporary theorists' accounts of imagination (as perceptual engagement, mental simulation, or make-believe, and Murray Smith's threefold "structure of sympathy"). Finally, I consider some difficulties in Meunier's model - his overly clustered concept of 'identification'; a tension between formal-phenomenological analysis and background cultural-historical preunderstanding; and his focus on character identification at the expense of background 'world' apprehension - that could be modified in order to enhance his original contribution to philosophical film theory.
\end{abstract}

Keywords: Emotion; film-philosophy; identification; phenomenology; Jean-Paul Sartre

The film experience is a perceptual experience that underpins the imaginary attitude of consciousness. - Jean-Pierre Meunier, The Structures of the Film Experience (p. 152)

Anyone approaching the topic of imagination in film could be forgiven for thinking of Augustine's famous quip concerning time: "What then is time? If no one asks me, I know what it is. If I wish to explain it to him who asks, I do not know." Many theorists have said as much of the imagination. As Tamar Gendler observes, attempts at taxonomizing imagination have not fared very

Hanich, J. and D. Fairfax (eds.), The Structures of the Film Experience by Jean-Pierre Meunier. Historical Assessments and Phenomenological Expansions, Amsterdam University Press, 2019 DOI 10.5117/9789462986565_SINNERBRINK 
well, mainly because there are so many distinct forms of imagining that are often bundled together and so many diverse research fields and subjective processes in which imagination comes into play. ${ }^{1}$ Kendall Walton, whose work on mimesis as make-believe has had a profound impact in aesthetics, confesses that, despite writing a book on the topic, he simply cannot spell out what the various conceptions of imagining have in common. ${ }^{2}$ Leslie Stevenson explores no less than "Twelve Conceptions of Imagination," ranging from "the ability to think of something not presently perceived, but spatio-temporally real" to "the ability to create works of art that express something deep about the meaning of life." 3 With such a bewildering array or meanings, functions, and purposes, the concept of imagination risks becoming theoretically intractable. Many theorists have therefore been at pains to distinguish psychological or cognitive aspects of imagination from the creative sense of imagination, even though these are clearly linked (in our experience of art, for example, or in practices of artistic creativity).

A glance at the history of aesthetics confirms this view. In the Critique of the Power of Judgment (Kritik der Urteilskraft), Kant famously identifies the faculty of imagination as the power of presenting an object in intuition that is not present to our senses. Kant further divided this capacity into the productive imagination (presenting an object that is independent of or 'precedes' experience) and the reproductive imagination (presenting an object through intuitions that have been experienced previously). ${ }^{4}$ Following Kant, the imagination (the 'poetic imagination') played a key role in the aesthetic philosophy of Schelling and the German Romantics, for whom art and poetry, as expressions of the poetic imagination, were central to the romantic critique of Enlightenment rationalism. In The Imaginary (L'Imaginaire), Jean-Paul Sartre argues on phenomenological grounds that imagination is distinct from perception; we can either perceive things or imagine them but not both at once. Images, moreover, are forms of intentional consciousness directed at the world, albeit as objects that have been "de-realized" and thereby posited as "present-absent" (the presentation of something absent). ${ }^{5}$ Indeed, for Sartre, the material aspect of an image (the analogon or analogical representation of something) serves as a visual prop for an intended object posited by the imagination. Looking at an image construed as an analogon (a painting, drawing, or photographic/film image, for example) enables us to freely posit the intended object as "irreal" - absent, non-existent, yet singular and definite - and thus as a noematic expression of the imaginary. One of Sartre's key concerns was to articulate the role of imagination in relation to visual images, a problem that remains of great 
interest to Anglophone aestheticians drawing on cognitivism rather than phenomenology. 6

Given Sartre's suggestive phenomenological account of the imagination, one might have expected that film theorists, certainly those within the so-called 'Continental' philosophical tradition, might have been eager to explore Sartre's analyses for the purposes of theorizing cinema. Yet Sartre's influence on film theory (despite his work on imagination and images) remains negligible. 7 While it is customary to mention Merleau-Ponty's "Film and the New Psychology," the most influential source of phenomenological theory remains Vivian Sobchack's Merleau-Pontian approach (drawing on elements of Husserl's phenomenology), which has generated a rich stream of phenomenologically-oriented theorization emphasizing the notion of the 'film body' and the haptic-synaesthetic dimensions of film experience. ${ }^{8}$ Nonetheless, it is true that, despite the recent proliferation of work in film theory describing itself as 'phenomenological,' there has been as yet little engagement within phenomenological film theory with the role of imagination in cinematic spectatorship. ${ }^{9}$ This is unfortunate, for it is difficult to explore the phenomenon of emotional engagement, and especially the role of empathic and sympathetic responsiveness, without examining the ways in which imagination is at play in cinematic experience. Cinema, after all, is precisely an art of presenting, via audiovisual images, what is absent as though it were present; it is one that depends, moreover, on what is implied off-screen, or audio-visually suggested, rather than directly shown or depicted. Indeed, imagination is central, as I shall discuss, to one key element of such engagement, namely evaluative judgment or moral 'allegiance' with characters in narrative film, which means that imagination - or the cinematic moral imagination - will play a key role in understanding and articulating theoretically the ethical potential of cinema.

It is for these reasons that the English translation of Jean-Pierre Meunier's Les Structures de l'expérience filmique: l'identification filmique from 1969 represents an important theoretical intervention in the field of contemporary film theory. Indeed, this text represents something of a 'missing link' in the historical narrative spanning the development of filmologie as a diverse interdisciplinary research program during the 1940s, 1950s, and 196os and its marginalization by the rise of structuralist, semiotic, psychoanalytic, and Marxist-Althusserian film theories during the 1970s. Bringing together philosophical, aesthetic, psychological, historical, sociological, and anthropological approaches, filmologie now presents itself belatedly as a timely model of interdisciplinary inquiry, showing us how humanistic, hermeneutic and empirically grounded scientific approaches can work together in exploring 
key problems in film theory. Meunier's phenomenological study of the modalities of identification in cinematic experience remains a landmark contribution to this movement, one with many theoretical resonances and unexplored potentials waiting to be explored today.

Meunier is also a missing link in a more theoretical sense, for he is one of the few film theorists to focus on the role of imagination in understanding audio-visual images. More specifically, he examines varieties of imagining (perceptual, affective-emotional, and cognitive) involved in processes of empathic/sympathetic responsiveness, emotional engagement, including moral-ethical evaluation of characters. Meunier's contribution thus offers a rich phenomenology of cinematic experience that seeks to do justice to the complex processes of identification. He analyzes the different modes of engagement with audio-visual images that contribute to our experience of perceptual and emotional responsiveness to moving images, and offers a timely defense of the concept of identification that emphasizes both its intersubjective and imaginative characteristics.

In what follows, I shall focus on imagination and its role in Meunier's phenomenological account of cinematic identification and explore some suggestive parallels with contemporary theorists' accounts of imagination (as perceptual engagement, mental simulation, or make-believe, as well as the threefold "structure of sympathy" that Murray Smith proposes as an alternative way of conceptualizing cinematic identification). ${ }^{10}$ Finally, I consider some difficulties in Meunier's model - his overly clustered concept of 'identification'; a tension between formal-phenomenological analysis and background cultural-historical pre-understanding; and his focus on character identification at the expense of background 'world' apprehension - that could be modified in order to enhance his original contribution to philosophical film theory.

\section{Meunier on Film Experience}

Meunier commences with the phenomenological insight that, before embarking on any empirical or scientific inquiry, we need to describe and analyze the basic structures of lived experience. Reflecting the influence of Merleau-Ponty, Meunier explores the "primacy of perception" in our experience of cinema: he rejects dualistic epistemological accounts that presuppose a disengaged subject confronting an external world of objects, and insists rather on the originary or 'primordial' relationship of perceptual openness towards the world - a relationship of practically engaged comportment, 
rather than of disengaged knowing. Our pre-theoretical relationship with the world, moreover, is defined as holistic, relational, and intersubjective: a primordial intersubjectivity or anonymous 'being-with' others in a shared world that is constitutive of human experience. This phenomenological account of intersubjective Mitsein (being-with) provides the basis for his theorization of cinematic experience, and in particular, of the complex phenomenon of identification. ${ }^{11}$

As has become apparent in the history of film theory, the concept of 'identification' - from psychoanalytical accounts of spectatorial 'suture' to recent cognitivist accounts of emotional engagement and moral sympathy - is at once influential and opaque. ${ }^{12}$ While acknowledging the contribution of Freudian accounts of identification in the development of psychic life, Meunier criticizes the 'empiricist' and 'intellectualist' assumptions that render the psychic life of others as impenetrable or obscure to the isolated self or ego. Instead, Meunier's phenomenological account of identification begins with an anonymous "primordial intersubjectivity"; understood as "a kind of generic co-existence of multiple consciousnesses" that remains "open to the world and to other people" (p. 48). It is against this generic intersubjectivity that singular relations between individuated subjects or individuals can emerge, transforming "primordial intersubjectivity" into "private intersubjectivity" within a shared social world (p. 48). Such relations of private intersubjectivity, moreover, involve reciprocal recognition - the recognition of others as subjects coupled with their recognition of me as a subject - which is the fundamental feature of what Meunier understands by 'identification': a relationship or practical intersubjectivity or relational comportment that has perceptual, affective-emotional, as well as cognitive-practical aspects. In this respect, Meunier's account of identification re-situates the concept within the phenomenological domain of lived experience. Identification, understood as practical intersubjectivity, involves somatic and affective, as well as emotional and practical, comportment with and towards others. It provides the basis for the emotional-evaluative attitudes of sympathy and antipathy, which are themselves nothing other than "the affective dimension of the comprehension of other people" (p.50) expressed in a variety of behaviors or relations of practical comportment within social reality.

\section{Three Attitudes of Spectatorial Identification}

Such an account of identification as intersubjective comportment offers a rich basis for describing the structures of spectatorial identification within 
cinematic experience. Following Merleau-Ponty, Meunier defines this as an experience constituted through perceptual gestalts or the configuration of visual elements; but cinematic spectatorship solicits quite distinctive attitudes of consciousness compared with ordinary perceptual experience. As Meunier points out, this has led a number of theorists to posit cinematic experience as situated "midway between the real and the unreal" (p. 69). He develops this claim into the thesis that "filmic consciousness" can be understood as "a variation of the major category of consciousness that constitutes the imaginary consciousness" (p. 69). Filmic identification, as a form of spectatorial comportment, is thus presented as an "imaginary attitude" with distinctive modalities depending on the particular kind of cinematic image to which the spectator attends. This is Meunier's most original contribution to film theory, which has, for the most part, ignored the role of imagination: an analysis of the three principal modalities of imaginary engagement with cinema pertaining to the film-souvenir (home movie), documentary, and fictional film formats.

Meunier's analysis of cinematic perceptual engagement is indebted not only to Merleau-Ponty but also to a number of lesser-known filmologie theorists (Francois Ricci, Jean-Jacques Rinieri, and Albert Michotte van den Berck). These theorists examined the status of cinematic perception as intermingling the registers of the real and the unreal, where this intermingling solicits different spectatorial attitudes depending on the character of the image being perceived. Their common phenomenological starting point is the widely shared observation that cinematic perception involves a vivid impression of reality coupled with an awareness of 'unreality,' that is, of the imagistic or representational quality of the moving image. For Meunier, this points to the important distinction between real perception, which posits its object as present and as existent, and cinematic perception, which does not posit its object as present but as "absent, or existing elsewhere, or not existing at all" (p. 77). Cinematic perception is directed towards a reality that, although it appears as "real," is not physically present: cinematic consciousness expresses "a relationship with the world, but a world that is not present" (p. 77). ${ }^{13}$ This apprehension of a perceived world that is presented as absent means that cinematic experience corresponds to key elements of the "imaging consciousness" that Sartre describes in The Imaginary (p. 77). Cinematic perception involves the "imaging function of consciousness" - in the phenomenological, rather than psychoanalytic, sense - that "renders present an object that we know is not there" (p. 78).

Meunier's analysis, distinguishing between different spectatorial attitudes (presentification, instruction, and participation) towards different 
modes of cinematic presentation (home movie, documentary, and fiction film), is original and impressive. Despite Sobchack's well-known criticism, namely that these three attitudes of consciousness and their corresponding forms of cinematic presentation are subjectively variable ("one person's fiction might be another person's documentary"), Meunier acknowledges that his schematic categorization of spectatorial attitudes should be taken as an analytic or theoretical artefact. ${ }^{14}$ In reality, spectators can move between all three modes of engagement (presentification, instruction, and participation) within the course of a single film-viewing; and there is also no firm "objective" distinction between the three "categories of film" he describes (p. 115) (home movie, documentary, and fiction), which can be combined in various ways in different kinds of cinematic works. ${ }^{15}$ Rather than focusing on putative properties of the cinematic work, his analysis emphasizes, rather, the solicitation of different "existential attitudes" (whether objects or subjects are posited as existing or not), which are not necessarily tethered to objective features of particular cinematic genres or styles.

There are a number of striking parallels, I suggest, between Meunier's phenomenological account of spectatorial attitudes, comprising the phenomenon of identification (different modalities of cinematic experience), and more recent analyses of emotional engagement and cinematic imagination. His model anticipates and reflects, for example, Murray Smith's influential threefold model of the "structure of sympathy" defining emotional engagement ('identification'): recognition, or what Meunier calls the "understanding" of individuated characters (p. 128); alignment, or what Meunier calls "affectivization and valorization" (p. 138) with regard to the experiential perspectives of characters; and allegiance with characters involving moral-ethical or aesthetic evaluation, which Meunier describes as imaginative "participation" focused on "sympathetic, valorized characters" (p. 139). Although these three aspects of identification are not as clearly or precisely marked out as in Smith's account of the structure of sympathy (there is some slippage between alignment and allegiance, for example), Meunier nonetheless anticipates Smith's important distinction between alignment with a character's subjective perspective or point of view, and moral-aesthetic allegiance involving a sense of imagined 'participation' with sympathetically portrayed or morally valorized characters. What could have been made clearer in Meunier's account is the possibility of alignment with a character's perspective occurring without necessarily being linked with the 'valorization' of that character, and that imaginative participation with valorized characters nonetheless typically depends upon 
effective perspectival alignment coupled with sympathetic depiction and moral evaluation of their specific traits, views, or actions.

Meunier's model of identification, moreover, not only resonates with Sartre's theory of imagination, but also with more recent cognitivist accounts of cinematic imagination as a form of perceptual imagining that uses moving images as audiovisual props for emotional and cognitive forms of 'simulation. ${ }^{16}$ Like Sartre, the audiovisual image serves as an analogon that enables varieties of perceptual imagining as well as emotional involvement in a fictional world. Like cognitivist theorists, such audiovisual images function as complex 'props' for imaginative forms of 'make-believe' that involve entertaining in imagination fictional characters, scenarios, and worlds in ways that do not entail corresponding attitudes of belief that would guide or solicit practical forms of action. The most significant difference with both Sartrean and cognitivist accounts, however, is that Meunier's phenomenological approach insists on a relational intersubjectivist model of perceptual and practical engagement with others within a shared 'being-inthe-world.' His model thus shifts from the solitary consciousness intending imaginary objects or the 'worldless' cognitive subject engaging in subjective forms of imaginative simulation to an intersubjectivist model of recognition that grounds our capacity for imaginative involvement within an originary intersubjectivity and shared sense of being-in-the-world.

This relational account of the phenomenon of imagination, moreover, encompasses individuated forms of intersubjectivity, which encompasses such recent theoretical insights and topics as affective mimicry, emotional contagion, as well as 'higher' cognitive forms of imagining (as in mental simulation or moral-normative evaluations). ${ }^{17}$ Here again Meunier's account provides a prescient 'missing link' between contemporary phenomenological and cognitivist accounts of imagining, emotional engagement, and the ethical evaluation of film.

\section{Three Problems with Meunier's Filmic Identification}

There are three problems, however, arising from Meunier's model of identification that I wish to consider further, suggesting that these could be theoretically revised drawing on contemporary phenomenological and cognitivist approaches. The first is to clarify the distinct senses of 'identification' at play here: Meunier's use of the term encompasses the phenomenological sense of primordial and private intersubjectivity providing the experiential basis for the development of personal identity through social interaction; the 
aesthetic sense of imaginative involvement and emotional engagement with individuals or characters within different modes of cinematic presentation (home movie, documentary, fiction film); and the psychoanalytic sense of introjection and projection as well as ego idealization and psychological modeling played out in imaginative and intersubjective registers. It would be desirable to distinguish more clearly between these three distinct senses of 'identification' (phenomenological, aesthetic, and psychoanalytical) and to articulate more precisely the conceptual relations between them. The phenomenological sense of identification, for example, occurs at an implicit, perceptually engaged but not explicitly conscious or 'thematized' level, which is quite different from what one would describe as 'unconscious' in a psychoanalytic sense. The explicit forms of 'identification' pertaining to emotional engagement with characters, in contrast, occur at a different level from either originary intersubjectivity or the psychologically gratifying, culturally-mediated emulation of movie stars (Meunier cites the popular cultural example of female fans going for the "Brigitte Bardot look" [p. 149]). Using the same term to cover all three processes obscures rather than clarifies the conceptual distinctions and relations between them.

At the same time, there remains an important potential in the concept of identification that is worth retrieving and revising. Berys Gaut, for example, argues that the concept of filmic identification, despite its phenomenological and cognitivist critics, should not be rejected but revised..$^{18} \mathrm{He}$ advocates a pluralist conception of identification that distinguishes between different aspects of the phenomenon, arguing that only some, rather than all, of these aspects can come into play in processes of identification. Indeed, if we construe the process of identification as involving a plurality of aspects (perceptual identification, affective identification, epistemic identification, and so on), which need not be activated all at once, we may rehabilitate the term theoretically in a way that accords with the folk sense of 'identifying' with characters in film, while at the same time maintaining important distinctions such as sympathizing with a character in moral terms. ${ }^{19}$ Nonetheless, it is clear that there are many aspects involved in such processes of identification that require more specification than the concept of identification generally affords. Meunier's model could therefore be adapted here, along the lines that Gaut suggests, in order to specify more precisely the pluralistic forms of identification at play in the three modalities of home movie, documentary, and fiction film, and to distinguish more explicitly between phenomenological, aesthetic, and psychoanalytical senses of identification.

The second problem is a tension arising between the formal-phenomenological analysis of spectator consciousness in respect to the three modes of 
intentional imagining, and the background cultural awareness of cinematic genres and conventions that operate in any 'immediate' subjective apprehension of audiovisual images (home movie, documentary, and fictional film). Meunier's analyses focus on the distinctive attitudes of existential positing in respect to the three modalities of moving image, but then treat these forms of subjective 'taking' as occurring independently of the hermeneutic 'background' or 'pre-judgements' inevitably shaping our engagement with (culturally and historically embedded) intentional objects such as filmic works, whether fictional, non-fictional, or reconstructive/memorial. This is not to deny the value and significance of undertaking the kind of subjective phenomenological descriptive analyses that Meunier offers. Rather, it is to suggest that these analyses could be more concretely situated within a hermeneutic 'horizon' of implicitly shared cultural-historical meaning that any contextually situated spectator would bring to such images and that would orient the manner in which spectators posit them as particular kinds of image. It is not immediately apparent on the face of the image whether it is personal/memorial, documentary, or fictional but soon becomes so once the contextual situation and background understanding of the viewer is taken into account. Adding this hermeneutic dimension to Meunier's phenomenological analyses would add the relevant contextual understanding and implicit situated knowledge that helps orient us affectively and cognitively in response to the contextually-defined varieties of audiovisual images we encounter.

The third problem is 'forgetting of world' characteristic of most psychological accounts of identification or spectatorial engagement. Despite drawing on phenomenological analysis of the primacy of perception and openness to the world, Meunier passes over the 'background' intelligibility or shared 'being-in-the-world' that make possible the identification with individuated characters that forms the focus of his phenomenological analysis. Since perception is attuned to an originary intersubjectivity within a relationally defined meaningful whole (a phenomenologically disclosed world), this suggests that filmic experience too, as perceptual and imaginative, is shaped via our affective-emotional and cognitive engagement with distinctive cinematic worlds. We do not simply encounter human figures, whether real individuals or fictional characters, in isolated abstraction from relational contexts or horizons of meaning; rather, it is against such background intelligibility or 'worldliness' that individuals or characters can show up as individuated personages that are perceptually recognizable or cognitively significant. It is these shared 'background' forms of meaning - or what we could call patterns of world-disclosure through 'mood' or 
affective attunement - that open up or reveal the 'foreground' phenomena of individuated characters appearing within a meaningful context of action. ${ }^{20}$ A phenomenological account attuned to specific cinematic world-contexts would shift the theoretical focus from individual perception to forms of intersubjective understanding, or enable us to move from a more narrowly author-based account to one that regards cinematic worlds as disclosing shared forms of meaning relating to extra-cinematic realities beyond that of the (narrative) film itself.

These three issues - refining and specifying the concept of identification; clarifying the relationship between phenomenological analysis of spectator experience and the background contextual knowledge that informs this experience; and contextualizing character engagement within the immersive experience of a cinematic world - could be elaborated further in order to revise Meunier's phenomenological account of imaginative identification in regard to different modes of cinematic presentation. This would provide a basis for developing Meunier's descriptive framework and integrating it with more recent work on the phenomenological and cognitive dimensions of affective and emotional engagement with both fictional and non-fictional film. ${ }^{21}$ In this way, the productive potential of Meunier's long-neglected work could be realized in a context that opens up an interdisciplinary inquiry into cinematic imagination inspired by the pioneers of the filmologie movement and would thereby contribute to contemporary film-philosophical approaches to theorizing cinematic experience and renewing the concept of identification. These comments are offered in recognition of Meunier's remarkable achievement: a rich phenomenological account of the basic structures of cinematic experience that shows how imagination, emotion, and cognition work together in our complex lived experience of moving images.

\section{Notes}

1. See Tamar Gendler's comprehensive entry on "Imagination" (2011) in the Stanford Encyclopedia of Philosophy: https://plato.stanford.edu/entries/imagination/ (Last accessed on 1 September 2017).

2. Kendall Walton, Mimesis as Make-Believe (Cambridge, MA: Harvard University Press, 1990), p. 19.

3. Leslie Stevenson, "Twelve Conceptions of Imagination," in British Journal of Aesthetics, 43:3 (2003), p. 238.

4. Immanuel Kant, Critique of the Power of Judgment, trans. Paul Guyer and Eric Matthews (Cambridge: Cambridge University Press, 2001 [1790]). More- 
over, what Kant called the "transcendental imagination" played a key role in the 'synthesis' of concepts and intuitions necessary for cognitive experience (at least in the A version of the Critique of Pure Reason).

5. Jean-Paul Sartre, The Imaginary: A Psychological Phenomenology of the Imagination, trans. Jonathan Webber (London: Routledge, 2010 [1940]). See Sarah Marshall, "Sartre and the Imaginary," Evental Aesthetics, 3:1 (2014), http://eventalaesthetics.net/evental-aesthetics-vol-3-no-1-2014/sarah-marshall-sartre-and-the-imaginary/ (Last accessed on 1 September 2017).

6. See Gregory Currie and Ian Ravenscroft, Recreative Minds: Imagination in Philosophy and Psychology (Oxford: Oxford University Press, 2002); Matthew Kieran and Dominic Lopes (eds.), Imagination, Philosophy, and the Arts (London: Routledge, 2003); and Walton, Mimesis as Make-Believe.

7. See J.D. Connor, "Sartre and Cinema. The Grammar of Commitment," in Modern Language Notes 116:5 (2001): 1045-1068.

8. Maurice Merleau-Ponty, "The Film and the New Psychology," in Sense and Non-Sense, trans. Hubert L. Dreyfus and Patricia Allen Dreyfus (Evanston, IL: Northwestern University Press, 1964 [1945]), pp. 48-59. Vivian Sobchack. The Address of the Eye: A Phenomenology of Film Experience (Princeton, NJ: Princeton University Press, 1992); Vivian Sobchack, Carnal Thoughts: Embodiment and Moving Image Culture (Berkeley, CA: University of California Press, 2004). Alan Casebier's Film and Phenomenology: Towards a Realist Theory of Cinematic Representation (Cambridge: Cambridge University Press, 1991), a Husserlian account of cinematic realism, has not been as influential as Sobchack's work, reflecting the selective appropriation of phenomenology within (Anglophone) film theory (Merleau-Ponty rather than Husserl, Sartre, or Heidegger). For a comprehensive critical discussion of the history of film phenomenology, see Christian Ferencz-Flatz and Julian Hanich, "What Is Film Phenomenology?" Studia Phaenomenologica, vol. 16 (2016): 11-61.

9. Two notable exceptions here are Julian Hanich's chapter "Intimidating Imaginations: A Phenomenology of Suggested Horror," in his Cinematic Emotion in Horror and Thrillers: The Aesthetic Paradox of Pleasurable Fear (New York and London: Routledge 2012), pp. 108-126; and Jane Stadler, "Imagination: Inner Sight and Silent Voices," in her Pulling Focus: Intersubjective Experience, Narrative Film, and Ethics (London and New York: Continuum, 2008), pp. 168-205. See also Julian Hanich, "Omission, Suggestion, Completion: Film and the Imagination of the Spectator," in Screening the Past, issue 43 (2018) http://www.screeningthepast.com/2018/o2/omission-suggestioncompletion-film-and-the-imagination-of-the-spectator/ (Last accessed on: 28 April 2018).

10. See Murray Smith, Engaging Characters: Fiction, Emotion, and the Cinema (Oxford: Oxford University Press, 1995).

11. Although Meunier cites Merleau-Ponty and Sartre, there is an implicit 'Heideggerian' layer to his phenomenological analysis that remains opera- 
tive rather than thematic (to use a phenomenological distinction). This is evident in his recourse to terms such as 'comportment,' 'being-in-the-world,' and emphasis on the intersubjective relationality or originary 'being-with' others in the world.

12. See Jean-Louis Baudry, "The Apparatus: Metapsychological Approaches to the Impression of Reality in the Cinema" and "Ideological Effects of the Basic Cinematographic Apparatus," in Leo Braudy and Marshall Cohen (eds.), Film Theory and Criticism: Introductory Readings, $6^{\text {th }}$ edition (New York: Oxford University Press, 2004), pp. 206-223 and pp. 355-365; Christian Metz, Film Language: A Semiotics of the Cinema, trans. Michael Taylor (New York: Oxford University Press, 1974); and Christian Metz, The Imaginary Signifier: Psychoanalysis and Cinema, trans. Celia Britton, Annwyl Williams, Ben Brewster, and Alfred Guzzetti (Bloomington, IN: Indiana University Press, 1982); David Bordwell, "Contemporary Film Studies and the Vicissitudes of Grand Theory," in David Bordwell and Noël Carroll (eds.), Post-Theory: Reconstructing Film Studies (Madison, WI: University of Wisconsin Press, 1996), pp. 3-36; and Stephen Prince, "Psychoanalytic Film Theory and the Case of the Missing Spectator," in David Bordwell and Noël Carroll (eds.), Post-Theory: Reconstructing Film Studies (Madison, WI: University of Wisconsin Press, 1996), pp. 71-86.

13. A phrase that anticipates Stanley Cavell's reflections on the ontology of film. See Cavell, The World Viewed: Reflections on the Ontology of Film, Enlarged Edition (Cambridge, MA: Harvard University Press, 1979), pp. 23-25.

14. Vivian Sobchack, "Toward a Phenomenology of Non-Fictional Film Experience," in Collecting Visible Evidence, ed. Michael Renov and Jane Gaines (Minneapolis, MN: University of Minnesota Press, 1999), pp. 241-254.

15. A film can deploy all three modes - for example, Michael Haneke's Benny's Video (1992) - within an overtly fictional mode of presentation.

16. See Gregory Currie, Image and Mind: Film, Philosophy and Cognitive Science (Cambridge: Cambridge University Press, 1995); and Walton, Mimesis as Make-Believe.

17. See Amy Coplan, “Catching Characters' Emotions: Emotional Contagion Responses to Narrative Film," in Film Studies: An International Review 8 (2006), pp. 26-38; Jane Stadler, Pulling Focus, pp. 196-201; and Carl Plantinga, Moving Viewers: American Film and the Spectator's Experience (Berkeley, CA: University of California Press, 2009), pp. 115-136.

18. Berys Gaut, A Philosophy of Cinematic Art (Cambridge: Cambridge University Press, 2010), pp. $258 \mathrm{ff}$.

19. Gaut, A Philosophy of Cinematic Art, pp. 260-261.

20. See Robert Sinnerbrink, "Stimmung: Exploring the Aesthetics of Mood," in Screen 53(2) (Summer 2012): pp. 148-163.

21. See, for example, Asbjorn Grønstad, Film and the Ethical Imagination (London: Palgrave MacMillan, 2016); Carl Plantinga, Screen Stories: Emotion and the Ethics of Engagement (Oxford: Oxford University Press, 2018); Robert 
Sinnerbrink, Cinematic Ethics: Exploring Ethical Experience through Film (New York and London: Routledge, 2016); and Jane Stadler, Pulling Focus.

\section{About the author}

Robert Sinnerbrink is Associate Professor in Philosophy and former Australian Research Council Future Fellow at Macquarie University, Sydney. He is the author of Terrence Malick: Filmmaker and Philosopher (Bloomsbury, 2019), Cinematic Ethics: Exploring Ethical Experience through Film (Routledge, 2016), New Philosophies of Film: Thinking Images (Continuum, 2011), Understanding Hegelianism (Acumen, 2007/Routledge 2014), and is co-editor of Critique Today (Brill, 2006). He has published numerous articles on the relationship between film and philosophy in journals such as the Australasian Philosophical Review, Angelaki, Film-Philosophy, NECSUS, Projections, Post-Script, Screen, Screening the Past, and SubStance. His current research interests include philosophical aesthetics, philosophy of film/film philosophy, critical theory, phenomenology, cognitivism, theories of emotion, moral imagination, and the relationship between ethics and aesthetics. He is a former member of the Executive Committee (2010-2016) and inaugural Chair of the Australasian Society for Continental Philosophy (2007-2010). He is a member of the editorial boards of the journals Film-Philosophy and Projections, an associate editor for the journal Film and Philosophy, member of the editorial advisory board of Parrhesia: A Journal of Critical Philosophy, member of the general editorial board of the journal Derrida Today, member of the editorial board for the online journal Transformations, and a member of the editorial board for the Brill Series on the Philosophy of Film. 


\section{II: ON THE HoME-MOVIE ATTITUdE}




\title{
'Me, Myself, and I': On the Uncanny in Home Movies
}

\author{
Vivian Sobchack
}

\begin{abstract}
The home-movie 'attitude' is one of Jean-Pierre Meunier's three modalities of 'filmic identification' in The Structure of the Film Experience. This essay both challenges and pays homage to Meunier's heuristic phenomenology. Accepting his invitation to elaborate upon it with specific cases, I thus focus on those instances when the home-movie viewer's off-screen self-image suddenly encounters its on-screen image-self in a structure of identification quite different from identification with on-screen others. Often experienced as 'uncanny,' this confrontation with one's 'self' not only adds nuance to, but also ruptures and/or transforms what Meunier considers the 'essential' characteristics and overall phenomenological function of the home-movie experience.
\end{abstract}

Keywords: Existential phenomenology; Meunier; filmic identification; self-preoccupation; self-image/image-self

I.

In a powerful summary of the essential phenomenological structure and meaning of viewer identification in the 'home-movie attitude,' Jean-Pierre Meunier considers the futility of its impossible intentional project. This is to somehow 'evoke' and 'render present' to ourselves those family members and friends who once existed for the off-screen camera - and more fully than they do in the film or the space-time in which we presently view them as 'keepsake' images. Indeed, our existential knowledge of their physical absence and temporal distance there and then is outweighed by our desire to be with them here and now as they were. Rather than looking at the film's specific images in the home-movie attitude, we see through them in an

Hanich, J. and D. Fairfax (eds.), The Structures of the Film Experience by Jean-Pierre Meunier. Historical Assessments and Phenomenological Expansions, Amsterdam University Press, 2019 DOI 10.5117/9789462986565_SOBCHACK 
attempt to evoke these individuals more generally, and to 're-presence' them in a present, yet paradoxically past, reunion of which we, ourselves, are an integral part. As "one of the poles" of this desire to "render a person present," Meunier emphasizes that "it is often our presence to the person that we try to evoke" (p.123). Indeed, "seeking a relationship of real intersubjectivity," it is "our own presence [that ] is constantly felt" (p. 123).

This realization of intersubjectivity in the home-movie attitude is, of course, impossible. The viewer's failed attempt at evocation and reunion leads not only to disappointment and compensatory nostalgia, but also to a sense of the existential absurdity of such an identificatory project. Our "will for a personal engagement," Meunier concludes, "is confronted with the void and remains suspended, without any possible outlet or any real signification" (p.123). Given we are "incapable of being engaged," our sense of self-presence becomes explicit, "felt all the more [and] entirely preoccupied with itself" (p.123). In sum, as viewers trying to connect with familiar others as they were 'elsewhen' and 'elsewhere' (even while some of them might now be 'as they are' in the room), we are always already bereft - irremediably, and absurdly, alone with ourselves on our side of the screen. ${ }^{1}$

Nonetheless, there is more to be said about "self-preoccupation" in the home-movie attitude. Meunier acknowledges that "there would be a great deal of nuance to add, and numerous specific cases to examine" (p. 123). In what follows, I examine one such specific case of the home-movie experience that adds nuance to, but also challenges, the particular phenomenological structure that Meunier describes as essential to it. This is the not uncommon instance in which a significant number of viewers come 'face to face' with their on-screen 'self' in an identificatory experience that is sensed as 'uncanny.' However, before elaborating, insofar as I am in sympathetic dialogue with, and also adopt, Meunier's phenomenological schema and filmic corpus, I need to address two related methodological issues that inform my discussion.

The first concerns the nature and scope of the film objects that, in concert with the viewer, Meunier considers co-constitutive of the home-movie attitude. These are "films made for private purposes, with the goal of acting as a keepsake or record of an event in the individual's life, such as weddings, vacations, family gatherings, etc." (Fairfax, fn. p. 155/156). Adopting this corpus allows me to ground my phenomenological variation both within and against Meunier's descriptions, and also limits what would, if expanded, add yet another highly significant - and unwieldy - variable. Most important, however, is that, although films made only for 'private purposes' may now seem a somewhat dated circumscription, Meunier's corpus is still culturally relevant today. Certainly, when The Structure of the Film Experience (Les Structures de 
l'expérience filmique:L'identification filmique) was published in 1969, ordinary people did not go about their world as we do now, constantly recording and screening everything in sight - including themselves - for public as well as private consumption. Indeed, Super-8mm film cameras appeared on the mass market only four years before Meunier's phenomenology. (Videotape and then digital camcorders were mass-marketed, respectively, in the mid-1980s and mid-199os, and smartphones in the early 200os.) His corpus thus includes the kinds of films made by most non-professionals at the time. These kinds of films are also commonplace today, if within a technologically expanded audiovisual context in which they - and their makers - have become increasingly available for public view. Thus, in certain circumstances discussed below, constant personal recording and 'familiarized' on-screen visibility may forestall the uncanny home-movie experiences I foreground here.

The second methodological issue involves both translation and terminology. Instead of using the common, and more inclusive, le film amateur, Meunier generically names his corpus le film-souvenir (a term I have found in no French dictionary). Apparently a neologism, the term foregrounds filmic objects whose primary solicitation is mnemonic, hyphenation both connecting and separating them from subjective acts of personal remembrance. ${ }^{2}$ Although $l e$ film-souvenir has preeminence in a previous essay I have written on Meunier's work, here I privilege its English equivalent, 'home movie. ${ }^{3}$ Connotations of personal remembrance may be lost, but those of 'home' are gained: in particular, the sense of familiarity, intimacy, and comfort that the uncanny subverts. In this context, 'home' also calls up the uncanny through its subversive German opposite 'unheimlich,' translated literally as 'unhomely.' Designating an experience in which what is familiar is suddenly turned disturbingly strange and secretive, the term is closely tied to key psychological and philosophical studies of the phenomenon (three later referenced here.) However, what follows is an existential phenomenology rather than a psychological etiology, psychoanalytic explanation, or philosophical extrapolation, and thus I have chosen to use the less affiliated, more generalized, and English 'uncanny.' It is also, dare I say, more 'familiar' to those who existentially experience its estrangement in the American cultural context this phenomenology describes.

II.

So now to those instances, in which we view ourselves in a home movie; when, in the existential gap between what I will call our objective 'image-self' and our subjective 'self-image,' 'I' comes suddenly face-to-face with 'me.' 
This is an identificatory encounter that a significant number of viewers find uncanny in its disconcertingly asynchronous reversibility and destabilizing reflections. Certainly, although common enough to generate public discourse, this experience is not inevitable. In particular, it seems less likely when the viewer's own agency brings their 'self-representation' into existence, whether before a bathroom mirror or, increasingly, in Skype video calls, YouTube videos, and 'selfies.' In such instances, the viewer tends to retain a relatively comfortable sense of 'self-possession.' This is not the case, however, for those who come upon themselves in home movies and experience not 'self-representation' but a disconcerting 'representation of one's self,' the latter filmed - and filtered - through someone else's agency and cinematographic perception (even if of a close friend or family member).

This encounter with 'one's self' on-screen suddenly disarticulates our usually transparent sense of 'one self' into two: a perceiving 'I' and a visible 'me.' In this regard, and given that his phenomenology greatly influences Meunier's own, here I turn to Maurice Merleau-Ponty, who elaborates: “[A] sort of dehiscence opens my body in two, and [...] between my body looked at and my body looking, [...] there is overlapping or encroachment." ${ }^{\prime \prime}$ Thus, an estranged self-consciousness arises at this intimate filmic reunion in disunion (and vice versa). The overlapping and encroachment of my image-self and self-image in their asynchronous difference and non-coincident reversibility not only preoccupies me (or is it 'I'?), but also displaces and destabilizes me (or is it 'us'?). For many viewers, this is an uncanny experience.

Certainly, this self-preoccupation affirms a phenomenological element Meunier considers essential to the home-movie attitude. Nonetheless, looking at one's image-self rather than the image of someone else negates what, for Meunier, is the essential phenomenological function of the home movie: its service as a medium through which we constitutively generalize and transcend the specificity of those on-screen, who are personally, and more expansively, known to us. Indeed, even when experienced as pleasing or funny rather than uncanny, one's own image on-screen tends to produce self-preoccupation, its ontic 'thereness' resistant to generalization and transcendence. When experienced as uncanny, however, this 'thereness' and its obdurate opacity intensifies and provokes three possible modalities of the uncanny, each of which is differently structured and thus experienced and responded to in different ways.

The first modality is what I call the 'axiological uncanny.' It arises as a crisis of self-perception in relation to the representation of one's self rather than the home movie's crisis of the unrealizable 'presentification' of others. The second, or 'epistemological uncanny,' is a cognitive crisis 
of self-knowledge. The third, or 'ontological uncanny,' is an existential crisis of self-identity. Progressive movement is thus from a sudden and disturbing sense that one is only partially known to one's self to the sudden re-cognition that one is always partially unknown to one's self, and then to the transformative revelation that one is ultimately unknowable to one's self. Throughout, just as with on-screen others, one's own existence is posited as 'real.' However, given that we each live our self both inside and out, it is presumed more intimately and fully known than the existence of even the most familiar others.

This presumption is put into question by the centrality of asynchronous time in the home-movie experience. That is, when off-screen 'I' encounters on-screen 'me,' time is spatialized in my past image-self's visibly different appearance and comportment from that envisioned as my present self-image. While this asynchronous disparity may generate a sense of nostalgia, it also may generate an uncanny experience in which the viewer's general sense of self-knowledge and self-possession is suddenly destabilized. We might suspect that the wider the temporal gap between the image-self and self-image, the greater their estrangement and the more intense the 'sense' of uncanniness. Nonetheless, it is when the image-self and self-image are most temporally proximate to each other that the 'sensation' of uncanniness is most perceptibly felt. Here, sense and sensation do not have the same temporal structure - duration tends to mark the one while immediacy marks the other. Time thus modifies the quality of the uncanny, which moves from a perceptible sensation of sudden perturbation to a more reflective (if still unsettling) re-cognition of self-estrangement to an encompassing existential apprehension that this estrangement and lack of self-possession is the grounding condition of one's very being. (This progression bears some relation to, respectively, the psychological senses of the uncanny associated with Sigmund Freud and the earlier Ernst Jentsch, and its philosophical sense for Martin Heidegger, each referenced below in the description of a specific mode of uncanny experience. ${ }^{6}$ )

\section{III.}

The 'axiological uncanny' is so-called because its experience is dominated by aesthetic judgments and questions of self-value. It emerges in the unexpected gap between the viewer's internalized and taken-for-granted self-image and the exteriorized, 'in your face' image-self, and occurs most often when both are temporally proximate. (There is often a similar gap between the 
sound of the image-self's externally represented voice and the self-image's internally heard one.) However, what is most uncanny and destabilizing is the sudden awareness of the disparity between subjective self-perception and objective representation. The emergence of the axiological uncanny thus not only undermines the viewer's security in their self-knowledge, but also raises doubts about intersubjectivity, belying the belief in it which otherwise grounds the home-movie attitude. Articulated silently, the viewer asks, "Is that really me?" and "Do other people really see me this way?"

In this regard, the axiological uncanny is the most literally superficial of modalities, and the viewer's self-preoccupation most apparent. The predominant response to its emergence is intensified attention to and excessive scrutiny of the image-self in all its specificity. Thus, opposite to the basic identificatory structure of the home-movie attitude, the viewer's activity is neither highly constitutive nor more expansive than what the screen provides. Instead, it is completely screen-dependent. Indeed, the constitutive activity of generalization is replaced by the activity of comparison, this between the image-self's external characteristics and those internally perceived - but now questioned - as constituting the selfimage. Correspondingly, this activity of comparison also entails ongoing aesthetic and personal valuation aimed at some form of reconciliation or self-recuperation.

Although fixated on the screen, the viewer still retains the longitudinal intentionality central to Meunier's home-movie attitude. This is a primary investment in the present moment of viewing, in which retention and protention play little part. Nonetheless, the viewer's malaise modifies the quality of this investment. It is greatly intensified by the viewer's close scrutiny, and (usually) negative judgment of what seems every specific detail and aspect of their on-screen image-self. Indeed, in an online forum titled "Do you feel uncomfortable watching yourself on video?," many posters write that they 'hate' watching themselves because, as the initial poster puts it, "I just don't look as I THINK I look [...] I literally squirm when I see myself [...] I look like someone I hardly recognize [...] I also pull very strange expressions and move my head more than necessary." Almost all the respondents agree, one of them writing, "I hate my voice and my nose always overtakes my face," and another, "I can't bear watching or hearing myself on video [...] I tend to think 'God, do I really look that bad?'” Only a very few posters do not have the same experience. However, as I have suggested earlier, all recorded themselves and, through this activity of 'self-possession,' feel sufficient familiarity to 'own' their on-screen image-self. One is an "actor/filmmaker"; another "recorded EVERYTHING" and put it 
on YouTube, and so "got pretty used to the way I looked and sounded"; and the last, who otherwise finds his image-self "awful," adds, "However, I think I look fine if I take it myself."

In this regard, the experience of the axiological uncanny's particular form of self-preoccupation significantly changes the viewer's overall intentional project or objective by reversing its direction. For Meunier, even if doomed to failure, what is essential to home-movie identification is the viewer's attempts to achieve 'real intersubjectivity' with on-screen others. Instead, here the viewer's intentional objective is 'real intrasubjectivity' with 'one's self' - that is, rather than overlapping or encroachment, the intimate integration of the estranged image-self with the presently familiar self-image. The achievement of this integration is also doomed to failure, for the desire that drives it is the fantasy of a fully-possessed and 'unified' self - a fantasy that the other two modalities of the uncanny progressively re-cognize and dis-solve. At best, then, viewers may achieve a reconciliatory, but less than equivalent, adequation of their self-image and image-self by re-solving the disparity between them.

Most often, this reconciliatory attempt at adequation is focused on superficial differences, such as hairstyle or weight, that are tied to and thus putatively 'caused' by the temporal gap between the image-self and self-image. These are differences that do not make much of an existential difference and so are used to 'explain away' the uncanny rather than lingering on its challenges to self-perception and self-knowledge. However, many viewers also appease the uncanny and repress their failure at fully integrating their off- and on-screen selves by adopting - as Meunier says of late French filmology - a "certain scientific attitude [...] consisting of [...] externalizing, in the domain of objective realities observable from the outside, phenomena whose reality is to be found internally, in the experience of the subject" (p. 33). Adopting such a "scientific attitude," the viewer becomes actively engaged not in the evocation of known others but, rather, in the invocation of impersonal experts whose explanations of the viewer's experience are objective. These are likely to reference the 'uncanny valley' hypothesis (influenced by Jentsch and Freud) that names the region of negative emotional response generated by humanoid robots very close to appearing human and yet not close enough, and/or the 'mere-exposure effect' hypothesis, which posits that one's repeated exposure to one's mirror image makes one's screen image uncanny because the latter is reversed from the intimately familiar one seen every day. ${ }^{8}$ These objective explanations of the phenomenon do not 'explain away' the experience of the uncanny; rather, their rational surety is palliative and comforting. Nonetheless, for many viewers, the experience 
of the axiological uncanny is recurrent and so repeatedly disturbing that they avoid home-movie screenings altogether. As one of the aforementioned posters writes, "I won't even watch my wedding video."

Avoidance, however, is definitely not a response to the 'epistemological uncanny' - indeed, quite the opposite. Although the viewer feels an initial frisson of estrangement from their home-movie image-self, this modality of the uncanny is dominated by a desire not to flee the image-self but to re-cognize it - that is, to learn and 'comprehend' it so as to regain the sense of self-possession. Moreover, given that the epistemological uncanny tends to emerge when the image-self is at a significant distance in time from the viewer's present self-image, the viewer's engagement is less screen-dependent than in the axiological uncanny, and feels less temporally urgent. This temporal distance also becomes spatial distance. That is, the viewer's attention literally expands from judgmental scrutiny of the smallest details and perceived aesthetic defects of the image-self to its comportment, gestures, and overall behavior in a broader context. As well, there is no comparative activity, nor is the primary intentional objective either an impossible intersubjectivity with on-screen others, or an impossible intrasubjectivity that fully integrates image-self and self-image. Indeed, this spatialized temporal distance transforms the viewer's home-movie attitude into one very much like - but not exactly like - what Meunier describes as the "documentary attitude", in which the intentional objective is new knowledge of, among other things, someone posited as existentially 'real' who is not oneself (p.124).

Given this transformation of attitude and intentional objective, the home movie is no longer temporally perceived only longitudinally, retention and protention subordinated to each present moment of viewing as irrelevant to evoking those absent others of whom we have more knowledge than their screen images give us. Rather, faced with our uncanny image-self which, though clearly familiar, seems suddenly distant and unknown to us, the home movie is now temporally perceived not only longitudinally but also, to use Meunier's term, "laterally" (p. 108). As in the documentary attitude, the viewer is still intent on the screen in the present moment, but also actively engaged in the retention of past screen information - albeit still not concerned with some projected future. Thus, learning more about the self one thought one already knew becomes a cumulative process that has no necessary teleology. Responding to the epistemological uncanny, we could say the viewer becomes 'apprenticed' to their image-self, not to focus on how it looks or sounds, but rather to learn more about how it behaves in the world and with others.

In this regard, the viewer's intentional objective in the epistemological uncanny is comprehension of the past image-self rather than its full 
integration with the present self-image. The existential distance between the two is respected, and a spatial as well as temporal 'long view' becomes the favored way to observe and add specificity to the general knowledge of one's comportment and behavior in a given context. Describing such identificatory engagement with documentary, Meunier uses the example of watching a film that focuses on a single doctor whom we see in the general and cumulative activities and contexts of 'doctoring.' In the documentary attitude, despite this doctor's singularity and specificity, we tend to see him as representative of other doctors who comport themselves and behave in a generally similar way; he is thus engaged as what, in logic, is sometimes called a 'typical particular.' ${ }^{10}$ However, in the context of the home movie, such epistemological engagement with our own image-self takes a different turn (even if we also happen to be doctors). Qualified by the uncanny, our identification operates in a reverse direction from that in Meunier's example. Here, then, I offer an example of my own: a home movie in which, in a distant past, I am playing with my then two-year old son. Given that, at the time, my focus was on him and not self-consciously on myself, I remember the experience only generally, if at all. Watching this long past maternal scene, my desire now is to 'learn' more of myself as a 'mother' through observation and comprehension of my image-self's particular motor/postural comportment and affective behavior as I interact with my child. Quite unlike identificatory engagement with Meunier's documentary doctor, whom I engage as 'representative' of many doctors, my identifactory intention in this home movie is to specifically 'differentiate' myself from other mothers within what I know as the activity and context of 'mothering.' Thus, in this mode of the uncanny, although my focus on my image-self's specificity is less intense and narrow in scope than in the experience of the axiological uncanny, it tends to be more so than it would be in the documentary attitude, in which I watch and learn 'real' but personally unknown 'others' rather than 'my self.' Here, again, the experience of the uncanny modifies the characteristics of Meunier's phenomenology.

In sum, this shift to a less urgent and affectively 'cooler' documentary attitude occurs within the home-movie attitude and is not a complete move from one to the other. Instead, it is a compensatory response to the uncanny that entails an epistemological re-cognition or taking up of one's past image-self in a more impersonal than personal mode of identification. Thus, the crisis generated by the epistemological uncanny is not, as in the axiological uncanny, a present and urgent crisis of self-perception but a more broadly temporalized crisis that provokes disturbing awareness of our always incomplete self-knowledge. Here, Freud's influential predecessor, 
Ernst Jentsch, is apposite. For him, the uncanny emerges from "intellectual uncertainty, so that the uncanny would always, as it were, be something someone does not know one's way about in."11 In the experience of the epistemological uncanny, this intellectual uncertainty is articulated not in the sudden question "Is that really me?" but in an intentionally extended quest to acquire more 'objective' knowledge of 'myself' - even as it will never be enough.

This brings us to the 'ontological uncanny', in which the existential question is "What really am I?" This is the most overwhelming and reflexive modality of the uncanny, although it need not be felt as a sudden physical sensation or as intellectual uncertainty. Rather, and recalling Meunier's summation of our heightened self-preoccupation in the home-movie attitude, the ontological uncanny is experienced as a "suspended" confrontation not only with one's "self" but also "with the void" (p. 123). This third uncanny modality of the home-movie experience, in which the self-image as 'I' comes face-to-face with the image-self as 'me', is the least screen-dependent and the most actively constitutive. Thus, of all the modalities, it would seem to best conform to the phenomenological characteristics that, for Meunier, distinguish the home-movie attitude from those associated with documentary and fiction. This, however, is not the case. With the emergence of the ontological uncanny, although the viewer transcends the screen's specificity and engages in highly constitutive activity, these operate in a radically opposite intentional direction from that of the home-movie attitude. Rather than looking outward and through the screen in the highly constitutive but vain effort to evoke the presence of familiar past others, the viewer's look rebounds from the opacity of the on-screen image-self and is directed back and inward. This sudden reflexive look away from the screen and into the depths of one's own 'being' is, in effect, the uncanny and invisible revelation of a 'voided' self. On-screen image-self, off-screen self-image, and the 'I' that purportedly subtends them all become "irremediably out of our grasp" (p. 124).

In the experience of the ontologically uncanny, the home movie's temporality is again altered - indeed, in this instance, radically transformed. Although it seems longitudinal, the presentness of the viewing experience provoked by the encounter with our on-screen image-self is not only intensified; it also becomes temporally extensive. That is, rather than excluding the temporal laterality of retention and protention, the present includes and condenses them. Thus, in Meunier's terms, we could say that, in the ontological uncanny, the viewer's constitutive activity lies not in generalizing the specificity of screen images but, rather, in generalizing the discrete segmentations of time itself. Suspended in this temporally dense and extensible 
present, and with screen images now only the pretext to internal revelation, the viewer apprehends the import of the ontologically uncanny. This is the awareness that one can never catch up with one's 'self,' for 'it' - whatever 'it' is - is always both temporally behind and ahead not only our, but also its own being. 'It' is always becoming other than what it (never) was, is, or will be. Confronting Meunier's 'void,' it is the viewer's 'self,' wherever it seems located, that is voided. Bereft of security not only in self-knowledge but also in 'self,' the viewer now finds 'themself' (a particularly charged plural pronoun here) in a spatio-temporal chasm. This is also an asynchronous yet reversible 'chiasm' between one's visible image-self, imagined self-image, and invisible 'I,' in which their relative discretion and relational differences fall away and the ungrounded viewer falls with them.

In this regard, the ontological uncanny is more related to Heideggerian description than those of Jentsch or Freud. What Heidegger terms Unheimlichkeit (or uncanniness) is not a physical sensation, intellectual doubt, or psychological quality. These, for him, are derivative rather than ontological experiences of the uncanny. Indeed, uncanniness is originary for Heidegger; he regards it as the 'ungrounding' that is, if paradoxically, the grounding structure of human existence. For him, human being is fundamentally uncanny, strange, and unknown to itself as what it is: "an unstable blend of presence and absence, concealment and unconcealment, hiddenness and appearance, which constitutes man's having to be at home precisely in his not being at home in the world. ${ }^{12}$ Certainly any film (or video) - by virtue of its function as medium - offers us an experience of precisely this unstable reversibility and oscillation of presence and absence, concealment and unconcealment, hiddenness and appearance. However, the home movie makes this instability not only its form but also its content. It thus progressively provokes, for many of us who suddenly encounter our 'self' on-screen, the uncanny fundament not only of home movies, but also of human being.

In closing, it need be said again that my exploration of this 'specific case' of engagement with the home movie is meant as an homage to Meunier's phenomenology of filmic identification. Despite his schematic brevity (or, perhaps, because of it), he grounds and describes the characteristics and 'coordinates' of our active engagements with the screen in clearly articulated intentional modalities of subjective knowledge, attitude, temporality, and affect. Meunier thus provides us a meaningful existential vocabulary that enables an illuminating comparative method of how the film experience is 'lived' and differentiated. Moreover, he has given us a powerful heuristic, and explicitly invited us to continue exploring this lived,' but always 'mediated,' experience in all its myriad historical, cultural, and aesthetic variations. 


\section{Notes}

1. Even if some on-screen people are physically present, they are not now as they were then; hence, their present presence is subordinate to the memorialized space-time that absorbs us (and likely them as well).

2. In this volume, see Marie-Aude Baronian's, "Remembering Cinema: On the film-souvenir," which specifically foregrounds this neologism's emphasis on memory.

3. See Vivian Sobchack, "Toward a Phenomenology of Non-Fictional Film Experience," in Collecting Visible Evidence, ed. by Michael Renov and Jane Gaines (Minneapolis, MN: University of Minnesota Press, 1999), pp. 241-254.

4. In this volume, for a different approach to recording oneself, see Christian Ferencz-Flatz's “You Talkin' to Me? On Filmic Identification in Video-Selfies."

5. Maurice Merleau-Ponty, The Visible and the Invisible, trans. Alphonso Lingis (Evanston, IL: Northwestern University Press, 1969), p. 123. Merleau-Ponty is making the larger point that the world is not a discrete 'object' nor are we, as embodied, discretely 'subjects.'

6. For differently inflected elaborations of the term unheimlich, see Sigmund Freud, "The Uncanny"[1919], in The Standard Edition of the Complete Psychological Works of Sigmund Freud, Vol. XVII (1917-1919): An Infantile Neurosis and Other Works, trans. and ed. by James Strachey in collaboration with Anna Freud et. al. (London: The Hogarth Press, 1955), pp. 217-256; Ernst Jentsch, "On the Psychology of the Uncanny" [1906], trans. Roy Sellars, Angelaki 2:1 (1997): pp. 7-16; and, for Martin Heidegger's term Unheimlichkeit, see Katherine Withy, Heidegger on Being Uncanny (Cambridge, MA: Harvard University Press, 2015).

7. "Do you feel uncomfortable watching yourself on video?" [Quoted respectively, Pinko, Pet1986, Suzywong63, HungerCult, Shadow2oog, KidRacchyy], Digital Spy, https://forums.digitalspy.com (Last accessed on 10 November 2017).

8. See "The Uncanny Valley: The Original Essay by Masahiro Mori" [1970], trans. Karl F. MacDormand and Norri Kageki, Spectrum.IEEE.org (Last accessed on 1 February 2018); and Theodore H. Mita, Marshall Dermer, and Jeffrey Knight, "Reversed Facial Images and the Mere-Exposure Hypothesis," Journal of Personality and Social Psychology 35:8 (1977), pp. 597-6o1.

9. "Do you feel uncomfortable?" Fluffymingo, Digital Spy.

10. Meunier does not use the term 'typical particular,' but his discussion of documentary 'representativeness' certainly merits it. On this mode of generalization, see Hubert Alexander, The Language and Logic of Philosophy (Albuquerque, NM: University of New Mexico Press, 1967), p. 232.

11. Quoted in Freud, “The Uncanny," p. 221.

12. Taylor Carman, rev. of Heidegger on Being Uncanny [Withy, 2015], European Journal of Philosophy 25:3 (2017), p. 901. 


\section{About the author}

Vivian Sobchack is Professor Emerita at UCLA, where she was Associate Dean and Professor at the School of Theater, Film and Television from 1992-2005. At the beginning of the 1990s, she was the main driving force behind the recuperation of phenomenology as a viable methodology in film studies with her book The Address of the Eye: A Phenomenology of Film Experience (Princeton University Press, 1992). Insisting on the embodied as well as material foundations of film-viewing and film production, she has elaborated an existential-phenomenological approach to moving-image media ever since, perhaps nowhere more elegantly than in Carnal Thoughts: Embodiment and Moving Image Culture (University of California Press, 2004). Her anthologized essay, "Toward a Phenomenology of Non-Fictional Film Experience" (1999), was the first major explication in English of Jean-Pierre Meunier's phenomenology of filmic identification. The first woman elected President of the Society for Cinema and Media Studies (1985-1987), Sobchack was honored in 2012 with the Society's Distinguished Career Achievement Award. She also served for two decades as the only academic on the Board of Directors of the American Film Institute (AFI). She still teaches a graduate seminar or two at UCLA each year and is currently working on an anthology of her own essays on popular moving-image media and American historical consciousness. 


\title{
Remembering Cinema: On the film-souvenir
}

\author{
Marie-Aude Baronian
}

\begin{abstract}
This paper reflects upon Jean-Pierre Meunier's term film-souvenir and how it enables us to conceive of different possible alliances between filmic practices and memory. Drawing from audiovisual testimonies and the work of contemporary filmmaker and media artist Atom Egoyan, the essay suggests that film-souvenir goes beyond Meunier's designation of the term as a specific filmic consciousness and even beyond its commonly accepted translation of 'home movie.' The French term opens up our understanding of film as always already related to memory, continually emphasizing the persistent nature of cinematic practices as not only driven by a desire to reproduce and learn or to immerse and phantasm, but also to remember.
\end{abstract}

Keywords: Memory; home movie; audiovisual testimony; Atom Egoyan; Jean-Pierre Meunier

\section{Introduction}

It all started with a book: a medium-sized paperback that had for years been standing on a shelf of a bookcase in the hall of my parents' apartment in Brussels. The book was part of my father's extended collection of essays on cinema, philosophy, and other related topics that inhabited the domestic décor of my childhood home. I had passed by the book every day for so many years without even touching it... until one day: a seemingly regular day that resulted in a paradigmatic and disciplinary epiphany that I only understood years later when pursuing academia. In the early and mid-199os, my interest for both philosophy and cinema was already clearly marked, as I had studied and graduated in both disciplines. At that time, however, my research was still a timid juxtaposition of cinema and philosophy and did

Hanich, J. and D. Fairfax (eds.), The Structures of the Film Experience by Jean-Pierre Meunier. Historical Assessments and Phenomenological Expansions, Amsterdam University Press, 2019 DOI 10.5117/ 9789462986565_BARONIAN 
not consider the more dynamic notion of the two fields 'with(in)' each other. Jean-Pierre Meunier's The Structure of the Film Experience (Les Structures de l'expérience filmique, 1969) was my first real encounter with the alliance of philosophy and cinema, and it proved to be a formative one. When I first read it, it influenced my perception not only of what philosophy (particularly phenomenology) is but, more significantly, what philosophy can do beyond itself. Now, Meunier's eye-opening text, as a long-time companion, continues to fuel my filmic sensibility and thought processes.

This anecdote, as personal and true as it is, is not actually that far removed from one of the main elements Meunier discusses in his book: the experiencing and encountering of an objet-souvenir. This (or my) 'souvenir-book' takes Meunier's film-souvenir as a pivotal entry point for understanding how the home movie (which might be associated with the family film, amateur film, etc.) engages with and provokes a specific filmic experience. It is from this notion of film-souvenir that I would like to draw a few thoughts.

\section{Film Practices, Memory Practices}

My interest in Meunier's book derived not solely from its phenomenological approach to film, which admittedly felt extremely refreshing when I was conducting my studies in philosophy, but was mainly guided by its peculiar attention to memory thanks to the term film-souvenir.

Notably, the book took on a special relevance when I became closely interested in the work of Canadian-Armenian contemporary filmmaker and media artist Atom Egoyan (on whom I have also been working for a long time now), whose work served as a perfect vis-à-vis for illuminating Meunier's thoughts. In his feature films, as well as in his shorts and video installations, Egoyan discusses the relationship between memory and (domestic) audiovisual technology, as well as how recording and filming devices stand as existential objects that influence how we perceive the world, ourselves, and others. Audiovisual technology pervades the integrality of Egoyan's work, either by being inserted prominently in the narrative or by exploring its modalities of presentation and preservation through lens-media installations, for example. ${ }^{1}$

Meunier defines the film-souvenir as a film that addresses an object that is existent and known; in other words, the opposite of a fiction film, whose object is unknown and non-existent. Further, "the home movie appears as a constitutive activity: it looks beyond the image, to the person-in-general 
that it depicts, in order to produce and maintain his existence even during the screening"2 (p. 88). In the home movie, the viewer is less apprehended by each detail that constitutes the image but, as Sobchack notes, is in a process of "recovery of the memory of the whole person or event." Thus, Meunier conceives of the film-souvenir through evocation and as a mnemonic tool through which the viewer relates to, or rather identifies with, an absent person or a past event. ${ }^{4}$

According to Roger Odin, the family film is "made by a family member about characters, events or objects that are, in one way or another, linked to this family's history and to the privileged use of those family members." There is thus a correspondence between the one who makes and produces the image and the one who potentially watches it. ${ }^{6}$ This explains why it is not always captivating or engaging to watch another family's home videos. Nevertheless, when we watch somebody else's 'foreign' home movie, we also land in the familiar, not just because your family could be $m y$ family, but also because, from a more formal point of view, the often grainy, shaking, unpolished images recall a specific filmic and aesthetic mode. ${ }^{7}$ The acquaintance is thus not so much solicited by the person or event on-screen (some 'generic' figures) as by its recognizable, 'familiar' aesthetics. Odin reminds us that the family film is usually characterized and perceived as animated photography. ${ }^{8}$ On that note, Meunier writes that photography

functions as an analogical representation of the absent person. But it lacks life. [...] If I desire to rediscover [retrouver] these known gestures, I can then, if I am an amateur filmmaker, project a film that represents the person in question, if they have been filmed on a certain occasion. The cinematic image, more than the portrait or the photograph, restores life and this time, I really do find the person (p. 87/88). ${ }^{9}$

Incidentally, in Egoyan's feature films, thanks to the inclusion of the videographic medium into the narrative, we often see characters who are precisely caught in such situations as watching, often obsessively, domestic videographic images, which they rely on to confirm or restore their existential being. Thus, Egoyan borrows the practice and the aesthetics of home movies in order to point to the question and complexity of cinema as a process of authorship and spectatorship. Here I can think, for example, of the short film A Portrait of Arshile (1995), but also the three features Egoyan made in the 1980 s (which historically coincide with the rise of domestic audiovisual technologies), as well as most of his lens-based media installations since the 199os. 
The film-souvenir plays with the evocation and recollection of a moment in time and space and is comparable to a photo album or an archive box that contains material traces charged with emotional values. Yet, the significance of what is portrayed in home movies is not solely to be found in its visual or topical arrangement, but mostly in the narrative around the time and space that belong to the 'imaginary' of the family life. As Sobchack puts it, "the film-souvenir tends to be a chronicle of temporal fragments that exists for us as a marker of experience and has little to do with causality."10

The constitutive engagement characteristic of the film-souvenir is stronger than the image itself simply because, beyond the screen, the filmed person means 'more.' The film-souvenir is therefore inevitably partial and 'unfinished' but is nevertheless perceived, during the viewing, as generalized (a "person-in-general" says Meunier [p. 86]). Though, as Egoyan often addresses in his films and videos, the image can become all that we know of a person we are supposed to know personally. In that sense, the film-souvenir complicates the idea of 'more' and 'less:' the portrayed person or matter is less than what he/she/it means, but often more by its very audiovisual and material existence, because, in the fllm-souvenir, it is the existential charge that is stronger and more salient than the epistemological one.

But the 'more' and the 'less' also have to do with a sense of failure. As Meunier writes: "We 'play' at believing in this presence, but we never get there since we are always aware of the absence of the object" (p.122). And he adds: "In the home-movie attitude, our behavior consists of a vain effort to 'presentify' the object, an attempt to enter into intersubjective relations with other people, which necessarily leads to disappointment" (p. 123). This type of identification entails a vain effort to induce a presence that "remains irremediably out of our grasp" (p. 124).

Here, I should mention another type of media object related to memory on which I have been working closely: audiovisual testimonies in the context of traumatic mass violence (such as the Armenian genocide). These filmic testimonies, I argue, somehow 'test' the notion of the film-souvenir. The lack and discomfort associated with audiovisual testimonies are not only ontological in the sense of 'uncanny' or of what is no more, but in the historical, social, and political circumstances that render the video testimonies even more relevant (and that also complicate the tension between the private and the public). In my own research for instance, I watched people who were watching, even discovering, testimonial videos of their close relatives who survived the genocide. Heirs and family members literally discovering, for the first time, that their parents or grandparents had not only been recorded or were taping themselves, but that such home video tapes exist in the first 
place. This forces us to redefine, more cautiously, what is really 'known' and how visual and cinematic media might play a significant and vital role. It is not just a matter of 'presentifying' a known person or event, but - in the context of mass violence - of asking the question: how does the 'known' interact with the 'unknowable' in terms of traumatic memory?

Significantly, I noticed that, most of the time, the private and intimate setting of the home video is the only space or territory where trauma can be told (or not) and transmitted to family members and how, often because of the lack of something else (such as a safe and shared repository for such stories to be heard), it could move from there (or not) to a more open and public space. This means that, despite their restricted visibility, these home videos allow for difficult stories to be inscribed (even if the telling of them is inherently complicated) and testify to an enduring historical and sociopolitical invisibility. At the same time, these audiovisual testimonies are not to be labeled as 'orphan films' in the sense of being abandoned, because they are somehow preserved but not exposed or circulated. ${ }^{11}$

To 'recover,' following the terminology of Meunier's film-souvenir, can almost be conceived in psychoanalytical terms here: something is saved, materially and psychically. This being said, family members do not automatically watch the films meticulously, also because there is an inevitable impossibility to watch those often painful and unbearable audiovisual testimonies. ${ }^{12}$ Pertinently, in many of Egoyan's films (which often deal with trauma, including the inherited traces of the Armenian genocide), we see characters who have a very fetishistic relationship with their home movies. In Egoyan's feature film Family Viewing (1987), for instance, the main character (a young man named Van) discovers the existence of videocassettes from his Armenian childhood that he did not know about (or remember?). It is, in that case, a (re-)discovery of something that has not been unveiled before. It literally creates a sense of newness of something that, materially speaking, was previously thought to be non-existent. ${ }^{13}$ This set-up slightly complicates the fact that, as Sobchack writes, "In the home-movie experience, I don't have to learn anything about my son from the images. Indeed, I know more of him than the images show me. I don't have to work at comprehending him (although I do have to work at evoking him)." ${ }^{\prime 14}$ So if Meunier argues that the film-souvenir does not teach us anything about the person represented, the question of learning about the material existence of the film and how it generates a specific filmic consciousness still remains. This is precisely why audiovisual family testimonies, often equated to home movies, are significant. Incidentally, in the short film A Portrait of Arshile that Egoyan made in the mid-199os, the filmmaker combines the intimacy of the familial 
home video and the testimonial legacy of the Armenian genocide; thereby not solely interrogating and blurring the difference between the private and the public, but insisting on the home recording as the only means to access family history and history in the broader sense.

In Egoyan's fiction film Family Viewing, Van accesses his Armenian childhood with his lost mother (an origin that was denied to him) through videocassettes. ${ }^{15}$ The videographic image is at once familiar and strange/ other; it is also at once recuperative and informative. More importantly, however, is the fact that the audiovisual testimonies exist: his being Armenian is possible and accessible through the home video. What Van experiences when he watches the cassettes is the comfort of existing 'again' together with the discomfort of having disappeared. The feeling of deceiving is, linked to the politics of denial, heavily connoted.

Thanks to the home videos, there is a rediscovery of something that has not been disclosed before. It creates a sense of newness in something that, materially speaking, was previously thought to be non-existent. This, once again, proves that, with the film-souvenir, it is often not only about the retrieving of a "person-in-general," as Meunier puts it, but, I would suggest, the retrieving of the object itself: the cassette, the medium as a recording and viewing machine and the imaginary that surrounds it; what we could term an 'audiovisual object-in-general.'

With the film-souvenir, the knowing usually precedes the viewing, and the viewing itself confirms or emotionally charges the knowing. But when a viewer watches a home movie of a person with whom he or she is intimately bound, without the knowledge that that moment was filmed or recorded (like in audiovisual testimonies or in Family Viewing), the viewing aprèscoup turns into an event in itself. Again, this is not due to what is precisely depicted and told in the moving image, but because of the very existence of the recording trace. It is not about learning in terms of content information, it is about learning of the material existence of the recording. The viewing consists in the presence of another self on-screen which is equated with another self as screen: a sort of double strangeness and sameness, or an unreachable (known) someone through the reachable screen. To put it differently, the film-souvenir could be designated as a film that aims to create another self at home in movies, one that stipulates a form of identification moved by a sense of familiarity and strangeness. In viewing and discovering such film-souvenirs, there is at once a feeling of sameness and otherness, that is activated through the medium, almost in the double sense of the word medium. 


\section{What Is Lost, What Is Preserved}

Let me now point to the translation of the term film-souvenir in Meunier's book. Departing from the assumption that any act of translation is marked by loss (due to the challenge of preserving the original meaning), a translation is in itself a mourning gesture, comparable to a souvenir of what is no more. ${ }^{16}$ Yet, a translation does not always only constitute a loss or even betrayal to the original text, as it can sometimes add something more to it.

Sobchack confesses (between brackets!) that the original French word film-souvenir is much more precise than its English counterpart and that the English translation might have certain limitations. ${ }^{17}$ Let me therefore draw from and stress the translator's 34 th footnote which explains that Meunier's term "refers to films made for private purposes, with the goal of acting as a keepsake or record of an event in the individual's life, such as weddings, vacations, family gatherings, etc." The translator's note also clearly indicates that even if "the English term 'home movie' comes close to this meaning," the question and role of memory is not apparent in this notion (p. 156).

If 'home movie' is the most appropriate translation, the French expression film-souvenir might address something beyond the distinctive forms of consciousness that Meunier designates. The hyphen indicates the closeness and dynamic relationship between souvenir and film and, in doing so, accentuates the value and motif of film as a mnemonic medium. ${ }^{18}$ If 'home movie' indicates 'home' and the type of private and 'familiar' family events that are recorded there, it also acknowledges something inherently related to memory. Thus, if I maintain the French term it is not for the sake of safeguarding Meunier's original language, but to highlight the interplay between film and memory that, in turn, welcomes a plurality of remembering filmic practices and variations without sticking to one category or corpus in particular. Moreover, there is not one film-souvenir attitude but a plurality of attitudes wherein, obviously, each context plays its role.

The notion of film-souvenir also surpasses its formal and cultural dimension to become, as it were, the consciousness of cinema itself. Here, cinema is to be understood as a web of various practices, of making and responding to moving images. It is as though, in the work of Egoyan, the French word and its English translation come together. That is, by using the aesthetics of the home video in his films, Egoyan not only touches upon the familial and intimate elements characteristic of this cinematic form, but also on the consciousness of cinema. By creating mise en abymes, such as the filmwithin-a-film trope, it is not only the technological and aesthetic process 
of cinema that is reduplicated, but the process of cinema as a remembering machine. ${ }^{19}$ What is more, Egoyan's filmic practices mirror, at various levels and from several viewpoints (e.g. narrative, personages), the notion that retrouver is both an illusion and the attracting force of cinema - what is no more (or even perhaps what has never been).

My proposition not only draws from the admitted fact that, as Meunier writes about these modalities, "we should not expect definitive conclusions" (p. 36), but that the film-souvenir enables us to think more broadly and purposefully of the filmic attitude (or a subjective relationship to the souvenir-object) as an 'impulse,' of film originating from an archival gesture and attitude (or even an 'archive fever' in a Derridean sense). ${ }^{20}$

In other words, not translating film-souvenir does not imply that the proposed translation of 'home movies' should be refuted, but that it could be valuable, beyond Meunier's own intentions, to think of the particularity of the film-souvenir as a form together with the particularity of film as souvenir (and vice versa). This also provides the opportunity to question the epistemic and imaginary knowledge vis-à-vis the people captured in the film-souvenir videos who are no longer there.

Further, as a more marginalized cinematic form (in comparison to documentaries and fiction films) and as somehow 'openly' defined and thus not strictly specified, the film-souvenir object acquires an added value in its capacity to be thought of beyond its textual and formal features. It forces us to ponder what makes it filmic in the first place.

Beyond the fact that Meunier's modalities are flexible (as he has admitted and Sobchack has insisted on), I wonder if the film-souvenir is not solely in the attitude of the spectator, but, as it were, in the attitude of cinema tout court. ${ }^{21}$ It is as though the film-souvenir epitomizes, in a sort of media-archeological fashion, the emergence of filmic practices (including proto-cinematic ones) and the numerous practices that pervade the digital age. In that case, could the film-souvenir not be the zero degree of cinematic practice; one that reminds us that, beyond the desire to comprehend (documentary) and to participate (fiction), film is an ongoing search for something or someone that is no more or, at the very least, 'out of focus'? In other words, the attitude-souvenir is an inherent recording and viewing attitude (memory as mediated). And if, as Meunier puts it, "the cinematic image truly plays the role of medium. It serves as an intermediary between the reality perceived and my current consciousness of this reality" (p. 88), I would add, the medium is not just a liaison provider, but also (despite its content) an end in itself.

Significantly, the film-souvenir is the only category for which Meunier does not really give an explicit or detailed example, reminding us quite 
evidently that those films are, and very often remain, untitled. Evidently, such family films do not have a theatrical life, and when they are viewed, they are seen in the context of private archives or collections. This is yet more proof of the film-souvenir's significance as a recording trace more than what it depicts or represents. Paradoxically, perhaps, in the film-souvenir, the viewer - because he or she views him or herself (or another 'alter ego' such as a family member) in those moving images - does not get pulled into the image, but rather it is the image (as mediating object) that pulls him or her in an affective mode of comfort and discomfort - the comfort of existing 'again' together with the discomfort of having disappeared. Indeed, as Sobchack summarizes, the images of the film-souvenir "are not apprehended for themselves, but rather as the catalyst to a primarily constitutive and generalizing activity that transcends their specificity in an attempt to call up and reactivate the 'real' and 'whole' person or event that is (or was) elsewhere and at some other time."22

In the film-souvenir, the image fulfills what it was intended to do in the first place: trace, track, and bring life to the life-world of the person filmed for the benefit of the viewer within his or her own life-world. The image is the intermediary through which the viewer can enter into a relation with and reach that someone or that something. Nevertheless, Meunier specifies that the image is a substitute or a simulacrum of a presence; this idea is also at the heart of Egoyan's practices and preoccupations. But if Meunier indicates that at no moment do we lose sight of this fact, it is, interestingly, rarely the case for many of the characters in Egoyan's films, who are viscerally depending on (and often addicted to) domestic audiovisual images and technologies.

The reason why Egoyan is constantly exploring the home movie is, as I have mentioned, to underpin and complicate the notion of cinematic practices as memory. For instance, what Meunier describes in the following quote is to be found everywhere in the work of Egoyan: "To a far greater extent than the photo, the home movie, by means of the life that movement confers on it, is conducive to inducing a high degree of nostalgia, regret, or other sentiments in us" (p. 109). In all his films and media projects, audiovisual and recording technology reflects the longing for what is no more, and because it is no more, it accentuates the longing, often articulated in a very obsessive and repetitive way.

Importantly, I do not wish to incite an all-encompassing conception of the viewing experience as one that is indifferent to the modalities or types of image that are viewed; rather, I suggest that the film-souvenir attitude is both particular to certain types of film and, ontologically speaking, of cinema. In other words, the spectatorial mode of the film-souvenir corresponds to 
specific objects (materially and immaterially) and, as it were, to the 'Object of cinema.' Therefore, I would imply that despite the fact that such films have often been perceived as marginal (academically and professionally), the unfinished character of the film-souvenir actually indicates that cinema itself remains unfinished; it is ongoing, infinite, and escapes all forms of strict delineation regarding how it manifests itself.

Also, the film-souvenir stresses the paradox inherent in all visual representation since it is an image of the world (a representation) but made within the lived world - a familiar and affective one in this case. It is a representation of something/someone that, while existing out of that image, can somehow be recuperated or, better, preserved, in that image. The film-souvenir therefore situates itself between the excess, the surplus, and the lack, the loss. It also, as noted above, lays itself between comfort and discomfort.

\section{Remembering Cinema}

Ultimately, maintaining the original term film-souvenir is a question not so much of being faithful to the original word, as reinforcing the possibility of focusing on attitudes rather than genres, on experiences rather than layouts, on existential engagements rather than filmic textual features. In doing so, it further concedes that Meunier's concepts themselves are forceful and dynamic, and, more generically, that cinema (filming and viewing) is somehow epitomized through the 'natural' gesture of recording and preserving the ephemerality of life (and of film). ${ }^{23}$

If, with the film-souvenir, Meunier paves the way for a largely neglected filmic practice that had long escaped any canonical place in academic studies and filmic institutions, it also condenses, with its apparent minimal means, what is at the core of the filming gesture. That is, the film-souvenir offers new directions to think of the large panel of non-theatrical practices, but it also ad minima translates the scopic and archival regime into which we are culturally and affectively immersed. It also implies a sense of being unfinished: because the concept itself is mobile and elastic and because the home movie relies on an unpolished format (even if nowadays there are plenty of apps that enable family images to become 'perfect,' leaving us with the question of what is 'unfinished' in the digital age $)^{24}$. More importantly, however, it is unfinished because cinema (in all its multiple practices) is constantly reinventing itself.

In the same way that Meunier's book opens up ways to (re-)think many concepts and categories central to film-philosophy and film theories, I 
would venture that the concept of film-souvenir is, similarly, a notion that enables us to ponder the tenacious and persistent being of cinema (and its 'others') and the multiple ways cinema involves a desire not just to reproduce and learn or to immerse and phantasm, but to remember. With the filmsouvenir it is cinema that - despite its inherent and possible failures, illusions, incompleteness - remembers (and, accordingly, forgets) itself.

\section{Notes}

1. To be sure, Egoyan's work is not a mere illustration of Meunier's ideas on the film-souvenir, but the artist's entire work is an ongoing exploration of it: not only from a narrative and character point of view, but also in terms of aesthetics and visual strategies and, even more significantly, when Egoyan pays particular attention to the presentation and viewing context (e.g., his video- and lens-based media installations that contribute to the 'Black Box, White Cube' discussions).

2. Meunier adds that "there is, on the part of consciousness, a positing of existence, a generalization of the matter of the image that refers to a person-in-general, who constitutes the locus of our attention, and finally, the creative activity" (p. 88).

3. Vivian Sobchack, "Toward a Phenomenology of Nonfictional Film Experience," in J.M. Gaines and M. Renov (eds.), Collecting Visible Evidence (Minneapolis, MN: University of Minnesota, 1999), pp. 241-254; here p. 244.

4. As Sobchack summarizes, "these objectively specific images, however, are subjectively generalized by the spectator in a vain effort to evoke presence that is, the whole ensemble of a well-known person's gestures and comportment or of temporal events surrounding those depicted on the screen." Ibid., p. 247.

5. $\quad$ Roger Odin, Le Film de famille (Paris : Méridiens Klincksiek, 1995), p. 27.

6. Needless to say, in the digital age, the lines between the private/family sphere and the public one are constantly put into question. This tension between the intimate and the collective is another key concern in Egoyan's work.

7. Inversely, in the digital age (and thanks to all sorts of technological devices and applications), the images tend to be too perfect.

8. More specifically, Odin says that this type of home video presents recurrent stylistic elements, such as an absence of closure, a narrative crumbling, an undetermined temporality, a paradoxical relation to space, a direct address to the camera, a rather incoherent juxtaposition of shots, and an interference of perception. See Le Film de famille, pp. 28-31.

9. The analogy between photography and recording technology is central to Egoyan's early films. That being said, one could note that Meunier falls short 
on the difference between photography and film (life being added simply by the fact that images are moving).

10. Sobchack, "Toward a Phenomenology," p. 248.

11. Some of the family videos (containing family stories marked by such tragedies as genocide) have very limited exposure: some are secretly preserved and are not shown to anyone outside of the family circle, while others function as oral testimony and are recorded and archived in specific locations such as the Zoryan Institute (a documentation center in the US and Canada dedicated to the Armenian genocide). In all these situations, however, the films are rarely shown to the general public.

12. There is also the potentiality, for the survivors and their heirs, that watching such testimonial home videos leads to triggering or reliving the original trauma. On these types of question, see Shoshana Felman and Dori Laub, Testimony: Crises of Witnessing in Literature, Psychoanalysis, and History (New York: Taylor \& Francis, 1991).

13. This is what Meunier and Sobchack suggest when they distinguish the specificity of the image from the whole ensemble the person, or the event to which it refers. We could also add that the recorded object, through its materiality, adds an extra layer to the understanding of a 'positing of existence' that is thus central here.

14. Sobchack, "Toward a Phenomenology," p. 251.

15. Thus, the film-souvenir can also, just like the documentary, have the ability to teach.

16. Here I think, for example, of Paul Ricœur who, in Sur la traduction, speaks of "une correspondance sans adéquation" or "une équivalence sans identité" (Paris : Bayard, 2003), p. 40 and p. 6o. Or, in a more radical way of what Derrida has written on this question in various essays. See, for example, $O f$ Hospitality, with Anne Dufourmantelle (Stanford, CA: Stanford University Press, 2000).

17. Sobchack, "Toward a Phenomenology," p. 248.

18. Needless to say, there is an analogy at play between the working of memory in the psyche and the working of film. If memory also alludes to a subjective and 'situated' trace of time as Jenny Chamarette puts it, memory is "a subjective trace of the experience of time or as a trace of the encounter with time - always in contact with time and temporality, but never encompassing it." See her essay "Memory, Representation of Time and Cinema," in P. Collier, A.M. Elsner and O. Smith (eds.). Anamnesia. Private and Public Memory in Modern French Culture (Oxford: Peter Lang, 2009), pp. 243-256.

19. The mise en abyme is close to what Meunier refers to when he writes "the likes of Godard and Varda have honed a certain number of procedures aiming to break the spectator's enchantment, and to invite them to take their distances. But these are, when it comes down to it, rather artificial and rarely used procedures" (p. 113). This last point could benefit from being updated and, on that note, most of Egoyan's filmic practices could be added 
to it. Egoyan often uses the domestic videographic medium as a metaphor for cinema, to create mirror effects.

20. See Jacques Derrida, Archive Fever: A Freudian Impression (Chicago: Chicago University Press, 1996) and Echographies of Television: Filmed Interviews (with Bernard Stiegler. Cambridge: Polity Press, 2002 [1996]).

21. Sobchack writes: "Perhaps the most important of Meunier's conclusions is that the structural form of cinematic identification does not depend necessarily (even if it does sufficiently) on the 'type' of film objectively unfolding on the screen. However each type of film may objectively and actively solicit our spectatorial consciousness, in the end, we will actively and subjectively 'take up' the film and position its existence and status as the kind of film object it is, based on a personal and cultural knowledge less deliberate than lived." Sobchack, “Toward a Phenomenology," p. 246. She further adds: "If we understand cinematic identification as a general comportment and attentive attitude toward the screen that is informed by personal and cultural knowledge, then one woman's irreal situation comedy may be another's home movie." Ibid., p. 247.

22. Ibid.

23. What is more, it is also a way to question the non-theatricality of film as a condition of possibility of its theatricality.

24. Here, it might also be worth mentioning that there are specific apps (such as "Super 8 Instant Video Footage") that simulate the worn-out Super-8 aesthetic as a way of evoking old home movies.

\section{About the author}

Marie-Aude Baronian is Associate Professor in Film and Visual Culture at the Media Studies department of the University of Amsterdam. She has lectured and published extensively on media, testimony and memory, ethics and aesthetics, film philosophy, fashion, French thought, and Armenian diasporic audiovisual practices. She has not only written on several filmmakers (e.g. Atom Egoyan, Sergei Paradjanov, the Dardenne Brothers), but she has also authored many articles on various artists, philosophers, and designers. Her work and research interests are interdisciplinary and include, next to film studies and philosophy, disciplines such as memory studies, fashion studies, Armenian studies, and material culture. Her most recent monographs include Mémoire et Image: Regards sur la Catastrophe arménienne (L'Age d'Homme, 2013; English translation in preparation) and Screening Memory: The Prosthetic Images of Atom Egoyan (Editions Académie Royale Belgique, 2017). She is also completing a monograph on Emmanuel Levinas and the moving image. Currently, she works on textile, clothing, and fashion in 
filmic practices and in cultural theory, which will also be the topic of her next book project. She is a member of the Amsterdam School for Cultural Analysis (ASCA) and a regular guest fellow and professor at the University of Michigan and the Goethe-Universität Frankfurt. 
III: ON IDENTIFICATION 


\title{
You Talkin' to Me? On Filmic Identification in Video-Selfies
}

\author{
Christian Ferencz-Flatz
}

\begin{abstract}
The present paper revisits Jean Pierre-Meunier's account of the social structure of film experience by adding a further term to his comparative analysis of home movies, documentaries, and films of fiction: video-selfies. Video-selfies are understood as the perfect starting point for an interpretation of the mutual relationships between authorship, protagonists, and viewer, which aims to clarify Meunier's conception of 'filmic identification' critically. The analysis of the video-selfies focuses on five aspects: perception, communication, affect, space, and movement. Following through this analysis, the paper shows that Meunier's approach can be useful not only in applying a theory of intersubjectivity to various forms of film experience, but also in drawing from the latter insights into key aspects of intersubjectivity.
\end{abstract}

Keywords: Phenomenology; intersubjectivity; communication; mirror perception

1.

Jean-Pierre Meunier's analysis of film experience is most notable, on the one hand, in that it regards the social, that is: the intersubjective structure of this experience as its most defining aspect; on the other hand, in that it pursues this aspect by means of a phenomenological variation, contrasting three forms of film experience, namely the home movie, the documentary, and the fiction film. Arguably, the most striking feature of this endeavor is its attempt to translate a theoretical framework visibly drawn from Sartre and Merleau-Ponty's phenomenology into the classical vocabulary of French filmology by specifically rephrasing the phenomenological account of

Hanich, J. and D. Fairfax (eds.), The Structures of the Film Experience by Jean-Pierre Meunier. Historical Assessments and Phenomenological Expansions, Amsterdam University Press, 2019 DOI 10.5117/9789462986565_FERENCZ 
'intersubjectivity' in terms of filmic 'identification' - today, one would certainly find it more appealing to proceed in the opposite direction. In his treatment of 'identification,' Meunier himself, in any case, rejects the default psychoanalytic understanding of the term as an objective psychological mechanism, which can be analyzed from without, in favor of its phenomenological interpretation as a subjective experience, which should be described from within. Accordingly, he comes to regard the subject's bodily, that is, motor and postural response to his encounter of other subjects as the grounding phenomenon of identification, while also pointing out its emotional, dramatic, and axiological aspects.

The second and richest part of his account applies this theoretical framework to film experience, stipulating from the onset that the latter can only be analyzed as such by taking into account its most significant variations. To this extent, Meunier sets out to investigate the differences that occur, firstly, in the structure of perception and movement, and secondly, in that of intersubjective identification, between home movies, documentaries, and fiction films. To be sure, the definitions given to these three categories are rather rough-hewn. Thus, according to Meunier, home movies are characterized primarily by the fact that their subject is known and real; in documentaries, the subject is unknown and real, and in films of fiction it is flatly unreal. However, the most significant point here is that, in Meunier's view, these differences necessarily entail a correspondingly different intersubjective experience and therefore also a differently structured experience of film. Thus, the experience of home movies is, according to Meunier, fundamentally driven by the viewer's effort to rememorize the person depicted in it - documentary film-viewing engages an attempt to understand that person, while fiction films demand the viewer to participate in the unfolding of the character's situation.

For sure, two main methodological objections can be raised against such an account from a phenomenological perspective. On the one hand, one may wonder to what extent this presentation still holds true to the promise of its title, namely to outline the structures of 'the' film experience phenomenologically. Does this perspective still allow envisaging film experience as such, as an overarching invariant, or are we, on the contrary, only left with classifying a variety of possible film experiences? On the other hand, if this latter is the case, are Meunier's three categories even sufficient? Is one not implicitly led to differentiate the structural characteristics of each of these categories further and further into a variety of subcategories, while also adding countless other similar categories, such that, in the end, the very task of a 'structural' analysis of film experience seems to be thrown overboard? 
With these two questions in mind, I will, in the following, try to point out an important omission in Meunier's reflections on filmic intersubjectivity. In doing so, however, I will simultaneously acknowledge his achievement by making use of a similar approach in adding a new term to his comparative list of typical film experiences: the video-selfie.

2.

In his brief analysis of home movies, Meunier makes the following description of their markedly evocative viewing experience:

As for each of the gestures that I see on the screen, I do not apprehend them in their own individuality, but as representations of multiple gestures in reality. It matters little whether the person represented carries out a given particular activity. The activity in itself is of no interest. What interests me is to find, through the manner in which this particular activity is accomplished, a more general mode of behavior, repeatedly perceived in the absent person. In short, what I seek to render present to myself is the person-in-general, such as I knew him in the multiple real perceptions that I have had of him (p. 88).

One can almost picture the scene referred to in this description: a nostalgic viewer endlessly re-watching the same old footage of a departed friend or spouse, while completely disregarding the particular content of the tape in his sole interest to retrieve the shard of real presence preserved on film. As touching and theoretically rewarding as this scene might be, it describes only a very particular experience of watching a home movie, as several of the papers in the present volume aptly point out. ${ }^{1}$ Watching a tape of my friend's wedding, which I could not attend, for instance, or some forgotten recordings from my childhood both entail viewing experiences that are hardly captured by Meunier's descriptions. One could, on the one hand, pinpoint the issue at stake here by simply noting that these descriptions in fact only apply to "watching our own home movies," as Vivian Sobchack puts it. ${ }^{2}$ In a somewhat broader perspective, one could, on the other hand, stress the fact that home movies are as such only meant for a limited 'intended audience, ${ }^{3}$ while the viewing experience of a third party would be different not least because it would always also contain an element of "trespassing." The fact is, in any case, that both formulations bring into play a further dimension in the social structure of the home-movie experience in addition to the viewer's apprehension of the film's protagonist, discussed by Meunier. This may concern the viewer's 
relationship to the author of that film (as implied when speaking of 'our own' home movies), or both the protagonist and the author's intentionality of their expected viewers (as implied when speaking of an 'intended audience'). What I mean to say here is that the social structure of a home movie - and, in further consequence, that of film experience in general - involves, from the outset, a more complex set of intentional relationships than just the sheer 'identification' of the viewer with the character, by specifically connecting the author, the protagonist, and the viewer in an intricate triangle of mutual references.

3 .

Of course, this observation is, to a certain degree, commonplace in film theory. As such, it is, for instance, already implicit in Christian Metz's attempt to complicate the question of filmic identification by putting it in relation to the so-called "identification with the camera." Instead, the point here is that, when considered in the perspective of the home-movie experience, the entire discussion shifts focus from the mere formal determinations of the cinematic apparatus to the concrete social intentionalities involved - and this is precisely the point at which one can also fruitfully bring into play video-selfies. In fact, paradoxically, video-selfies are the perfect starting point for an analysis of the intersubjective structure of film experience precisely because they do not necessarily involve other people. As such, they offer a double advantage: they allow us to pose the question of filmic intersubjectivity strictly as a matter of structural relationships, and not as a matter of relationships between people, while they are particularly prone to be tackled phenomenologically by referring solely to the experience of a single subject. Thus, if we regard video-selfies in their most basic form as films whose author, protagonist, and primary viewer are virtually one and the same individual subject, their phenomenology - which I will now try to pinpoint in five sketchy descriptions, focused on: perception, communication, affect, space, and movement - can easily show that the structure of mutual relationships they involve are by no means less rich or intricate than in the apparently more complex case of a feature film of fiction.

\section{a. Perception}

First of all, recording a video-selfie normally implies the use of a mirror or monitor reflection. Thus, the first and most elementary form of intersubjectivity it involves is the sheer perceptual exchange of the look into a 
mirror. This exchange has often been described. It is based on the dialectic of seeing and being seen. When looking from here at my reflection in the mirror there, I come to see myself back here from over there in following the reflection. This experience therefore necessarily entails a certain reversibility of perspectives, a mutual exchange between seeing and being seen, which is, above all, the defining feature of social interaction. ${ }^{6}$ Now, when recording a video-selfie, this relationship obviously becomes more complex. For, here, the subject no longer only regards, but also films him- or herself, and he or she is no longer only seen, but also poses for the camera, while the two gestures - that of filming and that of posing - both involve, in addition to their mutual reference to one another, an intentional reference to a future viewer. Of course, this viewer may not be considered explicitly and may not even be a different person at all, but the anticipation of a future viewing is as such nevertheless structurally implicit in the very act of recording something with a camera, just as it is in the act of, say, smiling for the camera. Moreover, the two gestures, that of filming and that of posing, are here not only themselves engaged in a dialectic of reversibility that reduplicates the original dialectic of the mirror reflection, but this dialectical relationship is as such also visibly captured on film in the composite expression of the protagonist, who is at the same time engaged in filming and posing for the camera. This unique expression, in which the intention of filming struggles with that of posing, arguably offers the most remarkable perceptual feature of selfies in general and video-selfies in particular, which, above all, prevents their superficial comparison to traditional self-portraits.

\section{b. Communication}

Secondly, the intersubjective intentionality of a video-selfie is recognizable in its specific form of communicative address. For sure, address can take various forms in a video-selfie depending on whether it is intended as a video message, a vlog post, a first-person documentary, or a live report. The important point here is that, regardless of such differences, the act of address is performed by a subject who films while regarding him- or herself in the mirror, and this specific circumstance also marks the communicative performance through and through. To be sure, the subject of a video-selfie does not simply address him- or herself, just as a TV presenter addressing viewers does not simply address the cameraperson. But, while indeed primarily addressing the intended viewer via the camera, the TV presenter is nevertheless in an ongoing agreement, that is: in a communicative or cooperative relationship with the cameraperson, which might not be 
immediately recognizable in his or her performance for the viewer, but which is nevertheless a distinctive part of its intersubjective complexity. Similarly, the fact that the communicative gesture of a video-selfie is marked by a permanent ascertainment of oneself in the mirror - that is, by perceptual exchanges with oneself that imprint on that performance - inevitably makes it acquire, to a certain degree, communicative qualities specific to mirror experiences. For instance, it is certain that part of the bashfulness of practicing a speech in front of the mirror implicitly stems from the ridicule of addressing oneself in general - for one of course already knows in advance what one might be saying, so that the gesture of speaking is, in front of oneself as an audience, unneeded and tends to fall flat. Thus, one might say, it is precisely due to this that a certain aspect of blankness and redundancy still implicitly characterizes the communicative performance of video-selfies in general, regardless of how well the subject has adapted to the medium.

\section{c. Affect}

Thirdly, the same feature also determines the affective dimension of intersubjectivity in video-selfies. Thus, it is well known that audiovisual recordings are generally better suited than sheer mirror reflections for assessing one's own performances. This is the case because they allow the subject to view him- or herself from the outside without constantly lapsing into the corresponding perspective from the inside. ${ }^{7} \mathrm{On}$ the other hand, it is presumably because, in contrast to mirror reflections, recordings lack the possibility of (literal) identification, that one often experiences a certain discomfort when watching oneself in a recording. ${ }^{8}$ This embarrassment is indisputably increased in an intersubjective context. For, if I as a subject may already feel some unease when privately regarding my own recorded image - an image of myself that I can no longer adjust by self-composure as in the case of mirror images - the embarrassment is distinctly enhanced in the presence of others, who witness not just my embarrassing image itself, over which I am now powerless, but also my own embarrassment in relation to it. One could certainly point to a similarly complex interweaving of self-perception and intersubjectivity in the embarrassment one feels when surprised by others while preening in the mirror. In any case, if one may concede that this unease is to a certain degree culturally and historically determined, it nevertheless constitutes the indispensable affective background for grasping the fact that video-selfies at core amount to sharing with others the private or intimate act of watching oneself in the mirror. Of course, one might 
hardly take notice of this fact when watching a video-selfie, as one might easily lose track of the circumstance that one's interlocutor in a video-call is - just like oneself - simultaneously regarding him- or herself in a monitor image. Nevertheless, these relationships fundamentally impact on the intersubjective affectivity of both, embroiling the viewing I, the viewed I, and the other in specific constellations of mutual reference.

\section{d. Space}

Fourthly, the aforementioned social structure of video-selfies also determines how we experience their specific spatial structure. Thus, one could go as far as saying that a film recorded by its protagonist as a video-selfie presents an entirely different experience of its film space than the exact same shot recorded by a different person. This is again the case, above all, because of the sheer fact that, in recording it, the protagonist films using a mirror. For this of course implies from the outset that the protagonist him- or herself also sees what we see. That is: he or she is not only the protagonist of the shot, but also its author and moreover, not only its author, but also our fellow spectator, with whom we actually share that specific view. Instead, insofar as the film essentially reflects what the protagonist him- or herself is seeing, the image itself can be interpreted at the same time both as an objective shot and as a subjective, point-of-view shot. In other words, it can be read both straightforwardly and in reverse, as a mirror view, even if the camera itself is of course not facing a mirror and even if it only films what it would also film if it were held by a different person. As a consequence of this ambiguity, the spatial positions of the protagonist and of the camera in relation to one another virtually become mutually interchangeable, such that, we could say, the protagonist can be apprehended at the same time in front and behind the camera, on and off screen, making the film image attain a strange sense of sphericity and enclosement.

\section{e. Movement}

Finally, a similar consequence can be derived with regard to the apperception of movement - and this includes both camera movements and the movements of the protagonist, which are here brought to coincide. Thus, on the one hand, the movements of the protagonist do not normally relate to their surrounding environment in a direct and unmediated fashion, but - insofar as the protagonist is continuously paying attention to the camera - only in relation to its mirror reflection, just like a car driven 
backwards while watching the rear mirror. Thus, the vantage point of the camera becomes, as in a rear mirror, the reference point for the orientation and interaction of the protagonist with his or her environment, conferring them a specific phenomenological deflection. Alternatively, this complex perceptual situation also renders the apperception of camera movements proper particularly complex - as becomes obvious, for instance, when considering GoPro video-selfies. For, in such a video-selfie, the camera in fact expresses the view of the protagonist not as a sheer extension of his or her sight, that is: as a direct prolongation of his own point of view, and thus as a simple form of "instrument mediated perception," but instead as a second, juxtaposed point of view added to his or her body, which parallels and mirrors the first, while all camera movements are kinesthetically ambiguous in that they can be read reversibly both in view of their anchoring in the point of view of the camera and in that of the opposing protagonist handling it.

$4 \cdot$

An in-depth phenomenological analysis would have to work out the articulations of these five moments in more detail in order to show how video-selfies bring about an entirely novel entanglement between the subjects' experience of themselves and their relationship to others: the equivocal experience of simultaneously watching oneself in showing oneself to others and of showing oneself to others in regarding oneself. What our brief observations have already shown, however, is that this line of inquiry obviously goes beyond the classical objection brought against filmic identification. According to this objection, the traditional treatment of identification by film theory only tackles the viewer's empathic engagement with the protagonist (secondary identification) while ignoring his or her grounding engagement with the camera (primary identification). In contrast to this, our present reflections have shown that primary and secondary identification are both insufficient to account for the social structure of film experience insofar as this experience is generally not reducible to the intentionalities of the viewer alone. In other words, it is not just the viewer who willingly or unwillingly 'identifies' with the protagonist and with the camera, but it is also the latter two who 'identify' with each other - and this is, in fact, precisely the point at which one could show that primary and secondary identification are fundamentally interlinked. For as long as the viewer 'identifies with the protagonist,' the protagonist's relationship to the camera in turn becomes part of how the viewer apprehends the camera, and insofar 
as the viewer 'identifies with the camera,' the camera and the cameraperson's relationship to the protagonist become an integral part of how the viewer relates to the character. In short: the social structure of the film experience essentially depends on how these mutual intentionalities are functionally interwoven. But, since this web of intersubjective relationships is certainly quite differently woven in video-selfies than, say, documentaries or films of fiction, the purpose of pointing this out cannot be - as already resulted from Meunier's considerations - that of defining an invariant, structural feature common to film experience in general. Instead, this approach could prove useful in two regards.

On the one hand, it could offer a theoretical framework better suited for specifically grasping possible variations in the social structure of film experience. For, indeed, since the structural relations between author(s), protagonist(s), and viewer(s) - in other words: the grounding interconnection between the social experience of filming and that of film-viewing - are by far not as neatly recognizable in the case of most types of documentaries and films of fiction as in that of home movies or video-selfies, it is only in contrasting them to one another that those structures become visible in their specificity. One could thus, for instance, take a most basic element of documentary filmmaking like the interview as a starting point for phenomenologically illustrating how the viewer's experience varies with the precise distribution of the interlocutors' intentionalities in addressing each other, respectively the viewer via the camera between an observational style recording of a discussion, a TV interview, an election show, or an Interrotroninterview by Errol Morris. The least one could observe in performing such a variation is that the interviewer and the interviewee generally differ in their relationship to the camera, insofar as the interviewer does not simply occupy the position of a 'protagonist,' as does the interviewee, but he or she is at the same time to some extent an agent of the 'authorship.' Thus, the mutual interrelation between viewer, author, and protagonist is obviously marked here by the fact that the latter two terms are more ambiguously structured and intertwined, while this structural complexity is undeniably pushed even further in the case of fiction films. For, since, in a regular fiction film, all protagonists in fact have a share in the authorship as actors, while being pure protagonists as characters, the viewer's experience of the film is simultaneously determined by the camera's non-existence for the character and by the actor's expressive and cooperative performance in relation to the camera, which defines that non-existence. Therefore, the social structure of the fiction film experience fundamentally varies not only with the explicit acknowledgement of the camera by the character, 
but implicitly also with the complexities of the relationship between the camera's behavior and the actor's expressivity in relation to it.

Be this as it may, however, such an approach is - as already stated - just one possible way of fructifying these considerations, and not the most philosophically rewarding in my regard. For, in fact, studying the social structure of film experience might prove not just a matter of applying prior philosophical theories on intersubjectivity to the case of film, but instead properly speaking also a way of uncovering novel and differently structured forms of social experience, as I briefly began to suggest here with regard to video-selfies. If this is indeed the case, then decoding these experiences could actually become a means for enriching and challenging those philosophical theories themselves. Speaking about video in the early 199os, Vilém Flusser claims: "whenever gestures appear that have never been seen before, we have the key to decoding a new form of existence. The gesture involved in manipulating a video camera represents in part a change to a traditional gesture. According to the hypothesis just presented, then, one way of deciphering our current existential crisis is to observe this gesture."9 As our reflections above have shown, the same statement could go for video-selfies as well, which are themselves, no doubt, "a change to a traditional gesture" that promises access to entirely novel experiences of sociality. If this is indeed the case, however, then the main question we should first and foremost pose with regard to Meunier's book concerns the extent to which reflecting on its second part and further developing it could also prove fruitful for expanding the scope of the first part.

\section{Notes}

1. See the essays by Vivian Sobchack and Marie-Aude Baronian.

2. Vivian Sobchack, "Toward a Phenomenology of Non-Fictional Film Experience," in Jane Gaines and Michael Renov (eds.), Collecting Visible Evidence (Minneapolis, MN: University of Minnesota Press, 1999), pp. 241-254, p. 248.

3. $\quad$ Richard Chalfen, Snapshot Versions of Life (Bowling Green, KY: Bowling Green State University Popular Press, 1987), p. 8.

4. Jamie Baron, The Archive Effect: Found-Footage and the Audiovisual Experience of History (London/New York: Routledge, 2014), p. 95.

5. Christian Metz, Psychoanalysis and Cinema. The Imaginary Signifier, trans. Celia Britton, Annwyl Williams, Ben Brewster, and Alfred Guzetti (London: Macmillan, 1983), pp. 42-57.

6. For sure, one might be reluctant to claim that mirror reflections involve an intersubjective experience since they only engage the subject in relation to 
him- or herself and not to others. However, there are at least three arguments to support such a claim. First of all, mirrors have an obvious preparatory social function: they anticipate others in that they allow the subject from the outset to regard him- or herself as he or she will be regarded by them. Secondly, mirrors are genetically linked to social interaction, since, as is well known, the ability to recognize one's own mirror image develops in children simultaneously with an extended ability for social cognition. Finally, the experience of regarding oneself in the mirror shares the phenomenological structure of an intersubjective experience, insofar as it involves the same reciprocity and reversibility of perceiving and being perceived. This latter point especially is at the core of my argument above. Cf. for this also Beata Stawarska, "Mutual Gaze and Social Cognition," Phenomenology and Cognitive Science, 5 (2006), pp. 17-30 and Christian Ferencz-Flatz, "Abormality and Perceptual Communication: Husserl on Exchanging Glances with Animals," Tijdschrift voor Filosofie , 8o/1 (2018), pp. 73-92.

7. The intersubjective structure of the mirror experience thus finds its most visible expression, from a phenomenological perspective, in the dialectic movement by which the viewing I constantly lapses into the viewed I and vice versa. One can vividly experience this reversion when practicing a speech or an act in front of the mirror. For, in striving to dissociate oneself from the viewed I so as to perceive oneself as another, the viewing I cannot maintain this posture in front of the mirror for long without constantly falling into the position of the viewed I with every gesture, statement, or grimace. Hence, the awkwardness that makes it, to a certain degree, easier to perform an act directly in front of others rather than to practice it in front of the mirror. This observation might shed an interesting light on Robert de Niro's famous mirror monologue in Taxi Driver (1976), not because the film accurately illustrates the aforementioned awkwardness, but on the contrary because it is completely lacking in it and the character addresses himself as another in front of the mirror with an estrangement that can only be attained by highly trained actors or madmen, while the scene can be for sure read as testifying to both.

8. See the essay by Vivian Sobchack in this volume.

9. Vilém Flusser, Gestures, trans. Nancy Ann Roth (Minneapolis, MN: University of Minnesota Press, 2014), p. 142.

\section{About the author}

Christian Ferencz-Flatz works as a researcher at the Alexandru Dragomir Institute for Philosophy and as an associated professor at the I.L. Caragiale National University of Theatre and Film in Bucharest. His research interests are phenomenology, critical theory, philosophy of history, film philosophy 
and image theory. With Julian Hanich, he co-edited the special issue of Studia Phaenomenologica XVI: Film and Phenomenology (2016). His most recent book publications include: Filmul ca situație socială. Eseurifenomenologice / Film as a Social Situation. Phenomenological Essays (in Romanian, 2018) and Sehen Als-ob. Ästhetik und Pragmatik in Husserls Bildlehre (Bautz, 2016). His papers have appeared in numerous philosophical and film scholarly journals. In 2016-2017, he was a fellow of the Alexander von Humboldt Foundation. 


\title{
Illuminating Reality: Cinematic Identification Revisited in the Eyes of Buddhist Philosophies
}

\author{
Victor Fan
}

\begin{abstract}
According to Jean-Pierre Meunier, identification is an intersubjective process. Yet, when it comes to theorizing the attitudes by which we identify, he seems to suggest that a permanent and individuated subject has been in operation all along. This aporia has been examined in the debate between Mādhyamaka (middle way) school (theory of the emptiness) and the Yogācāra school (theory of existence) of Buddhism, a discourse borrowed by Chinese film theorists since the late nineteenth century to scrutinize cinematic identification. This chapter argues that this aporia underlines not only how identification operates and why it must operate, but also how we inevitably return to it in our theorization.
\end{abstract}

Keywords: Buddhism and film theory; Chinese film theory and criticism; Mādhyamaka Buddhism; Yogācāra Buddhism; cinema ontology and identification; Jean-Pierre Meunier

\section{Introduction}

In the beginning of The Structures of the Film Experience, Jean-Pierre Meunier, based on the works of Maurice Merleau-Ponty and Angelo Hesnard, argues that cinematic identification is best understood not as a relationship between two individuated subjects. Rather, it is an inter-psychic connection that takes place on a level prior to individuation and subjectivization. ${ }^{1}$ In this sense, identification is not a process in which a pre-constituted subject becomes one with a pre-constituted object. Rather, it is a process of individuation, in which the divides between the self and the other, the subject and the object, and the

Hanich, J. and D. Fairfax (eds.), The Structures of the Film Experience by Jean-Pierre Meunier. Historical Assessments and Phenomenological Expansions, Amsterdam University Press, 2019 DOI 10.5117/ 9789462986565_FAN 
spectator's body in here and the image out there, are initiated. Then, towards the end of his book, drawing on the work of Jean-Paul Sartre, Meunier reminds us that, what we sense and perceive as individuals in the image is the presence of the absence of an individual whose image was captivated by the camera in the past. ${ }^{2}$ Identification therefore requires the spectator to: (1) 'presentify' in a home movie, i.e. to make present the absence of someone we have known all along; (2) 'personalize' in a documentary, i.e. to give personality to an individual who has been reduced by the documentary to a representation of a larger social group, and (3) 'affectivize' in a fiction film, i.e. to establish affective connections with an imagined character who has no existential value in our lived reality.

Between these two registers of understanding, there is an aporia. The understanding of identification according to Merleau-Ponty and Hesnard presumes an interdependent relationship between the spectator and the image. The individuation of these two parties renews itself at each moment of identification and each temporal point-instant of sense-perception. In this light, each party does not exist in its own right. The understanding of identification according to Sartre, however, presupposes the temporal permanence of a sentient body, which enables each sensory-perceptual point-instant to take place. It is this sensory-perceptual process that makes present the absence of the image, thus allowing the spectator to presentify, personalize, and affectivize the image as a subject.

Meunier's shift from the first register to the second is symptomatic of a philosophical struggle outlined in the beginning of Henri Bergson's Matter and Memory (Matière et mémoire, 1896). We cannot say that there is a permanent world out there that constitutes the mind in here (materialism), or that there is a permanent mind that projects a world out there (idealism). It is because our ability to sense and perceive and what we sense and perceive are interdependently related, that is, they arise and are extinguished in relation to each other. Nevertheless, despite our knowledge of this, it is extremely hard to theorize identification without imagining aje ne sais quoi from which a temporally and existentially permanent self is constituted. Yet, if understood this way, identification is ultimately not an intersubjective process, but an idealistic one, that is, the image is a milieu initiated from this je ne sais quoi that underlines the process of sense-perception. ${ }^{3}$

This question was first raised by Chinese intellectuals between the $1870 \mathrm{~s}$ and the 1890 s, who attempted to establish a comparative space between modern European philosophy and classical Chinese learnings - especially Buddhism - in order to foster an alternative mode of modernity. ${ }^{4}$ In the context of film criticism, since 1897 , film critics have borrowed concepts from 
Buddhism to address questions of ontology, spectatorship, and aesthetics. ${ }^{5}$ In this chapter, I argue that Buddhist philosophy can help us rethink how intersubjectivity is constituted in the process of identification. I do so by scrutinizing two schools of Buddhism: the Mādhyamaka (middle way) school (theory of the emptiness) and the Yogācāra school (theory of existence). Since the Second Buddhist Council (c. 334 BCE), scholars have regarded these two schools of philosophy as two dialectically opposed methods of reasoning. ${ }^{6}$ Yet, they are both based on the same underlying assumption: that our sensory-perceptual reality is made up of sentient beings and inanimate objects that exist interdependently, arise and are extinguished from one temporal point-instant to another, caused by a set of nidānas (interdependent relationships). It means that these beings and objects are merely lakșanas (forms) that have no existential values. They are anitya (impermanent) and anātman (not-having any existential value, or "empty"). ${ }^{7}$

\section{Historical Background}

Since the 1960 s and 1970s, Lacanian film theorists have pointed out that, in the cinema, the sensory-perceptual subject, who seems to exercise an agency looking at and constituting the image, is in fact constituted intersubjectively with the image. ${ }^{8}$ Yet, this interdependent relationship between the viewing subject and the image is extremely difficult to grasp experientially, since $m y$ sense-perception and my intellectual reasoning are inevitably based on my body. In the 1930s, Shanghai-based Taiwanese screenwriter and critic Liu Na'ou (1905-1940) used the theory of meditation proposed by Yogācāra Buddhism to examine how a spectator approaches cinematographic reality subjectively on the one hand, and how they become one with the image intersubjectively on the other. In the end, for Liu, the cinematographic experience is neither subjective nor intersubjective. ${ }^{9}$

In Europe and North America, Buddhism is often understood as a form of spiritualism. Ironically, all schools of Buddhism reject the notion of the spirit and Buddhism itself was developed out of a philosophical, not religious, discourse in ancient South Asia. ${ }^{10}$ The use of Buddhist philosophy as a critical vocabulary emerged in China around the Six Dynasties (220 or 222-589 CE). ${ }^{11}$ However, academic studies of philosophical Buddhism declined around the late Tang (618-907 CE) period. ${ }^{12}$ In the 1860 s, scholar Yang Wenhui (1837-1911), upon "rediscovering" Buddhist logic, established the Jingling kejing chu (Jingling Sūtra Publishing House) in Nanjing in 1866 (renamed the Zhina neixueyuan or China Inner Studies College in 1911). ${ }^{13}$ 
Seminars organized at the Publishing House and the College were attended by key intellectuals during the Republican period (1911-1949), including Ouyang Jian (1871-1943), Liang Qichao (1873-1929), Wang Guowei (1877-1927), Feng Zikai (1898-1975), and Thomé H. Fang (1899-1977). Many of them wrote comparative studies between Buddhism and European philosophy to propose an alternative mode of intellectual modernity. ${ }^{14}$

In addition, these scholars were inspired by the Kyoto School of philosophers: Suzuki Daisetsu Teitaro (1894-1966), Tanabe Hajime (1885-1962), and Nishitani Keiji (1900-1990). These philosophers criticized European modernity as a system based on the binary division between the self and the other. For them, Zen Buddhism provided a way to rethink human relationships and world politics in intersubjective terms. ${ }^{15}$ Nonetheless, the Kyoto School's anti-modernity position was appropriated by the militarists during the Sino-Japanese War (1937-1945) and the Pacific War (1941-1945), which was largely questioned by their Chinese counterparts. ${ }^{16}$

\section{The Twelve Nidānas and Middle Way Buddhism}

The basic principles common to all schools of Buddhism are the twelve nidānas (interdependent relationships), which constitute all phenomena. For Shakyamuni Buddha (c. 563 or 480 BCE-c. 483 or 400 BCE), our unawareness of them is called avidya (ignorance or unenlightened). The term "ignorance" is not to be taken negatively. Instead, it is the fundamental condition of existence. For example, a table is made up of pieces of wood assembled by a carpenter. Once assembled, this "table" is endowed with a lifespan: formation, endurance, deterioration, and emptiness. Without the interdependent relationships between the raw materials and the act of assembling them, there is no table and the time in which it dwells. We can say the same about a human body and anything that appears to exist in time. Our act of misrecognizing a being or an object as something that exists on its own, by ignoring the interdependent relationships that constitute them, is "ignorance." 17

For Shakyamuni Buddha, ignorance is interdependently related to samskara, a cause-and-effect chain from which all forms of existence come into being - a force of life. In Buddhism, it is also known as karma - causeand-effect cycle. ${ }^{18}$ The interdependent relationship between ignorance and force-of-life produces vijñapatis (consciousnesses): the abilities to differentiate, from which the abilities to sense, think, act, and become conscious are manifested (nāmarūpa or naming). ${ }^{19}$ Vijñapatis are sometimes 
interchangeable with the six vijñanas (consciousnesses of the eyes, ears, nose, tongue, body, and mind). With these consciousnesses, the six șadāyatana (entrances or organs) are initiated, which enable us to sparśa (come into contact with) äyatana (sense data). Such contact gives rise to vedanās (affections: pleasure, displeasure, non-pleasure, and non-displeasure) and generates trșnāa (desire). With desire, we develop upādāna (attachment) to the self and to those beings and objects desired as though they were bhava (those which exist). With existence, temporality arises, which is manifested through jāti (birth) and jarāmaraṇa (old age and death). ${ }^{20}$

The earliest pupils of Shakyamuni Buddha believed that nirvāna (release from ignorance) could be achieved by abandoning the self and senseperception, so that they could dwell in śūnyata (emptiness). However, in so doing, they effectively treat emptiness as that which exists. ${ }^{21}$ Between the second and first centuries BCE, the Mahāsāṃghika sect began to rethink the implications of the theory of nidannas. ${ }^{22}$ Supposed that all things sensed and perceived are constituted by the twelve nidānas, these beings and objects have no existential values, i.e. they are śünya (empty). At first glance, existence and emptiness seem to be two dialectically opposite modes of reality: the former corresponds to the Kantian notion of the phenomenon, the latter to the noumena (things-in-themselves). Between the second and third centuries CE, Buddhist scholar Nāgārjuna (150-c. 250 CE) argued, if emptiness simply refers to the absence of any existential value in the phenomenon, existence is empty, and emptiness is the foundation of existence - the two concepts are not identical, but they are also not different!"3

Therefore, nirvāna is not a release from nidānas in order to reach a state of śūnyata, but from our unawareness that nidānas and śūnyata are interdependently related. For Nāgārjuna, tathātā (the way it is, or the ultimate reality) lies in the mādhyamaka (middle way), or more appropriately, what remains after the differences between arising and extinction (existential difference), permanence and impermanence (temporal difference), identity and difference (spatial difference), and coming and going (difference in movement), have been deconstructed. ${ }^{24}$

In the cinema, for instance, we sense and perceive the image on-screen as a reality with its own temporality. Yet, such a reality is constituted by a set of interdependent relationships: light particles, a projector, a film crew that made the film, actors, and us as the spectators. The reality on-screen is therefore empty, and such emptiness is the foundation of cinematographic reality. Identification is, in this sense, a process initiated from an attachment to existence (temporality), and the self. For example, in a home movie, I form an attachment with the existence of the presence of the family member I 
seem to see on-screen, even though this human figure is absent (empty). Yet, for me, this human figure initiates affections in me. Also, its form or appearance (presence) suggests time: I can trace the memory of this family member; they appear to be here; and they should continue to exist in this filmic reality. I therefore attach my self to this figure as that which exists: I presentify it.

But then, for Nāgārjuna: (1) what existed in the past no longer exists; thus, existence in the past does not exist; (2) what will exist in the future does not exist, as existence in the future has not come into being yet; (3) in what we call the present, existence in the past has ceased to exist and existence in the future is yet to arise. In this sense, the presence, in which we dwell, is a difference between the past and the future, which has no existential value - or as Meunier argues, à la Sartre, a gap between retentionality and protentionality (p. 108). ${ }^{25}$ Yet, if neither the past, the future, nor the present has existential value, identification is an instantiation of attachment, an active ignoring of an assemblage of causalities that gives rise to both the sensory-perceptual body and the image. To presentify, personalize, and affectivize is to ignore wilfully that what we sense and perceive (in this case, the cinematic image and my body) is initiated out of an interdependent relationship between nidānas and śūnyata.

\section{Yogācāra Buddhism and the Theory of Seeds}

The process of identification can be nuanced with the theory of seeds proposed by Yogācāra Buddhism. For Yogācāra scholars, the first six consciousnesses interdependently arise with the self-consciousness (manas-vijñanna), sometimes called the seventh consciousness. For Mādhyamikas (scholars of Mādhyamaka Buddhism), the first six consciousnesses and the self are not identical concepts. However, the self is initiated when the six consciousnesses are initiated and what the "self" signifies is the summation of these six consciousnesses. Therefore, these concepts are not different. However, as I mentioned in the beginning of this chapter, for Yogācāra scholars, there must be a je ne sais quoi from which this interdependent relationship is initiated.

This problem is observed in Yogācāra meditation. First, a meditator observes that what they sense and perceive is an image (or milieu), given form by their own attachment (parikalpitah-sabhāva: form arisen from attachment). It is either an imagination (standalone image), a misrecognition (substance-image), or an image that seems to be initiated out of its own self-nature (nature-image). ${ }^{26}$ Then, a meditator observes that this image 
consists of forms constituted by the twelve nidānas (paratantra-sabhāva: forms arisen from interdependency). Yogācāra further divides causality into four categories: (1) hetu-pratyaya (immediate and circumstantial causes); (2) samanantara-pratyaya (chronological causes); (3) àlambana-pratyaya (encounter between two sense-media); and (4) adhipati-pratyaya (assisting causes). ${ }^{27}$ In this light, the image out there is empty and impermanent. Its existence and temporality are given form by the interdependent relationship between the six consciousnesses and the self. But if so, such an interdependent relationship seems to be existent and permanent.

To circumvent this problem, Yogācāra scholars propose the idea of the àlaya-vijñanna (storehouse consciousness). Within the storehouse consciousness, there lies an astronomical number of bijas (seeds). Each seed is an instantiation of the interdependent relationship between ignorance and force-of-life. When a seed is actualized, the first six consciousnesses arise interdependently with the self-consciousness. Each actualization of a seed initiates a series of smrtsis (awarenesses), and a sequence of awarenesses constitutes an image that exists in time. To complicate matters, Yogācāra scholars argue that seeds are not actualized sequentially, but as an ogha (avalanche). Hence, temporality is not made up of a sequence of awarenesses, but a fabric of interdependently related awarenesses, each producing its own cause-and-effect chain (samskara or force-of-life), and together with it, ignorance. This renewed interdependent relationship between force-of-life and ignorance is instantiated as a new collection of seeds. ${ }^{28}$ These seeds therefore carry with them memories from the past, a potentiality, which, once actualized, turns into consequences that will unfold in the future. In other words, the a laya-consciousness is the site where existence arises out of emptiness. An awareness of it is called parinispanna-sabhāva (ultimate reality).

\section{The Image and Identification}

In terms of the theory of seeds, how does identification work? Here, I scrutinize a photograph found in the family archive of my partner John Christiansen, which is a sepia medium close-up of his uncle John Adams when he was eighteen (see Fig. 9). Adams's picture was taken in autumn 1944 in a drugstore in Brooklyn when he was on leave from the army, shortly before he was sent to occupied France, where he died saving a wounded comrade on the battlefield. The portrait was taken with a low-quality camera and the entire image is out of focus. In this portrait, Adams wears 


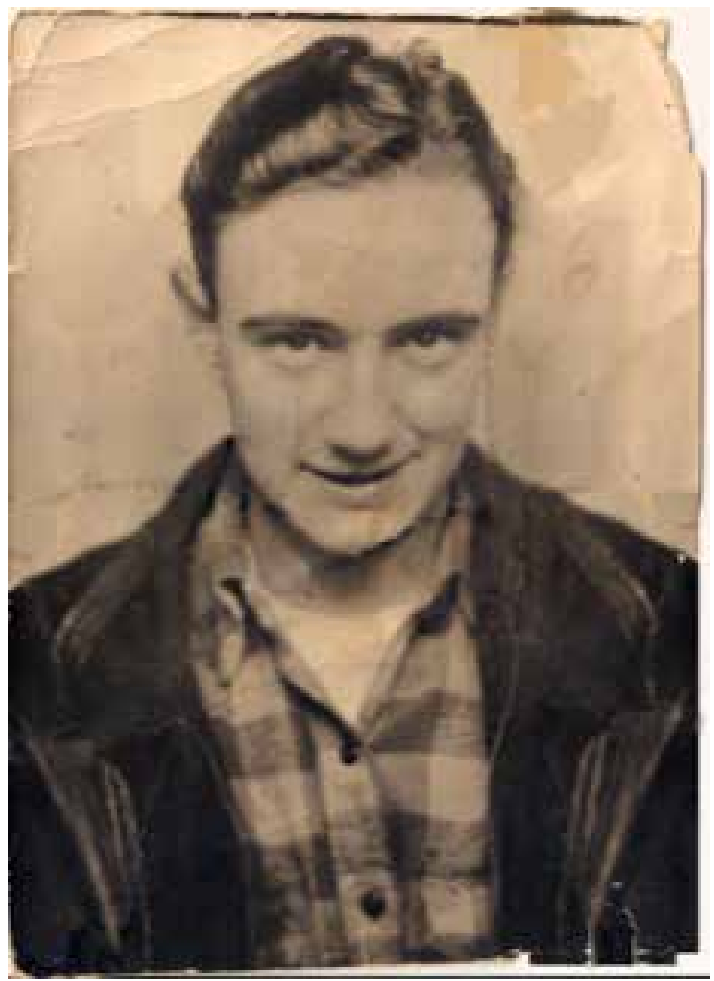

Fig. 9: Portrait of John Adams in Lower Manhattan, shortly before he was sent to Germany in Spring 1944 (d. Amanvillers, occupied France, September 11, 1944). Courtesy of John Christiansen.

a slightly oversized leather jacket. Underneath, he wears a plaid shirt with the top button open, thus revealing his white undershirt. Adams's head is slightly lowered, yet his eyes stare directly into the lens. Correspondingly, his crescent-shaped mouth is slightly open with a smile, as though the smile had yet to be completed or as though he were about to say something. In fact, his slightly lowered head seems to be arrested in the middle of an action. His strong nose sits in the middle of his face, his eyes are wide open and brightly lit, and his thick eyebrows frame the top of his eyes and give form to his tall forehead. His left ear (on frame right) is hidden from the camera, whereas his right ear (on frame left) juts out with a touch of humor. He has a young and handsome face with an air of defiance. He wears a smoothly and immaculately done quiff parted towards the left side of his skull. $\mathrm{He}$ is looking at you.

In Yogācāra Buddhism, a nature-image arises when the ability to sense, perceive, and (re)cognize encounters a set of sense data. In 1944, the image of Adams (as a living being) arose through the sensory-perceptual 
mechanism of the camera and a set of interdependent relationships. The camera mechanically preserved some of these relationships, especially the way light particles were related to each other and the way Adams comported and looked into the camera that day. Today, the photographic image of Adams arises again through my own sensory-perceptual process, dependent upon some of the same interdependent relationships that gave rise to Adams's existence. This in fact corresponds to André Bazin's understanding of photographic ontology. ${ }^{29}$ As Roland Barthes comments on Alexander Gardner's photograph of Lewis Payne in 1865 , shortly after he was executed for an attempted assassination of U.S. Secretary of State William H. Seward: "He is dead and he is going to die...." ${ }^{\circ}$

When I behold the photograph, the image is initiated from the operation of my first six consciousnesses, which are in turn dependent upon my selfconsciousness. This self-consciousness gives the series of sensory-perceptual instants that take place in the first six consciousnesses an impression of unity and integrity. The self therefore assumes the role of an observer and sees the image as a phenomenon initiated out of a set of interdependent relationships: immediate and circumstantial causes, chronological causes, encounters between two sense-media, and assisting causes. I then come to believe that the photographic image is a nature-image because of my attachment to the self and to the phenomenon.

The operation of the first six consciousnesses, under the supervision of the self, stimulates the seeds that have laid dormant in the âlaya-consciousness and produces more instantiations of ignorance (seeds). Each stimulation is triggered by an activation of a seed, from which an awareness is initiated. Once the first awareness is initiated, the entire sensory-perceptual operation is also initiated as a fabric of complex cause-and-effect chains, experienced by me as a chronological sequence. In this sequence, a second awareness arises, during which the self-consciousness seeks the permanence of the first awareness, i.e. I want this image to persist in time and to discern what it really is. Then, a third awareness arises, which determines what such an awareness is: I can determine that this image is the image of Adams, which exists in time. This is followed by a fourth awareness, in which the qualitative value (e.g. pleasure and displeasure) of the awareness is determined, which then triggers a sequence of awarenesses, which in turn constitutes the photographic image of Adams and the time in which it dwells. This is the way by which I presentify the image of Adams as Adams, a process of identification that is also a process of becoming Adams. In the cinema or a moving image, this process further gives form to birth and extinction, permanence and impermanence, similarity (continuity) and difference 
(discontinuity), coming and going - impressions that constitute temporality and spatiality. In short, I identify because my ālaya-consciousness cannot let go of the need to identify, and I cannot let go of presentifying myself.

\section{Conclusion}

What Yogācāra scholars and practitioners identify, however, is an impasse. The ālaya-consciousness never stops operating. Yogācāra scholars argue that it is a pure potentiality from which permanence and impermanence, existence and non-existence are initiated. Nonetheless, scholar Yin Shun (1906-2005) argues that the concept of the allaya-consciousness, understood this way, becomes a je ne sais quoi that closely resembles a "first cause." For him, älaya-consciousness is a powerful tool to explicate not only why we are incapable of letting go of the self and of permanence, but also why, in philosophy and theory, we often replicate the same impasse. For us, we can understand perfectly that identification is an intersubjective process. Yet, when we explain how we identify, we are always tempted to assume that a permanent self is in operation. ${ }^{31}$

Yin Shun therefore suggests that we revisit Mādhyamaka Buddhism for a possible way out of this impasse. According to the Vajracchedika Prajñāpāramitā Sūtra [Diamond Sūtra]:

All phenomena are like

A dream, an illusion, a bubble and a shadow.

Like a dew drop and a flash of lightning,

Thus should you view them. ${ }^{2}$

The cinematic image and our process of identification operate in a way similar to a dream, an illusion, a bubble, a shadow, a dew drop, and a flash of lightning. If we simply say that, because it is transient, that it does not exist, we deny the fact that it is a reality initiated out of the twelve nidānas. If we say that it exists, we deny the fact that its existence is empty. A film appears to us as a reality that has its own existential value, one that is initiated from the existential value of the photographed being or object in the past. Yet, it remains a set of sense data, an assemblage of light and shadow that runs 24 frames per second. One reality is not more real than the other, and we have a penchant to attach ourselves not only to the image as that which exists, but also to our "selves" as those which exist. In this sense, the cinema is a technical milieu in which these two modes of existence 
are neither identical nor different. In this technical milieu, identification is an intersubjective process. Yet, the intersubjectivity of such a process is often ignored both experientially and theoretically. It is because this entire process is driven, in the first place, by a samskara that carries memories from the past, memories from which the divide between the self and other, the spectator and the image, and the past and the future are all initiated.

\section{Notes}

1. See Maurice Merleau-Ponty, Phenomenology of Perception, trans. Donald A. Landes (London: Routledge, 2012); Angelo Hesnard, Psychanalyse du lien interhumain (Paris: P.U.F., 1957).

2. Jean-Paul Sartre, The Imaginary (1940), trans. Jonathan Webber (London: Routledge, 2004), pp. 17-20. This argument is adopted by André Bazin, "The Ontology of the Photographic Image," (1945), in What is Cinema? vol. I, trans. Hugh Gray (1967; repr. Berkeley, CA: University of California Press, 2005), pp. 14-17.

3. Henri Bergson, Matter and Memory, trans. N.M. Paul and W.S. Palmer (New York: Zone Books, 2002), pp. 25-26.

4. See, for example, Yang Wenhui, Yang Renshan ji [Collection of Essays by Yang Wenhui], ed. Huang Xianian (Beijing: Zhongguo shehui kexue chubanshe, 1995); Ouyang Jingwu, Weishi jiangyi [Lectures on Yogācāra Buddhism] (Taipei: Fojiao chubanshe, 1978).

5. Anon, "Guan Meiguo yingxi ji" [Viewing American Shadow Plays, August 11, 1896], in Ding Yaping (ed.), Bainian Zhongguo dianying lilun wenxuan [One Hundred Years of Chinese Film Theory and Criticism] (Beijing: Wenhua yishu chubanshe, 2002), pp. 1, 3-4; Gu Kenfu, "Fakanci" [Inaugurating Preface], Yingxi zazhi [The Motion Picture Review] 1, no. 1 (1920): p. 10; Hou Yao, Yingxi juben zuofa [Methods of Writing a Shadow Play] (Shanghai: Taidong shuju, 1926), pp. 13-23.

6. See Nalinaksha Dutt, Buddhist Sects in India (1978; repr., Delhi: Motilal Banarsidass Publishers, 1998); Janice J. Nattier and Charles S. Prebish, "Mahāsāṃghika Origins: The Beginnings of Buddhist Sectarianism," History of Religions 16, no. 3 (February 1977): pp. 237-272. See also, Yin Shun, Shuo yiqieyou bu weizhu de lunshu yu lunshi zhi yanjiu [A Study of the Śāstras and Philosophers of and Related to the Sarvāstivāda] (Taipei: Zhengwen chubanshe, 1968).

7. See, for example, Asanga, Yujiashi di lun [Yogācārabhümi-śāstra or Discourse on the Stages of Yogic Practice], trans. Xuanzang (Taipei: The Buddha Educational Foundation, 2014), juan 9:16-2o (pp. 1:321-29); Huang Jiashu, Za ahan jing daodu [Saṃyuktāgama: A Reading Guide], sūtras trans. Guṇabhadra (1999; repr., Taipei: Buddhall, 2006), sūtras 1-7 (pp. 235-256), 
11 (pp. 262-263), 58 (pp. 264-267), 68 (pp. 278-279), 262 (pp. 281-285), 274 (pp. 292-293), 297 (pp. 295-296), 309 (pp. 299-300), 319 (p. 302), 322 (pp. 304-305), 335 (pp. 308-309), 1171 (pp. 315-317), and 1173 (pp. 319-322). See also, Nāgārjuna, Dazhidulun [Mahāprajñāpāramitāśāstra or Great Treatise on the Perfection of Wisdom], trans. Kumārajiva (Taipei: Shihua guoji gufen youxian gongsi, 2007), juan 5:35-36 (pp. 233-234).

8. See, for example, Christian Metz, "The Imaginary Signifier," trans. Ben Brewster, Screen 16, no. 2 (1 July 1975): pp. 4-76.

9. Liu Na'ou, "Guanyu zuozhe de taidu" [On the Author's Attitude], Xiandai dianying [Modern Screen ] 1, no. 5 (October 1, 1933): pp. 1-2.

10. Fyodor Stcherbatsky, Buddhist Logic (1930-1932) (1993; repr., Delhi: Motilal Banarsidass Publishers, 2008), pp. 1-58.

11. For a study of Six-Dynasty aesthetics, see, for example, Chen Chuanxi, $\mathrm{Li}$ uchao hualun yanjiu [A Study of Six-dynasty Theories on Painting] (Beijing: Zhongguo qingnian chubanshe, 2015). A collection of art theories during this period can be found in Yu Anlan, ed., Hualun congkan [Anthology of Theories on Painting] (Beijing: Renmin meishu chubanshe, 1989), in two volumes.

12. Jiang Weiqiao, Zhongguo Fojiao shi [History of Chinese Buddhism] (Hong Kong: Hong Kong Open Page Publishing, 2013).

13. Jiang, 544 .

14. Ouyang Jian, Ouyang Jingwu ji [Collection of Essays by Ouyang Jian], ed. Huang Xianian (Beijing: Zhongguo shehui kexue chubanshe, 1995); Liang Qichao, Zhongguo Fojiao yanjiu shi [History of the Studies of Chinese Buddhism] (Beijing: Zhongguo shehui kexue chubanshe, 2008); Wang Guowei, Renjian cihua [On Human Literature] (Hong Kong: Zhonghua shuju Xianggang fenju, 1961); Yuji Norie, Dacheng qixinlun xinyi [Mahāyāna śraddhotpādaśāstra: A New Translation, 1914], trans. Feng Zikai (Hangzhou: Zhejiang renmin chubanshe, 2015); Thomé H. Fang, Zhongguo Dacheng Foxue [Chinese Mahāyāna Buddhism] (2012; repr., Beijing: Zhongghua shuju, 2015), in two volumes.

15. A collection of the writings of the Kyoto School philosophers can be found in Frederick Franck, ed., The Buddha Eye: An Anthology of the Kyoto School and Its Contemporaries (Bloomington, IN: World Wisdom, 2004).

16. Christopher Goto-Jones, ed., Re-Politicising the Kyoto School as Philosophy (London: Routledge, 2008).

17. Huang, Za ahan jing daodu, sūtras 293 (pp. 326-327), 296 (pp. 330-332), 300 (pp. 337-338), 364 (pp. 341-342), 373 (pp. 344-346), 388 (p. 348), and 404 (pp. 353-354). For śāstras, see Asanga, Yujiashi di lun, 9:16-20 (pp. 321-329); Nāgārjuna, Dazhidulun, juan 5:35-36 (pp. 233-234). For a modern discussion, see, Stcherbatsky, Buddhist Logic, pp. 119-145; Tam Shek-wing, Sichong yuanqi shen borë [Four Kinds of Nidānas and Profound Prajñā] (2005; repr., Taipei: Buddhall, 2014). See also, Yan Pei (Yen P'ei), Fojiao de yuanqi guan [On the Concept of Nidānas in Buddhism] (1981; repr., Taipei: Tianhua chu- 
ban shiye, 1997), pp. 1-32; Yin Shun, Fofa gailun [A Basic Discussion of Buddhist Theories, 1949] (2010; repr., Beijing: Zhonghua shuju, 2016), pp. 98-104.

18. See Yin Shun, pp. 98-104.

19. Lo Si-hin, Cheng weishi lun jiangji [Vijñaptimātratāsiddhi: A Lecture] (Hong Kong: The Dharmalakshana Buddhist Institute, 2015), pp. 83-84.

20. See note 18 .

21. See David Seyfort Ruegg, "Towards a Chronology of the Madhyamaka School," in Indological and Buddhist Studies, eds. L.A. Hercus, F.B.J. Kuiper, T. Rajapatirana, and E.R. Skrzypcazak (Canberra: Faculty of Asian Studies, 1982), pp. 505-530.

22. Guang Xing, The Concept of the Buddha: Its Evolution from Early Buddhism to the Trikāya Theory (London: Routledge Curzon, 2005), p. 66.

23. See Da borë jing gangyao [The Prajñāpāramitā: An Abridged Edition], sūtra trans. Xuanzang (Taipei: The Buddha Educational Foundation, 2016); see also, Yin Shun, Zhongguan lunsong jiangji [Lectures on the Mūlamadhyamakakārikā] (1952; repr., Taipei: Zhengwen chubanshe, 2014).

24. Yin Shun, pp. 66-67.

25. See Sartre, The Imaginary, pp. 17-20.

26. Lo, Weishi fangyu [Introduction to Yogācāra Buddhism] (Hong Kong: The Dharmalakṣaṇa Buddhist Institute, 2008), pp. 188-189.

27. Yin Shun, Zhongguan lunsong jiangji, pp. 66-67.

28. Bashiguiju song [Versus on the Principles of the Eight Consciousnesses], in Weishi si lun [Four Treatises of Yogacārā Buddhism], trans. Chen Peng (Kaohsiung: Fo Guang Shan zongwu weiyuanhui, 1998), pp. 269-298; Dignāga, Guan suoyuan lun song [Ālambana-parīkşā], in Chen Na si lun, Guan 4; Qu yin jiashe lun, in Chen Na si lun, Qu 1-2; Han Yanjie, Weishi xue gailun [General Concepts of Yogacārā Buddhism] (Taipei: Wenjin chubanshe, 1993), pp. 190-295; Lo, Weishifangyu, pp. 188-192; Renyou, Chenna xianliang lilun ji qi Hanchuan quanshi [Dignāga's Theory of Perception and Its Chinese Interpretations] (Taipei: Dharma Drum Culture, 2015); Xuanzang, Cheng weishi lun, juan 4 (pp. 24-31); Yin Shun, Dacheng qixinlun jiangji [Lectures on the Mahāyāna śraddhotpādaśāstra, 1950], śāstra Aśvaghoṣa, trans. Paramārtha (2010; repr., Beijing: Zhonghua shuju, 2014), pp. 59-61; Yin Shun, Weishixue tanyuan [Investigation into the Origin of Weishi Studies, 1944] (2011; repr., Beijing: Zhonghua shuju, 2014), pp. 108-137; Zhou Shujia, Weishi yanjiu [A Study of Yogacārā Buddhism] (1979; repr., Taipei: Heavenly Lotus Publishing, 2014), pp. 29-34; Yu Lingbo, Weishi sansong jiangji [Lectures on the Three Versus of Yogacārā Buddhism] (Kaohsiung: Fo Guang Shan zongwu weiyuanhui, 1998), pp. 131-144.

29. Bazin, "Ontology of the Photographic Image," pp. 14-17.

30. Roland Barthes, Camera Lucida: Reflections on Photography, trans. Richard Howard (New York: Hill and Wang, 1981), p. 95.

31. Yin Shun, Zhongguan lunsong jiangji, pp. 66-67. 
32. Lo, Nengduan jingang borë boluo miduo jing zuanshi $\cdot$ Borë boluomiduo xin jing jianglu [Vajracchedikā Prajñāpāramitā Sūtra: A Revised Edition with Interpretation · Prajñāpāramitā Hṛdaya sūtra: Lectures] (Hong Kong: The Dharmalakshana Buddhist Institute, 2007), pp. 188-189.

\section{About the author}

Victor Fan is Senior Lecturer at the Department of Film Studies, King's College London and Film Consultant of the Chinese Visual Festival. Fan graduated with a Ph.D. from the Film Studies Program and the Comparative Literature Department of Yale University, and an MFA in Film and Television Productions at School of Cinema-Television, University of Southern California. He is the author of Cinema Approaching Reality: Locating Chinese Film Theory (University of Minnesota Press, 2015). His new book Extraterritoriality: Politics and Hong Kong Media has recently been published by Edinburgh University Press. His articles have been published in peerreviewed journals including World Picture Journal, Camera Obscura, Journal of Chinese Cinemas, Screen, Film History: An International Journal, CLCWeb: Comparative Literature and Culture; in anthologies such as A Companion to Rainer Werner Fassbinder and American and Chinese-Language Cinemas; and in film magazines such as 24 Images: Cinéma, Dianying yishu [Film Art], Zihua [Zifaa or Word blossoms], and Siyi. His film The Well was an official selection of the São Paolo International Film Festival. It was also screened at the Anthology Film Archives, the Japan Society, and the George Eastman House. 


\title{
Whose Identification? A Brief Meditation on the Relevance of Jean- Pierre Meunier's The Structures of the Film Experience to Contemporary Feminist Film Phenomenology
}

\author{
Kate Ince
}

\begin{abstract}
This essay responds to Meunier's The Structures of the Film Experience from the perspective of feminist phenomenological film theory, whose development from the early 1990s onward it begins by tracing. It argues that Meunier's employment of Angelo Hesnard's phenomenological understanding of identification in Psychanalyse du lien interhumain (1957) offers a more promising way for historical film phenomenology to engage with current queer and feminist work in the field than does the scientifically skeptical response to queer and feminist film phenomenologies outlined by Christian Ferencz-Flatz and Julian Hanich in their 2016 essay "What is Film Phenomenology?" It draws on feminist phenomenologist Sandra Bartky's essay “Toward a Phenomenology of Feminist Consciousness" (1975) in support of this claim.
\end{abstract}

Keywords: Feminist phenomenology; feminist consciousness; female viewing subject; existential ethics; Sandra Bartky; Angelo Hesnard

\section{Introduction: Feminist Film Phenomenology in History}

My primary connection to film phenomenology is the work collected in my The Body and the Screen: Female Subjectivities in Contemporary Women's Cinema. ${ }^{1}$ This book comprises a set of readings of films directed by mostly well-known women filmmakers that is prefaced by a philosophical chapter

Hanich, J. and D. Fairfax (eds.), The Structures of the Film Experience by Jean-Pierre Meunier. Historical Assessments and Phenomenological Expansions, Amsterdam University Press, 2019 DOI 10.5117/ 9789462986565_INCE 
on theories of female subjectivity and a historico-critical chapter that attempts to trace a genealogy of feminist film philosophy, which (it finds) overlaps to a considerable degree with recent work in film phenomenology. I am actually more inclined to describe myself as a feminist phenomenologist than as a film phenomenologist, but have accepted the invitation to consider how Jean-Pierre Meunier's important volume The Structures of the Film Experience can inform and contribute to the feminist phenomenological strand of film theory I outline in the second chapter of The Body and the Screen for two reasons: first, I am a feminist phenomenologist who works particularly with French cinema and French film theory, as well as film theory and film philosophy more generally, and second, two of my publications gain a mention in the excellent editorial introduction to the recent issue of Studia Phaenomenologica written by Christian Ferencz-Flatz and Julian Hanich, which bears the reassuringly open title "What Is Film Phenomenology?"2 If only on this account, I must, it seems, be some kind of film phenomenologist.

Since the literature in which feminism and queer theory have begun to intersect with film phenomenology is not widely discussed in this volume, I shall begin with a brief summary of the history of feminist phenomenology. ${ }^{3}$ Although it may be dated to the publication of Simone de Beauvoir's The Second Sex (Le Deuxième Sexe) in 1949, or even earlier to the work of Husserl's doctoral student and assistant Edith Stein in the late 1910s, it did not really have an academic profile until 1980, when Iris Marion Young's essay "Throwing Like a Girl: a Phenomenology of Feminine Body Comportment, Motility, and Spatiality" was first published, followed four years later by Judith Butler's "Sexual Ideology and Phenomenological Description: A Feminist Critique of Merleau-Ponty's Phenomenology of Perception." Then, as I chart in The Body and the Screen, "the first book on [feminist phenomenology] in English was Linda Fisher and Lester Embree's co-edited Feminist Phenomenology, which was based on a symposium held in 1994, and the 2000 s and 2010 s have seen a steady growth of publication in the area and the formation of a Society for Interdisciplinary Feminist Phenomenology at the University of Oregon." ${ }^{5}$ Film phenomenology, as Ferencz-Flatz and Hanich set out in the introduction to their recent issue of Studia Phaenomenologica, took off in earnest in the late 1940s when Gilbert Cohen-Séat founded the Institut de Filmologie at the Sorbonne: many phenomenologically oriented essays appeared in the Revue internationale de filmologie during the fourteen years that this journal was published in Paris, including those by Henri Wallon and Albert Michotte van den Berck referred to by Meunier in The Structures of the Film Experience. 
I entirely agree with Ferencz-Flatz and Hanich that there are "two decisive moments in film phenomenology's history: the years of $1946 \mathrm{ff}$ (with 1947 as the key moment) and 199off (with 1992 as the crucial date). ${ }^{n 6}$ But my feminist phenomenological perspective on film phenomenology's history leads me to see the 1992 publication of Vivian Sobchack's The Address of the Eye, which draws on Iris Marion Young's take-up of Merleau-Ponty's and Simone de Beauvoir's phenomenology in the late 1970s and 1980s, and an article by Gaylyn Studlar in the special 1990 issue of the Quarterly Review of Film and Television on "Phenomenology in Film and Television," mentioned by Ferencz-Flatz and Hanich as marking out not just the second key intersection of phenomenological philosophy with film studies in the twentieth century, but the initial encounter of feminist film studies with phenomenological philosophy. What I call "the feminist phenomenological strand of film theory/philosophy" probably counts as many feminist philosophers in its number - de Beauvoir, Sandra Bartky, Iris Young, Luce Irigaray, Sonia Kruks - as it does film philosophers - Vivian Sobchack, Gaylyn Studlar, Laura Marks, and Jennifer Barker - but at least some of the second group would, I feel sure, describe themselves as feminists, despite the different object(s) of their philosophical attention not entailing the same degree of engagement with female identity and female subjectivity.

The Body and the Screen is concerned above all with the subjectivities of female characters, directors, and writers, but here, as part of the dialogue with Meunier's The Structures of the Film Experience, I want to take up an issue I fairly explicitly set aside in the book - the female viewer. I term 'her' "the female viewing subject," rather than "the female spectator" in order to distinguish a phenomenological approach to filmic identification (including Meunier's) from the approach to spectatorship pursued during the era of psychoanalytic/semiotic/Marxist film theory that prevailed from about 1970 until at least the late 1980 s. $^{7}$

\section{Identification in The Structures of the Film Experience}

Can Meunier's book contribute to an account of viewing au féminin? Addressing this question will turn around the concept of identification and the way it is employed by Meunier in The Structures of the Film Experience, which is not presented as exclusively phenomenological. Early in his book, he says that "depending on the subjacent theoretical conceptions or the nuanced considerations of the process, [identification] also goes by the names of 'emotional participation,' 'projection' or 'empathy'." (p.32) A little later, he states 
In their rush to apply the process of identification to the filmic situation, the majority of studies dedicated to the problem have, it seems, abusively simplified the data. Often, the original form of the Freudian mechanism has been 'transplanted' into the filmic situation without any changes. But this neglects the fact that the mechanism in question, in the framework of developments in psychoanalysis and other theoretical tendencies, had itself undergone various retouches, and nourished numerous controversies, and that it was thus rather hasty to utilize the notion of identification without subjecting it to a prior critical examination. (p. 33)

Meunier's mention here of "various retouches" made to the mechanism of identification theorized by Freud, and to the "numerous controversies" nourished by it, seems to allude principally to phenomenology - Merleau-Ponty's phenomenology of perception, certainly, but also other mid-twentieth century deployments of phenomenological philosophy. In effect, what Meunier does in this statement is steer carefully around one or more troubled chapters in the history of the concept of identification and turn a page (as it were) to a new chapter, in which he will deploy it in quite a singular way. This singularity, however, is not so much his own as Angelo Hesnard's in Psychanalyse du lien interhumain (Psychoanalysis of the Interhuman Link), a source Meunier quotes from no fewer than nine times in the "Perception" and "Identification" chapters of The Structures of the Film Experience. ${ }^{8}$ Meunier states quite unambiguously just before the start of Chapter 2 that it is Hesnard's understanding of identification and the way he deploys it in Psychanalyse du lien interhumain, that he will draw on for the main part of his study in Part Two: "Here we return to the theories of Hesnard, who by rethinking the concept [of identification] in the framework of a psychology enriched by the gains of phenomenological thinking, has unveiled its true meaning." (p. 48)

What are the key modifications Hesnard has made to identification in his rethinking of it? Filmic identification, Meunier explains,

came to be considered in its objective form, that is, as a psychic mechanism (a mechanism of projection and introjection) or as a function (an empathic function) destined to comprehend or explain the functioning of the objective models of the personality constructed by scientific theory. (p. 33)

This was understandable, since

[i]t is, after all, generally admitted that the psyche can be regarded as an object, a slice of the perceptual world, or even an externally observable 
apparatus. [...] But in adopting this point of view, which it often did, filmology exposed itself to the same reproach that, in the last few years, phenomenological thinking has addressed to the scientific attitude in general, and which has done much to weaken it. By transposing psychic phenomena to an external objectivized form, that is, by reducing them to the state of simple functions or mechanisms, their very nature was altered, and their meaning or signification was thereby lost. (p. 33)

In an extrapolation of a central insight of the pioneers of phenomenology (Husserl, Heidegger, and Merleau-Ponty), Meunier insists, against "the scientific attitude" that "[t]his meaning or signification can only be perceived if we place ourselves on the terrain from which these phenomena have been extracted - namely, lived, first person experience" (p. 33/34). The meaning of phenomena must be discovered "as they present themselves to the subject who experiences them."

\section{Levels of Generality in Phenomenological Description}

At this point in his presentation of Hesnard's de-objectivation of the mechanism of identification, Meunier touches on the issue of generality and particularity in phenomenological description, also considered by Ferencz-Flatz and Hanich in section 4.2 of "What Is Film Phenomenology?", entitled "Feminist and Queer Phenomenology." Meunier specifies that describing lived experience

is not a matter, of course, of elucidating particular forms of behavior - for example, a given identification of a given subject with a given person - through the concrete modalities of their realization, but, rather, of unveiling the invariable aspect in these particular forms of behavior. In other words, we must abstract real forms of behavior and the structures that we can locate in all forms of the same kind of behavior, which themselves are their specific, concrete realizations. (p. 34)

This statement of Meunier's appears to echo the preference Ferencz-Flatz and Hanich state for a search for invariability over particular differentiation when they take issue with queer and feminist critiques of a seemingly universal type of body experience. Such critiques of seemingly universal descriptions of (film) experience can be located on two levels, the two scholars state, either as a "problem of incompleteness" (the descriptions are wrong in their limitedness, and must be amended and complemented 
"by descriptions of specifically female and/or queer experiences"), or as a "problem of generality" (the descriptions' aspiration to universality is correct, but they are insufficiently specific, and "should be amended and complemented by more concrete descriptions"). ${ }^{9}$ The distinction made here between levels of critique is, to my mind, a spurious one, introduced for the purposes of refuting the anti-universalist stance(s) of queer and feminist film phenomenologists: the solution to a problem Ferencz-Flatz and Hanich claim to be $t w o$ problems is actually the same (the descriptions of film experience in question "must be amended and complemented" by the "more concrete" descriptions of "female and/or queer experiences").

Whereas Ferencz-Flatz and Hanich employ logical argument of a Husserlian kind to find fault with the critiques of universal (film) experience made of Merleau-Ponty by Vivan Sobchack and Judith Butler, Meunier affirms, in a positive recommendation more in tune with existential phenomenology, that the description of the lived experience of film should abstract directly from real forms of viewers' behavior and seek invariable structures in those forms of behavior. ${ }^{10}$ (This could be effected on descriptions supplied by groups of viewers who share a gender or a race just as easily as on the experiences of a mixed audience.) Meunier is aware that there is still abstraction involved in his recommended procedure for a 'de-objectivized' approach to the experiential description of film, and asks whether it "slip[s] back into the impasses of the scientific attitude," but answers his own question in the negative, since the abstraction at issue is, he says, a single rather than a double objectivation of the kind hitherto effected on analyses of filmic identification (p. 34). (It is the second stage of objectivation that situates the analysis "in an objective, externally observable model, and thus, as we said above [loses] its meaning for the subject and real nature" [p. 34]). Meunier's conclusion to this section of The Structures of the Film Experience is: "Thus, the basis for research must not be any kind of conception of man as an object of observation, but an explanation of man as an experiential subject." (p. 35)

In their interventions into film phenomenology, queer and feminist film scholars are also concerned with experiential subjectivity - the subjectivities of female and queer embodied subjects, rather than the aspirationally universal subjectivity of 'man.' The de-universalization entailed in basing research into film-viewing on specified types of viewing subject arguably maintains a focus on subjectivity, 'the real world' and meaning exactly where it is lost by aspiring to "generalities, invariant structures of experience [...] with an emphasis on sameness, solidarity, empathy" that Ferencz-Flatz and Hanich state to be one of the diverse motives for doing phenomenology (the alternative motive they mention is "to describe how an experience is 
individual, unique, particular, singular," which they suggest "is in the interest of a politics of recognition and emancipation"11). By outlining two levels of objectivation which can be effected upon the mechanism of identification (and potentially other psychic phenomena), Meunier introduces a level not allowed for by Ferencz-Flatz and Hanich's binary distinction between generality and individuality/uniqueness, a level that corresponds neither to the "pipedream of pretended neutrality" in subjectivity described by Gaylyn Studlar, nor to a wholly unique individual subject..$^{12}$ In other words, where Ferencz-Flatz and Hanich argue that a rejection of the sharing of experiences on the level of all viewers undermines claims for the sharing of experiences by identified sub-groups of film-viewers such as female viewers, Meunier's framework of two levels of objectivation makes it possible to argue simultaneously for difference (actual difference in embodiment or sexuality) and sharedness within identified sub-groups of film-viewers. Arguing for sharedness "only for a more specific level of generality and not for a more general level of generality" (Ferencz-Flatz/Hanich) is, Meunier would appear to agree (with me), not particularly difficult. ${ }^{13}$ Moreover, sharedness is not necessarily embraced "in the interest of a politics of recognition and emancipation." It may indeed be appropriate to consider feminist film phenomenology as "post-structuralist inflected" - putting it at the 'individual/unique/particular/singular/different' level of Ferencz-Flatz and Hanich's binary model of levels of generality - since feminist theory has been significantly shaped by post-structuralist questioning and deconstruction of the understanding of the subject as unitary and 'individual,' and has been more diverse and complex - more attuned to racial, social, and embodied differences between women - than the suggestion that it is held together by a "politics of recognition and emancipation" allows for some considerable time.

\section{Identifying with First-Person Experience, an Ethics of Method}

It is not only through his framework of two levels of objectivation, which offers feminist and queer phenomenologies of film a route via which to maintain an emphasis on their embodied difference while researching (quite possibly empirically) what unites them, that Meunier's approach to film phenomenology can act as a model for future enquiry in this field: there is an ethics to the very method he uses in The Structures of the Film Experience that could serve such future enquiry well. For Meunier approaches the sketch of the home-movie, documentary, and fiction-film modes of film 
consciousness he undertakes in Part Two of his book in the first person, enacting the retention of meaning and signification he insists on in at the start of his study. To quote Meunier again:

For us, it will not be a question of objectively representing to ourselves the experience of the spectator-subject, but, of placing ourselves within this experience, of attempting to describe and reveal its meaning, and specify its fundamental structures. (p. 35)

By doing exactly this in Part Two of The Structures of the Film Experience, Meunier enacts what could be called an ethics of identification ("placing ourselves within this experience"), which I would argue should be adopted by future film-phenomenological enquiry.

Sandra Bartky's essay “Toward a Phenomenology of Feminist Consciousness" - an approach to a particular type of consciousness that parallels Meunier's enquiry into film consciousness in The Structures of the Film Experience - offers some useful considerations for the path I am attempting to steer here. Bartky notes early in the essay that "To be a feminist, one has first to become one," which often "involves the experience of a profound personal transformation, a ['complex and multi-faceted'] experience which goes far beyond that sphere of human activity we regard ordinarily as 'political." ${ }^{\prime 14}$ This transformation entails altered behavior, and

These changes in behavior go hand in hand with changes in consciousness: to become a feminist is to develop a radically altered consciousness of oneself, of others and of what for lack of a better term, I shall call 'social reality.' [...] What is a fully developed feminist consciousness like? In this paper, I would like to examine not the full global experience of liberation, involving as it does new ways of being as well as new ways of perceiving but, more narrowly, those distinctive ways of perceiving which characterize feminist consciousness. What follows will be a highly tentative attempt at a morphology of feminist consciousness. ${ }^{15}$

The morphology Bartky goes on to attempt suggests that feminist consciousness is 'anguished' in a way politicized consciousnesses typically are: it manifests the "inner uncertainty and confusion which characterizes human subjectivity in periods of social change." ${ }^{16}$ Bartky rebukes Marxist scholarship for not paying sufficient attention "to the ways in which the social and economic tensions they study are played out in the lives of concrete individuals," confirming (since she also states this in different 
terms elsewhere in the essay) that this is her motivation for incorporating phenomenological description into Marxist analysis - in other words, for adding feminist consciousness to a body of scholarship that has only ever considered one mode of consciousness - class consciousness - at all seriously. ${ }^{17}$ How, though, is the temporality of feminist consciousness to be understood? Bartky elucidates as follows:

This consciousness [...] emerges only when there exists a genuine possibility for the partial or total liberation of women. This possibility is more than a mere accidental accompaniment of feminist consciousness. Feminist consciousness is the apprehension of that possibility. The very meaning of what the feminist apprehends is illuminated by the light of what ought to be. The given situation is first understood in terms of a state of affairs not yet actual and in this sense a possibility, a state of affairs in which what is not given would be negated and radically transformed. ${ }^{18}$

This project of negation and transformation constitutes transcendence as Sartre describes it in Being and Nothingness (L'être et le néant), but understanding "what we are and where we are in the light of what we are not yet" is a perspective Bartky considers insufficiently rooted in the actual, present world for feminism, a point that leads her to admit that there will be instances in which the possibilities apprehended by feminist consciousness are not realizable, because of unfavorable material conditions. ${ }^{19}$ Feminist consciousness, she implies with this observation, is not a property that can be acquired; it is a way of conceiving of the world that may come and go. The phenomenology of feminist consciousness Bartky attempts (and I am suggesting), which might serve feminist phenomenological explorations of film experience, is, it must be emphasized, phenomenological and not ontological: ontological questioning and theorizing are not appropriate approaches to the phenomenon at issue. And just as importantly, it is a politicized and political form of consciousness - feminist consciousness - and not the essentialistically defined gendered entity female consciousness that Bartky considers it possible and worthwhile to describe and approach in her essay. To enter into speculation about distinct female and male consciousness(es) would be to re-rehearse debates about the possible usefulness of essentialist theorizing for feminism that took place in the late 1980s and early 1990s, and therefore philosophically, as well as politically, retrograde.

Further aspects of feminist consciousness explored by Bartky in "Towards a Phenomenology of Feminist Consciousness" - that it is consciousness of victimization, and that it entails apprehensiveness, suspicion, or 'wariness' 
- are not in my view especially relevant to the pertinence the concept could prove to have for the specificity of women's experiences of viewing film..$^{20}$ Of the two quasi-definitions of the concept Bartky offers in her concluding paragraphs - that it "can be understood as the negating and transcending awareness of one's own relationship to a society heavy with its own contradictions," and that it is "the consciousness of a being radically alienated from her world and often divided against herself, a being who sees herself as victim and whose victimization determines her being in-the-world as resistance, wariness and suspicion," the first seems a better basis on which to move forward to the description of women's experiences of viewing films. ${ }^{21}$ Probably even more noteworthy for the possible rapprochement of Bartky's work with feminist phenomenological film theory, however, because it confirms the proximity of her discussion to existential phenomenology, is her statement "To develop feminist consciousness is to live a part of one's life in the sort of ambiguous ethical situation which existentialist writers have been most adept at describing." ${ }^{22}$ This observation coincides with my discussion, toward the end of the first chapter of The Body and the Screen, of female subjectivity as ethical in its ambiguity (for Beauvoir) or two-ness (for Luce Irigaray), a coincidence to which I draw attention simply in order to emphasize that the question of method, with which Meunier is concerned in The Structures of the Film Experience (and which may also be seen at work in Bartky's first-person approach in "Towards a Phenomenology of Feminist Consciousness"), is itself an ethical question. In The Structures of the Film Experience, Meunier does not comment directly as he proceeds on the first-person form he adopts when working through the viewing experiences that constitute the three attitudes of imaginary filmic consciousness (toward the film-souvenir, the documentary, and the fiction film), but he anticipates the value of this method in his introductory discussion of levels of objectivation, and states there: "The present study constitutes an attempt in this direction." (p. 35) The method he employs in Part Two of his book is one that values first-person subjective experience practically and ethically, as much as it does philosophically.

To conclude by recapitulating my argument in this essay, it has been that the intersection and confluence of contemporary queer and feminist film phenomenologies with historical film phenomenology will benefit from employing the 'ethics of method' I claim emerges in Meunier's The Structures of the Film Experience, and has previously been practiced by feminist phenomenologists such as Sandra Bartky. This ethics arises from Meunier's adoption of the phenomenological approach to identification, set out by Angelo Hesnard in Psychanalyse du lien interhumain, which Meunier implicitly observes in his 
explanation of the importance of de-objectivizing the concept of identification in the introduction to The Structures of the Film Experience and then practices in the highly original sketch of the home-movie, documentary, and fiction-film modes of consciousness he undertakes in Part Two of his book.

\section{Notes}

1. Kate Ince, The Body and the Screen: Female Subjectivities in Contemporary Women's Cinema (London and New York: Bloomsbury, 2017).

2. Christian Ferencz-Flatz and Julian Hanich, "What Is Film Phenomenology?", Editors' Introduction to Studia Phaenomenologica XVI (2016), pp. 11-61.

3. Some of the principal items of this literature are Jenny Chamarette's Phenomenology and the Future of Film: Rethinking Subjectivity beyond French Cinema (Basingstoke: Palgrave Macmillan, 2012) and "Embodying Spectatorship: From Phenomenology to Sensation," in E. Ann Kaplan, Patrice Petro, Dijana Jelača, and Kristin Hole (eds.), The Routledge Companion to Cinema and Gender (London: Routledge, 2016), pp. 311-321; my own The Body and the Screen and "Feminist Phenomenology and the Film-World of Agnès Varda," in Hypatia: A Journal of Feminist Philosophy 28:3 (online 2012, print 2013), pp. 602-617; Katharina Lindner's “Questions of Embodied Difference: Film and Queer Phenomenology," in NECSUS European Journal of Media Studies 1 (2) (2012), pp. 199-217 and Film Bodies: Queer Feminist Encounters with Gender and Sexuality in Cinema (London: I.B. Tauris, 2017).

4. Iris Marion Young, "Throwing Like a Girl: a Phenomenology of Feminine Body Comportment, Motility, and Spatiality," in Jeffner Allen and Iris Marion Young (eds.), The Thinking Muse: Feminism in Modern French Philosophy (Indiana University Press, 1989), pp. 51-70; Judith Butler, "Sexual Ideology and Phenomenological Description: A Feminist Critique of Merleau-Ponty's Phenomenology of Perception," in Jeffner Allen and Iris Marion Young (eds.), The Thinking Muse: Feminism in Modern French Philosophy (Indiana University Press, 1989), pp. 85-100. American philosopher Sandra Bartky's essay "Toward a Phenomenology of Feminist Consciousness" was first published in 1975, but became better known in the 1990 collection with six more of Bartky's essays Femininity and Domination: Studies in the Phenomenology of Oppression (New York: Routledge).

5. Ince, The Body and the Screen, p. 7 .

6. Ferencz-Flatz/Hanich, "What Is Film Phenomenology?", p. 23

7. The concept of spectatorship has continued to be used since that era, in a manner that ill befits the philosophically more diverse range of approaches to film-viewing to which it has given way.

8. Angelo Hesnard, Psychanalyse du lien interhumain (Paris: Presses Universitaires de France, 1957).

9. Ferencz-Flatz/Hanich, "What Is Film Phenomenology," p. 49. 
10. It is pertinent to note here that Husserlian phenomenology has had far less influence and impact on contemporary film phenomenologies than Merleau-Ponty's phenomenology of perception and lived embodiment: Ferencz-Flatz and Hanich observe of Allan Casebier's 1991 Husserlian study Phenomenology and Film that "Casebier's book failed not only to fundamentally revolutionize film theory, but also to have a noteworthy impact on it." Ibid., p. 39 .

11. Ibid., p. $5^{0}$ n129.

12. Quoted in ibid., p. 48.

13. Ferencz-Flatz/Hanich, "What Is Film Phenomenology?", p. 5o. Furthermore, Ferencz-Flatz/Hanich point out that “[p]henomenology was rediscovered as a helpful tool for more straightforward social or political goals. Among feminist and queer film phenomenologists we nowadays find attempts to "politicize" phenomenology, to make it less disengaged from activist thinking, and to combine film phenomenology with questions of gender and sex and, more generally, embodied difference." Ferencz-Flatz/Hanich, "What Is Film Phenomenology?", p. 48.

14. Bartky, "Toward a Phenomenology of Feminist Consciousness," p. 11.

15. Ibid., p. 12.

16. Ibid., p. 14 .

17. Ibid., p. 14.

18. Ibid., p. 14 .

19. Ibid., p. 15 .

20. Ibid. p. 18.

21. Ibid. p. 21

22. Ibid. p. 20.

\section{About the author}

Kate Ince is Reader in French Film and Gender Studies at the University of Birmingham, UK. Following authored books on the performance artist Orlan and French film director Georges Franju (Georges Franju, Manchester University Press 2005, also published in French as Georges Franju: au-delà du cinéma fantastique), she published essays on the contemporary filmmaking of François Ozon, Sophie Calle, Michael Haneke, Agnès Varda, and Sally Potter. Her third book, The Body and the Screen: Female Subjectivities in Contemporary Women's Cinema, was published in Bloomsbury's 'Thinking Cinema' series in 2017, and won first prize in the British Association of Film, Television and Screen Studies's Best Monograph competition of 2017-2018. She is on the editorial board of Studies in French Cinema, a member of the British Association of Film, Television and Screen Studies (BAFTSS), the Women's 
Film and TV History Network (WFTHN), and a regular contributor to the annual Film-Philosophy conference. Her essay 'Global Women's Cinema' appeared in the Routledge Companion to World Cinema, and an essay of hers on ethics and vulnerability in the films of Abderrahmane Sissako was published in the journal Paragraph. She is now Principal Investigator of the AHRC-funded network 'Serge Daney and queer cinephilia,' and is writing a study of the films of Mia Hansen-Løve, which will be published by Edinburgh University Press in 2020. 
IV: REFERENTIALITY AND MEDIATION 


\title{
Jean-Pierre Meunier's Modalities of the "Filmic Attitude": Towards a Theory of Referentiality in Cinematic Discourse
}

\author{
Guido Kirsten
}

\begin{abstract}
Meunier's reflections upon the differences between the "home-movie attitude," the "documentary attitude," and the "fiction attitude" can help to develop a theory of reference in cinematic discourse. Such a theory needs to take into account three fundamental ideas. First, reference is not constituted by the film alone but results from an interaction between film and viewer. Second, there are different kinds of objects (or entities with different "modes of being") that are referred to. These two ideas can be drawn more or less directly from Meunier's argument. The third idea is less obvious but logically implied: it is based on a differentiation between three dimensions of meaning: intensional (with an 's'), extensional, and referential meaning, all of which co-exist phenomenologically.
\end{abstract}

Keywords: Film theory; reference; intension; extension; realism; modes of reading

\section{Introduction}

In a brief note published in 1963 in Raymond Bellour's short-lived journal Artsept, Roland Barthes writes about Strangers of the Earth (Les inconnus de la terre, 1961), a cinéma-vérité documentary by Mario Ruspoli:

This film is a genuine investigation; Ruspoli lets his farmers speak and they immediately convey, through their direct, concrete language, the problems of the French peasantry today: their pitiful revenues, the antiquated technology, the generational antagonism between young and

Hanich, J. and D. Fairfax (eds.), The Structures of the Film Experience by Jean-Pierre Meunier. Historical Assessments and Phenomenological Expansions, Amsterdam University Press, 2019 DOI 10.5117/9789462986565_KIRSTEN 
old, the conflict between individual and the group, the demand for better living conditions and more freedom. Before our eyes, class-consciousness awakens and speaks of its own accord. ${ }^{1}$

Ruspoli had interviewed several peasants in Lozère (a department in the region of Occitanie, in southern France). Sometimes they discuss among each other in front of the camera. Yet, for Barthes, the film is not about these individuals, but about class-consciousness and the general "problems of the French peasantry today."

In the French original, this last phrase reads "les problèmes généraux $d u$ paysan français d'aujourd'hui," which reminds me of Jean-Pierre Meunier's la personne-en-générale ("the person-in-general"), who we tend to see, according to Meunier, when watching home movies. ${ }^{2}$ Meunier writes that "the consciousness of the home movie appears as a constitutive activity: it looks beyond the image, to the person-in-general that it depicts, in order to produce and maintain his existence even during the screening" (p. 88).

The two cases are also quite different, of course: Barthes, in his reading of Strangers of the Earth, merges several individuals into one collective singular ("the French peasant"), while Meunier claims that we look beyond one single person who is well known to us, to perceive her general traits, her gestures, her individual personality. But the cases are comparable in that the cinematic discourse's referents shift from what we immediately perceive - individuals in specific situations - to more abstract entities. Both thus raise questions for a general theory of referentiality in film.

\section{Meunier's Modalities}

Jean-Pierre Meunier's thoughts on the structures of film experience, and especially his differentiation of three "modalities of the 'filmic attitude,", can help formulate such a theory ${ }^{3}$ (p. 116). These three modalities (or forms, or types) of attitude are: the "home-movie attitude," the "documentary attitude," and the "fiction attitude."

In many aspects, these attitudes resemble three of Roger Odin's "modes of producing meaning and affect" which play a central role in his semiopragmatic approach: the "private mode," the "documentarist mode," and the "fictionalizing mode." Both authors have developed them from what they consider normal or typical ways of watching and apprehending the corresponding kind of film: home movie (the film-souvenir or the film de famille, respectively), documentary, and fiction film. ${ }^{5}$ Both are also 
eager to remark that films can be watched against the grain: applying the documentary attitude to a fiction film, or the fiction attitude to a home movie and so on. And they can be used in combination, as Meunier writes: "when looking closer, we can see that the attitudes described can succeed each other or intertwine with each other during the viewing of a single film" (p. 116). Besides, Meunier is quite aware (as is Odin) that his categories are ideal types, heuristically useful but relating only to a theoretically abstracted reality. ${ }^{6}$

These caveats need to be taken seriously, but they should not prevent us from reflecting upon the construction of the three modalities of filmic attitude, nor from making use of them for a theory of reference in the cinema. In Meunier's study, the first and fundamental distinction of the three different modes is based on the two factors existence and knowledge. The home-movie attitude "considers its object to be known and existing elsewhere," the documentary attitude "considers its object as existing but not known" (p. 152, emphasis mine), and the fiction attitude considers it to be non-existing - and therefore necessarily unknown prior to the experience of the fiction.

In the home-movie attitude, the viewer seeks to "render present" a person one is well acquainted with, to recognize what she knows about the absent person's physiognomy and comportment. As stated above, this implies a certain activity on the part of the viewer consisting of looking "beyond the image, to the person-in-general that it depicts" (p. 88). The image is enriched by the spectator's individual memories. Identification in the home-movie attitude consists in what Meunier calls an "incantatory" behavior; it serves to "presentify" the absent person. It therefore necessarily involves a dimension of latent frustration, because it makes one all the more aware that the person is truly absent. In sum, for Meunier, the overall purpose of the home-movie attitude consists in the presentification of a well-known but absent person by way of extending the image's content beyond itself and seeking an imaginary contact with the "person-in-general."

Inspiring as this claim is, I think it warrants a qualification, because not all home-movie consumption seems to work along this line. Imagine watching a friend's wedding video - a paradigm case of what Meunier calls the film-souvenir. The two brides - the year is 2019 - are standing in front of the celebrant, looking at her, and then at each other, as the camera zooms in on your friend's face. What you are likely to see in these images is less the "person-in-general" (her general behavior, her typical gestures), but the person-in-a-very-particular-moment. You wait for her smile in this special moment, and try to read her feelings (is there a slight hesitation behind the 
overall happiness?). This is not to deny that Meunier's description is valid for many cases of home-movie viewing, but what he sees as the home-movie attitude could well be only one of its sub-modes, another of which I have just hinted at.

A similar qualification might be helpful for Meunier's outline of the documentary attitude. This attitude posits, according to Meunier, its objects as existing, but not known to the spectator prior to the viewing. Its main purpose is to gain knowledge, via the film, about what are considered real world events or states of affairs. Therefore, the images acquire a greater degree of "autonomy"; they are less invested with prior beliefs than in the home-movie attitude. However, according to Meunier, "retention" and "protention" (the imaginary prolongation of the present movement into past and future, respectively) are still less important than they are in the fiction attitude: "[W]e can cut the film after any sequence, or even right in the middle of a sequence, without the spectator being truly frustrated by it," he claims (p. 110). This characterization of the documentary attitude must seem more doubtful today, after increasing tendencies towards narrative documentary, than at the time of Meunier's writing when classical documentaries and cinéma-vérité films seem to have constituted the paradigms. ${ }^{7}$ Here again, we might be tempted to regard what Meunier elaborates as the documentary attitude solely as one of its possible sub-modes.

The fiction attitude differs more radically from the two others as it does not posit the filmic objects, persons, and events as existing, even though they appear to be real. As Meunier writes: "the filmic world is erected as an autonomous reality" (p.112) (a "diegesis," he could have said in Souriau's wording). ${ }^{8}$ As the character's movement (when considered as such, not as the actor's movement) has no existence outside the diegetic world, it only gains meaning in relation to his or her other movements in the same film, whence results both the much greater importance of retention and protention and the "captivating" dimension of the fiction attitude (p. 113). With regards to identification, Meunier distinguishes two sub-modalities in the fiction attitude: a participation in the mode of "being-with" and a participation in the mode of "being-like" the character (p. 129).

\section{Consequences for a Theory of Referentiality}

What I find especially original in Meunier's theory is his differentiation of referential objects according to the respective attitude the viewer applies. As I aim to show, Meunier's ideas can help to sketch a theory of referentiality in 
cinematic discourse. Three ideas are of key importance here, two of which are explicitly stated by Meunier. I have already mentioned them but will reiterate them for the sake of clarity. The third one remains implicit (but appears to me to be a logical consequence) and needs to be explained.

The first idea is that its reference is not constituted by the film alone, but results from an interaction between film and viewer: "[W]e should also note that the positing of existence does not essentially depend on the type of film. [...] We can indeed posit a purely fictional character as existing, and we can also posit the Paul Anka of Lonely Boy as not existing" (p. 110). However, "each type of film solicits consciousness to comprehend it" in a way that renders one kind of reading far more probable than others. ${ }^{9}$ By implication, every other attitude appears as a "deviation" (p. 100).

The second idea is that there are indeed different kinds of objects - or objects with different "modes of existence" - that are referred to. ${ }^{10}$ The home-movie attitude's "person-in-general" is obviously a different kind of being than the documentary attitude's "object-yet-unknown" or the fictional attitude's "non-existing-person." Philosophical problems loom large here. And there are not only the three grand object categories of the three major types of attitudes, but also intermediate cases that pose particular complications. Within the domain of fiction, Meunier distinguishes two groups of films: "the purely fictional film, such as we find in heroic and fantasy genres" and "this other category of films closer to the real" (p. 97). Stories told in films belonging to the second category appear "lifelike, or at least possible," referring to "slices of lived experienced" (p. 98).

This type of fiction film "is perceptibly close to the documentary genre" but is "distinguished by the fact that it does not convey, beyond the image, a specific, existent, concrete reality." As an example, Meunier points to Bicycle Thieves (Ladri di biciclette) by Vittorio de Sica (1948), a film, he writes, that "is presented almost as a social observation" and "refers to something other than itself, a specific reality existing elsewhere." However, in contradistinction to what happens in the documentary, "this reality remains indistinct, vague and undifferentiated. Thus, the bicycle thief is not posited as existing in his specific reality, that is as a personal being, but he is valid as a representative of a number of anonymous beings existing in a certain period and sharing the same problems with him" (p. 98, emphasis mine). In this formulation, Meunier comes quite close to what Barthes said about Strangers of the Earth - only reversed: whereas Barthes had merged several real individuals into one abstract person, Meunier splits one fictional character into a group of "anonymous beings." Both authors, however, refer to a social reality outside 
the film. ${ }^{11}$ A little later Meunier writes: "The bicycle thief as such does not exist, but the existing reality that it [the film] illustrates confers on it a power of existence that gives it a certain substance of reality" (p. 98). This seems to be yet another kind of mode of existence of filmic entities. ${ }^{12}$

Again, the positing of this particular filmic entity (fictional-but-with-acertain-substance-of-reality) depends not only on the film, but also on the viewer. As Meunier explains, it is always possible to deny the ascription of that "substance of reality" - but, and this is important, only at the cost of also denying the existence of the underlying social structure: "At the same time as I break my belief in the bicycle thief as a fictional character, I must also, in order for this act to be complete, deny a certain social reality that this fictional character illustrates, and whose major characteristics he reproduces" (p. 98/99).

A telling historical instance of such a denial is François Truffaut's review of The Roof (Il Tetto, 1956), another neorealist film by De Sica and Zavattini, in which they portray a young newlywed couple who desperately search for a place to stay in Rome. Truffaut, angry young man and passionate hater of De Sica's cinema that he was, writes:

Concerning The Roof, I would only reproach De Sica and Zavattini for having radically deformed the reality they are referring to, for having distorted the housing problem by inventing facts that are not true, and for having evaded the real difficulties of this problem, substituting them with inappropriate sentimental considerations. ${ }^{13}$

This accusation of having invented 'alternative facts' (avant la lettre!) only makes sense within a realist reading of the film. Note that the accusation does not, of course, relate to the characters - that Luisa and Natale and all the other characters of The Roof were indeed invented, too, cannot bother Truffaut. What he minds is what he regards as false statements about real social structures such as the housing problem, thereby first assuming, then denying what the film appears to claim, namely its "substance of reality."14

This implies, and here I come to my third point and my more original contribution, that there are several layers of meaning which we need to differentiate. First, there are the sequences of moving images and sounds that have, as I have laid out elsewhere, both an intensional and an extensional dimension. ${ }^{15}$ The intension is what we immediately perceive in a scene (as soon as we read them "figuratively"); for example, a woman doing the dishes, a man in his pajamas taking water from the tap, seen in black-and-white in a medium-long shot (see Fig. 5$).{ }^{16}$ In other words, the 


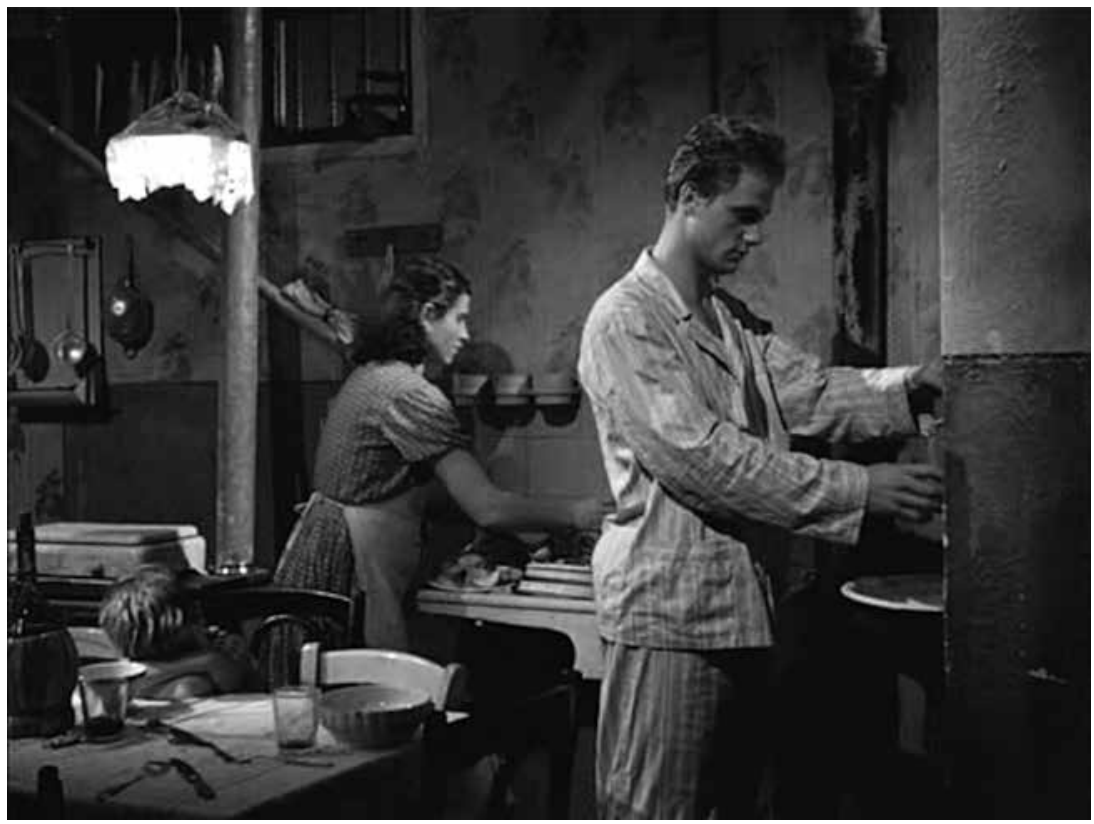

Fig. 10: Scene from The Roof by Vittorio de Sica.

intension is what the images and sounds represent in themselves, without reference to contextual knowledge except for the "tacit knowledge" of basic cultural "codes of iconic nomination" which allow us to identify objects in images at all. ${ }^{17}$

The extensional meaning refers to full-fledged entities: objects, persons, actions as constituent parts either of a pro-filmic situation or of a diegetic world. The intensional 'woman doing the dishes' can extensionally refer either to the fictional character of Giovanna in her kitchen (fiction attitude), or to the non-professional actor Maria di Fiori during the shoot (documentary attitude).

The distinction between intension and extension goes back to Gottlob Frege's famous distinction between Sinn (translated as 'sense') and Bedeutung (most often rendered as 'reference,' sometimes as 'meaning' or 'denotation' in English). In order to avoid confusion and because I would like to reserve the terms 'reference' and 'referential' for yet another dimension, I therefore prefer to use Rudolf Carnap's pair of terms intension and extension for Sinn and Bedeutung respectively, following their common use in analytical philosophy. ${ }^{18}$ One famous example which Frege used in order to introduce the distinction is the difference between the expressions 'morning star' and 'evening star,' which have different intensions (one being the star seen in 
the morning, the other the star in the evening) but the same extension (that physical object which is also called Venus). ${ }^{19}$ The very same logic applies to images, I would argue. Two photographic images of planet Venus can have different intensions (displaying different details of the surface structure, having been recorded from different viewpoints, one looking brighter and smooth and beige, the other appearing redder and hotter) but point to the same extensional entity. ${ }^{20}$

In his original text, Frege was skeptical about fictional extension. For him, sentences such as "Odysseus was set ashore at Ithaca sound asleep" and the name Odysseus in the same context lack Bedeutung, although they do have Sinn. The literary theorist Lubomír Doležel has characterized "Frege's doctrine as a semantics of one world with two languages." Doležel argues that this doctrine results in a counter-intuitive treatment of fictional names such as Odysseus or Hamlet as either empty or selfreferential. For him, using a possible world's theory as framework for his fictional semantics, such names "refer to an individual of a fictional world." ${ }^{22}$ This does not render Frege's distinction obsolete for fictional texts. According to Doležel, it is perfectly possible to use the "two-language" model to distinguish intensional and extensional structures of meaning for literature as well, the only difference being that in fictional texts the extension does not exist a priori, but is "stipulated" through the creation of a possible world. ${ }^{23}$

What I suggest is thus an adaption of Doležel's terms from the field of literary studies to that of film, where, mutatis mutandis, the same logic applies. In every film we watch - with the possible exception of purely abstract films such as Arnulf Rainer (Peter Kubelka, 1960) or The Flicker (Tony Conrad, 1965) - we deal with both an intensional and an extensional structure. The former refers to the immediate sense in its audiovisual layout (including camera perspective, lighting, optical filters, editing, sound design etc.), the latter to the ensemble of denoted (pro-filmic or fictional) entities.

According to Doležel, "intension is necessarily linked to texture, to the form (structuring) of its expression," and the "crucial role of intensional meaning is explained by aesthetic factors;" he even claims that "extensional meaning is aesthetically neutral; only on the level of intension is aesthetically effective meaning achieved." ${ }^{24}$ Gertrud Koch's similar formulation - "In the aesthetic experience, intensional meanings prevail" ${ }^{25}$ - is more cautious, and more accurate. There is no need to exclude the extensional from the realm of aesthetics completely (the choice for a certain layout of the fictional world can have aesthetic reasons and aesthetic effects), but it certainly seems right 
to regard the intensional meaning as aesthetically dominant. ${ }^{26}$ Furthermore, we can determine the relation of intension and extension as follows:

Although extensions and intensions can and must be differentiated in semantic theory, they are by definition complementary in the production of literary [and filmic, G.K.] meaning. Extensions are available only through intensions and conversely, intensions are fixed by extensions. ${ }^{27}$

We have access to the diegetic situation only through the audiovisual texture and its intension, but our knowledge of the diegesis also disambiguates elements of the intensional structure.

So far, so good. What Meunier's categories and his discussion of the possible denial of the "substance of reality" of realist fictional films show, however, is that the conceptual couple of intension/extension does not suffice. Consider the example from The Roof again. Intensionally, we perceive a woman doing the dishes and a man in his pajamas taking water from the tap in a black-and-white medium long shot. In the extensional dimension, we can have this intensional ensemble refer either, in the fiction attitude, to the fictional characters of Natale and his sister Giovanna in her kitchen, or, in the home-movie or the documentary attitude, to the non-professional actors Maria di Fiori and Giorgio Listuzzi during the shoot. But in order to understand the concepts of "the person-in-general" or the "denied substance of reality," it is necessary to consider at least a third dimension of meaning. I suggest calling this the referential meaning - a meaning which is determined by references to the external, non-filmic, or "afilmic" reality. ${ }^{28}$

Imagine you are Giorgio Listuzzi's sister and you are watching the scene from The Roof in Meunier's home-movie attitude. You would not care about the fictional story, but would focus on your brother's gestures, his corporeal attitude, maybe on his way of talking, the timbre of his voice. The reference would then be Meunier's "person-in-general." Or, alternatively, but still within the home-movie attitude, you could think of your brother in that very specific situation when he first stood in front of a camera, and perceive a suppressed nervousness in his gestures other viewers remain perfectly unaware of, because you have talked to him shortly before or after the shoot.

A film historian, on the other hand, could proceed from the identical extensional basis - the same profilmic situation - but refer to a different set of objects, e.g. Listuzzi and di Fiori as representatives of non-professional acting in Italy in the 1950s. Or she could analyze the cinematography and the mise en scène, including the lighting, the choreography of the actors, 
and the placement of props and realistic details in the room (in implicit comparison with other staging practices common around that time). ${ }^{29}$

Referring to these two sets of referent objects is not the standard mode of viewing, however. The Roof's institutional purpose is rather to be watched in the realist sub-mode of the fiction attitude. This means, as Meunier explains, not only to assume Natale's non-existence (as with every character in every fiction), but, paradoxically, also his existence as "a representative of a number of anonymous beings existing in a certain period and sharing the same problems with him" (p. 98). Alternatively, it is possible to deny the existence of these problems or to claim, like Truffaut, that the real problems are quite different, thus referring to an invented reality and thereby, but implicitly and ex negativo, to the real reality.

\begin{tabular}{|c|c|c|c|}
\hline & Intension & Extension & Reference \\
\hline 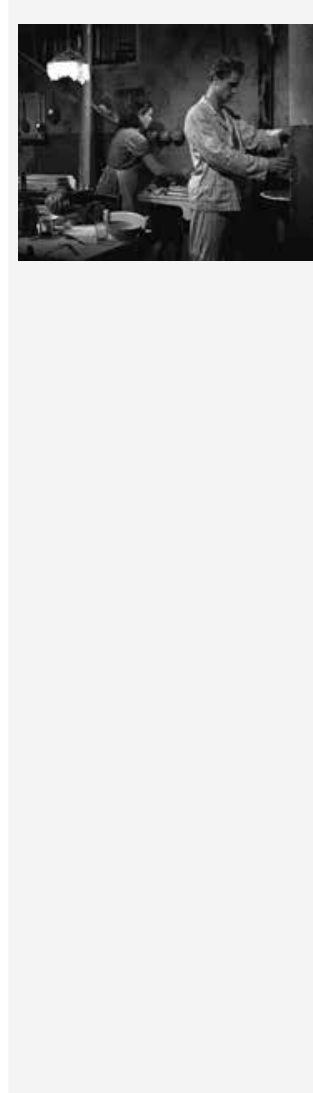 & $\begin{array}{l}\text { a woman doing } \\
\text { the dishes (before } \\
\text { putting a child } \\
\text { to bed), a man } \\
\text { in his pyjamas } \\
\text { taking water from } \\
\text { the tap, seen in a } \\
\text { black-and-white } \\
\text { medium-long shot }\end{array}$ & $\begin{array}{l}\text { a) pro-filmic } \\
\text { non-professional } \\
\text { actors Maria di } \\
\text { Fiori and Giorgio } \\
\text { Listuzzi during the } \\
\text { shoot } \\
\text { b) fictional } \\
\text { characters } \\
\text { Natale and his } \\
\text { sister Giovanna in } \\
\text { her kitchen }\end{array}$ & $\begin{array}{l}\text { a1.1) the "person(s)- } \\
\text { in-general" (home- } \\
\text { movie attitude 1) } \\
\text { a1.2) the "person(s)- } \\
\text { in-a-specific } \\
\text { moment" (home- } \\
\text { movie attitude 2) } \\
\text { a2.1) non-profes- } \\
\text { sional-actors-in- } \\
\text { Italy-in-the-1950s } \\
\text { (film historian } \\
\text { attitude 1) } \\
\text { a2.2) techniques of } \\
\text { mise-en-scène and } \\
\text { cinematography } \\
\text { (film historian } \\
\text { attitude 2) } \\
\text { b1) the problematic } \\
\text { housing situation } \\
\text { in Rome in the } \\
\text { 1950s (realist fic- } \\
\text { tion attitude) } \\
\text { b2) an "invented } \\
\text { reality" in distinc- } \\
\text { tion from the } \\
\text { real reality which } \\
\text { is referred to ex } \\
\text { negativo (skeptic's } \\
\text { fiction attitude) }\end{array}$ \\
\hline
\end{tabular}

Fig. 11: Intension, extension, and reference in the kitchen scene from The Roof. 
The crucial difference between extension and reference is that they imply different ways of looking beyond the given image. In referring to the extensional dimension we merely look 'through' the image into the diegetic world or back to the moment of production, treating it as quasi-transparent. But, in the referential dimension, we really look 'beyond' it, including thoughts, memories, beliefs, and imaginations of or about persons, things, and social structures that are absent in a much stronger sense.

\section{Conclusion}

What I have sketched here are merely the first tentative steps towards a theory of referentiality in cinematic discourse. I will end with two remarks. The first has to do with the relatively undetermined character of what I have called the referential meaning. Looking at the categories intension, extension, and reference in the table above (Fig. 11), we can note that their respective content becomes less clearly fixed when moving from the left to the right column: a scene's intension is completely determined by the combination of images and sounds (given our reading them 'figuratively,' which is something we practically always and automatically do)..$^{30}$ The extension is less fully determined, because it is possible to have the material refer either to their profilmic origin or to a diegetic universe.

Compared to the referential dimension, however, the extension is still relatively fixed, too. The aforementioned scene from The Roof offers several options for referential meaning. And even if we agree on a standard realist reading and agree that it is clearly about the housing problem in Rome in the 1950s (accurately described or not), one could also claim that the film is more generally about poverty, or about the unjust distribution of wealth: the "opposition of standards of living: bricklayers, who are badly housed themselves, construct buildings for others," as Raymond Borde and André Bouissy have put it. ${ }^{31}$ But then, why not say it is really about capitalist class society, or even more broadly about stratified forms of sociality as such? How wide should we draw the circle of reference?

This problem of where to set the limits of reference for a given cinematic discourse (ranging from a particular case to a general notion) may be less a theoretical then an empirical one: historical reception studies can help ascertain what sets of references were actualized by critics and other viewers, and detailed film analyses (informed by the film's discursive context) may discover how the work's inner organization shapes the probability of referring to this or that topic, of referring to a very specific case or a very general claim. 
My second concluding remark has to do with the phenomenological framework of Meunier's discussion. The reason why Meunier has not spelled out a differentiation of dimensions of meaning similar to the one I have outlined here (even though it does seem to be logically implied) is possibly that this would be at odds with his approach of describing "lived experience" (p. 34). In the lived film experience, intension, extension, and reference are all more or less immediately given. They are not separated phenomenologically. Together, irreducibly intertwined, they constitute the thick and complex texture of meaning in filmic discourses. In terms of the epistemology of film studies this indicates that what we need are fruitful articulations between phenomenological and other, more semiotic approaches.

\section{Notes}

1. Roland Barthes, "Preface to Les inconnus de la terre (Strangers of the Earth, Mario Ruspoli, 1961)," trans. Deborah Glassman, in Philipp Watts (ed.), Roland Barthes' Cinema (Oxford: Oxford University Press, 2016), p. 137.

2. $\quad$ Roland Barthes, "Préface aux Inconnus de la terre," Artsept, n. 2 (1963), p. 76 [emphasis mine].

3. Alternatively, Meunier speaks of "general" or "major" "types of attitude" (p.113) or different "forms" attitudes can adopt "according to the modalities of existence of the object under consideration" (p. 118).

4. Roger Odin, "Reflections on the Family Home Movie as Document: A Semio-Pragmatic Approach", in Karen L. Ishizuka and Patricia R. Zimmermann (eds.), Mining the Home Movie: Excavations in Histories and Memories (Berkeley, CA: University of California Press, 2008), pp. 255-271; p. 255.

5. $\quad$ Roger Odin, Les espaces de communication (Grenoble: PUG, 2011), pp. 103-122.

6. Roger Odin, De la fiction (Brussels: DeBoeck, 2000), p. 11.

7. In The Structures of the Film Experience, Meunier only mentions Lonely Boy (Wolf Koenig and Roman Kroitor, 1963), a quite interesting cinema-vérité style portrayal of the Canadian superstar Paul Anka, and the hyper canonical Nanook of the North (Robert J. Flaherty, 1922).

8. Etienne Souriau, "The Structure of the Filmic Universe and the Vocabulary of Filmology" [1951], trans. Marc Jones, in Vinzenz Hediger and Guido Kirsten (eds.), Filmology: Selected Writings from the Revue internationale de filmologie (Amsterdam: Amsterdam University Press [forthcoming]).

9. Roger Odin claims that it depends less on the film than on the viewing's "institutional context" or "space of communication."

10. Etienne Souriau, The Different Modes of Existence, trans. Erik Beranek and Tim Howles (Minneapolis, MN: Univocal, 2015 [1943]). Whether or not it actually makes sense to postulate different modes of existence is a key debate in contemporary philosophy. For a good introduction, see: Francesco 
Berto and Matteo Plebani, Ontology and Metaontology. A Contemporary Guide (London/New York: Bloomsbury, 2015). Even if one opts for a Quinean metaontology, which only allows for the (unqualified) existence of "real" entities, the talk of "modes of being," "fictional worlds," etc., is still valid in my opinion. It then points to the necessary, and not yet fully achieved, theoretical integration of these phenomena into the "standard view" (and thus to a probably rather complex rephrasing in Quine's language).

11. Social ontology, such as intended by John Searle and others, could be helpful here.

12. This reasoning corroborates the proposition I have made elsewhere, namely to postulate the "realist reading" as a sub-mode of the fiction attitude. Cf. Guido Kirsten, Filmischer Realismus (Marburg: Schüren, 2013), pp. 139-178.

13. François Truffaut, "Le Toit: La romance du tricheur," Arts 595 (Nov. 28, 1956), p. 3 (translation mine). Original version: "En ce qui concerne Le Toit je ne reprocherai à de Sica et Zavattini que d'avoir radicalement défiguré la réalité à laquelle ils se réfèrent, d'avoir faussé le problème du logement en inventant des données autres que les vraies et d'avoir escamoté les difficultés réelles de ce problème en leur substituant des considérations sentimentales, hors de propos."

14. Bazin, by contrast, lauds the "social realism of the film's descriptiveness," André Bazin, "The Roof" [1956], in Bert Cardullo (ed.), André Bazin and Italian Neorealism (New York: Continuum 2011), pp. 184-88; p. 185. And Borde and Bouissy (while regretting the film's ending as a false compromise) utter their esteem for the "very realistic description of a three-room flat where nine or ten persons pile up", Raymond Borde and André Bouissy, Le néoréalisme italien: Une expérience de cinéma social (Clairfontaine/Lausanne: Cinémathèque Suisse, 1960), p. 125 (translation mine). Original version: “La description très réaliste d'un appartement de trois pièces où s'entassent neuf ou dix personnes..."

15. Guido Kirsten, "Thesen zur Theorie des Filmstils: Intensionalität, Kontingenz und Wes Andersons Hotel Chevalier", in Julian Blunk, Tina Kaiser, Dietmar Kammerer, and Chris Wahl (eds.), Filmstil: Perspektivierungen eines Begriffs zwischen Ästhetik, Praxis und Theorie (Berlin: Edition Text \& Kritik, 2016), pp. 71-9o. Note that 'intension' (with an 's') is not to be mistaken for 'intention' or 'intentionality' (with a ' $\mathrm{t}$ ').

16. 'Figuratively' in the sense of Odin, De la fiction, pp. 18f.

17. Christian Metz, "The Perceived and the Named" [1975], trans. Steven Feld and Shari Robertson, Studies in Visual Communication, 6/3 (1980), pp. 56-68.

18. See Berto and Plebani, pp. 41-47.

19. Gottlob Frege, "On Sense and Reference" [1892], in Darragh Byrne and Max Kölbel (eds.), Arguing About Language (London/New York: Routledge, 2010), pp. $36-56 ;$ p. 37 . 
20. Compare nasa.gov/multimedia/imagegallery/image_feature_47.html and wired.com/2017/o1/gravity-waves-might-lighting-venus-upper-atmosphere/, for instance (Last accessed: 27 March 2018).

21. Lubomír Doležel, Heterocosmica: Fiction and Possible Worlds (Baltimore, MD/London: The John Hopkins University Press, 1998), p. 4.

22. Ibid., p. 16.

23. Ibid., p. 26.

24. Ibid., p. 138.

25. Gertrud Koch, Die Wiederkehr der Illusion: Der Film und die Gegenwart der Künste (Frankfurt/M.: Suhrkamp, 2016), p. 45 (translation mine). Original version: "Innerhalb der ästhetischen Erfahrung überwiegen die intensionalen Bedeutungen."

26. The diegetic can be thought of without reference to the camera and thus to découpage, whereas "intensional perception is always from a certain perspective” (Koch, ibid.) - and a film's intensional structure is most often made up of an articulation of a multitude of different perspectives.

27. Doležel, p. 142.

28. Note that my terminology differs from Bordwell's. For Bordwell, the "referential meaning" denotes "the diegesis, or spatio-temporal world, and [...] an ongoing story." It covers thus what I have called the extensional dimension. David Bordwell, Making Meaning: Inference and Rhetoric in the Interpretation of Cinema (Cambridge, MA/London: Harvard University Press, 1989), p. 8. The term "afilmic" is Souriau's ("The structure" [forthcoming]).

29. Meunier touches upon this kind of reading when he mentions the "critical attitude which brings about a type of perception that is quite different to that of the naïve spectator." It is characterized by "a willed distanciation and a taking into consideration of the film as an aesthetic object" - "a more complex attitude whose description warrants its own chapter" (p. 116). To be sure, there are many possible attitudes towards audiovisual texts. Odin mentions, aside from the "private," the "documentarist," and the "fictionalizing mode," an "aesthetic," an "artistic," an "energetic," a "fabulizing," an "argumentative/persuasive," and a "spectacular" mode (Odin, "Reflections," p. 255). He elaborates on these in several of his publications. Cf. Odin, Les espaces, passim. And the list does not need to be closed. In a response to an earlier version of this essay, Julian Hanich has suggested to take into account a "medium-conscious attitude" and a "hermeneutic attitude," none of which seems to be fully synonymous with any of the ones proposed by Odin.

30. In moving images, there are only rare instances of "double-intension." One of them is called The Spinning Dancer (sometimes the silhouette illusion). It was invented in 2003 by the web designer Nobuyuki Kayahara. What is exceptional with this image is that different observers can perceive motion in different directions: some see the animated ballerina spinning clockwise, others counterclockwise, some are even able to switch between the two di- 
rections. This ambiguity concerning the movement exists on the level of intension only, because the images do not relate to any extensional entity, real or fictional. Another example for such a double-intension regarding movement is the optical illusion Train Moves Both Ways, in which a train appears to be going into two opposite directions depending on which part of the image one focuses on: https://www.youtube.com/watch?v=ynx6pb8GVTA (Last accessed: 27 March 2018).

31. Borde and Bouissy, p. 125 [translation mine]. Original version: "L'opposition des niveaux de vie: des maçons mal logés construisent les buildings des autres."

\section{About the author}

Guido Kirsten is the principal investigator of the Emmy Noether research group "Cinematic Discourses of Deprivation: Analyzing the Representation of Precarity and Exclusion in European Fiction Film and Documentary" at the Filmuniversität Babelsberg KONRAD WOLF. Kirsten received his PhD in 2013 at the University of Zürich after which he worked as a postdoctoral researcher at Stockholm University and as a substitute professor at Johannes Gutenberg University Mainz. He is the author of Filmischer Realismus (Schüren, 2013) and co-editor of the anthology Das chinesische Kino nach der Kulturrevolution: Theorien und Analysen (Schüren, 2011; together with Karl Sierek) and the volume Christian Metz and the Codes of Cinema: Film Semiology and Beyond (Amsterdam University Press 2018; together with Margrit Tröhler). Since 2007, he is also a member of the editorial board of the German film and television studies journal Montage AV. Kirsten is specialized in film theory and the history of film theory, in questions of realism, representation, and filmic discourse, and in the theory and history of media dispositifs. Both in 2015 and 2016, Kirsten received an honorable mention at the Gesellschaft für Medienwissenschaft's Karsten Witte Award for best film essay of the year. 


\title{
Phenomenology, Immediacy, and Mediation: On Derrida, Meunier, and Landgrebe
}

\author{
Florian Sprenger
}

\begin{abstract}
This text explores three phenomenological approaches to immediacy from around 1970. At that time, phenomenological studies had to address the question of immediacy. Immediacy means that no mediation happens in a given relation, but, at the same time, it presupposes media because it presupposes a difference. A medium, however, cannot be immediate. If it were, the relational elements between which it mediates would be part of an unmediated relation. In this case, both separation of the elements and the medium's mediation in turn would be eliminated. Each of the three works discussed tries to rearrange this framework: Derrida by deconstructing its metaphysical foundations, Meunier by introducing filmic mediation, and Landgrebe by historicizing phenomenology as a struggle with immediacy.
\end{abstract}

Keywords: Media theory; Jacques Derrida; Jean-Pierre Meunier; Ludwig Landgrebe; immediacy

In the late 196os and early 1970s, three books were published that explored how phenomenology is fascinated by immediacy and challenged by mediation: Jacques Derrida's Voice and Phenomenon (La Voix et le Phénomène) in 1967, Jean-Pierre Meunier's The Structures of the Film Experience (Les Structures de l'expérience filmique) in 1969, and Ludwig Landgrebe's not-yet translated Der Weg der Phänomenologie. Das Problem einer ursprünglichen Erfahrung [The Path of Phenomenology: The Problem of Originary Experience] in 1971. Each of these studies presents its own explanation of the assumed immediacy of perception, and each of them has a different, more

Hanich, J. and D. Fairfax (eds.), The Structures of the Film Experience by Jean-Pierre Meunier. Historical Assessments and Phenomenological Expansions, Amsterdam University Press, 2019 DOI 10.5117/ 9789462986565_SPRENGER 
or less explicit conception of underlying processes of mediation. In this regard, Meunier proposes a conception of media that introduces immediacy into the phenomenological discussion and includes film as an example for the mediated immediacy of experiences.

The phenomenological tradition, to which all three books contribute, has from the beginning, been fascinated by immediacy. For example, Maurice Merleau-Ponty's The Structure of Behavior (La Structure du comportement) from 1942, an important point of reference for French phenomenology, addresses the question of the immediate givenness of experience on almost every page. The question of immediacy belongs to phenomenology's heritage and is part of the complex that every phenomenological study had to address at that time - and still has to address today, even though the technological conditions of our time have radically changed. The following short and preliminary remarks describe how the three books react to the challenge of immediacy. The observations converge in a conclusion that asks how to tackle the phantasms of immediacy today. The publication of the first translation of Meunier's book, half a century after it was written, is an opportunity to ask these questions again, because this translation has a place both within the past and within the present.

One of the reasons for this constellation around the year 1970, for the historical situatedness of the articulation of phenomenology's problem with immediacy, is that, around this time, the fundamental mediatedness of experience became obvious - a reason reflected by Meunier's approach to identification. Film is only one entity that gained theoretical value at that time. Television had already started to replace (or rather reframe) film as the dominant medium a few years beforehand. Of course, theorists like Walter Benjamin had articulated this approach earlier, but the institutional establishment of media theory begins in this period when Marshall McLuhan's theory of media was widely discussed in both North America and Europe. It is obvious that Derrida's and Landgrebe's texts demonstrate the unwillingness of philosophers to make sense of the media landscape of the time, but maybe they react to it in a deeper sense: they both explore the mediatedness of experience and find answers to the problem of immediacy. Meunier's book, meanwhile, is evidently part of this constellation, though he restricts mediated experience to film.

As a phantasm of unity and direct, continuous contact, immediacy is not restricted to phenomenology. Immediacy means that no mediation happens in a given relation, but at the same time it presupposes media, because it presupposes a difference that has to be bridged. Immediacy means the immediate relation of at least two elements. But when there 
are two, there needs to be a mediating third element. ${ }^{1}$ A medium, however, cannot be immediate. If it were, the relational elements between which it mediates would be part of an unmediated relation. In this case, both separation of the elements and the medium's mediation in turn would be eliminated. As relational in-betweens, media are the condition for the immediate connection of two elements with each other, since immediacy implies the collapse of the relation between two or more elements. However, in the immediacy of a relation, the medial connection of the elements and their necessary separation are at the same time erased - there must be two to become one and the one always stays separated. A medium, in this sense, can only be phantasmatically immediate. The history of media is accompanied by a history of phantasms of immediacy that reach from the unity of logos and speech contrasted with the separation of writing in Plato's Phaedrus to the idea that depictions of violence im-mediately affect their viewers, from scenarios of immersion into atmospheric media to the immediacy of film experience. ${ }^{2}$

The stakes of such immediacies entail historically different prospects of reward: they sublate the uncertainties and contingencies that lie in the separation between elements by promising to substitute multiplicity for unity; they present the prospect of an undivided community; in the form of a metaphysics, they hark back to an originary source (originärer Ursprung) from which everything else can be derived; they strive for an always already transmitted transmission in which delay or loss play no role; and they enable a primordial, uninterrupted access to the world via the senses. In the history of media, one can thus discern time and again an emphasis on the significance of media that is shot through with the 'reverie' of a media-less immediacy. ${ }^{3}$ The paradox of the immediacy of media that is thus generated consists in the negation of its own presuppositions. Immediacy displaces what ought to be explained to the realm of the unexplained and substitutes uncertainties with too-certain certainties.

This paradoxical constellation of immediacy is the starting point of all three books. In the context of phenomenology, the immediacy of experience is an important part of the epistemological framework. Each of the three books tries to rearrange this framework: Derrida by deconstructing its metaphysical foundations, Meunier by introducing filmic mediation, and Landgrebe by historicizing phenomenology as a struggle with immediacy. The latter two strive for an immediacy of experience, while Derrida attempts to dismantle these foundations. Despite the reference to an unmediated access to the world, the question of mediation intervenes into their selfassuring conception of phenomenology around 1970. The three books can 
be read as symptoms of an uneasiness with phenomenology's fascination with immediacy.

\section{Jacques Derrida and the Mediation of Immediacy in the Soliloquy}

Jacques Derrida introduces his conception of deconstruction in his publications from the late 1960 s and early 1970s, in which he investigates originary unities, essentialisms, and binaries in the history of philosophy and argues against the traditional equivalence of perception and access to the world, of appropriation and signification. He grounds his project on the observation that the phantasmatic paradox of immediacy, as one example of the essentialisms he criticizes, lies in the negation of its own presuppositions. This "coherence in contradiction [...] expresses the force of a desire."4 This desire, identified by Derrida as a dominant strain in the history of philosophy, aims at unity instead of separation, at direct contact instead of mediation. The deconstructive move shows that, in the binary opposition of immediacy and mediation, the suppressed necessarily intervenes in the ideal. As an instance of such unity, immediacy, Derrida explains, is a construct that appears to be unconstructed. "Immediacy is derived," as he writes in $O f$ Grammatology (De la Grammatologie). ${ }^{5}$ And he goes on to characterize such philosophies in the following terms: "As always, this archaeology is also a teleology and an eschatology; the dream of a full and immediate presence closing history, the transparence and indivision of a parousia, the suppression of contradiction and difference." ${ }^{6}$

In his deconstruction of Edmund Husserl's phenomenology, specifically of his Logical Investigations (Logische Untersuchungen, 1900-1901) in Voice and Phenomenon, Derrida explores how the personal subject of phenomenology is based on metaphysical presuppositions and develops a critique of phenomenology's foundational essentialisms. ${ }^{7}$ By taking into account "the instituting value of its own premises," this approach unsettles the tradition of phenomenology, the dominant philosophy in France at that time. ${ }^{8}$ Though it took a few years for Derrida to emerge as one of the leading proponents of what North American scholars would later call French Theory, the basic tools of his thinking are already at work in Voice and Phenomenon, published alongside Of Grammatology and Writing and Difference (L'Écriture et la différence).

In this book, Derrida works through Husserl's phenomenology of expression and indication as a key distinction that organizes his conception of language and speech. As Derrida demonstrates in a famous passage on Husserl's conception of language and the voice, there are no signs in 
soliloquies for Husserl, since the self-presence of the monologue prevents anything from being re-presented. Husserl writes:

Or shall we say that, even in solitary mental life, one still uses expressions to imitate something, though not to a second person? Shall one say that in soliloquy one speaks to oneself, and employs words as signs, i.e. as indications, of one's own inner experiences? I cannot think such a view acceptable [...] [In soliloquy] we are in general content with imagined rather than with actual words. One of course speaks, in a certain sense, even in soliloquy, and it is certainly possible to think of oneself as speaking, and even as speaking to oneself. ${ }^{9}$

In Husserl's view, soliloquies do not require any representational function of language since there is only the presence of the subject with itself. Selfpresence must not be imbued with any representation, even if the subject speaks with itself. In this presence, no repetition of the sign is necessary. Since nothing need be repeated, the soliloquy is sign-less. For Husserl, soliloquies invite us to search for sense beyond any materialization. In this perspective, the soliloquy is immediate and allows an unmediated relation of the self to itself because it is the self that speaks and listens at the same time. The self is immediately present to itself. There is no rupture or gap in the self in this idealizing conception. Derrida is interested in the extent to which Husserlian phenomenology depends on how consciousness does not communicate because it is present-to-itself and non-fissured. Nonetheless, it presupposes difference. To include this difference, Derrida argues, involves excluding self-identity, but also, at the same time, presupposes an identity that includes difference, albeit an identity that is fractured. Even the speaking self uses signs that differ in every repetition. Communication - even when curtailed in its most radical form in a soliloquy - presupposes a difference and thus a multiplicity: "This deconstruction of presence accomplishes itself through the deconstruction of consciousness, and therefore through the irreducible notion of the trace (Spur). ${ }^{10}$ Presence cannot be thought without absence, and absence does not simply replace but supplements presence. As Derrida argues, immediacy is derived. In this sense, the phenomenological subject is torn in itself, even though it remains unified through the soliloquy - it is immediate in its mediation.

Consequently, the presence of the speaking phenomenological subject is overburdened by metaphysics. Media, in this regard, can appear as immediate - the voice of the phenomenological subject can appear as a harbinger of self-presence. In his seminal text "Signature, Event, Context," which initiated 
the by now famous debate with John Searle, Derrida shows that the success of communication can never be accomplished - communication includes its failure. ${ }^{11}$ Noise, parasites, and dissemination can never be excluded as intended by metaphysical thinking. Instead, Derrida shows that the absence of writing makes possible that something is written: "Spacing (notice that this word speaks the articulation of space and time, the becoming-space of time and the becoming-time of space) is always the unperceived, the nonpresent, and the nonconscious." ${ }^{22}$ This temporal logic of repetition is characteristic for Derrida's notion of différance. Every mediation, in this sense, delays something, creates a difference that cannot be substituted. Différance, one could say, is the differentiating origin of differences, which can no longer be an origin because it produces a difference that comes before the origin. In this sense, immediacy is derived, but when it is derived, it cannot be immediate. As deferral and distinction, différance is a difference of a medium which has never been immediate.

\section{Jean-Pierre Meunier and the Immediacy of Film Experience}

Meunier's phenomenology of film is not touched by the questions posed by Derrida. There is no feeling of uneasiness toward the notion of immediate experience in his study. The book instead develops a new perspective on the mediation of experience by introducing a further layer: the structure of film as film experience. First published in 1969, we learn from Meunier's introduction to his book that he sees film as a medium which reflects the cultural biases, artistic output, and cultural developments of his time. For Meunier, film is the art form which offers the highest degree of identification for the viewer and is thus most relevant for an exploration of the complexities of human experience and its relation to the world:

In this conceptual framework, filmic identification is a variation of identification as a general mode of behavior, a particular type of identification corresponding to a particular type of relationship, one in which the object, although presenting almost all the characteristics that it possesses in perception, is presented as absent in its bodily physicality (p. 119).

Film, in other words, offers phenomenology a chance to test its assumptions with an aesthetic object: "These considerations, and others, will lead us to see filmic consciousness as a variation of the major category of consciousness that constitutes the imaginary consciousness" (p. 69). 
For Meunier, phenomenology means to take "phenomena such as they are immediately lived, and not such as they are conceived by virtue of some pre-established objective schema" (p.34). Consequently, immediacy appears as equivalent to life and lived, i.e. embodied experience. The opposite of immediacy, not named as such in this context, lies in the schematizing process of theorizing experience as an objective entity. There is no access to immediacy via theory, only via phenomenology. This approach offers an indirect key to the primordial dimension of subjectivity by "unveiling the invariable aspect in [...] particular forms of behavior" (p. 34). Drawing upon Maurice Merleau-Ponty, Meunier argues that an analytical conception of "cognitive operations" based upon an "adequate representation of reality" implies ignorance toward the bodily incorporation of perception as a "lived experience of phenomena" (p. 40) and the fact that the perceiving body is also the perceived body. Rather, perception, as a "primordial faculty that underpins our insertion in the world and all of our relations" (p. 38), deserves a different approach that is supposed to do justice to immediacy.

Perception, in the sense of Merleau-Ponty's phenomenology, is not simply the act of accumulating sensations, but rather a formed and structured process below the threshold of cognition. These forms and structures are the topic of phenomenology, which, at the time of Meunier's writing, had developed an elaborate instrument to describe them. Though Meunier describes this formed and structured process, perception can nonetheless appear as immediate, because the phenomenological relation to the world is "more immediate and more primitive than that described by analytic thought, basing itself on supposedly objective elements" (p. 41/42). What does Meunier mean by immediacy? And what happens to this immediacy characterized by the movement of images and a mode of identification similar to, but productively different from real-life experience, when the relation to the world is mediated by a relation to a film?

We can find preliminary answers to these questions in Meunier's approach to the phenomena of intersubjectivity. The immediate relation to the world that composes our bodies and subjectivities extends, he argues, to encounters with other persons: "I directly grasp the signification of their behavior, not through a cognitive operation, but through an immediate apprehension of their comportment" (p. 44). There is nothing in between, rather, the difference vanishes and makes way for a union of formerly separated entities: "The perception of other people [...] is an immediate given" (p. 44). It is impossible not to experience other people in an immediate way when we perceive them. "I grasp their intentions and, in a way, they become my 
own" (p. 44). The intersubjective world perceived by this phenomenological subject is composed in its immediate relation to the world.

In this sense, the experience of film as a medium that shows other people's lives on-screen is always mediated because film itself is a structure of perceivable elements, "in which the elements draw their meaning from their internal organization" (p. 71). Watching a film, the subject experiences the filmic world and the "world tout court" (p. 71) in an immediate and uninterrupted way, and it can only perceive individuals in the film with the same immediacy as individuals in reality - even though experience is mediated by film. The subject Meunier is interested in identifies with film and relates to the world through film in a similar way as it relates to the world through others. Similar to Husserl's subject, which perceives itself in the soliloquy, Meunier's subject perceives other people, preferably in a film. It is immediately present to them because it perceives them as it perceives itself.

Even if Meunier argues that film, as a medium, "is only a representation of the world," it nonetheless offers the world to us, "in the same manner as our unmediated sensations" (p. 71), although with a different attitude, because we know that we perceive a representation. Film, for Meunier, is a medium of immediacy, but he never tackles this paradoxical constellation. In the context of this approach to film, the immediacy of perception is a central element, because its primordial, non-cognitive dimension enables a "presence alongside the objects of the world" (p. 71). In his description of the home movie, Meunier explicitly refers to the mediation of film: "We can also say that in the case of the home movie, the cinematic image truly plays the role of medium. It serves as an intermediary between the reality perceived and my current consciousness of this reality." (p. 88) The difference between perceiving the real world and the represented world lies in different approaches toward this world, in different relations to it: "In the case of visual representation, we know that the behavior under consideration, despite presenting all the characteristics of perception, is not physically present." (p. 71) Even if we know that mediated film experience is mediated, we still perceive immediately and thus gain an immediate access to the world: "In perception, therefore, the objects are not 'believed' but immediately apprehended as existent." (p. 93) Even if, we could say, film mediates, we experience the world it presents in an immediate way because perception, in the phenomenological sense, can only be immediate. In this process of identification and relation, immediate experience is mediated.

On the one hand, then, Meunier's assumption of immediate experience is not up to date in light of Derrida's harsh critique of metaphysics, but on 
the other hand, it opens a new sense of the mediatedness of immediacy that is not present in Derrida's work. Though Meunier never problematizes immediacy and takes it as a given, his introduction of film as a medium of immediate experience complicates the question of immediacy for phenomenology. A phenomenology, we could argue following Meunier, that does not take into account the multiplicity of technologies of mediation that transform experience and our ways of world-making in specific ways can neither understand its technological condition, nor the immediacy that it employs.

\section{Ludwig Landgrebe and Philosophy's Struggle with Itself}

In this sense, phenomenology's appropriation of immediacy has a history. In 1971, the phenomenologist Ludwig Landgrebe, student of Edmund Husserl and teacher of Hans Blumenberg, outlines the scope of such a philosophical and phenomenological history of immediacy in a remarkable essay on the immediacy of experience. His book Der Weg der Phänomenologie: Das Problem einer ursprünglichen Erfahrung includes a chapter "On the Immediacy of Experience," in which he describes the foundations of this project:

The thinking of the $19^{\text {th }}$ century in all its decisive steps - not the ones which are usually included in the compendiums of the history of philosophy - can be understood, as it were, as an index of the fight of reason with itself. Reason attempts to determine itself in relation to the immediacy of experience, and in wrestling itself from the nets in which reason positioned itself, it enmeshes itself even further. ${ }^{13}$

Landgrebe goes on to expand how this struggle emerged when philosophy encountered the problem of conceiving the world through sensibility. The modern turn to epistemology, beginning with English empiricism and leading to Kant, questioned this access to the outside world and the possibility of knowledge about it. Even though, as Landgrebe explains, for Kant the Ding an sich (thing-in-itself) remained beyond knowledge and experience, his search for a source of knowledge in sensibility set the conditions for a new phase of the fight of philosophy with itself. The relation of the senses and the outside world subsequently became a prominent philosophical challenge. As Landgrebe argues, this unanswered, maybe unanswerable question crosses the centuries of philosophy and finally becomes the vantage 
point of phenomenology. Reason, as the foundational logos of philosophy, was confronted with a relation to the world beyond reason, and philosophy tried to make sense of this oscillation.

Landgrebe underlines that, for Hegel, the immediate became relevant as mediated, because the opposition between mind and matter or experience and world was itself conceived of as a product of thinking - which appears, from Landgrebe's point of view, as an impertinence because, for him, this dialectic removes the immediate from experience:

For Hegel, sensibility, which forms the material of all knowledge, cannot be the unique source of knowledge that it was for Kant, because this material cannot be understood as something in itself immediate. The supposed immediacy of sensibility needs to be proven as mediated. ${ }^{14}$

The importance of Kant - and the failure of Hegel - lies in the conception of the Ding an sich, which is in itself unknowable, but necessarily immediate. In Hegel's tendency to declare reason as the sole criterion for philosophy, Landgrebe assumes a tendency to abandon the world. Kant, on the other hand, tried to rearrange reason and sensibility in a way that gives justice to both reason and immediacy. Confronted with this question of the immediacy of experience, philosophy since then has taken up the task of determining itself in relation to immediacy, and has incorporated this challenge. Landgrebe goes on to explain that the importance of the immediacy of perception has been neglected by modern science and its focus on rational objectivity. What Landgrebe calls "the technical means of mass manipulation in cold calculation"15 is a result of this enacting approach to the world. It leads to a withering of immediacy and affect. To find a way out of this situation, it is necessary to reclaim an immediate connection to the world and the "inextricable rest that refutes to be conquered by scientific rationality." ${ }^{16}$ Consequently, Landgrebe defines the task of phenomenology in the twentieth century as reflecting this history of struggles in order to unite reason, sensibility, and immediacy. Husserl, in fact, describes the evidence of perception as an immediate opening up of reality.

In a decisive step in this history, Heidegger replaced the strict dualism of subject and object by the idea that the object is not given, but produced [hervorgebracht] and closely bound to the language that we use to explore the world. Thus, the relation of immediacy between subject and object is replaced by a more dynamic relation that allows for a different conception 
of immediacy as something that is not objectifiable. In this direction, Landgrebe continues the phenomenological approach as a reaction to the philosophical struggle with itself:

The logos of philosophical thinking as an exegesis of the immediacy of experience can only be clarified by a meditation [Besinnung] on the ways in which language, even before all conceptual thinking, is always an interpretation of reality. ${ }^{17}$

Referring to the late Heidegger and his turn to language, and resembling Husserl's conception of the soliloquy, Landgrebe looks for a new perspective on the immediacy of experience understood as a "hearing that does not want to rule [Vernehmen, das nicht herrschen will]." ${ }^{18} \mathrm{He}$ finds his solution in the fact that, though immediacy cannot be grasped by words, it also cannot be separated from the subject that experiences it. Phenomenology, Landgrebe argues, should not stop with the investigation of immediate experience, but instead take into account that such experience is mediated by language: "Every understanding of immediacy includes a self-understanding." ${ }^{.9} \mathrm{Im}-$ mediacy can only be articulated in language. In this sense, immediacy is necessarily included in the understanding of language. Immediacy happens when one understands oneself by understanding language. In the mediation of language, Landgrebe searches for immediacy and argues for a convergence of phenomenology and hermeneutics as a solution to the struggle of philosophy with itself.

\section{Conclusion}

Immediacy implies that the necessary separation between the two elements that are connected immediately is negated. As Michel Serres has stated, "A third exists before the second. A third exists before the others. [...] I have to go through the middle before reaching the end. There is always a mediate, a middle, and intermediary."20 Immediacy requires a medium, though it expresses the desire to eradicate its mediation. Rather than allowing an absorption by metaphysical unity, it is necessary to consider the differences that exist because there are media. That media operate with delays, that they isolate rather than unify, that they never transmit in real-time, that the gap between perception and world is irrefutable, and that film consists of still frames does not enter the picture if media are phantasmatically invested with immediacy. Media are always in danger of being replaced by immediacy if the very separation 
upon which they are premised is erased in phantasms of unity, presence, and immediacy. Landgrebe and Meunier seem to be aware at least of the condition of mediation that is necessary for immediacy, even if they strive toward an originary, unmediated connection. With Derrida, the goal must be to preserve the separation and to describe the difference of mediation not in terms of its elimination, but rather as distance as such. This is what Landgrebe and Meunier - more or less involuntarily - introduce to phenomenology.

To conclude, I want to come back to the point that the three studies of phenomenology presented here belong to a historical moment, at which immediacy itself became an explicit - and no longer implicit - problem for philosophy. Phenomenological thinking, as Derrida and Landgrebe show, has always been invested in immediacy, but, in the years around 1970, it became possible, and perhaps necessary, to articulate this problem as defining the scope of phenomenology. This is not the place to attempt to write a history of phenomenology's fascination with immediacy, but perhaps Meunier's book can be read as such a speculation. Of the three texts presented here, Meunier and Landgrebe present immediacy not only in the sense of an indubitable unity of self-presence, but also as a state that is dependent upon media that constitute the conditions of immediate experience: for Meunier, the possibilities of identification and world-making that are provided by film are part of its immediate experience; and for Landgrebe, the immediacy of understanding language depends upon the givenness of the medium of language. In this sense, they go one step further and incorporate mediation into phenomenology's fascination with immediacy.

At this point, it makes sense to ask for the place of the translation of Meunier's book in the present. If the original publication of 1969 was part of a historical situation, in which immediacy became a problem, then we should ask for the historical situatedness of the translation, and also for phenomenology's relation to it. Has this mediated immediacy of experience any relevance today? How can we rethink phenomenology's phantasms? To situate these questions, which of course cannot be answered here, it is necessary to understand how different today's technological condition is from that of 1970 . We currently witness, as, for example, Mark Hansen and Katherine Hayles have shown, a transition in which media no longer simply present or represent aesthetic material that can be perceived. Ubiquitous mobile technologies such as smartphones with location-based services, logistical media based on RFID (Radio Frequency Identification), or sensorial and autonomous technologies such as self-driving cars collect, Hansen writes, "huge amounts of data about behavior and our environment without our active participation, initiative or even consciousness." ${ }^{\text {21 }}$ In the face of this 
redistribution not only of agency, but also of perceptive faculties, Hansen argues, we should rethink what experience, apprehension, and subjectivity mean. We have to "abandon our object- or body-centered models of media experience for a radically environmental approach." ${ }^{22}$ Hansen describes the sensorial distribution of locative, mobile networks as an extension of sensorial faculties, in which mobile media create an ubiquitous environment of streams of information and energy. Humans and objects are woven into the fabric of this network. In a similar vein, Katherine Hayles demonstrates that the convergence of the most powerful locative technologies RFID and GPS necessitates a redefinition of the passage between human beings and technology, a critique of their politics, and consequently a new modification of the concept of mediation. ${ }^{23}$ In the environmentality of such media, agency no longer belongs to the presupposed status of a human subject - and this extends to experience. Indeed, Hansen does not call for an end of subjectivity, but for its redistribution, so that experience and mediation come together:

For the first time in our history and (very likely) in the history of the universe, we find our long-standing and up to now well-nigh unquestionable privilege as the world's most complex sensing agents challenged, if not overthrown, by the massively replicable and ubiquitously propagating technical capacity for sensing introduced by our smart devices and technologies. ${ }^{24}$

In this regard, Hansen tries to establish a phenomenology adequate to the changing technological conditions of our time. How is perception, we should ask, incorporated today, when human bodies are perhaps not the prime indicators of perceptive faculties? How can phenomenology find an answer to the challenges of ubiquitous, 'smart' media-technologies in a way that takes up the pathway shown by Meunier? What is an experience of film beyond film? How can we, with Derrida, deconstruct this technological condition of the present? ${ }^{25}$ And how can we situate ourselves in the struggle of reason with itself when we no longer fight for immediacy but for mediation?

\section{Notes}

1. Two seminal studies have explored this conception of media from historical and deconstructive perspectives respectively: John D. Peters, Speaking into the Air: A History of the Idea of Communication (Chicago: University of Chicago Press, 200o) and Briankle Chang, Deconstructing Communication (Minneapolis, MN: University of Minnesota Press, 1996). 
2. It is important to note the differences between the immediacy of experience and the immediacy of transmission that is an important phantasm in the history of media and media theory. The idea of an instantaneous transmission that takes no time and is everywhere at once is closely related to the sciences of electricity in the eighteenth century, the emergence of telegraphic networks in the nineteenth century, and Marshall McLuhan's theory of media in the twentieth century. The assumption of an immediacy of experience, on the other hand, is confronted with the problem of communicating experience: It is not possible to communicate experience as experience, it can only be mediated into language, pictures, or films. Florian Sprenger, Medien des Immediaten: Elektrizität, Telegraphie, McLuhan (Berlin: Kadmos, 2012). Parts of this paper rely on Florian Sprenger, "The Metaphysics of Media: Descartes' Sticks, Naked Communication, and Immediacy." Cultural Studies 30:4 (2016), pp. 630-649.

3. The concept of reverie has been invoked by Gaston Bachelard to describe the relation between the symbolic and the imaginary. See Gaston Bachelard, On Poetic Imagination and Reverie (Dallas, TX: Spring Publications, 1987).

4. Jacques Derrida, Writing and Difference (London: Routledge, 1967), p. 280. Derrida's involvement with phenomenology is well known: he wrote his master's thesis The Problem of Genesis in Husserl's Phenomenology in 1953 and translated Husserl's Origin of Geometry into French.

5. Jacques Derrida, Of Grammatology (Baltimore, MD: John Hopkins University Press, 1974), p. 157.

6. Ibid., p. 115 .

7. Jacques Derrida, Voice and Phenomenon: Introduction to the Problem of the Sign in Husserl's Phenomenology (Evanston, IL: Northwestern University Press, 2011).

8. Ibid., p. 4.

9. $\quad$ Edmund Husserl, Logical Investigations (London: Routledge, 1970), p. 191.

10. Derrida, Of Grammatology, p. 70.

11. Jacques Derrida, Limited Inc. (Evanston, IL: Northwestern University Press, 1988).

12. Derrida, Of Grammatology, p. 68.

13. Ludwig Landgrebe, Der Weg der Phänomenologie: Das Problem einer ursprünglichen Erfahrung (Gütersloh: Mohn, 1971), p. 129 (all translations of this text were done by Florian Sprenger). Original version: "Das Denken des 19. Jahrhunderts in seinen maßgeblichen Schritten - es sind nicht die, die zumeist in den Kompendien der Philosophiegeschichte verzeichnet werden - kann geradezu als der Index dieses Kampfes der Vernunft mit sich selbst angesehen werden, indem sie sich in ihrem Verhältnis zur Unmittelbarkeit der Erfahrung zu bestimmen und dabei den Netzen zu entwinden versucht, die sie sich selbst gestellt hat, wobei sie sich aber noch tiefer in sie hinein verstrickt." 
14. Ibid., p. 130. Original version: "Daher kann für Hegel die Sinnlichkeit, die den Stoff aller Erkenntnis bildet, nicht wie für Kant eine eigene Quelle der Erkenntnis sein, weil ja dieser Stoff selbst gar nicht als ein in sich bestehendes Unmittelbares begriffen werden kann. Die erscheinende Unmittelbarkeit der sinnlichen Gewissheit muß als eine vermittelte erwiesen werden."

15. Ibid., p. 127. Original version: "den technischen Mitteln der Massenlenkung in kalter Berechnung."

16. Ibid., p. 128. Original version: "ein unauflösbarer Rest, der sich der Bewältigung durch denkende wissenschaftliche Vernunft widersetzt."

17. Ibid., p. 140. Original version: "Der Logos des philosophischen Denkens als einer Auslegung des Unmittelbaren der Erfahrung [kann eine Klärung] nur in einer Besinnung auf die Art [finden], wie Sprache vor allem begrifflichen Denken schon immer eine Auslegung der Wirklichkeit [ist.]“

18. Ibid., p. 141. Original version: "Vernehmen, das nicht herrschen will.“

19. Ibid., p. 140. Original version: "Jedes Begreifen des Unrnittelbaren schließt schon immer ein Sichselbstverstehen in sich."

20. Michel Serres, The Parasite, 6th ed. (Minneapolis, MN: University of Minnesota Press, 1982), p. 53.

21. Mark B. N. Hansen, "Medien des 21. Jahrhunderts, technisches Empfinden und unsere originäre Umweltbedingung," in Erich Hörl (ed.), Die technologische Bedingung: Beiträge zur Beschreibung der technischen Welt (Frankfurt am Main: Suhrkamp, 2011), pp. 365-409, here p. 372 (my translation).

22. Ibid., p. 374 (my translation).

23. N. Katharine Hayles, "RFID: Human Agency and Meaning in InformationIntensive Environments." Theory, Culture \& Society 26:2-3 (2009), pp. 47-72.

24. Mark B. N. Hansen, Feed-Forward: On the Future of Twenty-first-century Media (Chicago: University of Chicago Press, 2015), p. 161.

25. Derrida's book On Touching:Jean-Luc Nancy, published in French in 2000, forty years after Voice and Phenomenon, gives some answers to this problem. Jacques Derrida, On Touching:Jean-Luc Nancy (Stanford, CA: Stanford University Press, 2007).

\section{About the author}

Florian Sprenger is Junior Professor for Media and Cultural Studies at Goethe-Universität Frankfurt, where he is also part of the graduate school "Configurations of Film." His research covers the history of media theory, the epistemology of artificial environments and the future of digital cultures. Among his recent publications are "The Network Is not the Territory: On Capturing Mobile Media" (in New Media \& Society) and Politics of Microdecisions: Edward Snowden, Netneutrality and the Architectures of the Internet (Meson Press, 2016). 


\section{V: PHENOMENOLOGICAL EXPANSIONS}




\title{
Cinema and Child's Play
}

\author{
Jennifer M. Barker
}

\begin{abstract}
This paper takes its cue from Jean-Pierre Meunier's brief references to children's games to ask what child's play might teach us about his model of filmic identification. Filmic identification, in Meunier's account, emerges from and against the background of "syncretic sociability," a state of "anonymous collectivity" that characterizes infancy and early childhood, but which never entirely disappears in the adult. By examining what Daniel Stern called "forms of vitality," we gain a clearer sense of how that shift between Meunier's "primordial intersubjectivity" and "private intersubjectivity" takes place. Forms of vitality also lend support to Meunier's nuanced descriptions of the affective relationship between spectators, characters, and films by bringing into focus the aesthetic movements through which that relation comes into being.
\end{abstract}

Keywords: Syncretic sociability; phenomenology; intersubjectivity; JeanPierre Meunier; child psychology; Daniel Stern

In The Structures of the Film Experience: Filmic Identification, Jean-Pierre Meunier addresses the question of the viewer's attachment to and investment in cinema and identification with the people and characters it presents to us. He identifies three modes of cinema - the home movie, the documentary, and fiction - each of which "solicits" from its viewer a particular "attitude" or form of engagement, including a specific way of engaging with its characters (whether those are fictional or real-world people), and with the time of its narrative in relation to real-world time in the case of the non-fiction modes. Along the way, he makes a brief but intriguing aside, pointing out that "the consciousness of the child can teach us a lot" about the way spectators engage with these filmic modes. "But this is not our concern," he continues, "We have only wanted to determine certain general attitudes of filmic consciousness, [...] outside of any deviation" (p. 100).

Hanich, J. and D. Fairfax (eds.), The Structures of the Film Experience by Jean-Pierre Meunier. Historical Assessments and Phenomenological Expansions, Amsterdam University Press, 2019 DOI 10.5117/ 9789462986565_BARKER 
This paper takes up the "consciousness of the child," not as a "deviation," but as a meaningful prehistory. Exactly what can child consciousness teach us about filmic modes and identification? Meunier's arguments rest heavily on the premise that filmic identification emerges from and against the background of what he terms "syncretic sociability," a state of "anonymous collectivity" that characterizes infancy and very early childhood, but that some psychologists and philosophers argue never disappears entirely. If this is true, we stand to learn something about adult spectatorship by attending to the complexity of infantile relations to the world and others in it. Specifically, by examining what developmental psychologists have termed "forms of vitality" and the early childhood play, in which they are the focus, we see just how participatory and interactive is the relation between spectator, character, and film in Meunier's account of filmic identification.

Many scholars of early childhood agree that the "anonymous intersubjectivity" Meunier describes (p. 118) is the originary mode of engagement between an infant and others in the world. Drawing on phenomenology, cognitive psychology, and neuropsychology, contemporary scholars of early childhood development elaborate - in more detail than Meunier's brief overview can do - just how "syncretic sociability" emerges and plays out, as well as how it anticipates, enables, and shifts into more 'private' forms of intersubjectivity, even as it lingers in some form. Bringing the psychology and phenomenology of childhood and child's play to bear on Meunier's theory of filmic identification also allows us to expand the discussion of filmic identification beyond narrative and character, to make room for formal, cinematic aspects of identification that are less emphasized by Meunier's account.

Though Meunier calls the consciousness of a child a "deviation" from the "generalized" spectator he pursues through the book, there is good reason to turn to childhood for clues regarding filmic identification as it pertains to adult spectators. Of course, childhood differs from adulthood in more ways than we can count, but as Merleau-Ponty says, in a series of recently translated lectures on child psychology and pedagogy, "adult functions are already represented in the child, but are not present in the same sense. It is analogous to a game of chess; all the pieces are there at the start and yet the face of the game changes." ${ }^{1}$

As Merleau-Ponty argues, children's mindsets demand to be engaged on their own terms, putting aside assumptions and comparative measures based on adult concepts and habits. If one approaches childhood in this fashion, one finds that structures inherent in early childhood are in some ways radically strange in comparison to those of adulthood, and yet they 
continue to play a meaningful role long after the development of new ones. Syncretic sociability is one of these structures.

\section{Syncretic Sociability}

Meunier quotes Merleau-Ponty, who claims that syncretic sociability is "a commerce with the world and a presence to the world which is older than intelligence" (p. 42). In this early stage in a child's relation to the world, the child has not arrived at a sense of the self, nor of others. As Merleau-Ponty writes, syncretic sociability (the term he adopts from Henri Wallon) is "the existence of a kind of precommunication, an anonymous collectivity with differentiation, kind of a group existence." It precedes a second stage, which is "the objectification of one's body, segregation, distinction between individuals. [...] Individual consciousness only appears later, along with the objectification of one's own body, establishing a dividing wall between the other and me and the constitution of the other and of me as 'human beings' in a reciprocal relationship."3

Meunier describes this stage as the foundation of a sense of oneself as a unique entity, a subject in the world.

It is on the basis of this indistinct, intersubjective syncretism that self-awareness, and the awareness of others, is structured in the child. Moreover, it is remarkable that the recognition of other people always precedes the awareness of oneself as a singular being. [...] The link to other people is provided with existence in the form of a coexistence of consciousnesses. As such, it precedes the formation of people as private subjectivities and is even the precondition for this process (p. 45/46).

Indeed, then and now, many psychologists and phenomenologists agree that this syncretic sociability never fully disappears. After all, writes Wallon, "could adult intelligence have remained rich and productive if it had really been forced to abandon the sources from which the child's intelligence springs?"4 Summarizing Merleau-Ponty, Talia Welsh writes that "all experiences are constituted by original, subjectless experience and thus all experiences express elements of original syncretic sociability." In other words, "this anonymous existence is not just a period of the subject's early life; it is interwoven within everyday existence." ${ }^{6}$

Meunier makes clear that "identification is founded on primordial intersubjectivity in order for it to be structured in relation to private 
intersubjectivity" (p. 46). For a clearer sense of how that shift between "primordial intersubjectivity" and "private intersubjectivity" takes place, we can look to Daniel Stern's work in developmental child psychology.

Stern's career-long investigation of interpersonal relations, including and especially those of infancy and early childhood, reflects an increasing overlap between the fields of phenomenology, psychoanalysis, cognitive psychology, and neuroscience on these issues. He agrees with those of his contemporaries in cognitive child psychology who argue that intersubjectivity is an "innate, emergent human capacity," but he parts company with them on the question of what precisely intersubjectivity is. ${ }^{7}$ While some have argued that the infant's tendency to imitate the parents' facial expressions suggests the infant does have a sense of self as separate from others, Stern "reserves intersubjectivity for the end of the first year, when the infant 'discovers he has a mind, that other people have minds [...] and that inner subjective experiences are potentially shareable."”

Stern does acknowledge that a certain kind of intersubjectivity exists in infancy, but he considers the term too broad to be useful. This prompts him to identify three categories, or stages, of "intersubjectivity" that develop between infant and parent. First, there is "interaffectivity," in which "the infant somehow makes a match between the feeling state as experienced within and as seen 'on' or 'in' another." 9 Following this, "interattentionality," or joint attention, emerges: here, child and parent expressly share an object of attention, as when a child looks back at the parent to confirm that (in Stern's example) it is safe to move forward to grasp a toy that appears beyond comfortable reach. Finally, with "interintentionality," the infant attributes to the parent "the capacity to understand the infant's intention," as when (in Stern's example) she demands a cookie and persists in her demand until the parent gives her the cookie or indicates explicitly that the demand has been refused. ${ }^{10}$

It seems clear that interaffectivity overlaps or coincides with syncretic sociability. In the context of filmic identification, it seems to align as well with the first and second of "the three aspects of identification" Meunier identifies: "its motor or postural aspect, its affective aspect, and its dramatic aspect" (p. 52). Because Stern considers interaffectivity to be both corporeal and affective, he would not likely differentiate, as Meunier does, between the first and second of these. He would consider both to be precursors to the third, the "dramatic" aspect of identification, in which self and other are singular entities whose attention and intentionality are shareable (whether they actually are shared or not). Thus, what Stern discovers of the earliest "interaffective" stage of infantile social relations sheds light on the motoric and affective aspects of filmic identification in Meunier's account. 
Interaffectivity is not a static state: it manifests in movement and time. A typical interpersonal encounter, he writes, is "a performance where the faces, bodies, tone of voice, etc. of the speaker and listener are the show for each other and for themselves, involving rapid shifts in arousal, interest, and aliveness."11 In early developmental stages, "preverbal infants (4 and 12 months) and mothers precisely time the starting, stopping, and pausing of their vocalizations to create a rhythmic coupling and bidirectional coordination of their vocal dialogues. This implies that they have 'captured' not only their own timing but that of the other as well." ${ }^{\prime 2}$

To understand precisely how human encounters unfold, Stern insists we must attend to the minutest flows of energy and force. These "forms of vitality," as he terms them, he considers to be the building blocks of infantile and, eventually, adult relations with others. Vitality forms are "the felt experience of force - in movement - with a temporal contour, and a sense of aliveness, of going somewhere. They concern the 'How,' the manner, and the style, not the 'What' or the 'Why'" of interpersonal relations. ${ }^{13}$ Here, as in all his work, he uses quite cinematic language to underscore their ubiquity and significance:

Zoom in to describe the 'dynamics' of the very small events, lasting seconds, that make up the interpersonal, psychological moments of our lives: the force, speed, flow of a gesture; the timing and stress of a spoken phrase or even a word; the way one breaks into a smile or the time course of decomposing the smile; the manner of shifting position in a chair; the time course of lifting the eyebrows when interested and the duration of their lift; the shift and flight of a gaze; and the rush or tumble of thoughts. These are examples of the dynamic forms and dynamic experiences of everyday life. The scale is small, but that is where we live. ${ }^{14}$

To tease out the experience of vitality - not only in humans, but in the inanimate world and in the temporal arts of dance, music, and cinema, for example - requires close observation and descriptive language. "To understand dynamic forms of vitality more clearly," he suggests we consider a lengthy list of words - among them, "exploding," "drawn out," "fluttering," "tense," "surging," "languorous," "swinging," “loosely," “fading," “fleeting," "halting." These are neither sensations nor emotions nor acts, he points out: they are not modality-specific, like sensations, nor are they goal-oriented, like intentional acts. Vitality forms are cross-modal: mothers do not exactly mimic children's precise sounds and movements, but transpose their vitality 
affects into another register, perhaps responding to an excited child's forceful outward thrusting of the arms with a sound, a vocalization that matches that movement's enthusiastic force and intensity. Likewise, no vitality form belongs exclusively to any one emotion; "anger can 'explode,' 'ooze out,' 'sneak up,' or be 'cold," for example, but "so could happiness and its smile." 6 "In short," Stern writes, "vitality forms are different from emotions in their nature, feel, non-specificity, omnipresence, and neurobiology."17 And yet, he insists, vitality affects are meaningful; "this is more than just 'embodiment."'18

Although Meunier focuses considerable attention on character attitude, personality, motivation, and behavior, he de-emphasizes the 'how' of the movements and gestures that express these things, and which certainly contribute to a spectator's response. After all, "without motion we cannot read in or imagine mental activity underneath, or thoughts, emotions, or "will."'19 In this respect, forms of vitality could be a useful tool for fleshing out Meunier's analysis of filmic identification.

Vitality forms in the cinema entail not just the movements of human bodies, be they fictional or documentary, but also film style, in the aesthetic sense (an authorial style, or an acting style, for example) as well as in a broader, more pertinent phenomenological sense that Merleau-Ponty describes as a "unity," which the world and everything in it has. Sounding very much like Meunier himself in his description of the way viewers of a home movie might identify friends or family members by their way of walking or smoking, Merleau-Ponty describes this "unity" as

comparable to that of an individual whom I recognize in an irrecusable evidentness prior to having succeeded in giving the formula of his character, because he conserves the same style in all that he says and in all of his behavior, even if he changes milieu or opinions. A style is a certain way of handling situations that I identify or understand in an individual or for a writer by taking up the style for myself through a sort of mimicry, even if I am incapable of defining it; and the definition of a style, as accurate as it might be, never presents the exact equivalent and is only of interest to those who have already experienced the style. ${ }^{20}$

Vitality forms can disclose the relation between affect, movement, and time in very precise ways. The speed of a human gesture or a camera movement, the inflection of a voice or intensity of a sound effect - these and innumerable other aspects of a film's style would lend support to Meunier's nuanced descriptions of the affective relationship the spectator has to a 
film's characters, whether fictional or belonging to a real-world context that may be intimately, or not at all, familiar to the spectator.

\section{Child's Play}

"Belief, in the cinema," writes Meunier,

is rather comparable to belief when playing. The child who plays 'cowboys and Indians' never ceases to regard his behavior as imaginary, but this does not negate the fact that during the game - that is, until the moment when he decides to stop playing - the child 'believes' that he is a 'cowboy', and 'believes' that his fellow players are 'Indians.' He is fascinated by the unreal world created by the game, just as the spectator is fascinated by the unreal world of the screen. (p. 95)

Child's play begins long before 'cowboys and Indians' and imaginary tea parties, even before patty-cake and peek-a-boo. It has its roots in the deceptively simple exchange of vocalizations, touches, and gazes between newborns and their parents or closest caretakers. In a sense, they are the child's first playground.

The continuity between the preliminary, purely affective play that dominates in the first year of life and the symbolic play that follows in later years parallels the relationship between syncretic sociability and the 'private' intersubjectivity that emerges later, in real-world interpersonal relations and in filmic identification.

In a study of child's play that is substantially informed by Stern's work, Silvia Español and her colleagues observed in the interactions between an adult and children, two and three years old, "a type of interactive play where child and adult, in a pleasant and organized fashion, actively manipulate the vitality forms of their own movements and sounds." ${ }^{21}$ In this kind of play, dubbed forms-of-vitality-play (hereafter hyphenated for clarity) the researchers were struck by "two essential traits: its non-figurative character, and its link with temporal arts." 22

The only 'content' in this category of play are the vitality forms themselves; there is no act of representation as in games of 'cowboys and Indians' or 'house,' for example. Instead, "the dyad [baby and parent] skillfully extracts some of the five events of forms of vitality (movement, time, force, space and intention/direction) and elaborates on them according to a repetitionvariation structure." ${ }^{23}$ Forms-of-vitality-play do, however, provide "a good 
runway for the development of symbolic play."24 Forms-of-vitality-play also "prepares the child to participate in the temporal arts that belong to his culture," as Stern has claimed. ${ }^{25}$ In the patterning of movements and sounds between child and adult, for example, the researchers identified certain patterns of repetition and variation "of small units of movements and sounds, resembling patterns that are present in the temporal arts. ${ }^{26}$ Across forms-of-vitality-play, symbolic play, and in the temporal arts, they find that "in all three, the backbone is the repetition-variation form." ${ }^{27}$

Although Meunier likens the suspension of disbelief in the film experience to a child's game of 'cowboys and Indians,' his own account of filmic identification bears closer resemblance to forms-of-vitality-play. Consider the two possible kinds of participatory identification with a fictional character that he sets out: "being-with" and "being-like." Giving the example of a spectator who identifies with the hero in a classic Western, he writes that, in this case,

participation takes on the allure of an attempt to 'be like' the hero. Here there is identification in the narrow sense of the term. In other words, there is an attempted fusion with the highly valorized character. The ego tends to establish with the personality of the hero a relation not of exteriority but of belonging. The center of reference is no longer the ego of the spectator but the personality of the hero, and participatory behavior consists of an effort to be this personality. This is, therefore, participation in the mode of 'being-like' (p. 130/131).

Against this kind of identification, he posits another mode he calls "beingwith." In this case,

while participating in her [the character's] existence, I remain situated with respect to her. In other terms, I do not engage my personal 'ego' in the character. [She] remains before me, in a relationship of exteriority. I live in connivance with her, in a sort of sympathetic complicity, but I remain a center of reference. As such, [her story] does not become my story, since I do not have a tendency to fuse with her, to be 'like her.' (p. 13o)

Paradoxically, in this latter mode we empathize and identify more closely with a character by maintaining our difference and distance from her.

Likewise, in forms-of-vitality-play, difference not only exists but plays a crucial role, this despite the fact that the self and other, the 'I' and the 'you,' have not yet been fully conceptualized, much less firmly codified. Español 
and her colleagues identify this as a hallmark of forms-of-vitality-play, distinct from the type of mimicry that comes just before it. Whereas the adult is the one who determines the dynamics of very early social play through repetition and difference, in forms-of-vitality-play, both adults and children manipulate their movements and sounds, "letting novelty emerge from their almost symmetrical exchanges" and creating a dialogic exchange. ${ }^{28}$

Part of the pleasure and excitement in forms-of-vitality-play lies in contingency. "For play to appear," Stern writes, there must be

a loose frame that permits spontaneity and unpredictability; the incorporation of accidents, errors, and rule violations; the momentary uncoupling from the other to explore and adjust inside yourself and then rejoin the partner; sometimes fiddling with the very timing of interactions and expectations so as to create variations and pleasurable violations; and other such nonlinear and frame-breaking features that enhance creativity. ${ }^{29}$

In fact, Stern points to evidence that infants develop a tolerance and even desire for contingency. Babies younger than three months are drawn to situations in which the vitality dynamics of adult behavior perfectly match their own. Around the age of four months, however, they begin to show a preference for events in which adult behavior is "highly but imperfectly contingent with their own." ${ }^{30}$

If Meunier's 'being-with' requires difference between self and other in identification, then, it is in forms-of-vitality-play that we see that difference coming into being, even though, at this stage, the self and other have not yet been clearly demarcated. This explains what Meunier says of children playing 'cowboys and Indians,' that they can quickly and easily shift from play to reality: they are cowboy and Indian, until they stop playing. This shift from being oneself to being another becomes easier with practice; perhaps forms-of-vitality-play offers precisely that.

Elsewhere in this volume, Daniel Fairfax points out how refreshing it is to see Meunier's allusion to five- and six-year-old children, rather than the infant who figures so strongly in apparatus and psychoanalytic film theories. On the other hand, I appreciate that even the infant, who (thanks to Meunier's emphasis on syncretic sociability) hovers just outside the frame of his discussion, is much more engaging than the one who figures in later film theory. That is, if we take Meunier's cue to think of cinema in terms of play, but focus our attention on forms-of-vitality-play rather than the symbolic play of later childhood, we bring into relief the significant 
difference between Meunier's idea of the spectator and the one imagined by apparatus theory. Meunier's spectator 'plays back' interactively with the film, bringing his or her own vitality forms into the mix, echoing Stern's argument that infants' perceptual activities are far more active and acute than traditional accounts have given us to believe.

\section{Vitality Affects and Filmic Identification}

Stern consistently uses distinctly cinematic language when describing infantile interpersonal encounters - he refers to the parents' vocal and gestural behavior as a "sound and light show" for the infant, for example and his own psychotherapy practice..$^{31}$ "I grew to realize how much occurs in a moment that lasts only seconds," he writes. "Once I got the hang of these techniques (e.g., freeze frame, slow motion, segment repeats) I could even use them, unsystematically, in real time, for very short stretches, to see my psychotherapy patients differently." ${ }^{2}$

It comes as no surprise, then, that in elaborating his concept of forms of vitality, Stern includes a lengthy discussion of Raymond Bellour's 1979 essay, "System of a Fragment (on The Birds)," one of several essays in which the film theorist examines classical cinema's definitive pattern of repetition and variation. 33 "Bellour does a micro-analysis of film, working with units lasting only seconds, using stop frame, replay, fast forward, and slow motion - all the techniques that baby watchers use to analyze the 'ordinary choreography' between mother and infant." 34 In Bellour's close reading, "flesh has been put on the narrative, and it has been imbued with powerful vitality forms. This use of Bellour's work is only one among multiple possible examples of the unique ways in which cinema can produce the dynamic feel of experience." 35

Stern's admiration for Bellour's work was mutual: the latter's 2002 essay on the "unfolding of emotion" in cinematic experience draws substantially on Stern's introduction of vitality affects in The Interpersonal World of the Infant, first published in 1985. In response to Stern's argument that vitality affects underscore not only our earliest human social relations but also prepare us for the experience of the temporal arts, Bellour writes,

The cinema immediately seems to fill the frame of such a vision. [...] All the resources of the shot, from the frame to the movements that move it, either in their inner limits, or in animating them through the camera movements - all the resources of the shot and series of shots serve the 
sustained deployment of vitality affects, under the pretext and according to the inclinations of psychological affects, supporting identifications with characters, with the fiction. ${ }^{36}$

\section{Still Life}

I want to end this piece with two brief examples of the way forms-of-vitality research resonates with Meunier's theory of filmic identification.

The patterns Stern and fellow researchers identify in clinical experiments bear some resemblance to patterns of attention and movement in the filmic experience. For example, he points out that

when a mother goes 'still face' while facing her infant, i.e. not moving her face at all, not even with slight expressions, the baby, or even a neonate, becomes upset within seconds. Newborns already have working peripheral vision that is designed to detect motion at the periphery. Accordingly, stillness is registered no matter where their focal vision is on the mother's face. ${ }^{37}$

This experiment recalls the scene in The Birds (Alfred Hitchcock, 1963), in which Melanie looks on in horror as a gas station patron ignites a trail of spilled gasoline near the diner where she and other townspeople have taken refuge. The scene has prompted startled laughter in undergraduates seeing it for the first time in my classroom. Perhaps they, like the baby in Stern's experimental example, are startled by the utter stillness of Tippi Hedren's face. Preternaturally still, she stares in shock as the trail of fire rapidly speeds out of control. The moment unfolds in nine shots, neat eye-line matches that intercut her still face (each time in a slightly different position, always motionless) with shots of the fire racing along the ground.

Her stillness is striking precisely because it contrasts not only with the movement of her fellow onlookers, but even with the movement of her own hair, blowing slightly in the breeze through the open window. Like an infant looking for signs of life in the mother's face, perhaps viewers are startled by the sudden absence of movement where one expects it. Interestingly, the shot of Mrs. Brenner's silent scream in response to farmer Dan Fawcett's ghastly corpse works in a similar fashion. There, the contrast plays out not so much in editing, but in sound and performance, between her paralyzed silence and the synchronous sound of the shot itself, including Mitch's voice asking her to explain what has happened. 


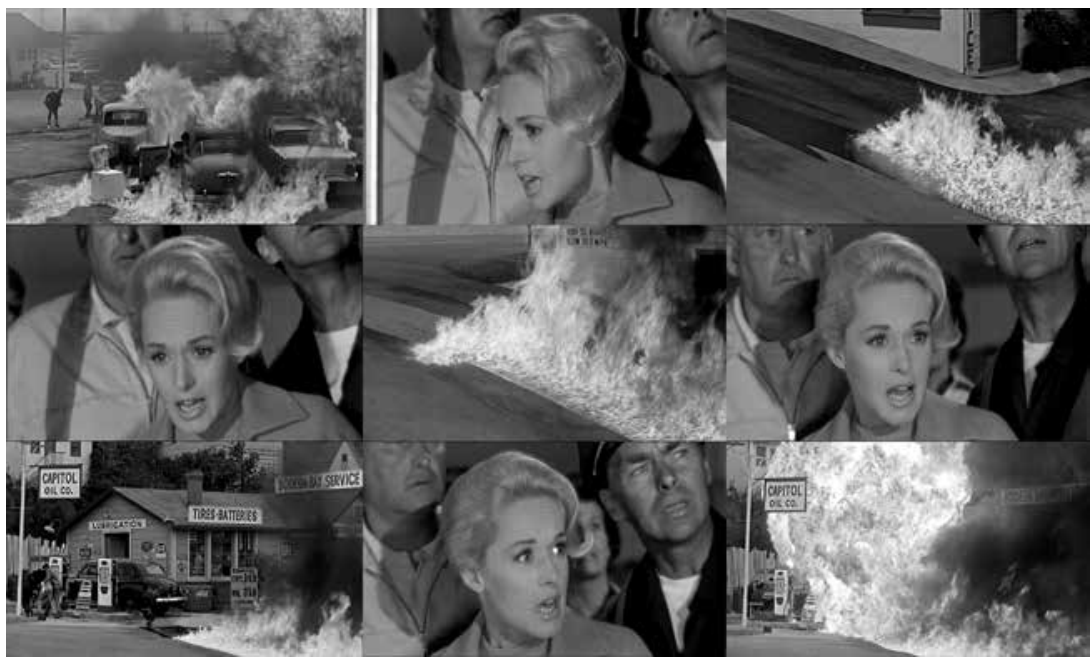

Fig. 12: Scene from Alfred Hitchcock's The Birds with Tippi Hedren.

"Compared to the infant's expectations and wishes, the depressed mother's face is flat and expressionless," writes Stern.

She breaks eye contact and does not seek to re-establish it. There is a disappearance of her animation, tonicity, and so on. Along with these invariants coming from the mother there are resonant invariants invoked in the infant: the flight of animation, a deflation of posture, a fall in positive affect and facial expressivity, a decrease in activation, etc. In sum, the experience is descriptively one of a micro-depression. ${ }^{38}$

Stern's description concerns an encounter that we certainly would not consider play. However, one can imagine a case in which the mother goes still in order to surprise the baby by playfully 'coming to life' again, provoking in the child a similar pattern of suspension and sudden arousal. In such a case of forms-of-vitality-play, the child and mother would be responding to one another's vitality forms (movements, sounds, expressions) in such a way as to create expectation, resonance, and surprise. Hitchcock is playing with us in exactly this manner, in this sequence.

By attending to vitality forms as they emerge in infancy, then, we arrive at a formal pattern in The Birds and an approach to it that plays nicely with Bellour's own argument about the semiotic structure of the film and its significance regarding the gendered gaze, identification, power, and authorship. This is a good example of the way psychoanalysis, phenomenology, 
and cognitive science might intersect productively in the film theoretical analysis of filmic identification.

The editing-studio segment of Dziga Vertov's Man with a Movie Camera (1929) provides another example. As children watch a magic trick with a mix of joyous and befuddled amazement, the film shifts to a series of successive freeze-frames, rendering each child's face suddenly still. These shots are followed by a sequence of adult faces, also in freeze-frame, as if frozen in response to the children's sudden stillness. After a short segment, in which we watch the film's editor (Elizaveta Svilova) constructing the sequence we have just watched, these same faces launch into movement again. Much later, the use of stop-motion animation produces a similar effect, when a tripod and camera assemble themselves on-screen before an audience of curious moviegoers. The jerky motions of machinery repeat but modulate the quick, small movements of the diegetic viewers who laugh, blink, lean forward, or raise an eyebrow in amused surprise or consternation at the apparatuses' antics. The play between stillness and movement, and more profoundly between human vitality forms and cinematic ones, exhibits the "momentary uncoupling from the other" that enables the creative "variations and pleasurable violations" Stern points to in forms-of-vitality-play.

Tom Gunning and Vivian Sobchack have discussed, separately, the uniquely cinematic experience of time. Gunning argues the "astonishment" attributed to early cinema spectators stems from the sudden transition from still image to moving image. ${ }^{39}$ Sobchack takes up Gunning's argument in an analysis of a trope in contemporary martial arts films, in which fast-moving action sequences suddenly cut to extreme slow motion for a long moment, before cutting back to speed again. ${ }^{40}$ She argues the astonishment that spectators might experience in such moments stems not from the speed or the slowness itself, or even from their drastic difference, but from the transition from one to the other, which reveals the uncanny co-presence of identity and difference. "What 'attracts,' is not simply 'still to moving' or 'moving to still' but, rather, the movement from one terminus to the other - indeed, the movement of movement itself, which, made visible in slow motion, occupies the uncanny space 'between' these end points, and reveals them both to be merely different 'dimensions of the same process."

The psychological research that I have discussed here raises the possibility that the "aesthetic of astonishment" (to borrow Gunning's phrase) on display in Vertov's film and exemplified by early cinema and the modern action film's trope of abrupt slowness, may stem from very early child's play, marked by "dialogic exchange" in which both child and adult "get to manipulate vitality forms letting novelty emerge from their almost 
symmetrical exchanges." ${ }^{22}$ This "play' involves not only vitality forms of the human figures on-screen, but also the film's, including not only frame rate but also the speed, intensity, force, and orientation of camera movements and bodies in motion, of sound, of light, and so forth.

Looking at adult film perception through the lens of forms-of-vitality-play supports Meunier's own reading of filmic identification, by casting the spectator as a much more active player in the experience than the apparatus theory that follows quickly on the heels of his 1969 text would have it. It has the added advantage of extending Meunier's discussion of 'identification' into the realm of aesthetics, rather than solely narrative and character. That is, although he frames his discussion of 'being-with' and 'being-like' squarely in terms of identification with characters embedded in stories (be those fictional or not, classically organized or not), using 'forms of vitality' to think through filmic identification allows us both to attend to formal qualities involved in any instance of filmic identification, and to consider filmic identification in films organized around formal play, rather than character and story.

Bellour draws a similar conclusion regarding vitality affects and film analysis: to see the bodies, objects, light, and camera movements as vitality affects, rather than as narratively motivated and meaningful characters, objects, and gestures

is not to say that therefore we cannot commit ourselves to aims of analysis that are meant to be, on one side, more figurative or figural in nature, on the other, more narrative or narratological. But the essential thing is that $[. .$.$] the two aspects are in the end forever linked just as they were$ at another level welded from their origin. And this, in such a way that such a link also proves to be free from all predestination, and open to the greatest chance, in life and in cinema. ${ }^{43}$

Forms-of-vitality-play also seems an appropriate analogue to moviegoing in that it emerges within the syncretic sociability that Meunier posits as a crucial support for the 'private' sort of identification a spectator experiences with characters. In this stage of life, "it is true that children have an ambiguous understanding of other people as subjects," writes Talia Welsh in her own take on Merleau-Ponty's child psychology lectures

But it is not the case that other people are objects for children. [...] Intersubjectivity is not a matter of discrete subjects. When I live in the world, it is not similar to watching a movie where things pass in front of 
me and I passively receive them. Nor do I experience my body like a thing that processes sensations akin to how a money-counter counts bills. ${ }^{44}$

Counter to Welsh's assumptions here, research into forms of vitality, when paired with Meunier's discussion of filmic identification, reminds us just how active watching a movie is for its spectators, who interactively play with narrative, actors, and the film itself.

\section{Notes}

1. Maurice Merleau-Ponty, Child Psychology and Pedagogy: The Sorbonne Lectures 1949-1952, trans. Talia Welsh (Evanston, IL: Northwestern University Press, 2010), p. 427.

2. Merleau-Ponty, Child Psychology and Pedagogy, p. 248. Meunier's "syncretic sociality" seems interchangeable with "syncretic sociability," Wallon's term for the same concept, a term later adopted by Merleau-Ponty. This essay employs the latter term, more commonly used in the context of phenomenology.

3. $\quad$ Merleau-Ponty, Child Psychology and Pedagogy, p. 248.

4. Henri Wallon, "The Psychological Development of the Child," International Journal of Mental Health 1:4 (1972), pp. 29-39, here p. 30.

5. Talia Welsh, The Child as Natural Phenomenologist: Primal and Primary Experience in Merleau-Ponty's Psychology (Evanston, IL: Northwestern University Press, 2013), p. 71.

6. Welsh, The Child as Natural Phenomenologist, p. $5^{0 .}$

7. Beatrice Beebe et al., "A Comparison of Meltzoff, Trevarthen, and Stern," Psychoanalytic Dialogues 13:6 (15 December 2003), pp. 777-804, here p. 791.

8. Beebe et al., "A Comparison of Meltzoff, Trevarthen, and Stern," p. 789. In addition to the helpful comparison between the theories of Andrew Meltzoff, Colwyn Trevarthan, and Stern in Beebe et al., see also Talia Welsh's discussion in The Child as Natural Phenomenologist of Meltzoff and Shaun Gallagher's work in relation (and opposition) to Merleau-Ponty's description of syncretic sociality, where the researchers draw conclusions from which Gallagher himself would later depart.

9. Daniel N. Stern, The Interpersonal World of the Infant: A View from Psychoanalysis and Developmental Psychology (New York: Basic Books, 1985), p. 132, quoted in Beebe et al., "A Comparison of Meltzoff, Trevarthen, and Stern," p. 791.

10. Summarized in Beebe et al., "A Comparison of Meltzoff, Trevarthen, and Stern," p. 791.

11. Daniel N. Stern, Forms of Vitality: Exploring Dynamic Experience in Psychology, the Arts, Psychotherapy, and Development (Oxford: Oxford University Press, 2010), p. 75. 
12. Ibid., p. 73 .

13. Ibid., p. 8.

14. Ibid., p. 6.

15. Ibid., p. 7 .

16. Ibid., p. 23.

17. Ibid., p. 28.

18. Ibid., p. 25 .

19. Ibid., p. 10.

20. Merleau-Ponty, Child Psychology and Pedagogy, p. 384 .

21. Silvia Español et al., "Forms of Vitality Play in Infancy," in Integrative Psychological and Behavioral Science 48:4 (2014), pp. 479-502, here p. 480.

22. Ibid., p. 480.

23. Ibid., p. 487 .

24. Silvia Español et al., "Forms of Vitality Play and Symbolic Play During the Third Year of Life," Infant Behavior and Development 40 (1 August 2015), pp. 242-251, here p. 242.

25. Ibid., p. 242.

26. Español et al., "Forms of Vitality Play in Infancy," p. 481.

27. Ibid., p. 487 .

28. Ibid., p. 487 .

29. Daniel N. Stern, "Face-to-Face Play: Its Temporal Structure as Predictor of Socioaffective Development," Monographs of the Society for Research in Child Development 66:2 (1 April 2001), pp. 144-149, here p. 146.

30. Stern, The Present Moment, pp. 73-74.

31. Stern, "Face-To-Face Play," p. 145.

32. Stern, The Present Moment, p. xii.

33. Raymond Bellour, "System of a Fragment (on The Birds)," in The Analysis of Film (Bloomington, IN: Indiana University Press, 2000), pp. 28-67.

34. Stern, Forms of Vitality, p. 94.

35. Ibid., p. 98.

36. Raymond Bellour, "The Unfolding of Emotions," trans. Paul Fileri and Adrian Martin, Rouge 8 (2008). Originally published as "Le dépli des émotions," Trafic 43 (Fall 2002), pp. 93-128.

37. Stern, Forms of Vitality, p. 10.

38. Daniel N. Stern, "One Way to Build a Clinically Relevant Baby," Infant Mental Health Journal 15:1 (Spring 1994): 9-25, here pp. 12-13, quoted in Arnold H. Modell, “A Note on Dan Stern's Vitality Affects," Psychoanalytic Inquiry 38:2 (17 February 2018), pp. 165-168, here p. 166.

39. Tom Gunning, "An Aesthetic of Astonishment: Early Film and the (In) Credulous Spectator," in Linda Williams (ed.), Viewing Positions: Ways of Seeing (New Brunswick, NJ: Rutgers University Press, 1989), pp. 114-133.

40. Vivian Sobchack, "'Cutting to the Quick': Techne, Physis, and Poiesis and the Attractions of Slow Motion," in Wanda Strauven (ed.), The Cinema of 
Attractions Reloaded, Film Culture in Transition (Amsterdam: Amsterdam University Press, 2006), 337-351.

41. Ibid., pp. 340-341.

42. Español et al., "Forms of Vitality Play in Infancy," p. 487.

43. Bellour, "The Unfolding of Emotions."

44. Welsh, The Child as Natural Phenomenologist, p. $5^{2}$.

\section{About the author}

Jennifer M. Barker is Associate Professor of Moving Image Studies in the School of Film, Media \& Theatre at Georgia State University. She researches in the area of moving-image studies, with particular interests in synaesthesia, cinema, and mind/body relations; moving image aesthetics, affect, and embodied spectatorship; performance studies; documentary studies; and film theory. She recently completed a fellowship with the Cinepoetics Center for Advanced Film Studies at Freie Universität Berlin. She is the author of The Tactile Eye: Touch and the Cinematic Experience (2009). Her work has also appeared in Somatechnics, Studia Phaenomenologica, Discourse, New Review of Film \& Television Studies, and Film-Philosophy, among others. 


\title{
Engines of the Historical Imagination: Towards a Phenomenology of Cinema as Non-Art
}

\author{
Vinzenz Hediger
}

\begin{abstract}
Combining Jean-Pierre Meunier's notion of film-souvenir, which originally only referred to home movies, with Daniel Yacavone's phenomenology of film form, this contribution sketches the outline of a phenomenology of film experience which covers the entirety of what Eric de Kuyper proposes to call the "vast-domain of cinema as non-art," a domain that includes orphan films, ephemeral films and other forms of utility films.
\end{abstract}

Keywords: Utility films; home movies; ephemeral films; historical experience; Jean-Pierre Meunier

The relation between film and the end of bourgeois culture is not so much captured in the term distraction [Zerstreuung] in which, after all, capitalism protects itself from its loss of metaphysical elevation. It is captured rather in what are interruptions in the production process: in a boredom that protects itself against organization, in a form of leisure in waiting.

- Heide Schlüpmann

I sincerely hope we can avoid the trap of auteurism this time around.

- Rick Prelinger

I.

In a recent essay, Daniel Yacavone notes that thanks to the works of Dudley Andrew, Vivian Sobchack, Jennifer Barker, and others, phenomenology has once again moved to the center of the debate in film theory, which it

Hanich, J. and D. Fairfax (eds.), The Structures of the Film Experience by Jean-Pierre Meunier. Historical Assessments and Phenomenological Expansions, Amsterdam University Press, 2019 DOI 10.5117/9789462986565_HEDIGER 
occupied before the advent of semiotics and post-structuralism. Yacavaone then takes Vivan Sobchack to task for focusing her phenomenology of film experience on the medium rather than the form of film. Sobchack, according to Yacavone, "advocates replacing a conception of cinematic experience rooted in the idea of filmmaker(s) as expressing subject(s) with that of a film itself as an 'expressing subject and object.'”' By contrast, Yacavone highlights the distinction between medium and form to argue for a phenomenology of film form that reinstates artistic expression, and with it an auteurist approach to film, as a primary concern.

While I am profoundly sympathetic with Yacavone's focus on form, what I want to propose here are the outlines for a phenomenology of film form for which artistic expression is, at best, a secondary concern. My interest is in what Eric de Kuyper, in a lucid critique of a conventional film historiography driven by categories like 'auteur,' 'nation,' and 'style' inherited from art history and literary studies, has called the "vast domain of cinema as nonart,"; in other words, the type of film that has variously been described as "ephemeral film" (by Rick Prelinger), "useful cinema" (by Haidee Wasson and Charles Acland), and "utility film" (by Yvonne Zimmermann and myself), which includes corporate films, science and research films, educational films, and home movies. ${ }^{2}$ Precisely because these films constitute such a "vast domain", such an important part of film history, we need an "aesthetic of film history," one that gives its "due to film as an aesthetic, and not just an art phenomenon," as De Kuyper wrote almost a quarter of a century ago. ${ }^{3}$ The wide availability of utility films in digital repositories today lends De Kuyper's call for an aesthetic of film history with renewed urgency.

Jean-Pierre Meunier's The Structures of the Film Experience (Les Structures de l'expérience filmique: L'identification filmique) can contribute to such an aesthetic. Meunier's book was one of the first treatises on film aesthetics, if not the first, to include home movies under the rubric of 'film.' While Meunier's choice of examples suggests that he was neither a cinéphile in the classical sense - his corpus includes films by non-canonical genre directors like Philippe Broca and James Bond movies - nor very concerned with the problem of artistic expression, his principal interest is in fiction films. Borrowing a triad of concepts from Sartre's The Imaginary (L'Imaginaire) to distinguish between three major attitudes of film-viewing and three modes of film experience - the fiction attitude, the documentary attitude, and the home-movie, or film-souvenir, attitude - he considers home movies almost by accident. But that accident has consequences: Meunier extends the field of film aesthetics to include the entire domain of cinema as non-art. 
Incidentally, in 1968, as Meunier was readying his book for print, the Advanced Research Projects Agency (ARPA) net, the US military's predecessor of the internet, took shape and Sol Worth developed the project of a democratized ethnography, at the heart of which he envisioned a videosharing platform creating a "world where symbolic forms created by one inhabitant are instantaneously available to all other inhabitants." Just as Meunier set out to expand the horizon of film theory, the outlines of the contemporary digital ecology emerged.

In this contribution, I want to argue that we can develop the outlines of a phenomenology of cinema as non-art by combining Meunier's concept of film-souvenir with Yacavone's phenomenology of film form. In a first step, I want to restate the challenge such a phenomenology poses, particularly to Yacavone's notion of form. In a second step, I discuss the experience of cinema as non-art and argue that, because of their lack of inherent interest, utility films refer viewers to their 'thrownness' (Geworfenheit), or, in less Heideggerian terms, to the limits of their personal and situated knowledge. Utility films thus work as virtual film-souvenirs and engines of the historical imagination. In a third step, I return to the problem of form and argue that disunity of form is what defines utility films as aesthetic devices. Incidentally, this also makes them a paradigm for an aesthetic of film history.

II.

Based on a rereading of Merleau-Ponty's seminal 1945 essay "Film and the New Psychology" and the passages dedicated to cinema in "Art and the World of Perception" from 1961, Daniel Yacavone argues that cinema's aesthetic potential lies in creating a "reflexive, knowledgeable, and sensitive consciousness" of the fundamental process of lived perception. In that sense, "narrative cinema made and experienced as art largely shares in [the] same dynamics as modern painting." For narrative cinema to be art and for the fundamental process of lived perception to become the object of a reflexive, knowledgeable consciousness, the presence of an auteur is required. Yacavone speaks of a "three-term, lived relation" between "two (or more) actual human subjects - the viewer and the filmmaker(s) - and one symbolic and communicative, as well as highly expressive object, i.e. the cinematic work of art as and when experienced. ${ }^{6}$ For this three-term, lived relation to result in the experience of art, the expressive object of film has to conform to certain standards. "The primary criterion for cinematic art," Yacavone writes, paraphrasing Merleau-Ponty, "consists in the successful 
creation of a distinctly aesthetic cohesiveness and expressive holism of formal and temporal (rhythmic) structure." The auteur is the guarantor of "expressive holism"; expressive holism enables cinema as art, which in turn is the focus of a phenomenological aesthetics of film.

The medium-form distinction thus aligns with the distinction between art and non-art. This considerably enlarges the already vast domain of cinema as non-art. Stanley Cavell once wrote that the question was not whether cinema could be art, but why it was spared the fate of becoming one for so long.7 Only with the advent of the nouvelle vague, Cavell argues, did cinema acquire a consciousness of its own history and thus become an art in the modern sense. Like Bordwell, Staiger, and Thompson, and like Bazin, who attributed the greatness of classical Hollywood cinema to the "genius of the system" rather than individual auteurs, Cavell understood Hollywood cinema as a system of conventions comparable to Greek temple architecture, i.e. as an authorless art. ${ }^{8}$

We can argue that Hollywood cinema achieves 'expressive holism' even without an auteur figure protruding into the viewer's consciousness at every turn. But there can be no doubt that the films at the center of Eric de Kuyper's thinking about an aesthetic of film history do not satisfy Yacavone's criterion of formal unity. Film archives typically include numerous unidentified or unidentifiable fragments. As deputy director of the Nederlands Filmmuseum in the 1990s, De Kuyper worked with Peter Delpeut and Mark-Paul Meyer to compile these "ruins of finished works," as he called them, into so-called "Bits and Pieces" reels. ${ }^{9}$ A continuing series, "Bits and Pieces" now consists of 623 fragments on 56 reels of 300 meters. ${ }^{10}$ They are screened in the film museum cinema and at festivals, as well as lent and sold to other archives and institutions.

The legal term for these "Bits and Pieces" is 'orphan film.' It classifies films as 'abandonware,' i.e. as material that has been abandoned by its owners and/or copyright holders or that is of unknown or unlocatable ownership. ${ }^{11}$ Timothy Corrigan and Patricia White describe orphan films as "any sort of films that have survived but have no commercial interests to pay the costs of their preservation." ${ }^{12}$ This description also covers the majority of utility films, i.e. films made for specific occasions such as fairs or shareholder meetings. Now collected in dedicated archives such as the Italian Archivio Nazionale del Cinema d'Impresa in Ivrea near Turin or the Prelinger collection (most of which is available online at www.archive. org), such films lost their value even in the eyes of the corporations and institutions which commissioned them once their mission was complete. Home movies, which can also be classified as utility films in that they were made to record specific occasions for a limited audience, turn into orphan 
films if and when they are abandoned by the people who made them and sold on flea markets or on eBay.

Scholars like Florian Hoof have studied the role of utility films in the emergence and consolidation of industrial organizations in the nineteenth and twentieth centuries. ${ }^{13}$ Others, like Alexandra Schneider, have provided the outlines of a theory of practice of home-movie filmmaking by looking for stylistic patterns in random film samples and reconstructing production histories from biographical cues. ${ }^{14}$

What is still missing is an aesthetic of utility films, an aesthetic of film history in the sense of De Kuyper. The real object of film history, argues Pierre Sorlin, is the event of projection and the experience of the screening. ${ }^{15}$ Projection alone does not endow the "Bits and Pieces" with the 'expressive holism' that would turn them into works of art according to Yacavone's criterion. Rather, it highlights the character of many of these films as fragments and 'ruins of works.' Fragments and ruins have, of course, long been a concern of aesthetics. Commenting on Stendahl's observation that the Colosseum in decay is more beautiful than it was in its original glory, Hartmut Böhme writes: "Ruins show a precarious balance of preserved form and decay, nature and history, violence and peace, memory and present, mourning and longing for redemption, which no intact edifice or object of art achieves." ${ }^{16}$ In that spirit, we can argue that a phenomenology of film form will only be complete if and when it accounts not just for expressive holism of complete works, but for the aesthetic specificity of bits, pieces, errant home movies, and other 'abandonware.'

III.

Fiction and documentary films are crafted to capture the attention of as large an audience as possible, unbound by limits of a specific time and place of viewing. Film canons imply the existence of works of inherent, universal, and enduring value. And while it took Hollywood until the $1950 \mathrm{os}$ to comprehend the longevity of film, it has been focused on the long-term exploitation of copyrights ever since. By contrast, unless we watch them with a "documentary attitude" in the sense of Meunier, i.e. with an eye to historical detail such as clothing and design, home movies appear to interest only those who made them or appeared in them, while passion for ephemeral films fades with the occasion for which they were made.

To say that other people's home movies and most ephemeral films lack interest is another way of saying that they are boring. As Patrice Petro and 
others have argued, boredom, defined as lack of interest, is a genuinely modern state of mind. ${ }^{17}$ The modern subject emerges in sixteenth- and seventeenth-century philosophy as the bearer of a reflexive consciousness, and of passions and interests. ${ }^{18}$ Only a subject capable of passions and interests can experience boredom as the absence of interest. If distraction, as Heide Schlüpmann argues, obfuscates the bourgeois world's loss of metaphysical elevation, boredom, defined as the absence of interest, points to that loss. Boredom undermines a state of affairs in which the passions and the interests are constantly activated towards some specific goal or purpose. More specifically, boredom marks the point where the production of subjectivity, which critics from Adorno to Lazzarato have identified as the modus operandi of the cultural industries, breaks down. ${ }^{19}$ If boredom can thus be read, as Schlüpmann suggests, as a critique of the production logic of modern bourgeois society, watching other people's home movies and other films devoid of interest becomes a critical, and even political, act. ${ }^{20}$ As Patrice Petro writes, "Hidden in the innovation of distraction and shock is the despair that nothing further will happen. Hidden in the negativity of waiting, however, is the anticipation that something (different) might happen." ${ }^{21}$ Perhaps paradoxically, Petro claims, boredom "habitualizes renewed perception." Renewing perception, of course, is the signature trait of art as understood by the Russian formalists. An aesthetic of cinema as non-art, then, has to account for this paradox: it is precisely by virtue of the fact that it is devoid of interest, i.e. inherently boring, that cinema as non-art behaves like art, and can perform the function of an artwork.

To understand this paradox better, we need to look at situations in which ephemeral films behave unexpectedly, (re-)awaken interest, and replace boredom with excitement: situations in which something indeed happens. One such instance occurred in the fall of 2004, when the Bergbaumuseum, the German National Museum of Mining in Bochum at the heart of the Ruhr Valley, organized a series of public screenings of mining films from their archive. There were more than 180 mines in West Germany in the early 1950s, with a large concentration in the Ruhr Valley. After the coal crisis of 1957/1958, the coal industry went into a managed decline; the last mines, in Bottrop and Ibbenbüren, closed in 2018. Founded in 1930 and opened in the 1950s, the National Museum of Mining is the largest of its kind in the world and holds an important film collection. Screenings are a regular feature of Industriekultur, the public celebration of industrial heritage. The films screened in 2004 dated from the 1930s through the 1960 os and covered public relations, work safety, recruitment, and advertising for coal. None of the films was from a famous director or otherwise known, but all screenings were packed. 
As much as by the films, I was enthralled by the spectacle of spectators experiencing the screenings in a palpably tactile way or, as the saying goes, with every fiber of their bodies. Work safety films were particularly instructive. They focused on workplace hazards, always exemplified in a dramatic scene of an accident. The audience - many of them former miners, who had been shown some of the films in their own training - tended to deride these scenes in the discussion after the screenings, mostly for the hammy acting. Rather than to the dramatization of danger, they appeared to respond to the evocation of their former workplace. In part, the discussions after the films re-litigated the labor conflicts of the 1970 s and 1980 s. But the politics of past decades alone could not explain the excitement of the audience.

As Jean-Pierre Meunier points out in The Structures of the Film Experience, the relational, intersubjective structure of the film experience always implies an element of contagion between spectators. Any spectator will also act as a second-order observer of the other spectators. He or she will track their responses and, more often than not, mimetically adjust to the response of the others in the cinema. ${ }^{22}$ Focusing on the spectator's relationship with the body on-screen, Meunier quotes the following passage from Hesnard:

My body of natural knowledge - my perceived body - finds in the body of the other person a kind of extension of its own intentions: our two bodies are inhabited by the same anonymous existence. Furthermore, our two bodies realize, or at least give a hint of, expressive and significative movements, and form a single system by completing each other (p. 44/45).

Vivian Sobchack later develops this thought into the idea of the film's body, a basic experiential structure, which enables our engagement with a film. Christiane Voss, in turn, speaks of the Leihkörper of the film, of the spectator as a "surrogate body." ${ }^{23}$ But the logic of extension also pertains to the other viewers: film and spectators aggregate as a plurality, rather than as atomized individuals. At the Bochum screening, however, the contagion by aggregation had its limits. Partly because the response of the other audience members was so intense, those who did not share their background, like myself, were confined to the position of outsiders or second-order observers. My response to the films was, in fact, largely predicated upon what they meant to the other members of the audience.

Extrapolating from self-observation and drawing on models and insights inherited from philosophy and psychology, theories of spectatorship usually assume an ideal spectator to be able to make general statements about viewer engagement. The feminist critique developed by Laura Mulvey and 
others in the 1970s and 1980s introduced gender as a key marker of the spectator subject, while cultural studies in the 1980 s added race and class to distinguish between modes of spectatorship. More recently, queer theory and intersectional analysis have contributed to differentiate current notions of spectatorship further.

One could, of course, describe my taking the position of second-order observer as a performance of class privilege. When I first took the job at Ruhr University, colleagues asked me how I was dealing with the 'culture shock' of trading Zurich, one of the richest cities in the world, with the post-industrial cityscape of Bochum. But I would argue that the challenge offered by the Bochum audience reaches beyond differences of race, class, gender, and sexual orientation.

One lesson that Gilles Deleuze retains from phenomenology is the heuristic value of epoché, the bracketing of established beliefs and consolidated (if not reified) concepts and categories. Highlighting Deleuze's concern with thinking immanence beyond the dualities of traditional metaphysics, Leonard Lawlor writes that the "challenge of immanence appears to be nothing less than the challenge with which phenomenology confronts traditional metaphysics. ${ }^{24}$ As Deleuze argues himself, the concept of the image in his cinema books offers an underhanded critique of the unacknowledged transcendentalism of the then-dominant psychoanalytic theories of spectatorship. ${ }^{25}$ For Deleuze, the image is not something perceived or gazed at by the spectator; rather, spectatorship is something folded into and out of the image as event.

Along similar lines, one of the lessons of the Bochum screening seems to be that we need to account for the specifics of the viewing event rather than frame it in terms of the conceptual abstraction of a viewing subject and the declination of its attributes. More specifically, I would argue that the Bochum audience's response points to the role of what Michael Polanyi proposes to call "tacit knowledge," while my reaction to that response highlights the importance of what Donna Haraway calls "situated knowledge," the specific knowledge of the researcher and its experiential limits. Tacit knowledge, the non-propositional knowledge acquired through personal experience, which Hesnard seems to refer to as "natural knowledge," plays into every event of viewing a film. ${ }^{26}$ At a general level, we understand the conventions of cinema without necessarily being able to name and describe them. At a more individual level, we respond to a film as it relates to our personal experience, and we infuse the film's world with our knowledge of a given space, situation, or conflict. To put it in more Deleuzian terms, we affect the film as it affects us. As we engage with a narrative film, that affect 
remains subordinate to the emotional engagement which is patterned into the narrative structure of the film. But with films like the mining films, which elicit no strong emotional engagement based on narrative or visual invention, the knowledge with which we affect the film takes center stage, and in a way overwhelms the film. As Jean-Pierre Meunier argues, the film experience is "a perceptual experience that underpins the imaginary attitude of consciousness" (p. 152). What Meunier writes about home movies also applies to utility films: "There is a constitutive activity on the part of consciousness. In short, consciousness constantly exceeds the image, which serves precisely as a medium between the reality perceived in the past and my present consciousness of this reality" (p. 107). In her work on the home movie, Vivian Sobchack draws on Meunier's typology of viewing attitudes to argue that we can shift from one attitude to the other even as we watch a film. As the discussion after the screenings suggested, the Bochum audience explored all three attitudes. They adopted a fiction attitude towards the characters in the films, exploring the being-with and being-as modes of the fiction attitude (or alignment and allegiance, to use the terms of Murray Smith's model of character participation), ultimately finding the characterization unconvincing, as they indicated in their critique of the acting and the mise en scène. ${ }^{27}$ They adopted a documentary attitude, treating the films as purveyors of knowledge about the world, which led to the debate about labor strife and work safety regulation. Most importantly, however, they treated the films as film-souvenirs, even though they were clearly not watching a home movie of any kind. Perhaps based on an element of self-recognition in the being-as mode, the vicarious participation in the character's experience, the reality perceived in the past through these films was their own. In that sense, the former miners responded to the films with an excess of consciousness, which was based in their tacit knowledge of the workplace, while I reflexively responded to their perception of a reality in the past, which I had not lived and could not access.

One could argue that this split describes the viewing situation of any ephemeral film: there are those who have grounds to respond to the films, and there are those who do not. In a unique way, and more than conventional fiction and documentary films, the viewing situation of utility films exemplifies the situatedness of the viewer's knowledge. Arguing for a feminist objectivity, Donna Haraway writes that objectivity is not about "transcendence and splitting of subject and object" but "about specific and particular embodiment," and that only "partial perspective promises objective vision." ${ }^{28}$ The viewing situation of ephemeral films makes that partial perspective palpable. The experience of the film fragment, of the 
ruins of works, and of works that are in ruins because they lost their original mission, is itself fractured and fragmented, an experience in ruins, and we have to understand it as such.

If the Bochum miners overwhelmed the mining films with an excess of consciousness fueled by their lived experience of the industrial past, the films required a different excess of consciousness, a different feat of the imagination, of those who did not share that past. They had to treat these films as virtual film-souvenirs, as films that worked as film-souvenirs for others but could only work as such for them if they imagined having shared the same experience. In the case of the Bochum screening, this meant imagining the experience of working in a coal mine, an epitome of the industrial world, from the vantage point of a post-industrial lived world. Yet a reliving of the past as it had been, a wie es gewesen in the sense of nineteenth-century German historian Ranke, remained out of reach for such an act of imagination. Ineluctably, it remained coupled with a second-order observation of others experiencing their remembrance of the past as it had been first hand. A comparison to two other types of film, the trailer and the historical drama, can help us define what such an act of the imagination entails. If the movie trailer presents the film in the form of a virtual memory, i.e. as we would remember it had we already seen it, the utility film challenges us to imagine what we would remember had we lived what it refers to, had we lived through its specific occasion. ${ }^{29}$ And where the historical drama produces subjectivity, addressing and interpellating its viewers as members of a polity and an "imagined community" whose history the film purports to tell, the utility film returns the viewer to her "partial perspective that promises objective vision."

Lest we shift to what Meunier calls the "documentary attitude" and content ourselves with a historicist curiosity for period detail, the utility film works as an engine of the historical imagination in a reflexive way. It is an aesthetic device, i.e. it has the potential to renew perception and to elicit as Yacavone states, a "reflexive, knowledgeable, and sensitive consciousness" of the fundamental process of lived perception, precisely insofar and because the boredom it promises clears the space for the historical imagination to do its work. In that sense, if the film experience is indeed, as Meunier argues, a perceptual experience that "underpins the imaginary attitude of consciousness" (p. 152), it is the film-souvenir that invites the strongest effort of the imagination - or, more specifically, the utility film, the ephemeral film or home movie, imagined as a virtual film-souvenir by those who do not share the past reality to which the film refers. This might also explain why the home-movie fragment has become such a popular technique in narrative 


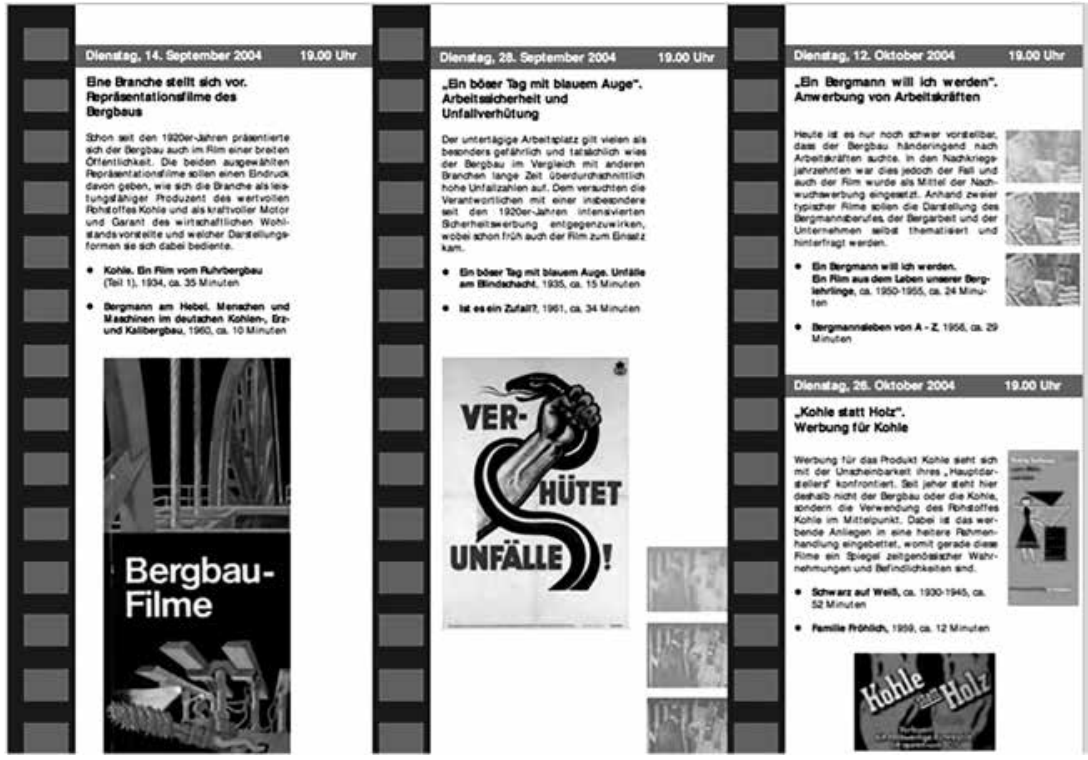

Fig. 13: Program of the mining film screenings at the German Museum of Mining, Bochum, September-October 2004. @ Deutsches Bergbaumuseum.

cinema: it invites an excess of consciousness that anchors the fiction film more deeply in the lived experience of the viewer. It has been argued that the industrial film, a key format of the utility film, is a parasite, a function rather than a format that can shift shapes according to the situation..$^{0} \mathrm{But}$ in terms of aesthetic experience, the relationship can be reversed, and it can be the fiction film that thrives on the strength of the film-souvenir, or rather of the virtual film-souvenir.

IV.

But if film-souvenirs are indeed, as Meunier writes, a "medium between the reality perceived in the past and my present consciousness of this reality" (p. 107), then what about their form?

According to Yacavone, form only exists in a given medium as expressive holism. Whether it be a fragment, a ruin, a concoction with an ephemeral purpose or an aid to the memory of someone we never knew, most utility films lack an auteur and a primary aesthetic purpose, both of which would be required to achieve expressive holism. In retrospect, some industrial films from the format's golden age, i.e. the 1950 and 1960 s, can be reappraised 
as forgotten milestones of modernism. Robert Menegoz's Only the Fogs Are Grey, a 1965 documentary for Thyssen steelworks photographed by Sacha Vierny, comes to mind, or the collaborations between industrial filmmakers and pioneers of electronic music in 1960 Italy. ${ }^{11}$ Yet Only the Fogs Are Grey is a recruitment film, extolling the virtues of a highly automated steel factory to potential hires among the moviegoing public. Such films are the Schroedinger's cats of cinematic art: they are art and non-art at the same time.

We could contend that the external purpose of a film like Only the Fogs are Grey is no longer relevant today and treat the film as a self-sufficient artwork. But this would obfuscate the historicity of our viewing situation, and with it, the aesthetic specificity of the film. Viewing, from our post-industrial vantage point, an industrial film from the golden age requires an effort of the historical imagination to compensate for the limits of our situated knowledge: it requires, if you will, post-industrial objectivity. As a consequence, whatever form we can claim for a utility film must be a form in a "medium between the reality in the past and my present consciousness of this reality" (p. 107).

Phenomenology emerged in response to an existential contradiction, which also posed a fundamental challenge to philosophy: the discrepancy between the rapidly expanding scientific knowledge about the world and the subject's fading conceptual grasp of the unity and totality of that world. For philosophy to stay true to its mission, it had to find a way to bridge that gap. ${ }^{32} \mathrm{~A}$ return to 'the things themselves' and the study of the constitutive acts of consciousness of a being embedded in the lived world, rather than of the ontological structure of the world as a totality of being, was the answer. On a much smaller scale, the project of a phenomenology of film form which includes cinema as non-art responds to a similar challenge: to provide a conceptual grasp for a 'vast domain' of films without having to resort to a selective criterion like authorship or the primacy of aesthetic purpose to seize the unity and totality of its object.

In the absence of an author, the viewer has to step in and provide the form that distinguishes the utility film as an aesthetic object. Just as the lack of interest was the key to understanding the structure of the utility film experience, the lack of formal unity provides the key to its form. Utility films are ephemeral not just because of their purpose, but because of their form: where art can rely on the relative solidity of 'expressive holism,' the form of the utility film is ultimately the fleeting, transitory work of the historical imagination, which operates in the medium "between the reality perceived in the past and my present consciousness of that reality." When the production of subjectivity breaks down and an expressive authority fails to materialize, the productive subject gets to play and takes responsibility for form. 
But we would be remiss if we thought that the formal disunity and ephemeral was a sufficient criterion to distinguish De Kuyper's "vast domain of cinema as non-art" from cinema as art. In fact, one could argue that, in the contemporary digital ecology, the conditions of intelligibility of cinema as art are now aligning with those of cinema as non-art. Dominique Païni points out that a true film history has only become possible with the emergence of digital image technologies. The film exhibition, which, starting in the 199os helped cinémathèques redefine their mission in the face of the competition from high-quality home video formats like the DVD, creates historical meaning by juxtaposing film fragments with other fragments, texts, material objects, and photographs. ${ }^{33}$ De Kuyper's vision of an aesthetic of film history that comprises fragments and ruins of works has become the default mode not just of the history of cinema as non-art, but of the history of cinema as art. Merely a stepping stone on the path towards the film forms that really matter in Meunier's phenomenology of film experience, the utility film, by virtue of its formal disunity, turns out to be a paradigm of a true history of cinema.

\section{Notes}

1. Daniel Yacavone, "Film and the Phenomenology of Art: Reappraising Merleau-Ponty on Cinema as Form, Medium, and Expression," New Literary History 47:1 (Winter 2016), pp. 159-186, here p. 165.

2. $\quad$ Eric de Kuyper, "Anyone for an Aesthetic of Film History?" Film History, vol. 6, no. 1, 1994. pp. 100-109, here p. 107.

3. Ibid., p. 108.

4. Sol Worth, "Towards and Anthropological Politics of Symbolic Form [1968]," in Larry Gross (ed.), Studying Visual Communication (Philadelphia, PA: University of Pennsylvania Press, 1981), pp. 85-107, here p. 85 .

5. Yacavone. "Film and the Phenomenology of Art," p. 177.

6. Ibid., p. 173 .

7. Stanley Cavell, The World Viewed: Reflections on the Ontology of Film (New York: Viking Press, 1971).

8. David Bordwell, Janet Staiger, and Kristin Thompson, The Classical Hollywood Cinema: Film Style and Mode of Production (London: Routledge, 1985); André Bazin, "On the politique des auteurs," in Jim Hillier (ed.) Cahiers du cinema: The 195os: Neo-Realism, Hollywood, New Wave (London: BFI/Routledge \& Kegan Paul, pp. 248-259).

9. De Kuyper, “Anyone for an Aesthetic of Film History?", p. 102.

10. Christian Olesen, "Found Footage Photogénie: An Interview with Elif Rongen-Kaynakçi and Mark-Paul Meyer," in NECSus - European Journal of Cinema and Media Studies, vol. 2, no. 2 (2013), pp. 555-562. 
11. Denis W.K. Khong, "Orphan Works, Abandonware, and Missing Markets for Copyrighted Goods," International Journal of Law and Information Technology, vol. 15, no. 1 (2006), pp. 54-89.

12. Timothy Corrigan and Patricia White, The Film Experience: An Introduction (Boston: Bedford / St. Martin's, 2004), pp. 391-398, here p. 392.

13. See, for instance, Florian Hoof, Angels of Efficiency: A Media History of Management Consulting, trans. Daniel Fairfax (Oxford: Oxford University Press [forthcoming]).

14. Alexandra Schneider, "Autosonntag (1930) - A Film Safari in the Swiss Alps," Visual Anthropology 15:1 (2002), pp. 115-128; Alexandra Schneider, "Home Movie-Making and Swiss Expatriate Identities in the 1920's and 1930's," Film History 15:2 (2003), pp. 166-176.

15. Pierre Sorlin, "Ist es möglich, eine Geschichte des Kinos zu schreiben?" montage/av 5:1 (1996), pp. 23-37.

16. Hartmut Böhme, "Die Ästhetik der Ruinen," in Dietmar Kamper and Christoph Wulf (eds.), Der Schein des Schönen (Göttingen: Steidl, 1989), p. 287 (translation mine). Original version: "Die Ruine zeigt eine prekäre Balance von erhaltener Form und Verfall, von Natur und Geschichte, Gewalt und Frieden, Erinnerung und Gegenwart, Trauer und Erlösungssehnsucht, wie sie von keinem intakten Bauwerk oder Kunstobjekt erreicht wird."

17. Patrice Petro, "After Shock / Between Boredom and History," Discourse 16:2 (1993), pp. 77-99. Patricia Meyer Spacks, Boredom: The Literary History of a State of Mind (Chicago: University of Chicago Press, 1995).

18. Albert O. Hirschmann, The Passions and the Interest: Political Arguments for Capitalism before its Triumph (Princeton, NJ: Princeton University Press, 1977).

19. Maurizio Lazzarato, Signs and Machines. Capitalism and the Production of Subjectivity (Cambridge, MA: MIT Press, 2014).

20. Heide Schlüpmann, "Kinosucht," in Frauen und Film vol. 33 (Rotbuch Verlag, 1982), pp. 45-50.

21. Petro, "After Shock," p. 87.

22. See also Julian Hanich, The Audience Effect: On the Collective Cinema Experience (Edinburgh: Edinburgh University Press, 2018), chapters 5 and 6.

23. Christiane Voss, "Film Experience and the Formation of Illusion: The Spectator as 'Surrogate Body' for the Cinema," Cinema Journal, vol. 5o, no. 4 (2011), pp. 136-150.

24. Leonard Lawlor, "The End of Phenomenology: Expressionism in Deleuze and Merleau-Ponty," Continental Philosophy Review, vol. 31, no. 1 (1998), pp. 15-34, here p. 15 .

25. Deleuze states as much in an interview with Cahiers du cinéma. Cf. Gilles Deleuze, "The Brain is the Screen. Interview with Gilles Deleuze on 'The Time-Image," in Discourse 20:3 (1998), pp. 47-55.

26. Michael Polanyi, The Tacit Dimension (Chicago: The University of Chicago Press, 1966). 
27. Murray Smith, Engaging Characters: Fiction, Emotion, and the Cinema (Oxford: Clarendon Press, 1995).

28. Donna Haraway, "Situated Knowledges: The Science Question in Feminism and the Privilege of Partial Perspective," Feminist Studies, vol. 14, no. 3 (1988), pp. 575-599, here p. 583.

29. Vinzenz Hediger, Nostalgia for the Coming Attraction: American Movie Trailers and the Culture of Film Consumption (New York: Columbia University Press [forthcoming]).

30. See the introduction by Vinzenz Hediger and Parick Vonderau in Vinzenz Hediger and Parick Vonderau (eds.), Films that Work: Industrial Film and the Productivity of Media (Amsterdam: Amsterdam University Press, 2009), pp. 9-16.

31. Alessandro Cecchi, "Creative Films for Creative Corporations: Music and Musicians in Experimental Italian Industrial Films," in Vinzenz Hediger, Florian Hoof, Yvonne Zimmermann, and Scott Anthony (eds.), Films That Work Harder: The Circulations of Industrial Filmy (Amsterdam: Amsterdam University Press [forthcoming]).

32. Edmund Husserl, The Crisis of European Sciences and the Transcendental Phenomenology: An Introduction to Phenomenological Philosophy (Evanston, IL: Northwestern University Press, 1970), pp. 14-18.

33. Dominique Païni, Le temps exposé: Le cinéma de la salle au musée (Paris: Cahiers du Cinéma, 2002).

\section{About the author}

Vinzenz Hediger is Professor of Cinema Studies at the Goethe-Universität Frankfurt. He is the author of Nostalgia for the Coming Attraction. American Movie Trailers and the Culture of Film Consumption (Columbia University Press, forthcoming), as well as the co-editor of Films That Work: Industrial Cinema and the Productivity of Media (Amsterdam University Press, 2009). He works on marginal film forms, film theory, and the history of film theory. He is a co-founder of European Network for Cinema and Media Studies (NECS, www.necs.org), a past president of Gesellschaft für Medienwissenschaft (www.gfmedienwissenschaft.de), the founding editor of Zeitschrift für Medienwissenschaft (www.zfmedienwissenschaft.de), a principal investigator at the Cluster of Excellence "The Formation of Normative Orders" (www. normativeorders.net), and a member of Mainz Academy of Sciences and Literature. 


\title{
When Viewers Drift Off: A Brief Phenomenology of Cinematic Daydreaming
}

\author{
Julian Hanich
}

\begin{abstract}
Inspired by Jean-Pierre Meunier and expanding some of his original ideas, this article looks at cinematic daydreaming as an act of consciousness viewers are sometimes engaged in over and above the perception of the film. After defining the term 'cinematic daydreaming,' I distinguish three relations the daydream can have to the film. Subsequently, I offer a concrete description of the cinematic daydreaming experience by focusing on five aspects: (1) the degrees of controllability, (2) the declining attentiveness to the perceptual surroundings, (3) the attenuated power of the film, (4) the shift into a more private mode, and (5) the distinction between intrusive daydreams that interfere with the film and extensive daydreams that enrich it.
\end{abstract}

Keywords: Viewing experience; Jean-Pierre Meunier; mind-wandering; ruminating; experimental film; slow cinema

\section{Introduction ${ }^{1}$}

Psychologists claim that we spend up to $50 \%$ of our waking life daydreaming, and on average we experience 2000 daydream segments per day. ${ }^{2}$ Even when we are involved in maximally demanding tasks with high stakes, we reportedly devote a minimum rate of $10 \%$ to daydreaming. ${ }^{3}$ Although we should be skeptical about such exact quantifications when it comes to our mental life, these astonishingly high numbers might tempt us to assume that daydreaming also occurs when we watch a film. And why not? Imagine you watch Hou-Hsiao Hsien's Goodbye, Dragon Inn (2003) or Godfrey Reggio's 
Koyaanisqatsi (1982) and all of a sudden you realize - and maybe feel a bit surprised, annoyed, guilty, or embarrassed upon discovering it - that you have spent a considerable amount of time in what Freud once called your mind's private theater. Involuntarily, the inner magician of your mind has conjured up for you an effortless flow of visual memories and imaginings: your magnificent trip to Taiwan or the US, the place where you want to spend your next holiday, the conference trip that you still need to book, the heated discussion you might have with your friends about the film... Your perception of the film momentarily receded to the background of attention while you were immersed in your own daydream.

Instances like these, which seem to me much more common than usually admitted or even realized, have not yet received the attention they deserve in film studies. Inspired by Jean-Pierre Meunier's The Structures of the Film Experience (Les Structures de l'expérience filmique: L'identification filmique), I will investigate daydreaming as an act of consciousness that viewers sometimes are engaged in over and above the perception of the film. The article does not provide an exegesis of Meunier's work or an excavation of the origins of his thought, but is meant to showcase how some of Meunier's original ideas can be expanded. As Meunier has shown us, our filmic consciousness is neither always completely bound to the film, nor is it a static affair. What makes his book so valuable is that it points to the protean character of filmic consciousness, where the film may be the center of the viewer's attention in one moment (fiction consciousness) and a mere instigator for memories in another (home-movie consciousness). My discussion of cinematic daydreaming will yield further evidence for how dynamic and ever-changing the viewer's consciousness is: we do not at all remain locked in one mental state while watching a film but often drift off. It speaks to the clear-sightedness of Meunier's little book that this was anything but consensus when it appeared in 1969, a year that marks the onset of a period when the dominant strand within film theory began to describe the film spectator as a dupe essentially dominated by the medium.

Almost 50 years later, the picture has changed: Meunier and other film phenomenologists like Vivian Sobchack have tremendously enriched our understanding of what goes on in our conscious, albeit often pre-reflective experience of a film. The stream of consciousness - to use an old term by William James again en vogue among philosophers of mind - is in a constant flux and is remarkably multilayered. Fiction consciousness, documentary consciousness, and home-movie consciousness can fluctuate; emotions, moods, affects, and various bodily sensations may flow into each other; different forms of time, space, and image consciousness can take turns; 
perceiving, imagining, remembering, and - yes - daydreaming might cooccur or alternate... While film phenomenologists admit that many facets of the film experience occur at the margins of consciousness (partly because they are too habituated to attract meta-awareness), they insist that these facets are nevertheless part of our conscious experience. Not only can they be described - only a proper description allows us to gain a fuller picture of the richness of the viewing experience. Not least, a phenomenological description raises awareness of what we rarely reflect on. Daydreaming, I argue, is precisely such a hardly-ever-noticed act of consciousness.

To be sure, the daydream has been a recurring topos in the history of film. Take the Surrealists' 'irrational enlargement' of the film wherein the viewer does not follow the 'rational' demands of comprehension and understanding, but freely follows a spontaneous chain of associations initiated by a seemingly irrelevant detail of a film usually suppressed by the film's demands on sense-making. ${ }^{4}$ As Adrian Martin claims, for the Surrealists, the term 'irrational enlargement' is "really just their fancy name for daydreaming." 5

Theorists have also compared film to daydreaming or drawn an analogy between the spectator and the daydreamer. In their influential book Movies: A Psychological Study from 1950, Martha Wolfenstein and Nathan Leites, for instance, claimed that films are the common daydreams of a culture. ${ }^{6}$ In his Theory of Film from 1960 , Siegfried Kracauer oscillates between the terms "dream" and "daydream": films supposedly lower the viewer's consciousness and thus invite dreaming, but they also cater to the desires and daydreams of their audiences; they can look like dreams and contain dreamlike elements that send the audience dreaming, but they also make the viewers enter episodes of daydreaming. ${ }^{7}$ Last but not least, we may cite Christian Metz who, in The Imaginary Signifier (1977), claims that the flux of the fiction film and its diegetic character resemble our daydreams, and some autobiographical or narcissistic films, which derive directly from the daydreams of their authors, are even more like reveries. Moreover, the daydreamer and the viewer, due to the "relative lowering of wakefulness," find themselves in comparable psychic states. And finally, Metz also diagnoses, in the "social life of our age," there is a "functional competition" between the fiction film and the daydream, where the film is often victorious. ${ }^{8}$

Inversely, we also find psychologists who have compared daydreaming to watching a film: the daydreamer is likened to a "devout cinemagoer" and a melodramatic daydream is described as "a prototypical filmic tearjerker;" the daydreamer is seen as "camera, film, projector, and screen" at 
the same time. ${ }^{9}$ Be that as it may, such comparisons and analogies will not occupy me in this essay: I presuppose that watching a film is not identical to daydreaming and whether it is similar to it is a question of debate.

Instead, I will take a brief but close look at the viewer's experience of cinematic daydreaming: those passive moments when, in the words of Daniel Yacavone, "our attention and concentration wanes, and we mentally 'wander away' from a film and its demands" or when we actively start to 'build castles in the air' by imagining or contemplating a chain of vivid scenes related or unrelated to the film. ${ }^{10}$ Note, however, that I do not want to overvalue cinematic daydreaming as a positive act of resistance along the lines of Benjaminian distraction or to postulate it as a preferable mode of film-watching. My account of the cinematic daydream aims at a detailed description, not a normative prescription. As Meunier puts it: "phenomenology is above all a method aimed at a description of our immediate experience. Renouncing, at least provisionally, the theoretical explanations that reason or scientific intelligence have been able to construct, it represents a return to the lived experience of phenomena [...]" (p. 40).

Naturally, we can expect considerable differences in daydreaming proneness among individual viewers. For instance, age seems to be an important influencing factor: psychologist Eric Klinger reports findings which show that both vividness and frequency reach their peak during the teens and early twenties and then gradually decrease. ${ }^{11}$ However, these individual differences are not something I pursue here. My brief phenomenology will focus on cases in which a cinematic daydream actually occurs.

\section{Cinematic Daydreaming Defined}

Before answering the question what is it like to experience a daydream while watching a film, however, we first need to define the contours of the concept. As late as 2009, Klinger noted that "there has clearly not been a consensual definition." ${ }^{\prime 2}$ More recently, analytic philosophers like Fabian Dorsch, Zachary Irving, and Evan Thompson have tried to conceptualize daydreaming and mind-wandering more clearly. ${ }^{13}$ While I have profited from their conceptual rigor, I have opted for a somewhat wider usage of the term. In what follows, 'cinematic daydreaming' will serve as an umbrella term for a host of related phenomena that can occur while watching a film such as mind-wandering, ruminating, fantasizing, being lost in thought, building castles in the air, drifting off, reverie, and absent-mindedness. The reason for uniting this range of different, if similar, phenomena under the umbrella 
term 'cinematic daydreaming' derives from the fact that I primarily want to make room for the Meunier-inspired intuition that the film experience is not film-devoted pure and simple. However, it is certainly possible - at a later stage even desirable - that different variants or subtypes of cinematic daydreaming should be distinguished phenomenologically. ${ }^{14}$

As a working definition, I suggest defining cinematic daydreaming as an act of consciousness in which a viewer - voluntarily or involuntarily - enters into a chain of sensory presentifications (Vergegenwärtigungen) of something that is either absent or non-existent, and which partly removes attention from the immediate perceptual surroundings of the viewer and thus draws attention, however slightly, away from the film: the imagination-filled perception of the film that philosophers in the wake of Husserl have called "image consciousness" is complemented or even pushed aside by other forms of consciousness like mind-wandering, ruminating, free-floating imagining, etc. Importantly, the chain of sensory presentifications involved in these other acts of consciousness is unguided by the film (even if it can certainly be related to it) and is thus at one remove from the film's perceptual affordances.

The cinematic daydream may be a brief burst of a few seconds, but it can also occur in an extended fashion. In either case, it either ends smoothly, when the daydream has run its course, or abruptly, when it is somehow interrupted. It can involve a pleasurable form of free-floating imagining, but it can also involve displeasure and annoyance when the daydream comes in the form of a worrying rumination or is considered, afterward, as having interrupted the film experience. It can involve the past, the future, hypothetical things, but also the here and now of the viewing environment - for example, when the erotic atmosphere of the cinema inspires a viewer to fantasize.

What is more, the temporal dynamics of cinematic daydreaming implies a chain of imaginings, memories, or thoughts - often (but not necessarily always) moving from one topic to another. ${ }^{15}$ Take Eric Rohmer's Cahiers du Cinéma review of Rossellini's Voyage to Italy (1954), in which the future nouvelle vague director remembers how his "imagination was wandering about" and how he felt plunged "into very absurd reflections":

I confess that I have, while I was watching the film, made reflections far removed from the drama itself; in the manner of a spectator who, entering the cinema between two meetings, and more concerned with his business than the show, is surprised to try to read the time on the watch that an actor wears on his wrist. ${ }^{16}$ 
Moving freely from fiction consciousness to documentary consciousness and beyond, Rohmer recognizes the patterns on George Sanders's jacket, wonders about the actor's age and how much older he has grown since Rebecca (1940) and All About Eve (1950), reflects on the haircut of Ingrid Bergman, considers the different structures of the skulls in the catacombs, and ponders new methods of archeology.

Note, however, that it is not easy to draw a strict line between daydreaming and imagining. ${ }^{17}$ In my broad understanding, free-floating imagining should be considered a form of daydreaming, whereas imagining steered from outside is not. The latter would be the case when someone tells you to imagine something, when a book guides your imagination, or when a film makes you mentally visualize something. It is easier to distinguish daydreaming from other mental states. Dreams, hypnagogia, fever dreams, hallucinations, deliberate problem-solving thoughts, and memories must not be confused with daydreams (even though memories, for instance, can certainly become part of daydreams). ${ }^{18}$

\section{The Cinematic Daydream and Its Relation to the Film}

The exact contents of spectators' daydreams - what they daydream about while watching a film - are too varied and idiosyncratic to dwell on here. It seems that, in principle, everything a person may daydream in everyday life can also become the content of a daydream during a film. More relevant for a phenomenology of cinematic daydreaming is the daydream's relation to the film. Here, we can broadly distinguish three types.

First, the daydream is directly linked to the film: just like Rohmer in the example above, the viewer daydreams about the film - its narrative, its characters, its world, its creators, its actors, its special effects. A viewer may briefly stray away from narrative absorption and daydream about how Max Ophüls and his cameraman Christian Matras filmed the opening sequence shot of La Ronde (1950): how must the set have looked to move the camera so elegantly for so long and how did Ophüls and Matras interact with their actors and extras during the shooting of the scene?

A viewer may also engage in a reverie about what it would be like to live in the world depicted in Byambasuren Davaa and Luigi Falorni's documentary The Story of the Weeping Camel (2003): what would he do when confronted with - what for him comes across as - the monotonies and hardships of a monadic life in the Mongolian Gobi region? ${ }^{19}$ Similarly, when I recently watched Koyaanisqatsi, I caught myself wondering about the people whose 


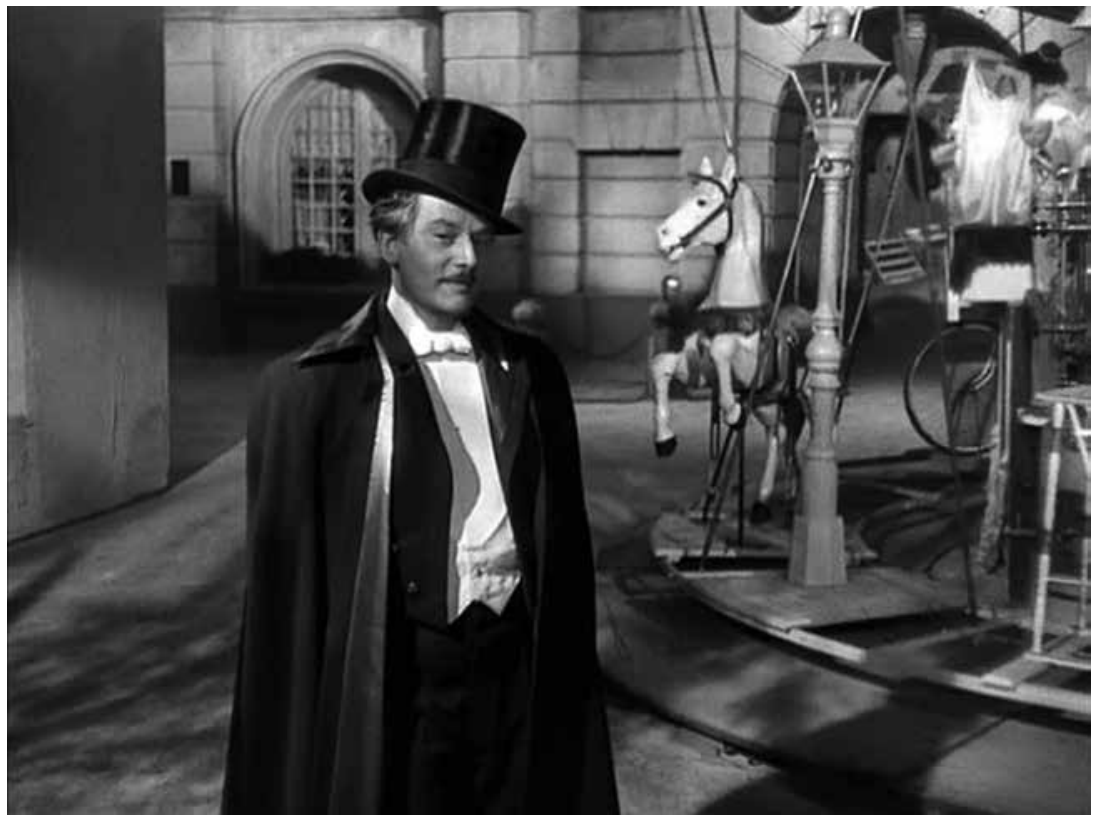

Fig. 14: The opening scene of Max Ophüls's La Ronde with Anton Walbrook.

intense, quizzical faces Ron Fricke's camera captures in slow-motion on the streets of New York: what has happened to these people in the intermittent 35 years, are they still alive, and what do they look like today? (I also came to realize that Roland Barthes had asked similar questions when looking at André Kertész's photograph of little Ernest from 1931: "Is it possible that Ernest is still alive today: but where? how? What a novel!" $)^{20}$

However, as much as these instances of daydreaming are linked to the film, it is important to distinguish them from what I have elsewhere called "bounded imagination" (and what Elaine Scarry dubs "imagination-underauthorial-instruction"): moments when the film seems to invite - or even force - us to imagine something it does not show, but strongly suggests. ${ }^{21}$ In this case, the intertwinement of the viewer's act of consciousness and the film as aesthetic object are differently structured, since the viewer's imagining seems necessary to concretize the film fully and thus to turn it from a work of art into an aesthetic object (in the sense defined by the phenomenological aesthetics of, for instance, Roman Ingarden). ${ }^{22}$

Second, the daydream can be indirectly linked to the film: the film somehow incites the daydream, but its narrative, characters, world, creators, actors, or special effects do not themselves play a role in it. Think of a viewer watching a sadly moving melodrama that sparks thoughts about the future 


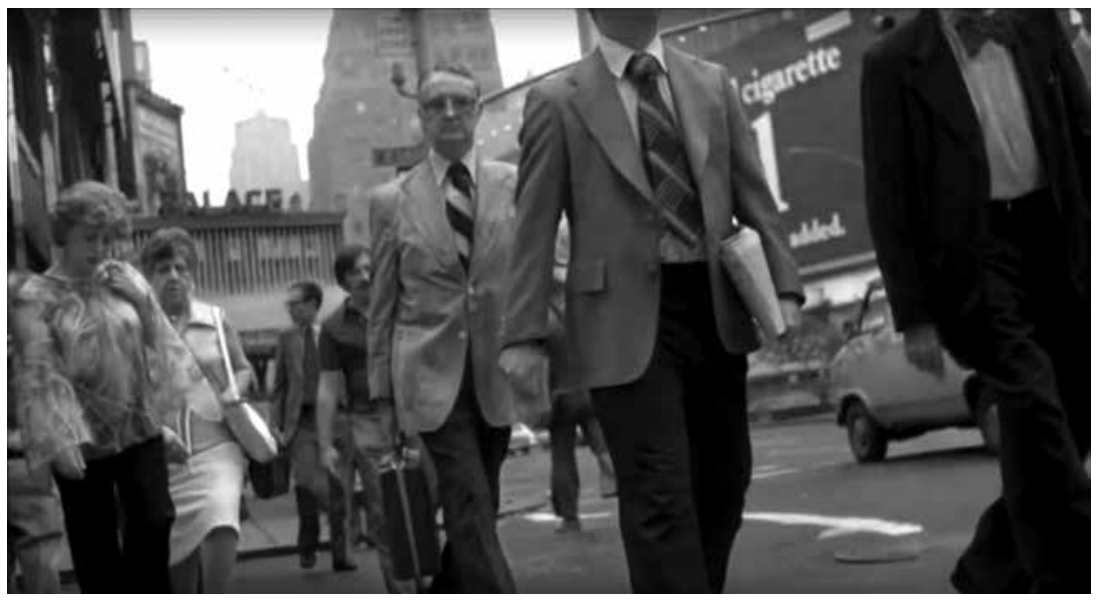

Fig. 15: Some passersby in Godfrey Reggio's Koyaanisqatsi.

death of the viewer's grandmother, father, brother, or daughter: the viewer's thoughts are carried away and he begins to daydream about the funeral, the speech of a close relative, the deep feeling of loss wearing him down and so on. Or think of a young viewer who watches a horror film alone at home while his parents are out for a party: the film turns the dark living room into an unsafe, threatening place that sparks fearful daydreams of burglars outside the window, a looming monster in the creaking wardrobe, and an ensuing fight for survival. Not least, the politics of an engagé documentary such as An Inconvenient Truth (2006) or I Am Not Your Negro (2016) may all of a sudden remind a viewer that he always wanted to be more active in environmental matters or anti-racist campaigns, and he begins to think about what steps to take the following days.

The third type of relation comprises all those daydreams that are not at all linked to the film, when the viewer is carried away into foreign territory entirely unconnected to the movie. ${ }^{23}$ Consider this: you start watching the film after a meeting in which you made a stupid mistake, or you had a heated debate with your best friend in which he insulted you in an unusual way. You try to focus on what is happening on the screen, but your thoughts keep drifting off, wandering back to that mistake or insult and the way you should have behaved. Or, while watching Andy Warhol's Haircut (1963) or Eat (1964), your mind begins to wander: from the dinner afterwards ... to the Christmas presents you have to buy ... to the tennis match that you want to watch on Friday to ... alas ... many other things. While we might claim that Haircut or Eat's monotony in some sense 'incites' a flight from boredom via fancy (the film would thus be indirectly related to the daydream after 
all), it may be better to speak of the film as the reason for daydreaming and not its cause. The viewer's daydream occurs in order to escape the film's monotony, but the film does not set it off.

Meunier, for his part, has shown us how the viewer's dependence on the filmic images varies between the filmic modes: while the home movie makes us look beyond the screen to existing, previously experienced reality, the non-existing, autonomous reality of the fiction film demands that our attention is focused on the screen. Analogously, cinematic daydreaming can be linked directly or indirectly to the film, or not at all.

\section{The Experience of the Cinematic Daydream}

Let us now move on to a more concrete description of the experience of cinematic daydreaming. I will focus on five aspects: (1) the degrees of controllability, (2) the declining attentiveness to the perceptual surroundings, (3) the attenuated power of the film, (4) the shift into a more private mode, and (5) intrusive daydreams that interfere with the film vs. extensive daydreams that enrich it.

\section{Degrees of Controllability: Active vs. Passive Daydreaming}

Cinematic daydreaming can be actively and voluntarily initiated and pursued. Take the example from La Ronde: precisely because I am actively following the film, I am seriously interested in finding out how Ophüls and Matras have staged the opening scene. I actively, with a certain effort and multitaskingly, pursue these thoughts and visually presentify to me the potential scenarios in a comparatively vivid way. Hence, my presentifications are not 'gray' inferences or abstract hypotheses, but 'colorful' daydreams that accompany my perception of the film. Not everyone would agree with such an inclusive position, though. Dieter Lohmar, for instance, argues that, while daydreams can be actively initiated, we subsequently have to give ourselves over passively to their unfolding. ${ }^{24}$ Others, like Elaine Scarry, define daydreams as voluntary: "Indeed it would be hard to see - given its fadedness and other failings - why we would devote ourselves to this ghostly practice if it did not have the virtue of the voluntary." 25

However, Scarry's position seems too one-sided to me: it flies in the face of the worrying and ruminating daydreams that keep creeping into our ongoing activities involuntarily. Surely, daydreams can also passively and 
involuntarily overcome me. In this case, the mind seems to take over from the self without me realizing it at first. Zachary Irving draws attention to grammatical constructions we use in which the subject is not a human agent: "we would say 'my mind was wandering' or 'Luke's mind wandered' rather than 'I was mind-wandering' or 'Luke mind-wandered.' [...] when our minds wander, we don't feel responsible for our thoughts; our minds are what wanders, not us. ${ }^{\prime 26}$ Here, the daydreams occur effortlessly and unguided, and I glide into them unknowingly: "Frequently we realize that we are engaging in these acts only after we have been indulging in them for some time. By a sort of psychic repercussion, we find ourselves caught in their midst - in medias imagines, as it were," Edward Casey writes. ${ }^{27}$ Frequently, such moments of 'waking up' from the daydream come with an emotional response. We may be surprised or annoyed by our own reverie when we realize we have missed important parts of the film (as, in contrast to reading a book, we cannot go back, at least when we sit in a cinema where the movie progresses relentlessly). Alternatively, we may feel guilty or embarrassed, especially when a friend or neighbor nudges us, whispers to us, and points out something on the screen we have overlooked because we were too deeply sunk in our own daydreams.

\section{Declining Attentiveness to the External Perceptible Surroundings}

As Irving notes, daydreaming is a conscious experience: "This is intuitive: when a person's mind wanders, the lights don't go out. Rather, she experiences a stream of memories, imaginings, inner speech etc." ${ }^{28}$ Similarly, Gaston Bachelard observes that the "night dream is a dream without a dreamer. On the contrary, the dreamer of reverie remains conscious enough to say: it is I who dream the reverie, happy with this leisure in which I no longer have the task of thinking.,"29 Since the daydream occupies consciousness at least to some degree, the daydreamer becomes less aware of the perceptible surroundings: even though we can certainly watch a film and concurrently fall into an episode of daydreaming, daydreaming always backgrounds perception, however minimally.

Here we can distinguish various degrees of visual intensity, of transparency or obliqueness: from the weak and vague daydream that allows you to 'see through' it to the strong and concrete type that almost fully 'blocks' your perception of the film (to a lesser degree, this is also the case for the auditory intensity of the daydream). Hence, the more the daydream dominates consciousness, the more the film is relegated to the fringes of 
consciousness, even if one still 'picks up' visual (and auditory) information. With regard to filmic imagining, I have elsewhere spoken of episodes of 'mental superimposition' or 'mental double-exposure. ${ }^{30}$ We can also utilize these metaphors for the daydream: the concurrent perception of filmic images and the daydream are, as it were, layered on top of each other. The more the film and the daydream are part of the field of consciousness the more we can say the viewer is engaged in a form of multitasking: watching the film and daydreaming at the same time. What is more, while daydreaming, the viewer is suspended between three different worlds: (a) the physical world of the cinema or any other viewing surrounding, (b) the filmic world (which may or may not be fictional), and (c) the mental world of the daydream. Depending on the strength of the daydream, the locatedness in these three worlds varies.

\section{The Attenuated Power of the Film}

Since daydreaming backgrounds perception, at least minimally, we experience the film as wielding much less power over us than in moments of intensified absorption (such as deep fictional immersion and awe-inspiring aesthetic enthrallment). ${ }^{31}$ In fact, cinematic daydreaming occurs in moments when the film seems to be bereft of its 'grip' over us. This can be for many reasons. First, the film unintentionally does not 'captivate' us any longer (or has not been 'gripping' to begin with) and our attention starts to drift off. Second, we can 'wrest' ourselves actively from the film by initiating an episode of daydreaming when we think this is more appropriate, or we are 'torn away' passively from the film by penetrating thoughts that interfere with the film experience. Third, the attenuated power of the film can also intentionally derive from its aesthetics, an aesthetics that does not want to 'chain' us to its narrative and style but grants us more freedom to drift off into daydreaming. Below, we will see how some experimental films seem to invite episodes of daydreaming, but we could also think of slow cinema. As Eric Rohmer remarks in his review, Rossellini's film allowed him "absurd reflections $[. .$.$] of which a more sustained tempo in the plot would not have$ left me the leisure." ${ }^{2}$

This attenuated power of the film can be experienced as liberating, but it can also imply constraints and frustration. Not feeling guided and captivated by a film may result in disagreeable boredom; and when we seem to be under the 'spell' of our wandering mind, which strays away even though we actually would like to follow the film, we may regret the lack of power of the film. 


\section{A Shift into Privacy}

The daydream also implies an abandonment, however minimal, of the outside world and a shift into a more private realm. This aspect of privacy has two components. First, watching a film entails perceiving something that is outside of me. It is clearly located beyond myself, there on the screen. The daydream, instead, is experienced as much closer to me, almost 'inside' of me. As Bachelard puts it: "Truly inhabiting the whole volume of his space, the man of reverie is from anywhere in his world, in an inside which has no outside. It is not without reason that people commonly say that the dreamer is plunged in his reverie. The world no longer poses any opposition to him." ${ }^{33}$ To be sure, the talk of an 'inside' is not without its problems. What Edward Casey notes about imagining also goes for daydreaming: "Far from inhabiting a concrete setting, imagined possibilities are typically projected into a spatio-temporal limbo that is felt to be neither external nor internal to the imaginer." 34 Still, the daydream is more private because we know that - unlike the perceivable images and sounds of the film - it is not available to others. The daydream constitutes a world decidedly not shared by others (hence the well-known feeling of being excluded from someone else's world who is 'lost in his thoughts'). There is no shared daydreaming of the same content.

Second, the daydream is also private in the sense that it is a world in some way connected to me and my own identity: it is filled with what $I$ personally daydream about. Eric Klinger writes: "Most people view their daydreams as very private affairs that they feel less comfortable describing to other people than when they are describing their real experiences." ${ }^{35} \mathrm{At}$ the same time, this does not imply that one has fully lost contact with the here and now of one's viewing surroundings. Unlike in dreaming proper, the film is relegated to the margins of consciousness at best, but it is still somehow 'gleaming' or 'shimmering.'

Still, even in cases of film-related daydreaming, personal elements from outside the film itself 'adhere' to it, 'cluster' around its images, 'push' it from the center of consciousness: our mundane joys, hopes, concerns, worries or anxieties are invited into - or force themselves upon - our film experience.

\section{Intrusion vs. Extension of the Film Experience}

Expressions like 'seeing through' the daydream, the daydream 'blocking' perception, or Casey's in medias imagines hint at the intermediary character of daydreams: their in-betweenness. The daydream can therefore be 
experienced - in retrospect - as an intruder: It is as if the daydream has pushed itself 'between' you and the film and has created a barrier for your smooth perception of the film. Take this not-so-unusual example. While you would like to focus on the film, your mind keeps drifting away to a potential revenge scenario: how can you pay back the massive annoyance of the person sitting behind you in the cinema, who answered your request to stop kicking against your chair with an extremely impertinent remark? You play through various possibilities to get even, from informing the cinema manager to throwing the content of your five-liter cup of popcorn at him. The more the daydream is experienced as intrusive, the more it will be considered as a form of distraction, almost like the annoying neighbor sitting behind you.

But there are two reasons why daydreaming may be experienced as quite the opposite of distraction and intrusion. First, from the viewer's perspective, daydreaming may be very welcome. Think of drifting back to the extremely positive email you received before starting to watch the film and the pleasurable trains of thought it initiates for you. Hence, any negative definition of daydreaming as "an occurrence of thoughts [...] unrelated to the task being carried out at the moment of their occurrence," as Stawarczyk et al. put it, must be rejected as too sweeping. ${ }^{36}$ Instead, with Irving/Thompson, we can claim that "individuals switch tasks when their minds begin to wander." 37 For the viewer-turned-daydreamer, the daydream thus becomes the main task carried out at the moment, before the film gains predominance again and the daydreamer transforms back into his role of focused viewer just an instant later. Or consider the case of an utterly boring moment during a film - the umpteenth action sequence in a superhero movie, for instance - wherein daydreaming can come as a momentary exit strategy from boredom's imprisonment. This is another lesson to be learned from Meunier's book: Just like the home-movie consciousness that "looks beyond the image, to the person-in-general that it depicts, in order to produce and maintain his existence even during the screening" (p. 88), the daydream consciousness leads the viewer beyond the image into a stream of private thoughts and imaginings. The former evokes the act of remembering, the latter the act of daydreaming.

Second, daydreaming may also be considered an intentional goal of the film - or at least one may feel legitimized and even encouraged to enter daydreaming episodes by the film's aesthetics. Think of Paul Sharits and his flicker film N:O:T:H:I:N:G (1968): for Sharits, it was an explicit goal to let the viewer reach "totally new levels of awareness," as he put it. He claims to have based the color development of the film on the Tibetan Mandala of 
the Five Dhyani Buddhas "which is used in meditation to reach the highest level of inner consciousness": "I am not at all interested in the mystical symbolism of Buddhism, only in its strong, intuitively developed imagistic power." ${ }^{8}$ While it is not clear what exactly Sharits means by "new levels of awareness," "highest level of inner consciousness," and "imagistic power" (the film is certainly close to the drug experiments of the 1960 s and the counter-cultural interest in Buddhist meditation), we can assume that he would not have been averse to a daydreaming viewer.

In fact, we can create a whole list of canonical experimental films whose explicit purpose - or at least implicit invitation - seems to involve daydreaming: Empire (1964), The Flicker (1965), Wavelength (1967), RR (2007)... Some cases of slow cinema - for instance, films by Tsai Ming-Liang, Albert Serra, or Apichatpong Weerasethakul - equally seem to open themselves up to daydreaming viewers. These films 'harness' the viewer's daydreams: the perception of the film is extended and enriched by the viewer's drifting mind. ${ }^{9}$ To round off this brief phenomenology of cinematic daydreaming, we could therefore distinguish between intrusive and extensive daydreams. On the one hand, there are reveries that lead us entirely away from the film into the mundane. On the other hand, we find daydreams that extend the world of the film - and thus immerse us even deeper in its world.

\section{Notes}

1. I would like to thank Weihong Bao, Daniel Fairfax, Christian Ferencz-Flatz, Adrian Martin, and Vivian Sobchack for helpful comments and suggestions.

2. Eric Klinger, "Daydreaming and Fantasizing: Thought Flow and Motivation," in Keith D. Markman, William M.P. Klein, and Julie A. Suhr (eds.), Handbook of Imagination and Mental Simulation (New York: Psychology Press, 2009), pp. 225-239, here p. 228.

3. Ibid., p. 228.

4. The Surrealist Group, "Data Toward the Irrational Enlargement of a Film: The Shanghai Gesture," in Paul Hammond (ed.), The Shadow and Its Shadows: Surrealist Writings on the Cinema, Third Edition, Revised and Expanded (San Francisco: City Lights Books, 2000), p. 121. See also Adam Lowenstein, Dreaming of Cinema: Spectatorship, Surrealism, and the Age of Digital Media (New York: Columbia University Press, 2014), pp. 20-23.

5. Personal conversation with the author.

6. Martha Wolfenstein and Nathan Leites, Movies: A Psychological Study (Glencoe: Free Press 1950).

7. Siegfried Kracauer, Theory of Film: The Redemption of Physical Reality (New York: Oxford University Press, 1960). 
8. Christian Metz, The Imaginary Signifier (Bloomington, IN: Indiana University Press, 1982), pp. 132-136.

9. Quoted from: Hedwig Katzenberger, Der Tagtraum: Eine phänomenologische und experimentelle Studie (Munich: Reinhardt Verlag, 1969), pp. 26 and 45; James Morley, "The Private Theater: A Phenomenological Investigation of Daydreaming", Journal of Phenomenological Psychology 29 (1998), pp. 116-134, here p. 132.

10. Daniel Yacavone, Film Worlds: A Philosophical Aesthetics of Cinema (New York: Columbia University Press, 2015), p. 240.

11. Klinger, "Daydreaming and Fantasizing," p. 234.

12. Ibid., p. 226.

13. Fabian Dorsch, "Focused Daydreaming and Mind-Wandering," Review of Philosophy and Psychology 6 (2015), pp. 791-813; Zachary C. Irving, "MindWandering Is Unguided Attention: Accounting for the 'Purposeful' Wanderer," Philosophical Studies, 173 (2016), pp. 547-571; Zachary C. Irving and Evan Thompson, "The Philosophy of Mind-Wandering," in Kalina Christoff and Kieran C. Fox (eds.), The Oxford Handbook of Spontaneous Thought (Oxford: Oxford University Press, 2018), pp. 87-96.

14. Analogously, we can see how subtypes of what Meunier rather broadly calls "home-movie consciousness" are distinguished and described in the contributions to this volume by Vivian Sobchack and Christian Ferencz-Flatz.

15. Philosophers like Irving and Thompson distinguish mind-wandering from ruminating along the axis instability-stability: mind-wandering implies drifting from topic to topic, whereas ruminating remains fixed on a single topic. But this seems to me a difference of degrees rather than in kind, as surely one does not think of only a single thing when one ruminates, but revolves around different aspects of a topic, even if this occurs within a narrower range than in mind-wandering. See Irving and Irving/Thompson.

16. The review was written under Rohmer's original name. Maurice Schérer, "La Terre du miracle," Cahiers du Cinéma 47 (May 1955), pp. 38-41, here p. 40.

17. Opinions are divided on this issue. Katzenberger, for instance, suggests using the German term Phantasie as a synonym for Tagtraum: "because all daydreams are fantasies, even though [...] not all fantasies are daydreams." Katzenberger, Der Tagtraum, p. 35. Klinger, on the other hand, writes that "both daydreaming and fantasizing are poorly defined concepts, and they are by no means the same thing." Klinger, "Daydreaming and Fantasizing," p. 226.

18. For a comparative phenomenology of imagining, hallucinating, remembering, and fantasizing, see Edward S. Casey, "Comparative Phenomenology of Mental Activity: Memory, Hallucination, and Fantasy Contrasted with Imagination," Research in Phenomenology 6 (1976), pp. 1-25.

19. I have used the gender-specific terms 'he' and 'his' throughout, but they should be understood as referring to all genders, unless explicitly stated. No offense or sexism is intended. 
20. Roland Barthes, Camera Lucida: Reflections on Photography, trans. Richard Howard (New York: Hill and Wang, 1981), p. 83.

21. Julian Hanich, Cinematic Emotion in Horror Films and Thrillers: The Aesthetic Paradox of Pleasurable Fear (New York: Routledge, 2010), p. 110; Elaine Scarry, "On Vivacity: The Difference Between Daydreaming and ImaginingUnder-Authorial-Instruction," Representations, $5^{2}$ (1995), pp. 1-26.

22. Roman Ingarden, The Literary Work of Art (Evanston, IL: Northwestern University Press, 1973).

23. Psychoanalysts might, of course, claim that the daydream implies the fulfillment of an unconscious wish and hence the film may well have to do with the daydream in an unconscious way after all.

24. Dieter Lohmar, Phänomenologie der schwachen Phantasie: Untersuchungen der Psychologie, Cognitive Sciences, Neurologie und Phänomenologie zur Funktion der Phantasie in der Wahrnehmung (Dordrecht: Springer, 2008), p. $15^{8}$.

25. Scarry, "On Vivacity," p. 18.

26. Irving, "Mind-Wandering," p. $55^{\circ}$.

27. Edward S. Casey, Imagining: A Phenomenological Study, 2nd ed. (Bloomington, IN: Indiana University Press, 2000), p. 69.

28. Irving, "Mind-Wandering," p. 553.

29. Gaston Bachelard, The Poetics of Reverie: Childhood, Language, and the Cosmos (Boston: Beacon Press, 1969), p. 22.

30. Julian Hanich, "Omission, Suggestion, Completion: Film and the Imagination of the Spectator," Screening the Past, 43 (2018), n.p. http://www. screeningthepast.com/2018/o2/omission-suggestion-completion-film-andthe-imagination-of-the-spectator/ (Last accessed on: 28 April 2019).

31. For the difference between immersion and enthrallment, see Hanich (2010), pp. 64-66.

32. Schérer, "La Terre du miracle," p. 40.

33. Bachelard, Poetics of Reverie, p. 167.

34. Casey, "Comparative Phenomenology," p. 14.

35. Klinger, "Daydreaming and Fantasizing," p. 225.

36. David Stawarczyk, Steve Majerus, Michalina Maj, Marital van der Linden, and Arnaud D'Argembeau, "Mind-Wandering: Phenomenology and Function Assessed with a Novel Experience Sampling Method," Acta Psychologica 136 (2011), pp. 370-381, p. 370.

37. Irving/Thompson, "Philosophy of Mind-Wandering," p. 90.

38. http://paulsharits.com/about-paul/about-films-by-paul/ (Last accessed: 13 November 2017).

39. This extension and enrichment is by no means restricted to non-narrative experimental works, but can occur in fiction films as well. For an example from the comparable case of a visit to the opera, see Casey, Imagining, pp. 140-141. 
About the author

Julian Hanich is Associate Professor of Film Studies at the University of Groningen. He is the author of two monographs: The Audience Effect: On the Collective Cinema Experience (Edinburgh University Press, 2018) and Cinematic Emotion in Horror Films and Thrillers: The Aesthetic Paradox of Pleasurable Fear (Routledge, 2010). With Christian Ferencz-Flatz, he co-edited a special issue of Studia Phaenomenologica on "Film and Phenomenology" (2016), and with Jane Stadler and Jens Eder he worked on a special issue of NECSUS on "Emotions" (2019). In his research, he focuses on film and emotion, film phenomenology, the collective cinema experience, and film style. Together with Michael Wedel, he is currently writing a book about the German silent-film director Friedrich Wilhelm Murnau. His articles have appeared in Screen, Cinema Journal, New Literary History, Projections, NECSUS, Movie, Film-Philosophy, Jump Cut, New Review of Film and Television Studies, and others. In 2018, he was awarded a fellowship with the Cinepoetics Center for Advanced Film Studies at Freie Universität Berlin. 


\section{List of Illustrations}

Fig. $1 \quad$ Jean-Pierre Meunier's private copy of his book. 10

Fig. 2 Meunier during the first part of the interview on

23 November 2017 in Frankfurt am Main.

Fig. 3 Meunier in 1972 during a public lecture that was part of the requirements to acquire the doctoral degree in his faculty.

Fig. 4 The unexpected death of Boris (Aleksey Batalov) in Mikhail Kalatozov's The Cranes Are Flying.

Fig. 5 Jean Gabin as the Lieutenant Maréchal in Jean Renoir's Grand Illusion.

Fig. 6 Françoise (Marie-José Nat) and Jean-Marc (Jacques Charrier) in André Cayatte's Anatomy of a Marriage.

Fig. 7 Jean-Paul Belmondo admires Humphrey Bogart on a film poster promoting The Harder They Fall (Mark Robson), in Jean-Luc Godard's Breathless.

Fig. 8 The faces of Liv Ullmann and Bibi Andersson in a merged close-up from Persona (Ingmar Bergman).

Fig. 9 Portrait of John Adams in Lower Manhattan, shortly before he was sent to Germany in Spring 1944 (d. Amanvillers, occupied France, September 11, 1944). Courtesy of John Christiansen.

Fig. 10 Scene from The Roof by Vittorio de Sica.

Fig. 11 Intension, extension, and reference in the kitchen scene from The Roof.

Fig. 12 Scene from Alfred Hitchcock's The Birds with Tippi Hedren.

Fig. 13 Program of the mining film screenings at the German Museum of Mining, Bochum, September-October 2004. (C) Deutsches Bergbaumuseum.

Fig. 14 The opening scene of Max Ophüls's La Ronde with Anton Walbrook.

Fig. 15 Some passersby in Godfrey Reggio's Koyaanisqatsi. 
